Florida International University FIU Digital Commons

6-30-2016

\title{
The Degradation of Pharmaceutical Pollutants in Wastewater Catalyzed by Chloroperoxidase and the Construction of Chloroperoxidase H105R Mutant
}

Qinghao He

Florida International University, qhe001@fiu.edu

DOI: $10.25148 /$ etd.FIDC000780

Follow this and additional works at: https:// digitalcommons.fiu.edu/etd

Part of the Biochemistry Commons, Enzymes and Coenzymes Commons, Genetics Commons, Medical Biochemistry Commons, Medicinal Chemistry and Pharmaceutics Commons, Other Chemicals and Drugs Commons, and the Other Pharmacology, Toxicology and Environmental Health Commons

\section{Recommended Citation}

$\mathrm{He}$, Qinghao, "The Degradation of Pharmaceutical Pollutants in Wastewater Catalyzed by Chloroperoxidase and the Construction of Chloroperoxidase H105R Mutant" (2016). FIU Electronic Theses and Dissertations. 2540.

https://digitalcommons.fiu.edu/etd/2540 
FLORIDA INTERNATIONAL UNIVERSITY

Miami, Florida

THE DEGRADATION OF PHARMACEUTICAL POLLUTANTS IN WASTEWATER CATALYZED BY CHLOROPEROXIDASE AND THE CONSTRUCTION OF CHLOROPEROXIDASE H105R MUTANT

\author{
A dissertation submitted in partial fulfillment of \\ the requirements for the degree of \\ DOCTOR OF PHILOSOPHY \\ in \\ CHEMISTRY \\ by \\ Qinghao He
}

2016 
To: Dean Michael R. Heithaus

College of Arts, Sciences and Education

This dissertation, written by Qinghao $\mathrm{He}$, and entitled The Degradation of Pharmaceutical Pollutants in Wastewater Catalyzed by Chloroperoxidase and the Construction of Chloroperoxidase H105R Mutant, having been approved in respect to style and intellectual content, is referred to you for judgment.

We have read this dissertation and recommend that it be approved.

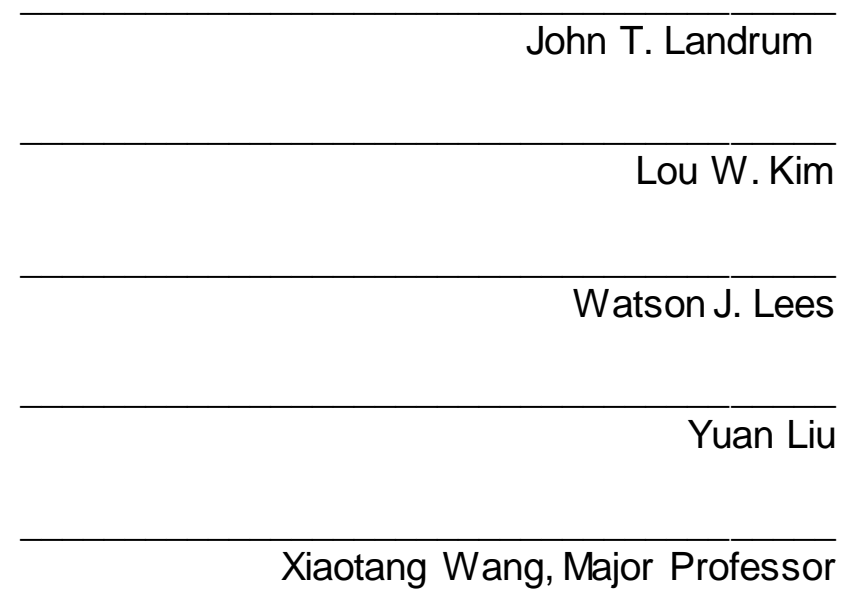

Date of Defense: June 30, 2016

The dissertation of Qinghao He is approved.

Dean Michael R. Heithaus

College of Arts, Sciences and Education

Andrés G. Gil

Vice President for Research and Economic Development and Dean of the University Graduate School

Florida International University, 2016 
(C) Copyright 2016 by Qinghao He

All rights reserved. 


\section{DEDICATION}

I dedicate this dissertation to my father Wenlong He and my mother

Ronghua Wan. Without their support and encouragement, the completion of this work would not have been possible. 


\section{ACKNOWLEDGMENTS}

The completion of this work is the outcome of many people's contribution. During my five years' graduate study at Florida International University. Most importantly, I would like to express my sincerest gratitude to my major professor,

Dr. Xiaotang Wang, for his continuous encouragement, understanding and support. He was always there to guide me in becoming a good researcher by keeping passion and ambition in my project, developing independent thinking and never to give up. He also taught me how to be a responsible individual to benefit others and society with his excellent patience. Without his consistent help and guidance, the completion of this project would not have been possible.

I am immensely grateful to all my committee members, Dr. John T. Landrum, Dr. Lou Kim, Dr. Watson Lees and Dr. Yuan Liu, for their professional assistance and many intelligent and helpful suggestions during the years. I also want to acknowledge my labmates and friends, Lin Jiang, Elwood Kwong, Elena Shersher, and Yongjian Guo for their inspiring discussion and kindly assistance. We helped and encouraged each other like brothers and sisters. It has been an unforgettable experience in my whole life to work in such a warm and kindly lab.

I would like to express my appreciation to Dr. Kevin O'Shea and Dr. Stanislaw F. Wnuk for giving me extraordinary professional suggestions in organic chemistry related to my work. I also would like to thank Dr. Luis E. Arroyo-Mora from Dr. Anthony P. Decaprio's lab for teaching me LC-Q-TOF mass spectrometry, from the very basic knowledge such as sample preparation to troubleshooting the machine, and Vanessa Linero from the same lab for guiding 
me to use Triple-Quadrupole mass spectrometer. Also, I would like to thank Dr. Palmer Graves and Dr. Uma Swamy for guiding me to be a good teaching assistance. In addition, I would like to thank all my family and friends for their understanding, support and encouragement. Finally, I would like to acknowledge the Department of Chemistry and Biochemistry, Florida International University. 


\begin{abstract}
OF THE DISSERTATION
THE DEGRADATION OF PHARMACEUTICAL POLLUTANTS IN

WASTEWATER CATALYZED BY CHLOROPEROXIDASE AND THE

CONSTRUCTION OF CHLOROPEROXIDASE H105R MUTANT
\end{abstract}

by

Qinghao He

Florida International University, 2016

Miami, Florida

Professor Xiaotang Wang, Major Professor

Trace amounts of pharmaceuticals have been detected in water, from nanograms per liter to micrograms per liter, and have a negatively effect in the aquatic environment and an increased potential risk of drug poisoning for human and animals. In order to address the problem, drug degradation catalyzed by chloroperoxidase (CPO) has been investigated. CPO is a heme-containing glycoprotein secreted by the fungus, Caldariomyces fumago, it catalyzes two major types of oxidations, two one-electron oxidations as catalyzed by most peroxidases and two-electron oxidations which are rare for conventional peroxidases.

Five common drugs from a variety of classes (acetaminophen, carbamazepine, sulfamethazine, diclofenac and naproxen) which were persistent in the environment have been studied. The metabolites of each drug were identified and the pathways of degradation were proposed. All of them were found to be $100 \%$ degradation efficiency in the $\mathrm{CPO}-\mathrm{H}_{2} \mathrm{O}_{2}-\mathrm{Cl}^{-}$system which the 
catalyzation only required low concentration of CPO (normally nanomolar level) as well as relatively low concentration of $\mathrm{H}_{2} \mathrm{O}_{2}$ as cofactor. This degradation method is economic and highly efficient, the results of my experiment extensively support the hypothesis that CPO has a great potential in the environmental application.

A new mutant of CPO has been constructed to investigate the role of histidine 105 in the active site of distal pocket. Histidine 105 was suggested to play an essential role in modulating the chlorination activity by forming hydrogen bond with glutamic acid 183 , histidine has been replaced by arginine to generate $\mathrm{CPO}$ H105R mutant. The construction and transformation were a success but the protein was expressed as apoenzyme, suggesting the mutagenesis to a larger arginine residue at position105 disturbed the heme incorporation. 


\section{TABLE OF CONTENTS}

CHAPTER

PAGE

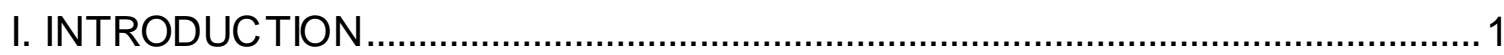

1.1 The occurrence of pharmaceutical pollutants in water ................................. 1

1.2 The treatment for removal of pharmace uticals in water ................................. 3

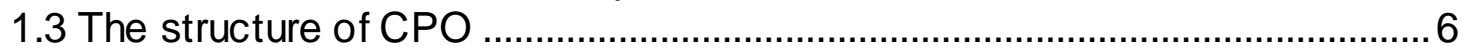

1.4 The mechanism of CPO catalyzed reactions ...........................................10

1.5 CPO catalyzed reactions ..........................................................................11

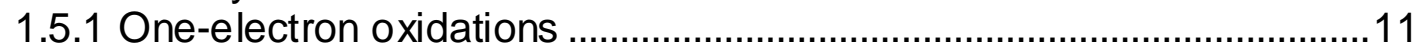

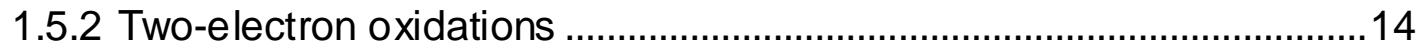

II. CPO-CATALYZED CHLORINATION AND POLYMERIZATION OF

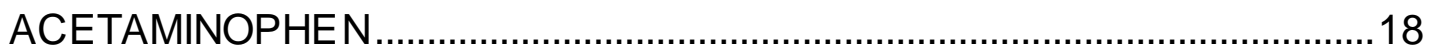

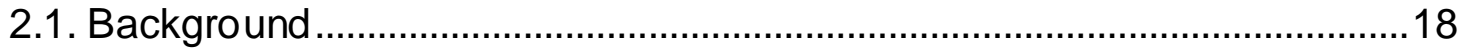

2.2 Experimental Procedure ….................................................................

2.2.1 Material .......................................................................................... 18

2.2.2 UV-Visible spectrophotometry ......................................................19

2.2.3 Liquid chromatography and mass spectrometry .................................19

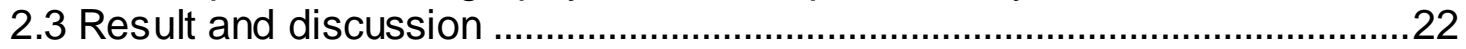

2.3.1 UV-Vis study of CPO-catalyzed degradation of APAP ........................22

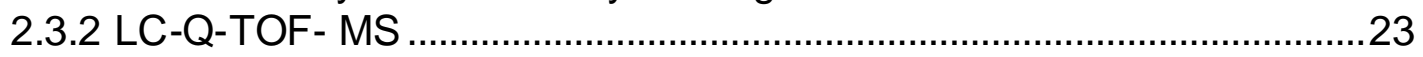

2.3.3 Triple-quadruple LC/MS/MS ..........................................................25

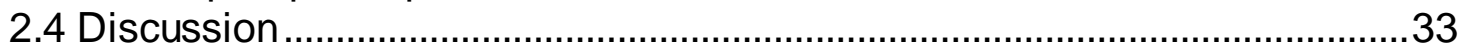

III. CPO-CATALYZED DEGRADATION OF CARBAMAZEPINE ..........................35

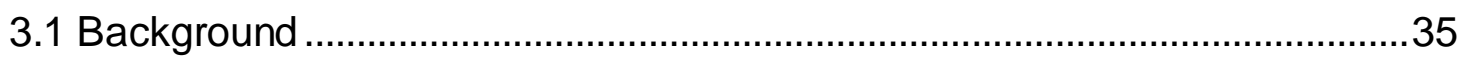

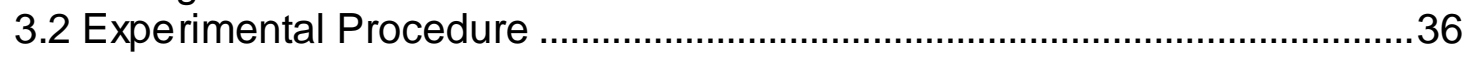

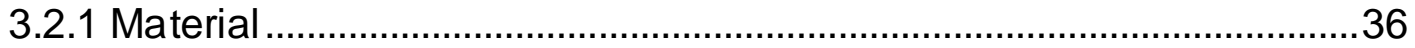

3.2.2 UV-Visible spectrophotometry ........................................................36

3.2.3 Liquid chromatography and mass spectroscopy .................................38

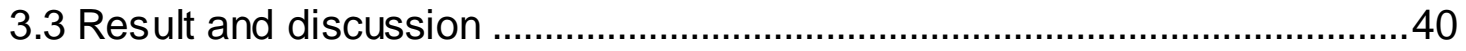

3.3.1 UV-Vis study of CP O-catalyzed degradation of carbamazepine .......40

3.3.2 The effect of chloride on the degradation of CBZ ................................41

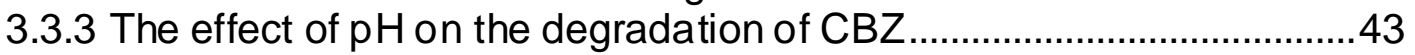

3.3.4 The effect of $\mathrm{H} 2 \mathrm{O} 2$ concentration ....................................................... 43

3.3.5 The kinetic parameters of CBZ degradation catalyzed by CPO .........44

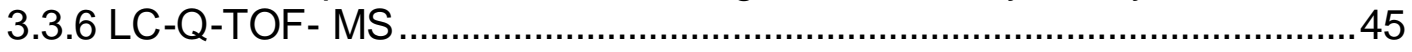

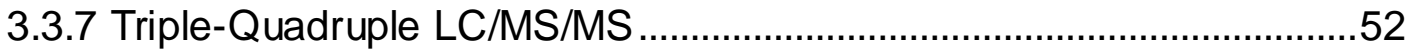

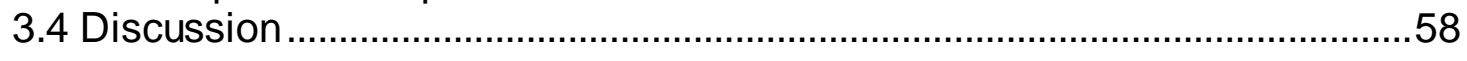

IV. CPO-CATALYZED DEGRADTION OF SULFAMETHAZINE ........................61

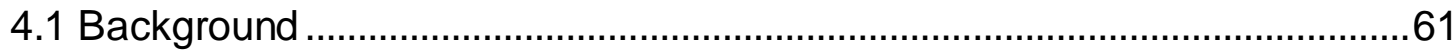

4.2 Experimental Procedure ..........................................................................61 


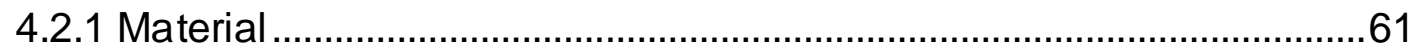

4.2.2 UV-Visible spectrophotometry ........................................................61

4.2.3 Liquid chromatography and mass spectrometry...................................62

4.3 Result and discussion .............................................................................64

4.3.1 UV-Vis study of CPO-catalyzed degradation of carbamazepine ........64

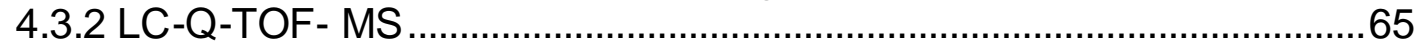

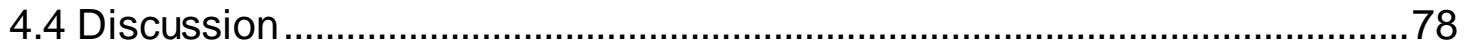

V. ENGINEERING THE HYDROGEN BOND OF CPO BY MUTANT H105R .....81

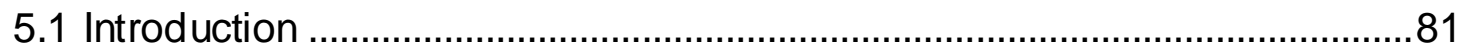

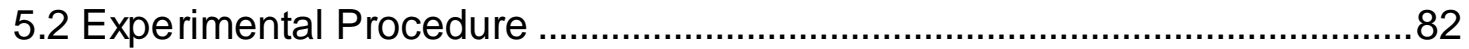

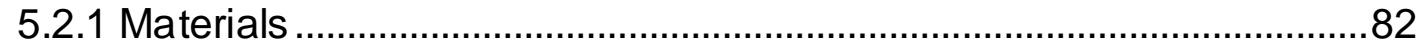

5.2.2 Construction of H105R mutant and plas mid propagation ....................83

5.2.3 Transformation into A. niger and selection for expression ....................85

5.2.4 Expression of the H105R mutant protein ..............................................86

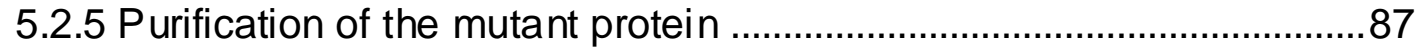

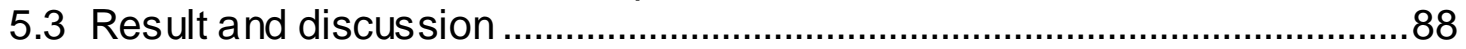

5.3.1 Mutant DNA sequencing ................................................................... 88

5.3.2 Transformaiton and expression result ...............................................8

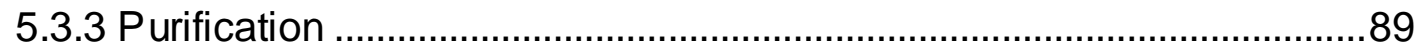

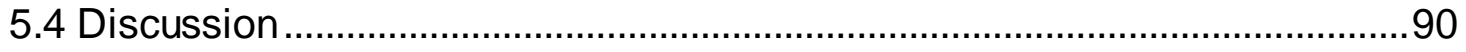

VI. DEGRADATION OF NON-STEROIDAL ANTI-INFLAMMATORY DRUGS

DICLOFENAC AND NAPROXEN BY CHLOROPEROXIDASE ....................92

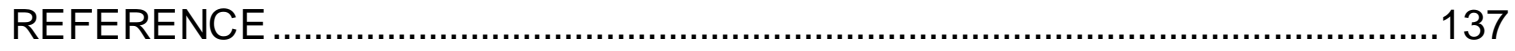

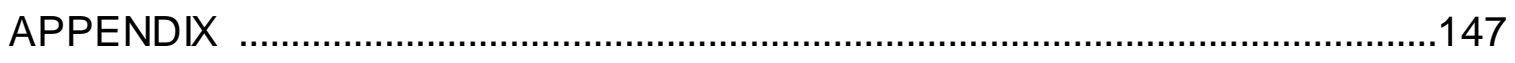

VITA 


\section{LIST OF TABLES}

TABLE

PAGE

Table 1.1 Conventional and advanced wastewater treatment and their removal range efficiency of pharmaceuticals.

Table 2.1 Accurate-Mass LC-Q-TOF-MS data for the identification of APAP and its metabolites.

Table 2.2 Information of the proposed isomers .................................................29

Table 3.1 The kinetic parameters of CBZ degradation catalyzed CPO. …...........45

Table 3.2 Accurate-Mass LC-Q-TOF-MS data for the identification of CBZ and

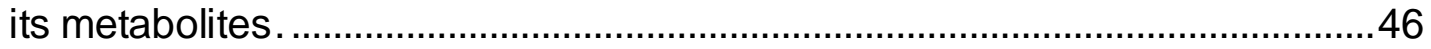

Table 3.3 The optimizer data of CM4, CM5 and CM7 .......................................55

Table 4.1 Accurate-Mass QTOF-LC/MS data for the identification of SMZ and its metabolites catalyzed in $\mathrm{CPO}-\mathrm{H}_{2} \mathrm{O}_{2}-\mathrm{Cl}^{-}$system. ......................................66

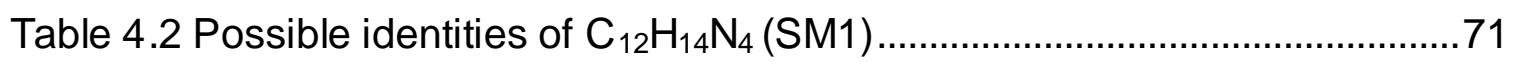

Table 4.3 Accurate-Mass LC-Q-TOF-MS data for the identification of SMZ and its metabolites catalyzed in $\mathrm{CPO}-\mathrm{H}_{2} \mathrm{O}_{2}-\mathrm{Br}^{-}$system......................................76 


\section{LIST OF FIGURES}

FIGURE

PAGE

Figure 1.1 Fate of human and veterinary pharmaceuticals in the environment. ....2

Figure 1.2 Crystal structure of CPO was presented by Pymol software ................ 7

Figure 1.3 Slice of CPO crystal structure with surface presentation ...................... 8

Figure 1.4 CPO active site presented by Pymol software (PDB entry 1CPO) with important amino acids in the distal pocket ................................................ 9

Figure 1.5 The general mechanism of CPO catalyzed reation .............................12

Figure 1.6 The oxidation of ABTS catalyzed by CPO …….................................13

Figure 1.7 The dehalogenation of trihalophenol catalyzed by CPO ….................13

Figure 1.8 The mechanism of CPO catalyzed one electron oxidation of fluorophenol............................................................................................14

Figure 1.9 Reactions catalyzed by CPO in phosphate buffer with chloride ions .16

Figure 1.10 The chlorination of aromatic substrates catalyzed by CPO in phosphate buffer with chloride ions

Figure 2.1 UV-Vis Spectra of APAP, APAP with $\mathrm{H}_{2} \mathrm{O}_{2}$ and its metabolites at

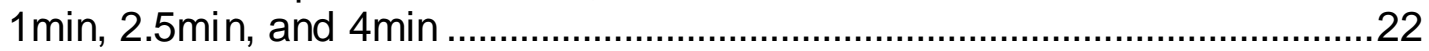

Figure 2.2 The targeted MS/MS spectra of APAP and its metabolites .................27

Figure 2.3 The relative area of each metabolite .................................................28

Figure 2.4 The proposed mechanism of the degradation of APAP catalyzed by CPO present by primary structure of each metabolites

Figure 2.5 Extracted chromatogram of APAP and its metabolites detected by Triple-Quadrupole LC/MS/MS.

Figure 2.5 (Cont.) Extracted chromatogram of APAP and its metabolites detected by Triple-Quadrupole LC/MS/MS.

Figure 3.1 UV-Vis Spectra of CBZ with $\mathrm{H}_{2} \mathrm{O}_{2}$ and its metabolites at 1 min, $2.5 \mathrm{~min}$ and $4 \mathrm{~min}$ 
Figure 3.2. The effect of chloride on the degradation of CBZ .............................42

Figure 3.3 The effect of pH on CBZ degradation ...............................................43

Figure 3.4 The effect of $\mathrm{H}_{2} \mathrm{O}_{2}$ concentration ....................................................44

Figure 3.5 The effect of CBZ concentration .....................................................44

Figure 3.6 The targeted MS/MS spectra of CBZ and its metabolites ..................48

Figure 3.6 (Cont.). The targeted MS/MS spectra of CBZ and its metabolites .......49

Figure 3.7. The percentage of each metabolites measured by compound area 50

Figure 3.8 The area of metabolites with limited $\mathrm{H}_{2} \mathrm{O}_{2}$ at $1 \mathrm{~min}, 3 \mathrm{~min}$ and $5 \mathrm{~min}$ detected by Accurate-Mass LC-Q-TOF-MS .................................................

Figure 3.9 The chromatograms of CBZ and its metabolites .................................53

Figure 3.9 (Cont.) The chromatograms of CBZ and its metabolites .....................54

Figure 3.10 The proposed mechanism of the degradation of CBZ catalyzed by CPO.

Figure 4.1 UV spectrum of SMZ degradation catalyzed by CPO .........................65

Figure 4.2 (cont.) The targeted MS/MS spectra of APAP and its metabolites .....69

Figure 4.3 The percentage of each metabolites measured by compound area ..69

Figure 4.4 The area of metabolites with limited $\mathrm{H}_{2} \mathrm{O}_{2}$ at 1 minute, 3 minutes and 5 minutes detected by Accurate-Mass LC-Q-TOF-MS ...........................71

Figure 4.5. The chromatograms of CBZ and its metabolites ...............................73

Figure 4.5. (cont.) The chromatograms of CBZ and its metabolites .....................74

Figure 4.6. The proposed mechanism of the degradation of SMZ catalyzed by $\mathrm{CPO}-\mathrm{H}_{2} \mathrm{O}_{2}-\mathrm{Cl}$ - system presented by primary structure of each metabolite ..75

Figure 4.7 The percentage of the three metabolites measured by compound

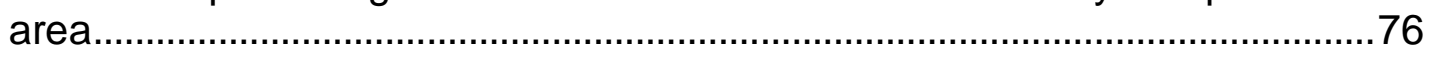

Figure 4.9. The mechanism of SMZ bromination catalyzed by CPO ……….........78 
Figure 5.1 The Proposed mechanism of His 105 in the cleavage of the

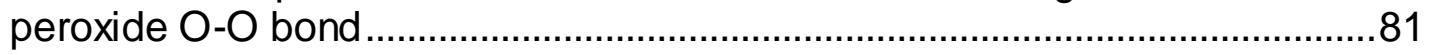

Figure 5.2 The CPO expression vector pCPO3.1-AmdS.....................................84

Figure 5.3 DNA sequence of H105R mutant ....................................................

Figure 5.4 H105R mutant grown on 1.2 sorbitol selective agar plate ...................88

Figure 5.5 The ABTS activity of H105R cultures since the second day of inoculation. Samples were run in triplicate........................................................89

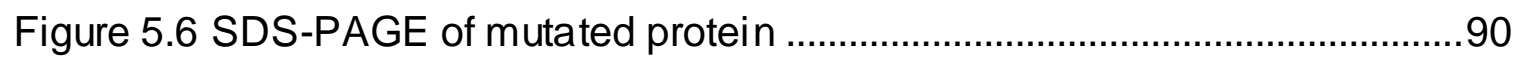

Figure 5.7 UV-Vis spectra of H105R mutant ....................................................90 


\section{LIST OF ABBREVIATIONS AND ACRONYMS}

ABBREVIATION

A

ABTS

AMDOPH

Amds

A. niger

A. nidulans

APAP

Asp

CBZ

CE

COSY

CPO

DEAE

DNA

dNTP

E

E/Glu

ee
FULL NAME

Alanine

2,20

azinobis(3ethylbenzothiazoline6sulfonic acid)

1-acetyl-1-methyl-2-phenylhydrazide

A.nidulans acetamidase gene

Aspergillus niger

Aspergillus nidulans

N-acetyl-p-

aminophenol/Acetaminophen

Aspartic acid

Carbamazepine

Collision energy

Correlation spectroscopy

Chloroperoxidase

Diethylaminoethanol

Deoxyribonucleic acid

Deoxyribonucleotide

Extinction coefficient

Glutamic acid

Enantiomeric excess 


\begin{tabular}{|c|c|}
\hline EE2 & Estrogen $17 \alpha$-ethinylestradiol \\
\hline $\mathrm{FbF}$ & Find by Formula \\
\hline FIA & Flow injection analysis \\
\hline $\mathrm{His} / \mathrm{H}$ & Histidine \\
\hline HPLC & $\begin{array}{l}\text { High performance liquid } \\
\text { chromatography }\end{array}$ \\
\hline LC-Q-TOF-MS & $\begin{array}{l}\text { Liquid chromatography Quadrupole } \\
\text { Time-of-Flight mass spectrometry }\end{array}$ \\
\hline LC-QQQ-MS & $\begin{array}{l}\text { Liquid chromatography Triple- } \\
\text { Quadrupole-mass spectrometry }\end{array}$ \\
\hline LDH & Lactate dehydrogenase \\
\hline MCD & Monochlorodimedone \\
\hline MRM & Multiply reaction monitoring \\
\hline $\mathrm{m} / \mathrm{z}$ & Mass-to-charge ratio \\
\hline NAPQI & $\mathrm{N}$-acetyl-p-benzoquinone imine \\
\hline NMR & $\begin{array}{l}\text { Nuclear magnetic resonance } \\
\text { spectroscopy }\end{array}$ \\
\hline NOE & Nuclear overhauser effect \\
\hline NOESY & $\begin{array}{l}\text { Nuclear overhauser enhancement } \\
\text { Spectroscopy }\end{array}$ \\
\hline ОTC & Over-the-counter \\
\hline$R$ & Arginine \\
\hline P450 & Cytochrome P450 mono-oxygenase \\
\hline
\end{tabular}




$\begin{array}{ll}\text { PCR } & \text { Polymerase chain reaction } \\ \text { PglaA } & \text { A. niger glucoamylase promoter } \\ \text { Phe } & \text { Phenylalanine } \\ \text { ppm } & \text { Parts per million } \\ \text { RRHD } & \text { Rapid Resolution High Definition } \\ \text { Rz value } & \text { Reinheitzahl value } \\ \text { RT } & \text { Retention time } \\ \text { SDS-PAGE } & \text { Sodium dodecyl sulfate polyacrylamide } \\ \text { SMZ } & \text { gel electrophoresis } \\ \text { STP } & \text { Sulfamethazine } \\ \text { TCC } & \text { Sewage treatment plant } \\ \text { TtrpC } & \text { Thermostatted column compartment } \\ \text { UV } & \text { A. nidulans anthranilate synthetase } \\ \text { UV-Vis } & \text { terminator } \\ \end{array}$




\section{CHAPTER I.}

\section{INTRODUCTION}

1.1 The occurrence of pharmaceutical pollutants in water

Trace amounts of pharmaceuticals have been detected in water from nanograms per liter to micrograms per liter. Pharmaceuticals are chemicals that arise from natural sources or through artificial synthesis with the purpose to treat disease with highly specific biological targets. Even with lower concentration than regular contaminants, pharmaceuticals could still target biological organisms efficiently due to their properties. Pharmaceutical overdose or prolong exposure increase the potential risk of drug poisoning for both human and animals. Also, the hazards of pharmaceutical in the aquatic environment have been widely discussed in recent years. [1, 3]

The annual consumption of prescribed drugs is about 100 tons in Germany, not including over-the-counter (OTC) drugs, so the actual total should be much more than the prescribed amounts. The pharmaceutical compounds that enter in the aquatic environment are mainly from human and veterinary medicines. The urine and feces from humans and animals affect the environment by different pathways. Human pharmaceuticals arise from their excretes and passed into sewage and are partially removed through the sewage treatment plant (STP) before entering the surface water that will goes through a series of process forming the drinking water we intake. Veterinary pharmaceuticals enter the environment similar to the human route where the animal's excretes form contaminate manure which affect the soil and ground water by soil fertilization. 
Rainfall makes liquid manure and digested sludge flows into surface water. Soil and ground water may get contaminants from digest sludge applied in STP treatment. Another contaminated source is the disposal of pharmaceuticals in domestic waste without any previous treatment, leachates flow from the waste to landfill site, and continue to ground water and surface water. Finally, these detectable amount of pharmaceuticals reaches the drinking water sources. (Fig. 1.1). $[3,4]$

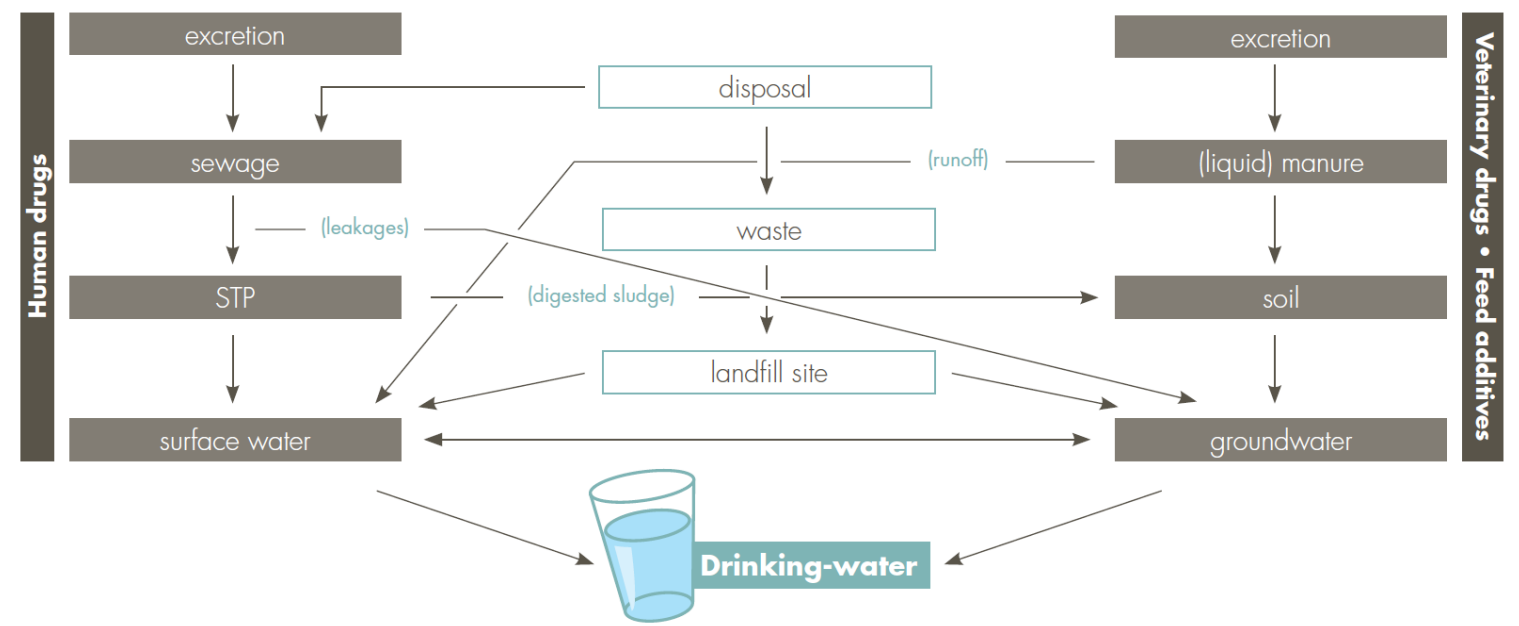

Figure 1.1 Fate of human and veterinary pharmaceuticals in the environment. [1, 4]

The trace amouts of pharmaceuticals are not likely to have acute toxicity but have showed chronic ecotoxicity effects in animals. The lowest observed effect concentration (LOEC) of diclofenac on organ level for rainbow trout (Oncorhynchus mykiss) was in the same range as the detected concentration of the drug in wastewater.[5] The endocrine disrupter drugs have dramatically negtive effects on aquatic animal such as fathead minnows, with environmentally relevant concentrations (less than $1 \mathrm{ng} / \mathrm{L}$ ) of estrogen $17 \alpha$-ethinylestradiol (EE2), 
showed adverse effects on fertilization and sex ratio and even secondary sex characteristics.[6, 7]

The impact of trace amount drugs in environment cannot be regardless, antibiotics resistant bacteria were detected in the surface water with highest average concentration of $78.31 \mathrm{ng} / \mathrm{L}$. [8] Even in low concentration, antibotics can affect microorganism as signaling hormones, potentially threaten aquatic ecosystems and the public health[9]

In drinking water, more than 10 drugs were detected frequently, the concentration of drug could achieve concentration as high as $270 \mathrm{ng} / \mathrm{L}$ (clofibric acid), and the concentration of drug metabolites could reach $0.9 \mathrm{ug} / \mathrm{L}$ (AMDOPH deriving from dimethylaminophenazone). Currently, there is no rountine test for monitoring the concentration of drug in drinking water. The risk of low concentrations of pharmaceuticals maybe minor, but with scarce information about the effects of chronic drug exposure, it still has the potential to affect human health negatively. The risk assessment of pharmaceutical in aquatic enviroment still needs to be evaluated in the future.[10-12]

After 2006, the new compounds approved in Europe have to complete the assessment of enviromental toxicity and fate datasets, the older medicine are still need to consider of their persistence and harzards.[13]

1.2 The treatment for removal of pharmaceuticals in water

There are two types of wastewater treatment, conventional treatment and advanced treatment (Table 1.1). 
Active sludge is the typical treatment of conventional treatment process, the removal efficiencies were varying regarding different factors such as temperature of degradation, and hydraulic retention time.[14] The biological filtration including the STP treatment, a process to remove contaminants in municipal wastewater, and produce environmental friendly metabolites, has been found to be insufficient to eliminate all persistent pharmaceutical residues. [15] The removal rates are inconstant due to the diversity of drug properties, for example, carbamazepine is resistant in STP but have different removal rate in active sludge.[16]

Advanced treatments are widely investigated in the removing drugs in wastewater. Ozonation, microfiltration and ultrasound can achieve up to $100 \%$ degradation. 
Table 1.1 Conventional and advanced wastewater treatment and their removal range efficiency of pharmaceuticals.

Wastewater treatment

Conventional wastewater treatment

Activated sludge

Biological filtration

Primary settling

Coagulation, filtration and settling

Sand filtration

Advanced wastewater treatment

Ozonation

Ozonation/ultrasound and sonocatalysis

Ozonation and catalytic ozonation

UV irradiation

Photolysis (UV/hydrogen peroxide)

Dark and light Fenton

$\mathrm{UV} / \mathrm{TiO}_{2}$

Biomembrane

Microfiltration and reverse osmosis

Reverse osmosis

Ultrasound

\section{Removal range}

(\%)

$-193-100^{a}$

6-71

3-45

$5-36$

$0-99$
1-100

23-45

$>9-100$

29

$52-100$

$80-100$

$>95$

23-99

$91-100$

$62-97$

24-100

${ }^{a}$ The removal efficiency is negative due to the calculation method, the hydraulic retention time is considered. The influent sample and effluent sample are not absolutely related. Anc carbamazepine, the negative removal efficiency is consistent, it is suggested the metabolit carbamazepine can be converted to parent compound by enzyme activity in STP. [1]

The application of ozonation with $\mathrm{H}_{2} \mathrm{O}_{2}$ is used in wastewater recycling for indirect potable reuse to degrade persistent organic pollutant. [1] However, the advanced treatments are needed to be further investigated considering the application possibility to individual pharmaceuticals, for instance, ozonation the high efficiency normally is activated by relatively high concentration of $\mathrm{O}_{3}$. The 
oxidized products might be resistant to the ozonation and contain high acute toxicity. [17] Different economic and efficient wastewater treatments are required to be developed considering the complexity of pharmaceutical pollutions.

\subsection{The structure of CPO}

Chloroperoxidase (CPO) is a heme-containing glycoprotein secreted by the fungus Caldariomyces fumago. The molecular weight of CPO is approximately 42,000 Daltons. Ferriprotoporphyrin IX is found to be its prosthetic group.[18] CPO consists of 299 amino acids, the tertiary structure of CPO mainly consists of eight alpha helical segments and a small beta pair (Fig. 1.2).[19] It has an active site similar to that of P450s and peroxidase. In comparison with P450s and peroxidase, the cysteine 29 is the heme ligand of CPO in the proximal pocket resembling P450s. The polar distal side is similar to peroxidase, whereas the acid-base catalyst in the active site of CPO responsible for the cleavage of the peroxide $\mathrm{O}-\mathrm{O}$ bond is glutamic acid 183, instead of histidine which is typical in other peroxidase. [20] [21]

There is a narrow channel connected the protein surface to the heme center, halogen ions are found to bind in the narrow channel, the halogen ion binding sties found suggested the pathway of halides from the protein surface to heme active center. In addition, there is a wide channel which suggest to be the binding site of bulky molecules, reaction such as oxidation, epoxidation might happen here (Fig 1.3).[21] 
In conventional heme peroxidases, histidine residue is the acid-base catalyst, whereas glutamic acid 108 (Glu 183) is the acid-base catalyst of CPO. Generally

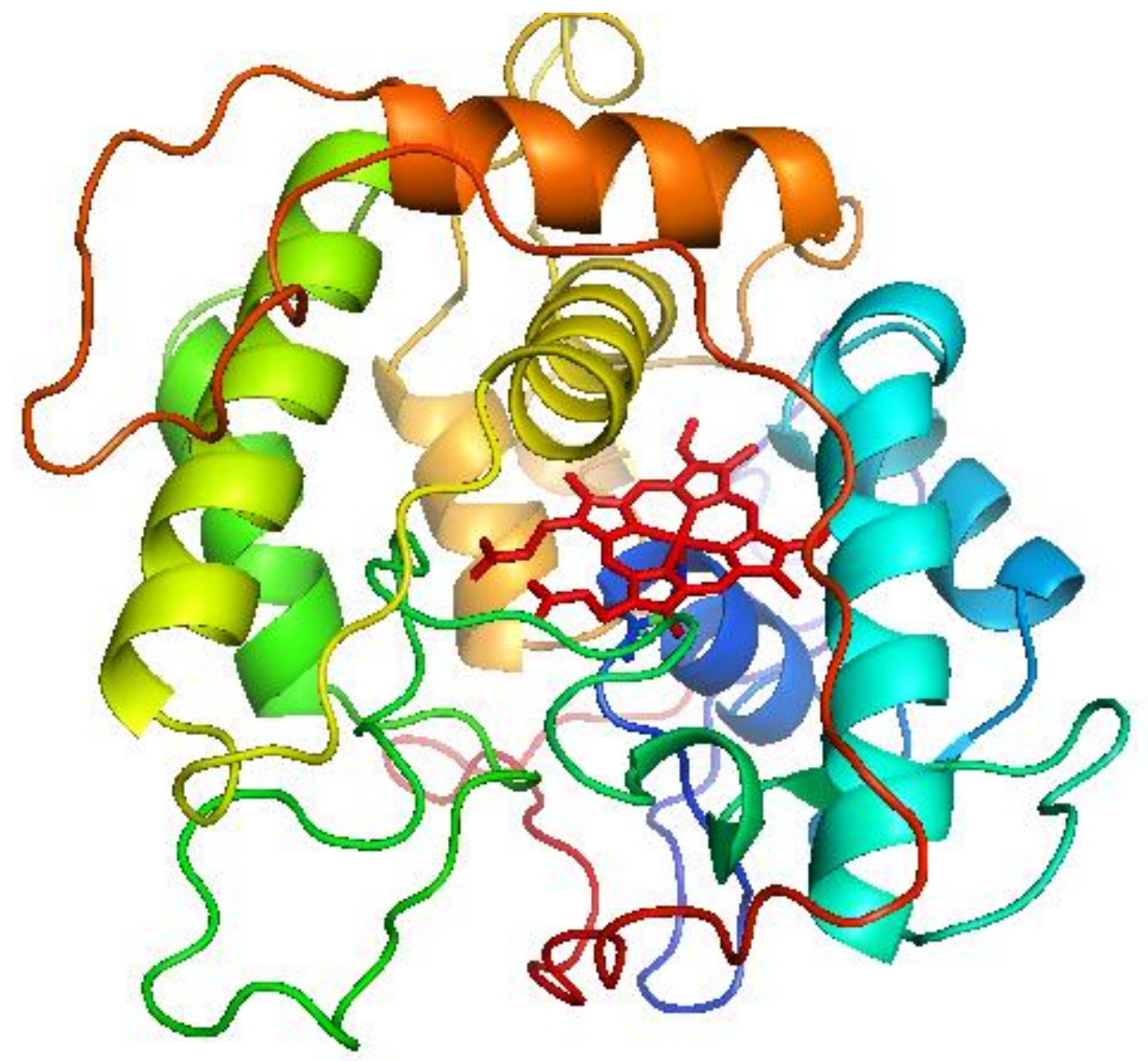

Figure 1.2 Crystal structure of CPO was presented by Pymol software, the protein data bank (PDB; http://www.pdb.org) entry 1CPO was used. Heme prophyrin was depicted as red color, located in the center of protein. [20]

for heme peroxidase, the catalyst residue interact with another amino acid to cleave the peroxide bond. In CPO, the residue suggested to interact with Glu183 assisting in the formation of compound I is His105.

In conventional heme peroxidases, histidine residue is the acid-base catalyst, whereas glutamic acid 108 (Glu 183) is the acid-base catalyst of CPO. Generally 
for heme peroxidase, the catalyst residue interact with another amino acid to cleave the peroxide bond. In CPO, the residue suggested to interact with Glu183 assisting in the formation of compound I is histidine 105.

His 105 is hydrogen bonded to Glu 183 and Asp 106, the hydrogen bondings facilites the cleavage of peroxide bond and positioning Glu 183 properly with relation to heme center during the catalyzation. [20, 21, 23] Two pheylalanine residues (Phe 103 and Phe 186) are close to the heme iron and thought to interact with hydrophobic substrate and control the substrate to access the heme center (Fig 1.4). [21] There is also other result that occurs because of the

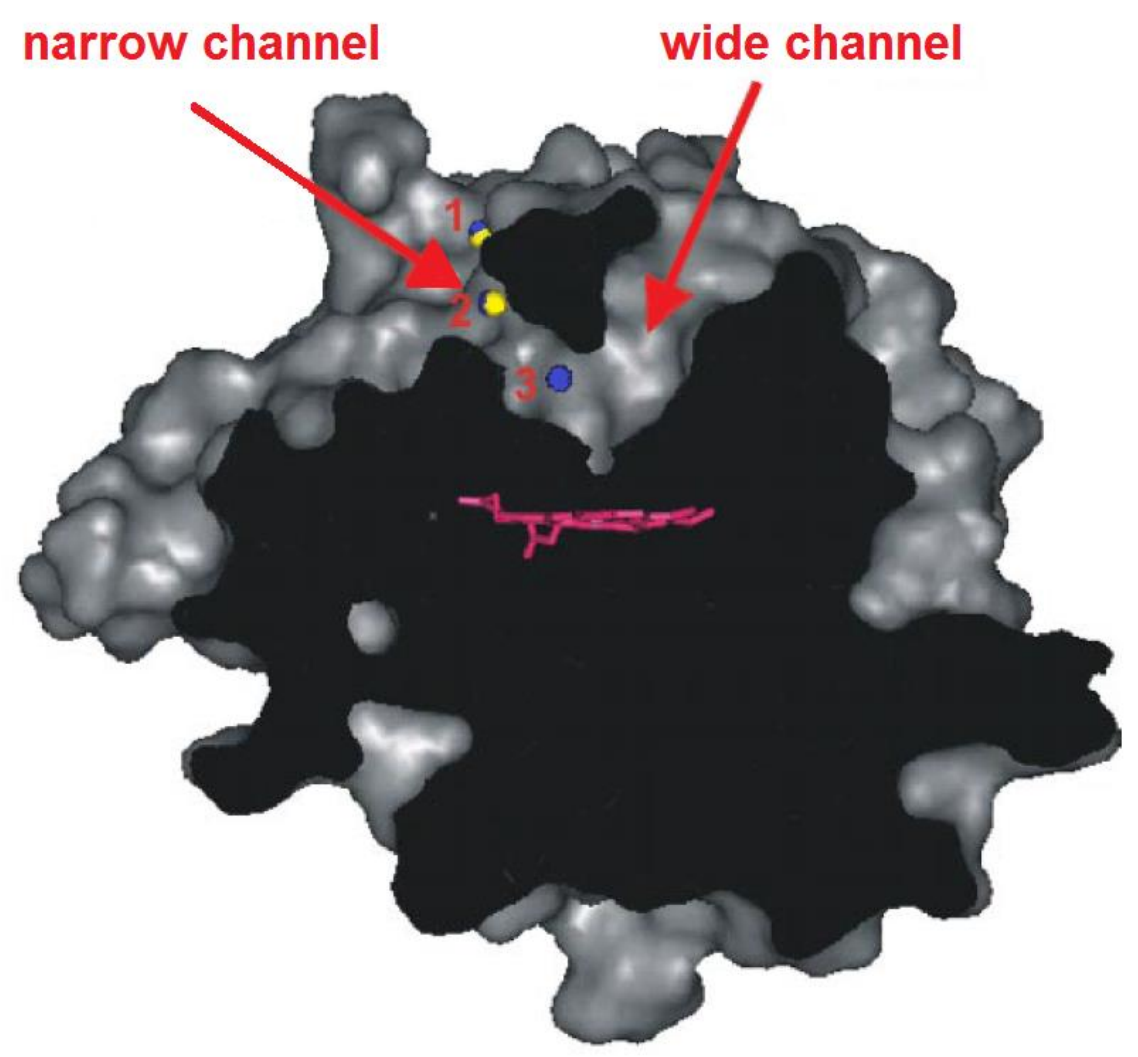

Figure 1.3 Slice of CPO crystal structure with surface presentation. Heme is depicted in magenta, narrow channel and wide channel are marked by arrow. Yellow sphere presents bromide and blue sphere presents iodide. The binding sites of halide are labeled by numbers (1 -3$)$ in red color. [22] 
modification of histidine residues, suggested His 105 affected epoxidation and peroxide dismutations but not decreased peroxidation rate.[24] CPO might have multiply reactive sites regarding the same reaction, and the role of $\mathrm{H} 105$ still needs to be further investigated by other techniques to unravel the mechanism of CPO.

His 105 is hydrogen bonded to Glu 183 and Asp 106, the hydrogen bondings facilites the cleavage of peroxide bond and positioning Glu 183 properly within heme center during the catalyzation. [20, 21, 23] Two pheylalanine residues (Phe 103 and Phe 186) are close to the heme iron and thought to interact with hydrophobic substrate and control the substrate to access the heme center (Fig 1.4). [21] There is also other result based on the modificatiion of histidine residues, suggested His 105 affected epoxidation and peroxide dismutations but not decreased peroxidation rate.[24] CPO might have multiply reactive sites for

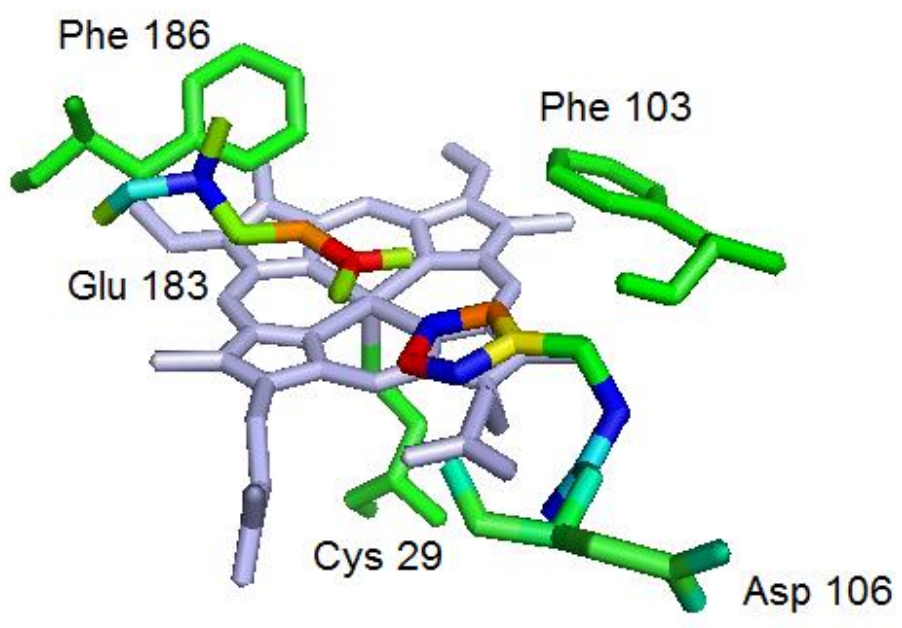

Figure 1.4 CPO active site presented by Pymol software (PDB entry 1CPO) with important amino acids in the distal pocket. Heme is depicted in grey. His 105 was proposed to form hydrogen bonds with Glu 183 and Asp 106, conferring the proper position of Glu183 and the orientation to form compound I.Phe 103 and Phe 186 were observed to be close to heme center, might control the access of substrate by polarity. [21] 
the same reaction, and the role of $\mathrm{H} 105$ still needs to be further investigated by other techniques to unravel the mechanism of CPO.

\subsection{The mechanism of CPO catalyzed reactions}

The complex structure of the CPO active site associates with the multiple functions of CPO. The general catalytic cycle of CPO starts from the resting state of the enzyme, the native ferric center binds by $\mathrm{H}_{2} \mathrm{O}_{2}$ at the heme iron and to form the oxo-ferryl cation radical intermediate called compound I, during the reaction, two electrons from the heme center are transferred to $\mathrm{H}_{2} \mathrm{O}_{2}$ and cleaved the $\mathrm{O}-\mathrm{O}$ bond, producing $\mathrm{H}_{2} \mathrm{O}$. Compound $\mathrm{I}$ is involved in different types of chemical reactions. In the dismutation pathway, compound I will continue to react with $\mathrm{H}_{2} \mathrm{O}_{2}$ to generate $\mathrm{O}_{2}$ and $\mathrm{H}_{2} \mathrm{O}$, and be reduced back to its resting state. In the $\mathrm{P} 450$ pathway, the organic substrate $(\mathrm{RH})$ is hydroxylated and compound $\mathrm{I}$ is reduced back to ferric resting state.

Another pathway is peroxidation by forming another reactive intermediate compound II, the oxo-ferryl intermediate. During the process, one electron from compound $\mathrm{I}$ is transferred to an organic molecule $(\mathrm{AH})$, converting $\mathrm{AH}$ to the radical molecule $(A) \cdot[25,26]$ Electron is transferred to the organic substrate from compound II, and CPO returns to the resting state.[27] In general, another major pathway of compound $\mathrm{I}$ is halogenation by interacting with halide $(X)$ to form compound $\mathrm{X}$, a ferric intermediate. Compound $\mathrm{X}$ will halogenate organic substrate $(\mathrm{AH})$ and generate hydroxyl ion $\left(\mathrm{OH}^{-}\right)$, returns back to its resting state (Fig. 1.5). 
Compound I with strong oxidizing ability is also proposed to generate hypochlorous acid / hypobromous acid, or $\mathrm{Cl}_{2} / \mathrm{Br}_{2}$ as the active intermediates in the oxidative chlorination. They are presumed to diffuse into the medium and to oxidize the substrate externally or react with substrates within the active sites. [28-32] The chlorination mechanism of CPO will be further discussed and confirmed in my research.

1.5 CPO catalyzed reactions

CPO catalyzes two major types of oxidations; they are two one-electron oxidations as catalyzed by most peroxidases and two-electron oxidations which are rare for conventional peroxidases.

\subsubsection{One-electron oxidations}

The one electron oxidations of CPO include peroxidation and dehalogenation and polymeration driven by radical. $[33,34]$ The typical peroxidation of CPO is the oxidation of 2,2'-azinobis-3-ethylbenzothiazoline-6-sulfonic acid (ABTS), it is used as ABTS assay to measure the peroxidase activity of CPO / mutant CPO (Fig 1.6). [35]

Dehalogenation was found in trihalophenols and fluorophenols (Fig 1.7) According to the general mechanism, fluoride is not involved in halogenation catalyzed by CPO, whereas in dehalogenation, fluoride of substrate is reacted. Both reactions show the potential application of CPO in environmental pollutant treatment. In the defluorination of fluorophenols, dimers and trimers were generated in one electron oxidation. [33, 34] The function of polymerization showed in some other peroxdase is also found in CPO catalyzed reaction. [34, 35] 


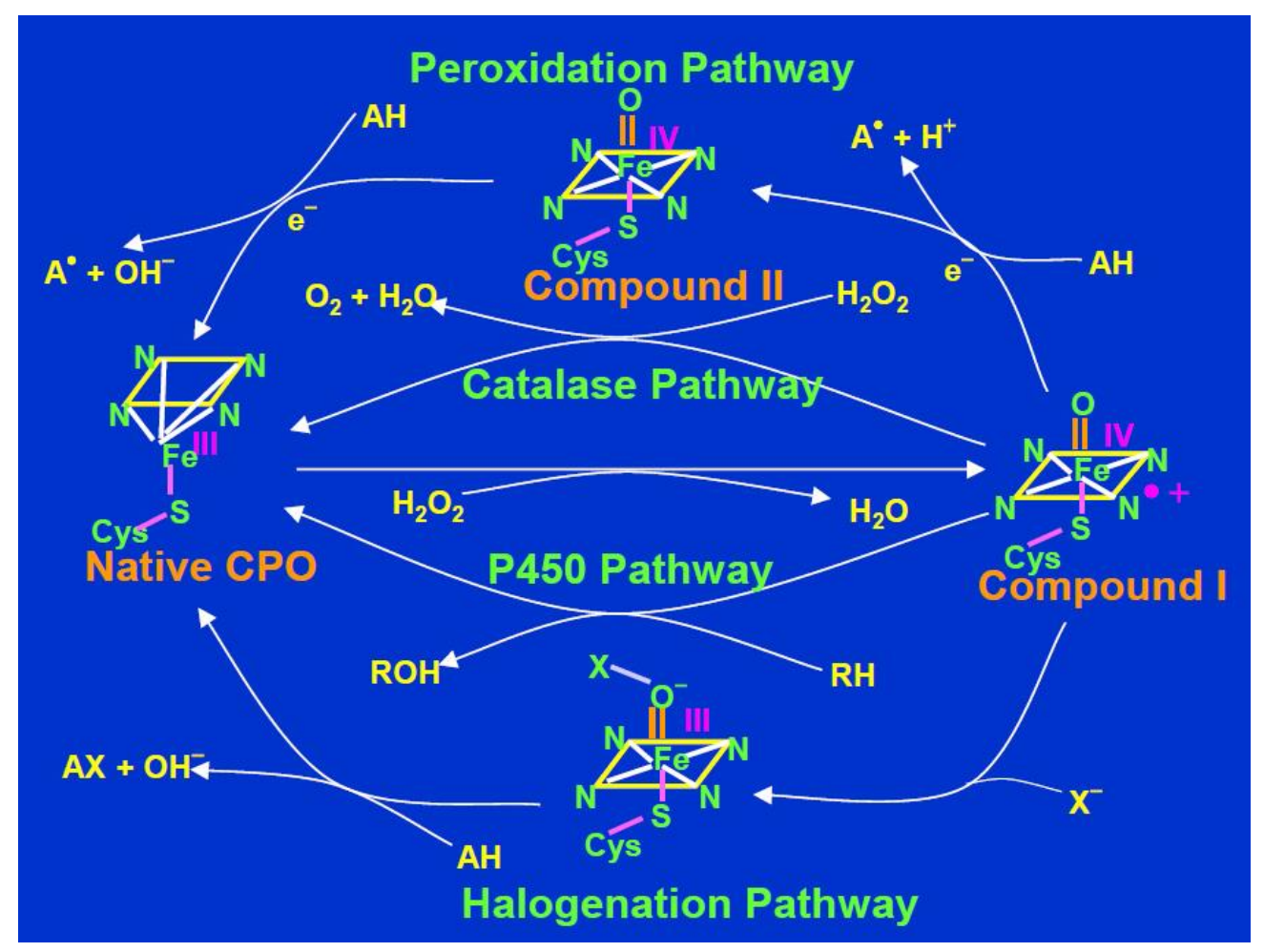

Figure 1.5 The general mechanism of CPO catalyzed reation. AH presents the substrate, the oval presents the heme; compound I and II present the ferryl intermediates; X presents halogen atom (except $\mathrm{F}^{-}$).[29] 

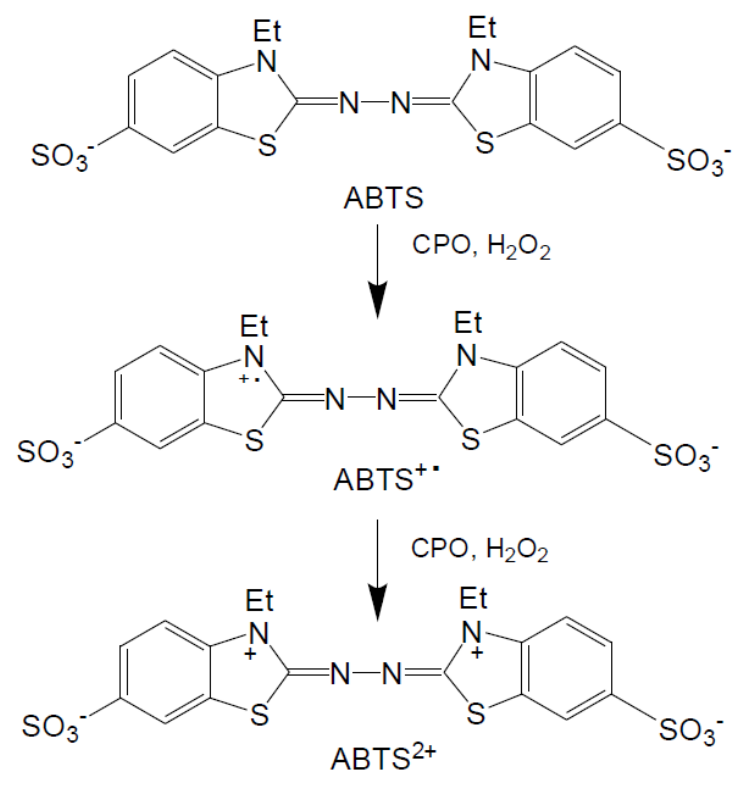

Figure 1.6 The oxidation of ABTS catalyzed by CPO.[36]

Dehalogenation was found in trihalophenols (Fig. 1.7)and fluorophenols (Fig 1.8) According to the general mechanism, fluoride is not involved in halogenation catalyzed by CPO, whereas in dehalogenation fluoride of substrate reacted. Both reactions show the potential application of CPO in environmental pollutant treatment. In the defluorination of fluorophenols, dimers and trimers were generated in one electron oxidation. [33, 34] The function of polymerization showed in some other peroxdase is also found in CPO catalyzed reaction. [34, 35]

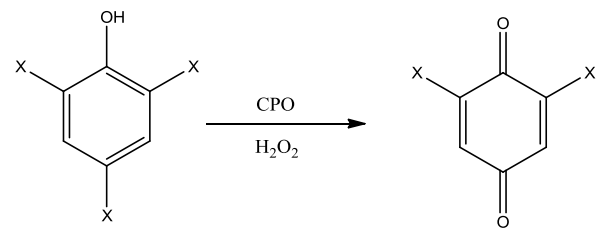

Figure 1.7 The dehalogenation of trihalophenol catalyzed by CPO.[33] 
<smiles>Oc1ccc(-c2ccc(O)c(F)c2)cc1F</smiles><smiles>Oc1ccc(-c2cccc(F)c2)cc1F</smiles><smiles>Oc1c(F)cccc1-c1cccc(F)c1O</smiles><smiles>Oc1cc(F)c(Oc2cccc(F)c2)cc1Oc1cccc(F)c1</smiles><smiles>Oc1ccccc1F</smiles><smiles>CC#CC</smiles><smiles></smiles><smiles>C=CC=C</smiles><smiles>CC(C)(C)[C@H]1CC(=O)C=CC1=O</smiles><smiles>CSc1ccc(O)c(C2=CC(=O)C=CC2=O)c1</smiles><smiles>Oc1ccc(F)cc1-c1cc(F)ccc1O</smiles><smiles>C1CCCC1</smiles><smiles>C1CCCCC1</smiles>

1)

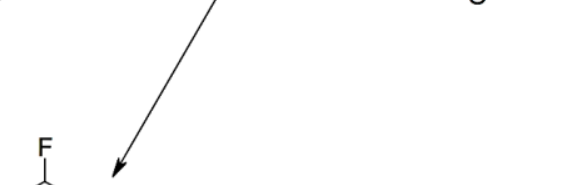<smiles></smiles><smiles>O=C1C=CC(Oc2cc(F)c(F)cc2Oc2ccc(F)cc2)C=C1</smiles>

Figure 1.8 The mechanism of CPO catalyzed one electron oxidation of fluorophenol.[34]

\subsubsection{Two-electron oxidations}

The two-electron oxidations includes halogenation and oxygen transfer as the major reactions. The significant function of CPO was found as the chlorination of monochlorodimedone (MCD), this reaction is routinely used as MCD assay to measure the chlorination activity of CPO /mutant CPO (Fig 1.8a). Other halogenation can also be carried out by bromide or iodide ions.[37] There are other substrates catalyzed by CPO 
in the halogenation, such as phenol. (Fig .1.9), 1,3-cyclopentanedione and alkenes (Fig 1.8b) [37-39] The oxidative chlorination catalyzed by CPO for halogenated phenols or phenols typically generated different isomers, which will be discussed in my research.

The other important two-electron oxidation consists of epoxidation with enantioselectivity, hydroxylation examples are showed in figure 1.8c [40]

\subsection{The application tendency of CPO}

The structural and functional features of CPO are suggested its potential as industrial and environmental biocatalysts, the catalyzation only needs relatively low concentration $\mathrm{H}_{2} \mathrm{O}_{2}$ as cofactor which is economic and safe in application.

To synthesize biological or pharmaceutical chemicals, CPO is an ideal candidate. The enantioselectivity of oxidation catalyzed by CPO was relatively high regarding the reaction of oxidizing primary alcohols to the corresponding aldehydes, and result could be improved with lowered temperature and at fixed $\mathrm{pH}$ to achieve a higher enatiomeric purities (ee). In addition, tert-butyl hydroperoxide was used instead of hydrogen peroxide.[41]

The fate and mechanism of azo dye degradation catalyzed by CPO was investigated and the high efficiency of the reaction implied the possibility of CPO application in the large scale wastewater treatment.[28, 42]

Recently, the degradation of sulfamethoxazole was investigated by utilizing CPO with active sludge to increase the drug degradation efficiency. [43] The potential of CPO application in degrading different pharmaceuticals will be analyzed in my dissertation.

To stabilize CPO and increase the recyclability of the enzyme the catalyst was conjugated to poly (hydroxypropyl methacrylate-co-polyethyleneglycole methacrylate) membranes, which enhanced the storage and thermal stability compared to the free CPO. Immobilization of CPO will be one tendency of CPO application, a research will be 
done to introduce CPO to the large scale application.<smiles>CC1(C)CC(=O)C(Cl)C(=O)C1</smiles><smiles>O=CCO</smiles><smiles>CC1(C)CC(=O)C(Cl)(Cl)C(=O)C1</smiles>

(a)<smiles>O=C1CCC(=O)C1</smiles>

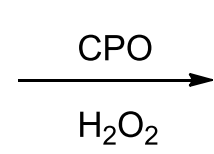<smiles>O=C1CCC(=O)C1(Cl)Cl</smiles><smiles>CC(C)=C(C)C</smiles><smiles>CC(=O)O</smiles><smiles>[X]C(C)(C)C([X])(C)C</smiles>

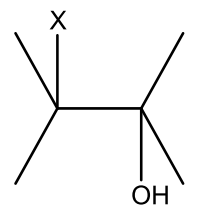

(b)<smiles>C=CC=CCCC</smiles><smiles>CCCCC1OC1C(C)O[Na]</smiles><smiles>C=Cc1ccccc1</smiles><smiles>O=CCOC(=O)O</smiles><smiles>c1ccc(C2CO2)cc1</smiles>

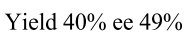<smiles>O=CCc1ccccc1</smiles><smiles>C=C(C)c1ccccc1</smiles><smiles>CC(=O)O[Na]</smiles>

(c) Yield 90\%, EE 25\%<smiles>CC(C=O)c1ccccc1</smiles>

Figure 1.9 Reactions catalyzed by CPO in phosphate buffer with chloride ions. (a) The chlorination of MCD catalyzed by CPO.[38] (b) The examples of halogenation by ,3cyclopentanedione and alkenes.[38, 39] (c) The typical examples of epoxidation and hydroxylation catalyzed by CPO with the yields and enatiomeric purities (ee).[41] 


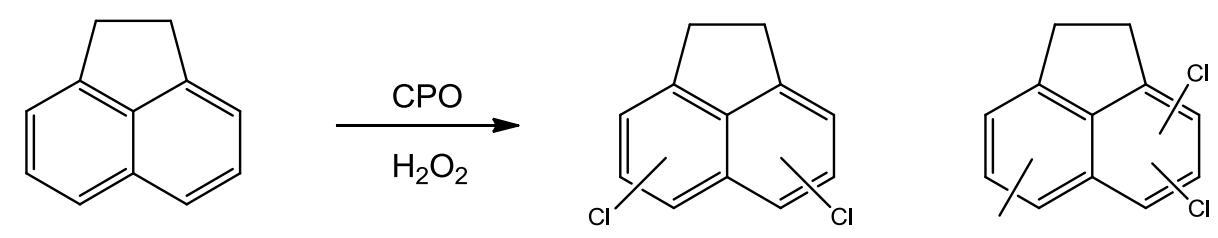<smiles>Cc1c2ccccc2c(C)c2ccccc12</smiles>

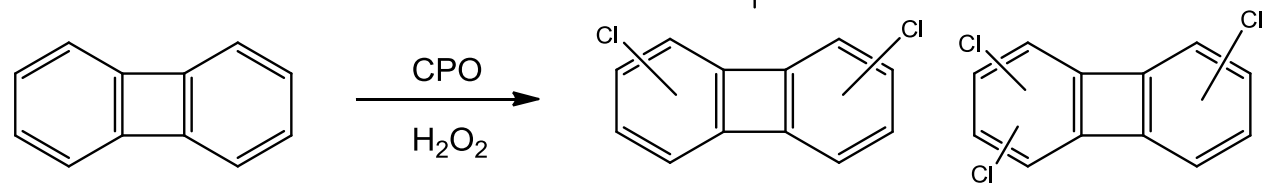<smiles>CC(C)(C)c1ccc2c(c1)Cc1ccc(Cl)cc1-2</smiles><smiles>Cc1ccccc1-c1cccc2cc(C(=O)O)ccc12</smiles>

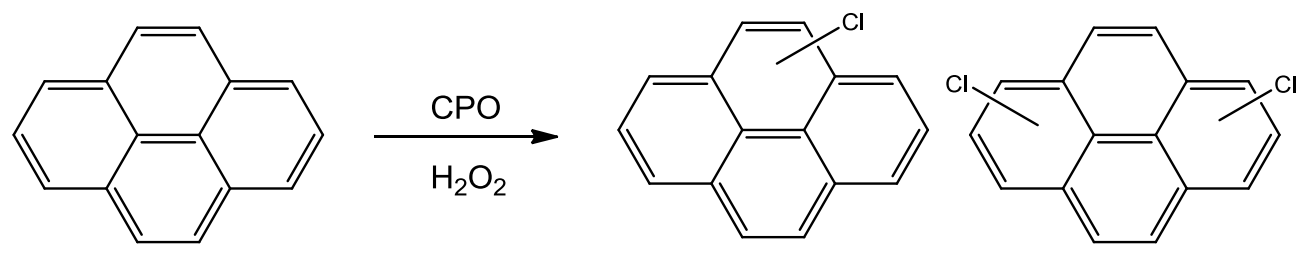<smiles>CC(C(=O)O)C(=O)O</smiles>

Figure 1.10 The chlorination of aromatic substrates catalyzed by CPO in phosphate buffer with chloride ions.[39] 


\section{CHAPTER II.}

\section{CPO-CATALYZED CHLORINATION AND POLYMERIZATION OF ACETAMINOPHEN}

\subsection{Background}

Acetaminophen ( $\mathrm{N}$-acetyl-p-aminophenol, APAP), also known as paracetamol, is an active ingredient in over-the counter medicines and widely used for relieving fever and pain. The production of APAP was estimated to be in the kiloton level in the USA per year.[44] Overdose causes serious liver damage because of the formation of $\mathrm{N}$-acetyl-p-benzoquinone imine (NAPQI).[45] APAP is ubiquitous in the natural environment, detected as $1.89 \mu \mathrm{g} / \mathrm{L}$ in ground water in the U.S.A[46] Occurrence of APAP as a contaminant in wastewater and drinking water increased the risk of human health and investigations of biodegradation of APAP.[47, 48]

Bioremediation catalyzed by CPO is a potential treatment as a consequence of its environmental friendliness and low cost investment. The efficiency of APAP degradation catalyzed by CPO would be investigated, the metabolites and pathway would be proposed in this experiment.

2.2 Experimental Procedure

\subsubsection{Material}

Chloroperoxidase (CPO) is a heme-containing glycoprotein secreted by the marine fungus Caldariomyces fumago. The isolation of CPO proposed in this study was a modification of the protocol reported by Morris and Hager[18] where acetone was used as precipitating agent instead of ethanol as the fractionation 
solvent. CPO with $R z=1.45\left(R z\right.$ is purity standard defined as $A_{398} / A_{280}=1.44$ for pure enzyme) was applied in all reactions. All solvents were HPLC grade or Optima $^{\circledR}$ LC/MS grade, purchased from Thermo Fisher Scientific Inc. (Waltham, MA, USA). Water was produced by using a Milli- $Q^{\circledR}$ Biocel $^{\mathrm{TM}}$ Ultra-Pure water purification system equipped with $0.22 \mu \mathrm{M}$ membrane filter cartridge (EMD Millipore, Billerica, MA, USA), and an organic removal cartridge (Evoqua Water Technologies, Lowell, MA, USA).

\subsubsection{UV-Visible spectrophotometry}

A VARIAN UV-Vis spectrophotometer (Cary 200 Bio) was used to collect the UV spectra of the degradation products. The drug solution was scanned by dissolving $0.11 \mathrm{mM}$ APAP in $100 \mathrm{mM} \mathrm{KH}_{2} \mathrm{PO}_{4}$ buffer with $20 \mathrm{mM} \mathrm{KCl}$ at $\mathrm{pH} 2.75$. The same solution was monitored after mixed with $0.55 \mathrm{mM} \mathrm{H}_{2} \mathrm{O}_{2}$. The reaction was initiated with the addition of $5 \mathrm{nM} \mathrm{CPO}$ and UV-Vis spectrum was recorded for the reaction time: 1 minute, 2.5 minutes, and 4 minutes.

2.2.3 Liquid chromatography and mass spectrometry

\subsubsection{Sample preparation}

To investigate the degradation efficiency, $62.56 \mu \mathrm{M}$ APAP was reacted with $321.56 \mu \mathrm{M} \mathrm{H}_{2} \mathrm{O}_{2}$ and $0.43 \mathrm{nM} \mathrm{CPO}$ for 1 hour at room temperature. Mixture was centrifuged at 3,000 g in Centriprep ${ }^{\circledR}$ centrifugal filter unit with a 30,000 Dalton cut-off membrane (EMD Millipore, Billerica, MA, USA). The yielded products was collected after centrifuged for $1 \mathrm{~min}$. Ethyl acetate was used to extract the filtrate while shaking vigorously, and the supernatant was evaporated to dryness by using nitrogen gas. The dried metabolites were dissolved in $\mathrm{H}_{2} \mathrm{O}$ /methanol (95:5 
$\mathrm{v} / \mathrm{v}$ ) to make the final concentration $1 \mathrm{mg} / \mathrm{L}(\mathrm{ppm})$. Sample was stored at $-20{ }^{\circ} \mathrm{C}$ in a freezer or immediately run in the LC-Q-TOF-MS mass spectrometer system.

A low concentration of $\mathrm{CPO}$ and $\mathrm{H}_{2} \mathrm{O}_{2}$ reaction sample was prepared as follows: $6.86 \mu \mathrm{M} \mathrm{H}_{2} \mathrm{O}_{2}$ was added directly to Centriprep ${ }^{\circledR}$ centrifugal filter unit with the same membrane size as described above. Then $66.20 \mu \mathrm{M}$ APAP were added, catalyzed by the addition of $1.28 \mathrm{nM} \mathrm{CPO}$ in the $100 \mathrm{mM}$ phosphate buffer with $20 \mathrm{mM} \mathrm{KCl}$ for 3 minutes and 5 minutes. The experiments were run in triplicate. The dried metabolites were dissolved in $\mathrm{H}_{2} \mathrm{O} /$ methanol $(95: 5 \mathrm{v} / \mathrm{v})$ to make an approximate concentration of $1 \mathrm{mg} / \mathrm{L}(\mathrm{ppm})$, and detected by LC-QTOF-MS system immediately.

The high concentration of APAP sample was prepared by mixing $413 \mu \mathrm{M}$ APAP with $2 \mathrm{mM} \mathrm{H} \mathrm{O}_{2}$, catalyzed by $2 \mathrm{nM}$ CPO for 35 minutes at room temperature. The extraction was carried out by ethyl acetate, and the organic layer was dried by nitrogen gas. Metabolites were dissolved in $1.5 \mathrm{~mL}$ $\mathrm{H}_{2} \mathrm{O} /$ methanol $(95: 5 \mathrm{v} / \mathrm{v})$ to make an approximate final concentration of $5 \mathrm{mg} / \mathrm{L}$ (ppm). The sample was filtrated through $0.22 \mu \mathrm{M}$ polyethersulfone syringe filter. The sample was stored in a freezer at $-20^{\circ} \mathrm{C}$, detected both in Q-TOF-LC-MS system and Triple-quadrupole LC-MS/MS system.

2.2.3.2 Instrumentation and chromatographic separation

The Agilent 1290 Infinity UPLC system coupled with Agilent 6530 Q-TOF mass spectrometer was used for the chromatographic separation and identification of the metabolites. The Agilent MassHunter Data Acquisition Software (rev. B0.06.00) was used to control the UPLC and the mass 
spectrometer. Mass Hunter Qualitative Data Analysis Software (Rev. B.07.00 was used for data mining and identification. An Agilent ZORBAX Eclipse plus $\mathrm{C}_{18}$ Rapid Resolution High Definition (RRHD) column (100 mm×1.8 $\mu \mathrm{m})$ was applied, the column temperature was set at $30{ }^{\circ} \mathrm{C}$ via a thermostatted column compartment (TCC). An infinity 1290 automatic injector was used to Inject $1 \mu \mathrm{L}$ (microliter) of the sample to the column. A flow rate of $0.4 \mathrm{~mL} / \mathrm{min}$ was used and a aqueous mobile phase A consisting of water with $5 \mathrm{mM}$ ammonium formate with $0.1 \%$ formic acid and the organic mobile phase B consisting of acetonitrile with $0.1 \%$ formic acid. The optimized chromatographic gradient was at 0 minute, $95 \% \mathrm{~A}$ and $5 \% \mathrm{~B}$ and $\mathrm{B}$ increased linearly to $95 \%$ over 8 minutes, this gradient was maintained for 1 minute. The positive ionization mode was applied during all experiments.

In full scan MS mode, the accurate mass data of the molecular ions were processed through the Agilent MassHunter Qualitative Analysis software. The collected retention times and confirmed formulas of every metabolite were applied in targeted MS/MS mode to identify metabolites information.

Additionally an Agilent 6460 Triple-Quadrupole LC/MS/MS mass spectrometer was used to increase the detection sensitivity of the isolated metabolites that were initially identified by the LC-QTOF mass spectrometer. The same column and elution program previously used in the LC-QTOF was employed in the LCQQQ-MS system.

\subsubsection{Data Mining and Database development.}

To create a database of all metabolites with optimized parameters, several 
search algorithms were used in Mass Hunter Qualitative Data Analysis Software. One of this algorithms was Find by Formula $(\mathrm{FbF})$ which allow the search of a compound using its molecular formula. The search could include not only the formation of the molecular ion $[\mathrm{M}+\mathrm{H}]^{+}$but also the formation of adducts (like ammonium or sodium adducts) typically observed under the ionization conditions in electrospray. The samples were initially infused into the system by flow injection analysis (FIA) and later subjected to chromatography. Additional work was performed by LC-QQQ-MS detection for those metabolites present at low levels of concentration.

2.3 Result and discussion

2.3.1 UV-Vis study of CPO-catalyzed degradation of APAP

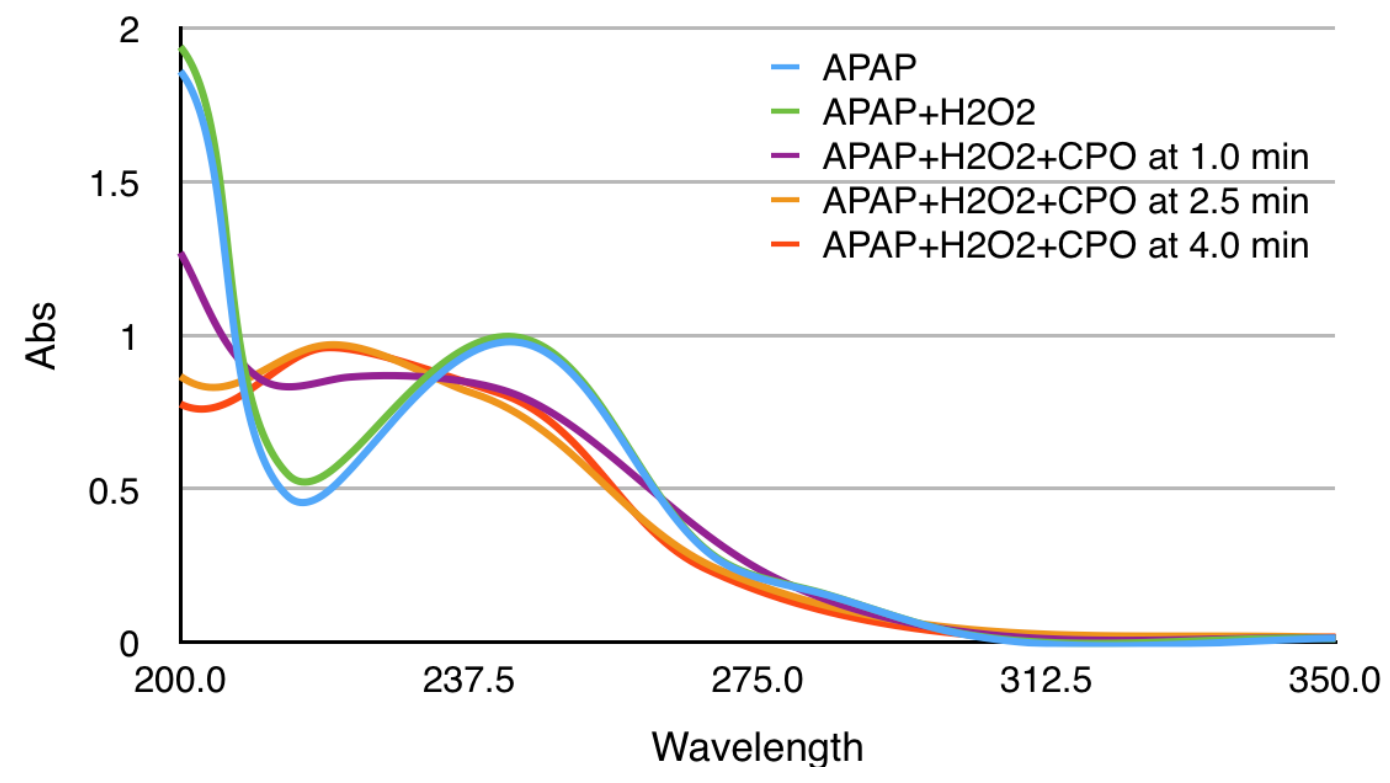

Figure 2.1 UV-Vis Spectra of APAP, APAP with $\mathrm{H}_{2} \mathrm{O}_{2}$ and its metabolites at $1 \mathrm{~min}, 2.5 \mathrm{~min}$, and $4 \mathrm{~min}$.

The UV-Vis Spectrum of APAP $(0.11 \mathrm{mM})$ were scanned in $100 \mathrm{mM} \mathrm{KH}{ }_{2} \mathrm{PO}_{4}$ 22 
buffer with $20 \mathrm{mM} \mathrm{KCl}$ at $\mathrm{pH} 2.75$. The Spectrum of APAP showed a strong absorption at $242 \mathrm{~nm}$. After mixed with $0.55 \mathrm{mM} \mathrm{H}_{2} \mathrm{O}_{2}$, the absorption curve increased slightly due to absorbance of $\mathrm{H}_{2} \mathrm{O}_{2}$. 1 minute after addition of $5 \mathrm{nM}$ CPO, the $477 \mathrm{~nm}$ absorption decreased, and increased at $4 \mathrm{~min}$. The absorption at 218 increased after $1 \mathrm{~min}$, and stopped increasing at $2.5 \mathrm{~min}$ (Fig. 2.1). The absorption of metabolites covered the absorption of original drug, which made the detection of kinetic parameter of APAP degradation catalyzed by CPO impossible.

The same reaction was carried out under the same condition except for the absence of chloride ion $(\mathrm{KCl})$ in phosphate buffer. Without $\mathrm{KCl}$, the absorbance did not change after the addition of CPO. Chlorine ion is necessary in the degradation of APAP in $\mathrm{CPO}-\mathrm{H}_{2} \mathrm{O}_{2}-\mathrm{Cl}^{-}$system.

\subsubsection{LC-Q-TOF- MS}

To investigate the degradation efficiency of APAP in $\mathrm{CPO}-\mathrm{H}_{2} \mathrm{O}_{2}-\mathrm{Cl}^{-}$system, $62.56 \mu \mathrm{M}$ APAP was reacted with $\mathrm{H}_{2} \mathrm{O}_{2}(321.56 \mu \mathrm{M})$ and $\mathrm{CPO}(0.43 \mathrm{nM})$ for 1 hour, the sample was analyzed by LC-Q-TOF-MS, APAP was not observed, the degradation efficiency by low concentration of CPO could achieved $100 \%$, suggesting the potential of the application of CPO in large-scale waste water treatment.

There were 7 APAP metabolites (coded from AM1 to AM7) confirmed by different retention times and accurate mass-to-charge ratios $(\mathrm{m} / \mathrm{z})$. The elemental formula, retention time, the relative mass difference between the observed mass and the mass of the target compound (in parts per million), and the difference 
between the observed mass and the mass of target compound (in milliDaltons) were collected (Table 2.1).

Table 2.1 Accurate-Mass LC-Q-TOF-MS data for the identification of APAP and its metabolites.

\begin{tabular}{|c|l|c|c|c|c|c|}
\hline Code & \multicolumn{1}{|c|}{ Formula } & $\begin{array}{c}\text { Retention time } \\
(\mathrm{min})\end{array}$ & $\begin{array}{c}\text { Experimental mass } \\
(\mathrm{m} / \mathrm{z})\end{array}$ & $\begin{array}{c}\text { Theoretical mass } \\
(\mathrm{m} / \mathrm{z})\end{array}$ & $\begin{array}{c}\text { Diff } \\
(\mathrm{ppm})\end{array}$ & $\begin{array}{c}\text { Diff } \\
(\mathrm{mDa})\end{array}$ \\
\hline APAP & $\mathrm{C}_{8} \mathrm{H}_{9} \mathrm{NO}_{2}$ & 2.986 & 151.0623 & 151.0633 & -7.06 & -1.07 \\
\hline AM1 & $\mathrm{C}_{8} \mathrm{H}_{8} \mathrm{CINO}_{2}$ & 3.713 & 185.0244 & 185.0246 & 1.27 & 0.23 \\
\hline AM2 & $\mathrm{C}_{16} \mathrm{H}_{16} \mathrm{~N}_{2} \mathrm{O}_{4}$ & 3.436 & 300.1110 & 300.1115 & 1.59 & 0.48 \\
\hline AM3 & $\mathrm{C}_{16} \mathrm{H}_{15} \mathrm{CIN}_{2} \mathrm{O}_{4}$ & 4.157 & 334.0720 & 334.0724 & 1.12 & 0.38 \\
\hline AM4 & $\mathrm{C}_{8} \mathrm{H}_{7} \mathrm{Cl}_{2} \mathrm{NO}_{2}$ & 4.822 & 218.9854 & 218.9847 & -3.23 & -0.71 \\
\hline AM5 & $\mathrm{C}_{16} \mathrm{H}_{14} \mathrm{Cl}_{2} \mathrm{~N}_{2} \mathrm{O}_{4}$ & 4.673 & 368.0331 & 368.0328 & -0.82 & -0.30 \\
\hline AM6 & $\mathrm{C}_{24} \mathrm{H}_{23} \mathrm{~N}_{3} \mathrm{O}_{6}$ & 4.051 & 449.1578 & 449.1587 & -1.94 & -0.87 \\
\hline AM7 & $\mathrm{C}_{24} \mathrm{H}_{22} \mathrm{CIN}_{3} \mathrm{O}_{6}$ & 4.567 & 483.1200 & 483.1197 & 0.59 & 0.29 \\
\hline
\end{tabular}

The mass spectrum of each individual metabolite found (7 in total) are included in Appendix I. The mass accuracy of the standard drug (APAP) was calculated and the values ranged between $0.37 \mathrm{ppm}$ and $9.75 \mathrm{ppm}$. The relative mass differences of metabolites were between $0.59 \mathrm{ppm}$ and $3.23 \mathrm{ppm}$. The mass differences of all compounds were less than $1.1 \mathrm{mDa}$. This method was proved to be efficient for determination of the metabolites of APAP.

Dimer (AM2) and Trimer (AM6) were formed, their chlorinated products were observed as AM3, AM7 respectively. For chlorinated metabolites, the isotope peaks were detected as the conformation of addition of chlorine atom. For AM1, AM3 and AM7, the two major peaks of each spectra separated by $2 \mathrm{~m} / \mathrm{z}$ units and peak heights are in the ratio of $3: 1$, proved these molecules contain one chlorine atom. For AM4 and AM5, there were 3 lines in the molecular ion region 
$(M+, M+2$ and $M+4)$ with gaps of $2 \mathrm{~m} / \mathrm{z}$ units between them, and with peak heights in the ratio of $9: 6: 1$, it was confirmed that both compounds contain 2 chlorines.

The structures of each metabolite were confirmed in targeted MS/MS by retention time and fragment ions (Fig. 2.2). The concentration of AM7 was low, the majority form of AM7 was [M+Na] $]^{+}(472.1453 \mathrm{~m} / \mathrm{z})$.

\subsubsection{Triple-quadruple LC/MS/MS}

Agilent Technologies 6460 Triple-quadrupole LC/MS/MS in multiply reaction monitoring (MRM) mode was applied in investigation of metabolites of APAP. Data were analyzed with Agilent MassHunter Qualitative Analysis software. After the formula of metabolites was confirmed by LC-Q-TOF-MS, Individual metabolites were assessed with a more sensitive analytical technique (LCQQQ-MS). For example, AM1 showed one solid peak with a mass corresponding to $\mathrm{m} / \mathrm{z} 186.03$ in Q-TOF both in full scan mode. The use of an MRM method in Triple-quadrupole LC/MS/MS, two peaks were clearly eluted at different retention times. For detection of isomers in complex biological matrix, Triple-quadrupole shows excellent sensitivity and selectivity for target compounds by filtering out the purities with the same molecular weight as targeted products.

The specific parameters, including optimized fragmentor voltage and collision energy (CE) for different MRM transition has been determined by flow injection analysis without column (FIA) with MassHunter Optimizer software (Appendix II). Routine MRM mode, more than one MRM transition per compound is used to 
avoid false-positive results, two transitions are monitored for one compound in most cases. 
$\mathrm{C}_{8} \mathrm{H}_{9} \mathrm{NO}_{2}$ (APAP)

x10 ${ }^{6}$ +ESI Product Ion (rt: $2.879 \mathrm{~min}$ ) Frag=135.0V CID@16.0 (152.0694[z=1] -> **) Acetaminophen...

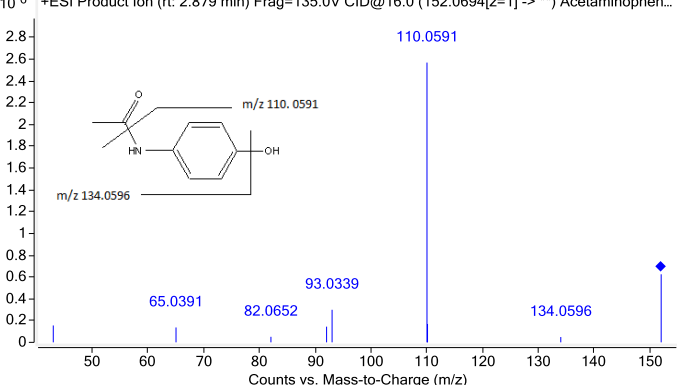

$\mathrm{C}_{16} \mathrm{H}_{16} \mathrm{~N}_{2} \mathrm{O}_{4}$ (AM2)

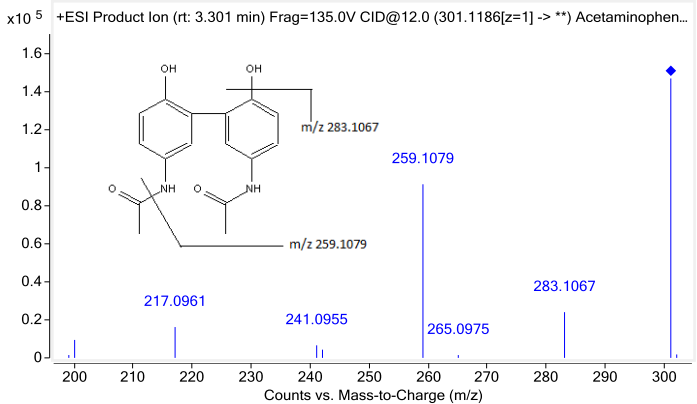

$\mathrm{C}_{8} \mathrm{H}_{7} \mathrm{Cl}_{2} \mathrm{NO}_{2}$ (AM4)

$\times 10^{4}$ +ESI Product lon (rt: $4.386 \mathrm{~min}$ ) Frag=135.0V CID@16.0 (335.0794[z=1] -> **) Acetaminophen....

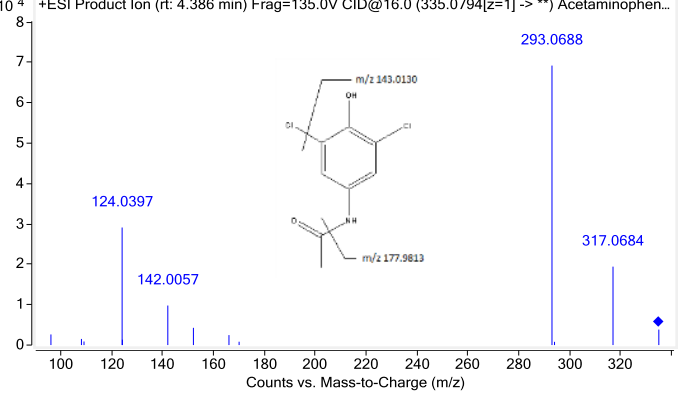

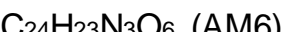

x10 4 +ESI Product lon (rt: 4.015 min) Frag=135.0V CID@12.0 (484.1272[z=1] > **) Acetaminophen...

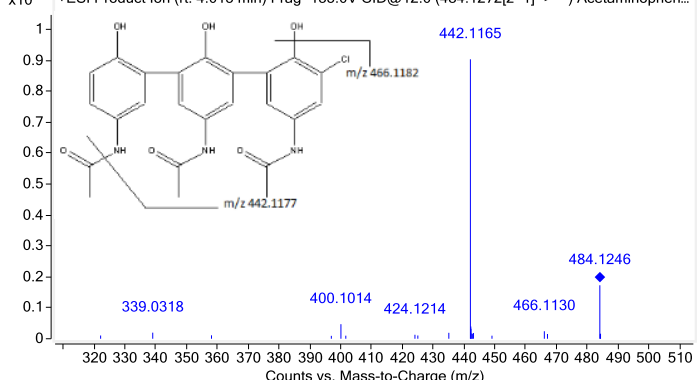

$\mathrm{C}_{8} \mathrm{H}_{8} \mathrm{CINO}_{2}(\mathrm{AM} 1)$

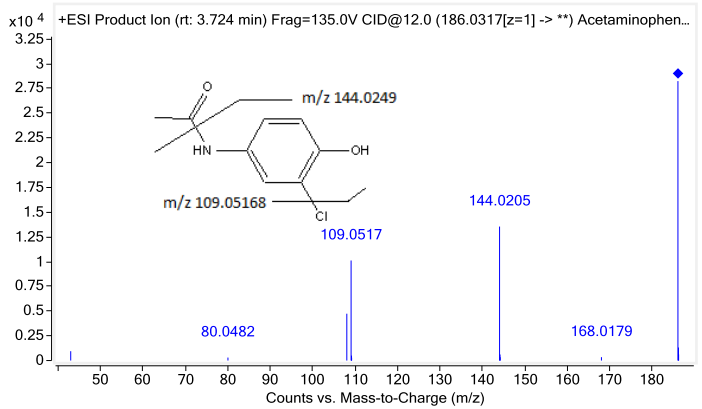

$\mathrm{C}_{16} \mathrm{H}_{15} \mathrm{ClN}_{2} \mathrm{O}_{4} \quad(\mathrm{AM} 3)$

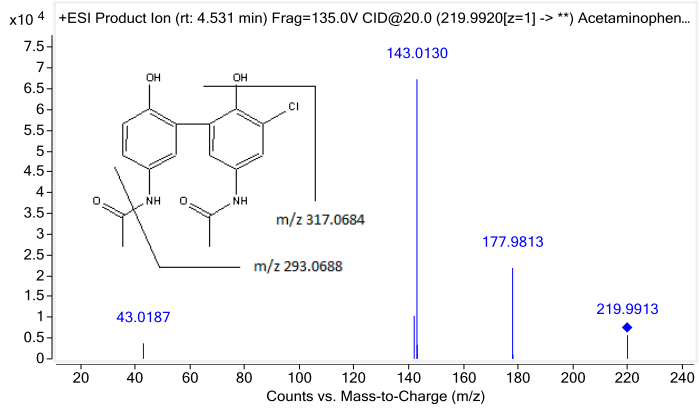

$\mathrm{C}_{16} \mathrm{H}_{14} \mathrm{Cl}_{2} \mathrm{~N}_{2} \mathrm{O}_{4}$ (AM5)

x10 4 +ESI Product Ion (rt: 4.829 min) Frag=135.0V CID@12.0 (369.0415[z=1] -> **) Acetaminophen...

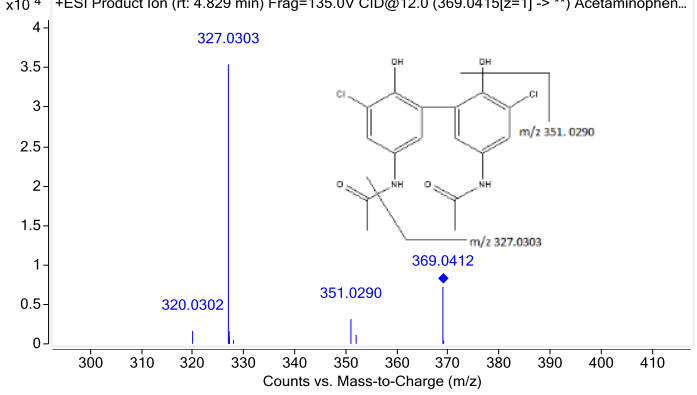

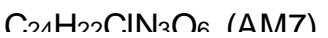

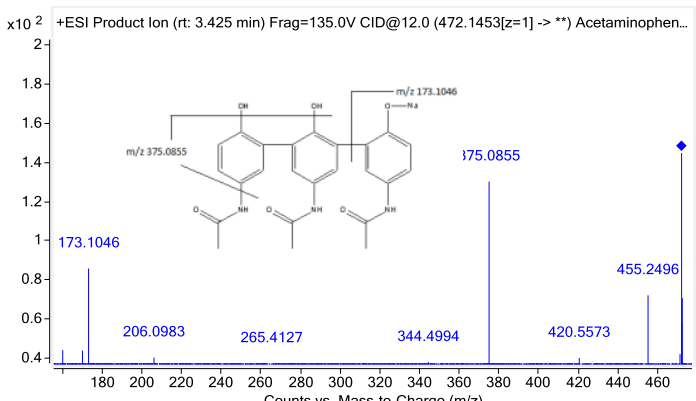

Figure 2.2 The targeted MS/MS spectra of APAP and its metabolites. 
The relative area in chromatogram was used to measure the abundance of each metabolite (Fig. 2.3a). AM1 and AM2 were the major product. To investigate the mechanism of the degradation, limited concentration of $\mathrm{H} 2 \mathrm{O} 2$ was added to the reaction, the ratio of APAP and $\mathrm{H} 2 \mathrm{O} 2$ was 10:1. At first 3 minutes, the formation of AM2 was predominant within 5 minutes. The proportional area was consistent with the degradation by higher concentration H2O2. (Fig. 2.3b). There were no other metabolites observed at the first reaction stage, suggesting the mechanism that AM3, AM4, AM5, AM6 and AM7 were formed from AM1 and AM2 (Fig 2.4).
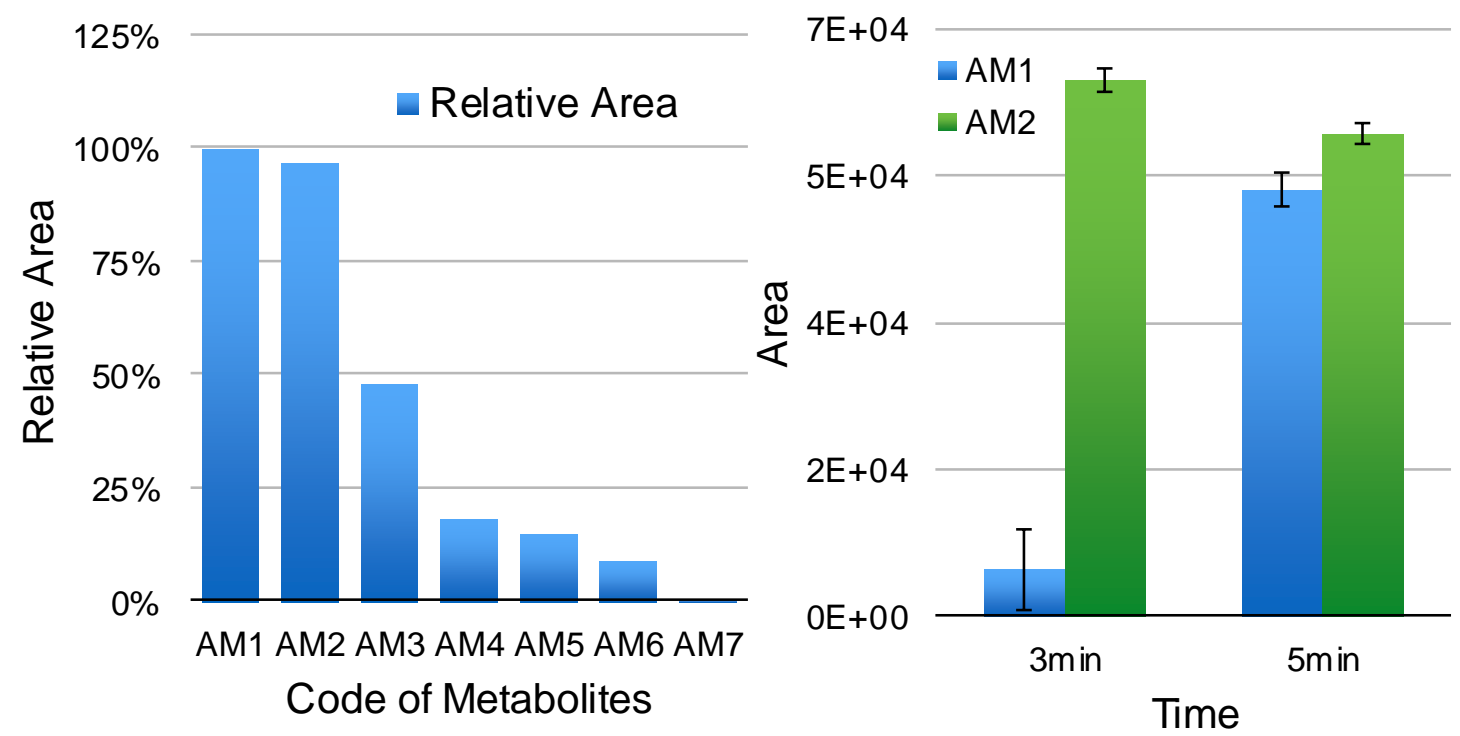

Figure 2.3 The relative area of each metabolite. (a) In high concentrated sample, the area of AM1 was set as $100 \%$, compared with AM1, AM2 -AM6 is $96.94 \%, 48.08 \%, 18.12 \%, 8.93 \%$, respectively. The area of AM7 was only $0.06 \%$. (b) The area of AM1 at 3 min was 5602 with error is 4879, at $5 \mathrm{~min}$ increases dramatically to 50800 with error 2103; AM2 is 63866 at 3 min with error 1452, and 57423 at 5 min with error 1201 .Each experiment was run in triplicate.

The different elution times of the same formula was considered as isomers. In addition, the exist of isomers could also be suggested with distinctive product 
ions by the same fragmentor voltage at different retention time (Table 2.2). The concentration of AM7 is too low to detect the different elution time of isomers. The other 6 metabolites showed a good resolution.

To consider the relatively low concentration isomers, all optimized MRM transitions were loaded into the MassHunter Acquisition software for performing data analysis. The chromatograph of each formula was extracted by Agilent MassHunter Qualitative Analysis software with the proposed structures, the first structure shown on the chromatogram is the proposed primary structure with highest concentration (Fig 2.5.)

Table 2.2 Information of the proposed isomers (RT presents retention time).

\begin{tabular}{|c|c|c|c|c|}
\hline Code & $\mathrm{RT}(\min )$ & Area & Share transitions & Specific transitions \\
\hline AM1-1 & 4.220 & 517761 & \multirow{2}{*}{$43,54,73,81,82,109,168$} & $53,80,144$ \\
\hline AM1-2 & 3.923 & 34544 & & \\
\hline AM2-1 & 3.664 & 812260 & \multirow{2}{*}{$108,259,283$} & $43,127,154,172,182,200,217$ \\
\hline AM2-2 & 4.292 & 64986 & & \\
\hline AM3-1 & 4.405 & 223747 & \multirow{3}{*}{43} & $142,170,198,199,215,257,293,317$ \\
\hline AM3-2 & 4.890 & 66386 & & $124,142,199,293,317$ \\
\hline AM3-3 & 9.397 & 111378 & & \\
\hline AM4-1 & 5.090 & 77208 & \multirow{2}{*}{$43,52,79,143,178$} & \\
\hline AM4-2 & 4.776 & 4866 & & \\
\hline AM5-1 & 5.423 & 375540 & & 218,326 \\
\hline AM5-2 & 5.704 & 104506 & & 218,326 \\
\hline AM5-3 & 4.943 & 71328 & & 326 \\
\hline AM5-4 & 5.551 & 54057 & & 326 \\
\hline AM6-1 & 9.714 & 36531 & \multirow{4}{*}{57} & $191,253,433$ \\
\hline AM6-2 & 9.046 & 5142 & & 71 \\
\hline AM6-3 & 8.480 & 5122 & & 71 \\
\hline AM6-4 & 8.838 & 2809 & & 71 \\
\hline
\end{tabular}




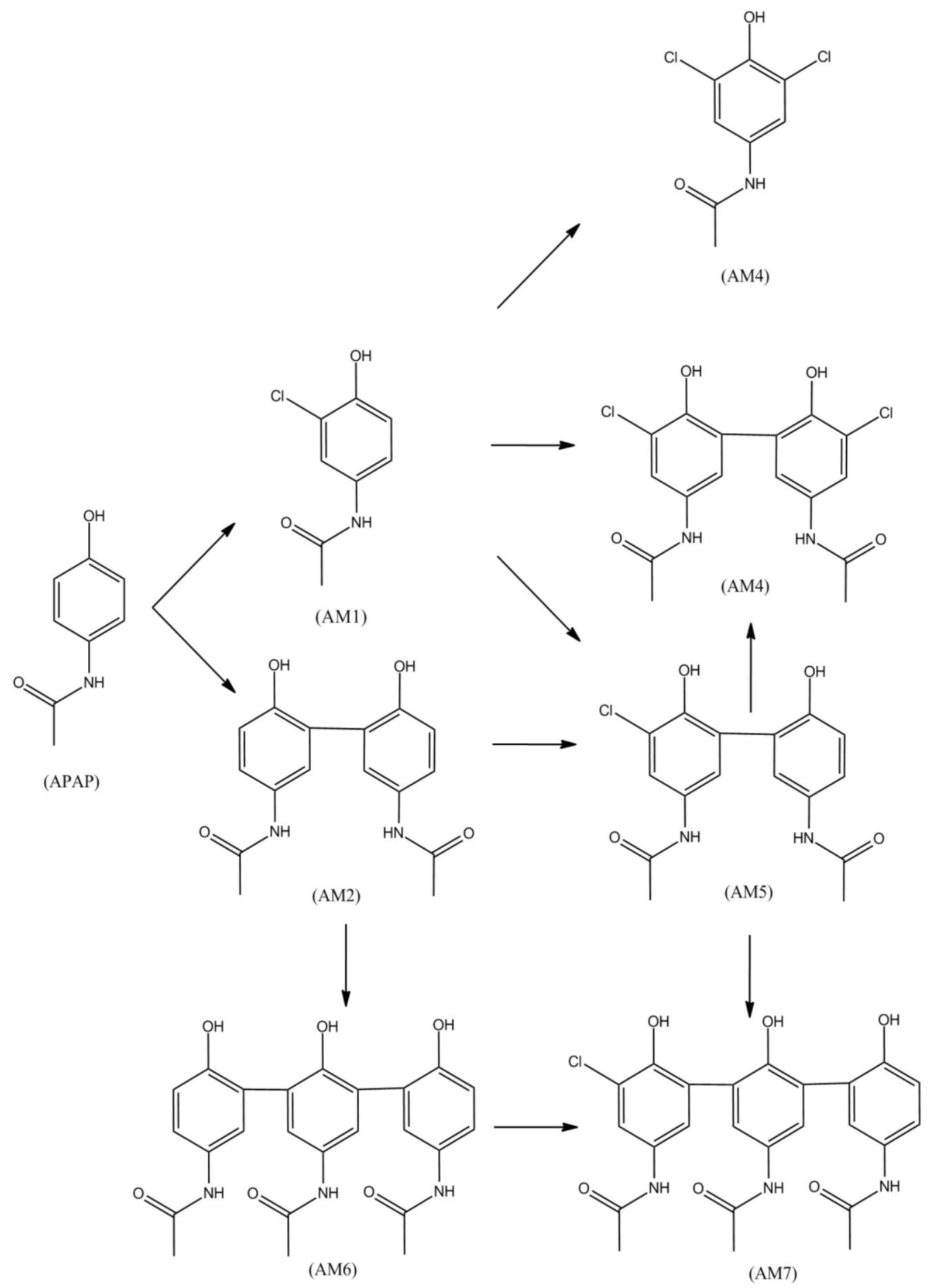

Figure 2.4 The proposed mechanism of the degradation of APAP catalyzed by CPO present by primary structure of each metabolites. 

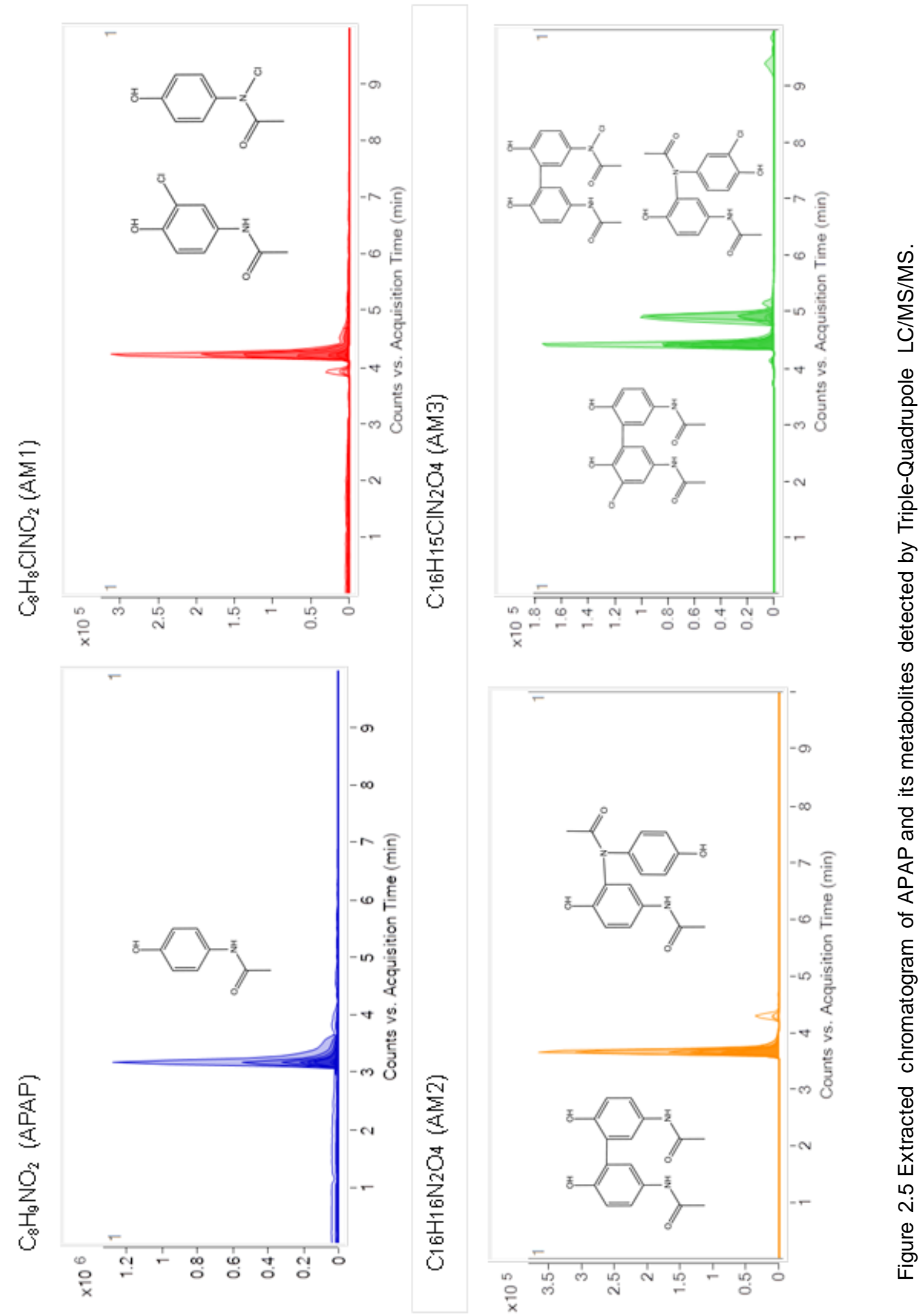

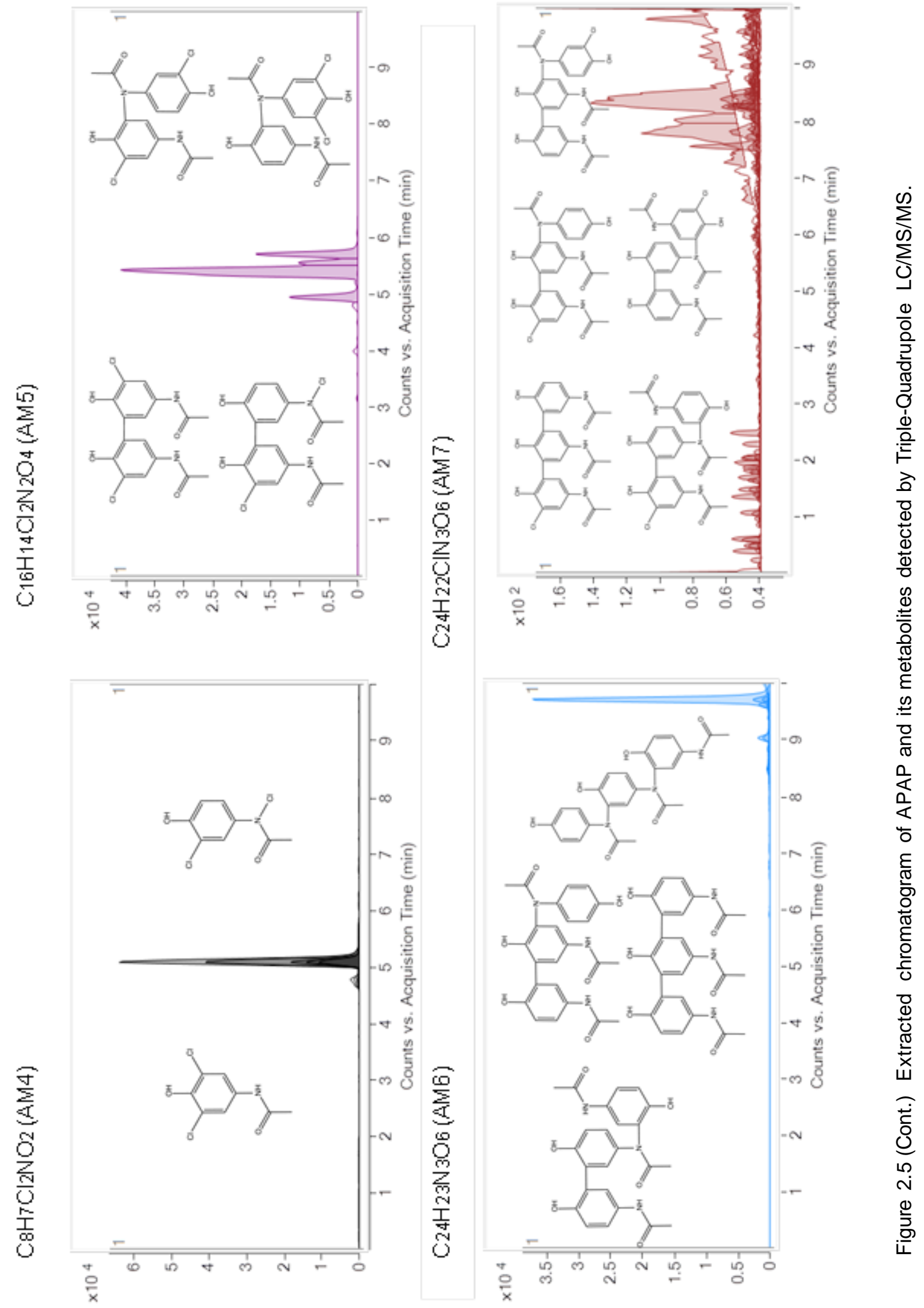


\subsection{Discussion}

NAPQI is the significant hepatotoxicity intermediate product of APAP catalyzed by the cytochrome P450 enzyme.[49] CPO shares the similar structure of P450 in proximal heme iron thiolate ligand,[50] but obviously, for catalyzing the degradation of APAP, the function of chlorination and dimerization is preferred instead of oxidation. For degradation of APAP, CPO- $\mathrm{H}_{2} \mathrm{O}_{2}-\mathrm{Cl}^{-}$system works differently from hypochlorite and $\mathrm{P} 450$, suggesting the specific ability of detoxification of APAP. AM1 is a chlorinated APAP product, previously AM1-1 was reported in nitration processes of acetaminophen in nitrifying activated sludge as a low concentration transformation product. [51]

AM1-1 and AM4-1 are two ring chlorination metabolites of APAP. They were detected after APAP $(10 \mu \mathrm{mol} / \mathrm{L})$ reacted with hypochlorite $(57 \mu \mathrm{mol} / \mathrm{L})$ for 1 hour, 88\% APAP was transformed. The approximate concentration of two chlorinated metabolites was $7 \%$ of the initial APAP. The concentration was relatively low when compared with the experiment catalyzed by CPO. When APAP mixed with hypochlorite, two toxic quinoidal oxidation products were produced, 1,4benzoquinone and $\mathrm{N}$-acetyl-p-benzoquinone imine (NAPQI) accounted for $25 \%$ and $1.5 \%$ of the initial acetaminophen concentration, respectively, which were not detected in $\mathrm{CPO}-\mathrm{H}_{2} \mathrm{O}_{2}-\mathrm{Cl}^{-}$system. Evaluation on the toxicity of the final products indicated that, CPO has the potential application in the purification of waste water when compared with regular chlorine disinfection systems.

AM4 was two electron-withdrawing chlorine substituent, compared the LDH leakage in hepatocytes with APAP, the LDH leakage was $36 \%$, and APAP was 
about $51 \%$. Other analogues at the 3,5 positions were tested $(R=-F,-B r$, and $-I)$, the value were from $42 \%$ to $15 \%$. Besides, these halogenated products decreased the inhibitory potency towards cyclooxygenase, showed the deceased function of drug, both evidences implied that the halogenation of APAP in waste water by $\mathrm{CPO}-\mathrm{H}_{2} \mathrm{O}_{2}-\mathrm{Cl}^{-}$system could decrease the cytotoxicity and drug effect in human body.[49]

Dimer (AM2), trimer (AM6) and their chlorinated products (AM3, AM5, and AM7) were identified in CPO catalyzed reaction. Both dimer and trimer were detected in the horseradish peroxidase catalyzed polymerization of APAP, there were two dimers and three trimers detected by $500-\mathrm{MHz}$ proton magnetic resonance spectroscopy.[35] The number of polymerized isomers generated by CPO catalyzed reaction were consistent with horseradish peroxidase catalyzed polymerization, and we proposed the same structure of each isomers. In the polymerization by horseradish peroxidase, the polymers formed primarily through a covalent bond between carbons ortho to the hydroxyl group due to the high unpaired electron density, and to a lesser extent, between the carbon ortho to the hydroxyl group and the amino group of another APAP molecule, as the isomer ratios observed from chromatograms of CPO catalyzed reaction. 


\section{CHAPTER III.}

\section{CPO-CATALYZED DEGRADATION OF CARBAMAZEPINE}

\subsection{Background}

Carbamazepine (CBZ) is widely used in the treatment of epilepsy, trigeminal neuralgia and bipolar disorder. [52] CBZ has been studied as persistent anthropogenic pollutant which is detectable in surface water, ground water, and even in drinking water. In Germany, the annual consumption of CBZ was over 80 tons, and the concentrations detected were $6.3 \mu \mathrm{g} / \mathrm{L}$ in STP effluent, $26 \mathrm{ng} / \mathrm{L}$ in urban groundwater, $762 \mathrm{ng} / \mathrm{L}$ in surface water, $1640 \mathrm{ng} / \mathrm{L}$ in raw sewage, and 65$86 \mathrm{ng} / \mathrm{L}$ in tap water.[4, 7, 53] In other European surface water, the highest concentration was reported from 110-800 ng/L. [1] In addition, $420 \mathrm{ng} / \mathrm{L} \mathrm{CBZ} \mathrm{was}$ detected in the ground water used for public drinking water supply in USA. [46]

$10 \mu \mathrm{g} / \mathrm{L} \mathrm{CBZ}$ showed obviously cytotoxic to gill cell of fish.[54] It was reported that $\mathrm{CBZ}$ administration caused tumors in rats for 2 years drug treatment, and reduced the humoral and cellular immune responses, and induced spleen cellularity.[55, 56] Therefore, Long time exposure to CBZ in drinking water is a potential risk to human health.

The common water treatment is effective to degrade CBZ, even with some new biodegradation method was investigated such as biodegradation by algea, fungus, phtocatalysis, etc. [4, 57-59] CPO has the potential to apply in degradation of CBZ due to its high efficiency (catalyzed within minutes), less expensive (work with nanomolar level enzyme) and its stability in acidic wastewater $(\mathrm{pH} 2.0-5.0)$. The $\mathrm{CBZ}$ degradation efficiency in water, the kinetic 
parameters and the products of CBZ catalyzed by CPO was investigated in this experiment.

The aim of this experiment was to investigate the potential application of CPO in the degradation of CBZ. The efficiency of CPO in the degradation of CBZ was measured. The operating conditions including the concentration of $\mathrm{Cl}^{-}$, reaction buffer $\mathrm{pH}$, and the concentration of $\mathrm{H}_{2} \mathrm{O}_{2}$ was optimized, and under the optimized conditions, the enzyme kinetic and degradation pathway was studied.

3.2 Experimental Procedure

\subsubsection{Material}

All material and chemicals used were the same as described in section 2.2.1.

\subsubsection{UV-Visible spectrophotometry}

\subsubsection{UV-Vis spectrum of degradation}

A VARIAN UV-Vis spectrophotometer (Cary 200 Bio) was used to collect the UV spectra of the degradation products. The drug solution was scanned by dissolving $0.07 \mathrm{mM} \mathrm{CBZ} \mathrm{in} 100 \mathrm{mM} \mathrm{KH}_{2} \mathrm{PO}_{4}$ buffer with $20 \mathrm{mM} \mathrm{KCl}$ at $\mathrm{pH} 2.75$. The same solution was monitored after mixed with0.35mM $\mathrm{H}_{2} \mathrm{O}_{2}$. UV spectra were recorded after the addition of $5 \mathrm{nM} \mathrm{CPO}$ for 1 minute, 2.5 minutes and 4 minutes. The degradation efficiency was calculated according to Equation (1)

Efficiency $(\%)=\frac{A_{0}-A_{t}}{A_{0}} \times 100$

\subsubsection{Effect of diverse parameters on CPO degradation}

The effect of the concentration of chloride was investigated. Degradation was carried out in $100 \mathrm{mM}$ phosphate buffer at pH 3.0 with $0.07 \mathrm{mM} \mathrm{CBZ}$ and 0.07 
$\mathrm{mM} \mathrm{H} \mathrm{H}_{2}$, concentration of chloride was increased from 0 to $20 \mathrm{mM}, 285 \mathrm{~nm}$ wavelength was monitored immediately after $2.5 \mathrm{nM}$ CPO was added.

The degradation rate at $\mathrm{pH}$ range of 2.0 to 5.0 was investigated to probe the effect of $\mathrm{pH}$ on $\mathrm{CPO}$ catalyzed reaction. The reaction was carried out in $100 \mathrm{mM}$ phosphate buffer with $20 \mathrm{mM} \mathrm{KCl}, 0.07 \mathrm{mM} \mathrm{CBZ}$, and $0.07 \mathrm{mM} \mathrm{H}_{2} \mathrm{O}_{2} . \mathrm{H}_{3} \mathrm{PO}_{4}$ and $\mathrm{KOH}$ were used to adjust $\mathrm{pH}, 285 \mathrm{~nm}$ wavelength was monitored immediately after the addition of $2.5 \mathrm{nM} \mathrm{CPO}$. The calculated time was from 0.2 to 0.4 minute.

The degradation rate of CBZ was determined by different concentration of hydrogen peroxide from $0.07-0.71 \mathrm{mM}$ in $100 \mathrm{mM}$ phosphate buffer with $20 \mathrm{mM}$ $\mathrm{KCl}$ and $0.07 \mathrm{mM} \mathrm{CBZ}$ at $\mathrm{pH}$ 3.0. $285 \mathrm{~nm}$ wavelenth was monitored immediately after the addition of $5 \mathrm{nM} \mathrm{CPO}$. Rate from 0.1 mintute to 03 minute was calculated as degradation rate.

It was assumed that the degradation would follow Michaelis-Menten kinetics, and the Lineweaver-Burk plot Equation was used to calculate Michaelis-Menten constant $\left(K_{m}\right)$ and maximum reaction rate $\left(V_{\max }\right)(2)$, where the $[S]$ presents the concentration of substrate (CBZ), $V$ presents the initial reaction rate, the rate was calculated by monitoring at $285 \mathrm{~nm}$ absorbance from 0.1-0.2 minute. The reaction was carried out in $100 \mathrm{mM}$ concentration of $\mathrm{KH}_{2} \mathrm{PO}_{4}$ buffer with $20 \mathrm{mM}$ $\mathrm{KCl}$ at $\mathrm{pH} 2.75$, the concentration of $\mathrm{CBZ}$ was varying from $0.02 \mathrm{mM}$ to $0.11 \mathrm{mM}$. UV was started to monitor immediately after adding $0.35 \mathrm{mM} \mathrm{H}_{2} \mathrm{O}_{2}$.

$$
\frac{1}{V}=\frac{K_{m}}{V_{\max }} \times \frac{1}{[S]}+\frac{1}{V_{\max }}
$$


The turnover number ( $k_{\text {cat }}$ ) was obtained by the equation (3), calculated from the maximum reaction rate $\left(V_{\max }\right)$ and the concentration of $\mathrm{CPO}\left(E_{0}\right)$.

$$
V_{\text {max }}=k_{c a t}\left[E_{0}\right]
$$

All experiments were triplicated and data reported were mean values of three independent measurements with standard deviation.

3.2.3 Liquid chromatography and mass spectroscopy

\subsubsection{Sample preparation}

To investigate the degradation efficiency, CBZ was dissolved in methanol to make stock solution $(21.19 \mathrm{mM}), 10.59 \mu \mathrm{M}(2.5 \mathrm{mg} / \mathrm{L}) \mathrm{CBZ}$ was reacted with 107.19 $\mu \mathrm{M} \mathrm{H}_{2} \mathrm{O}_{2}$ and $2.9 \mathrm{nM} \mathrm{CPO}$ for 10 minutes at room temperature. Mixture was centrifuged at $3,000 \mathrm{~g}$ in Centriprep ${ }^{\circledR}$ centrifugal filter unit with 30,000 Dalton cut-off membrane (EMD Millipore, Billerica, MA, USA). The filtrate was collected after centrifuged for $1 \mathrm{~min}$. Ethyl acetate was used to extract the filtrate while shaking vigorously. The remove the organic solvent, nitrogen gas purge was applied to dry the sample. The dried residues were dissolved in $\mathrm{H}_{2} \mathrm{O}$ /methanol $(95: 5 \mathrm{v} / \mathrm{v})$ to make the final concentration approximate $1 \mathrm{mg} / \mathrm{L}(\mathrm{ppm})$. The sample was stored at $-20{ }^{\circ} \mathrm{C}$ in a freezer, or immediately run in LC-Q-TOF-MS mass spectrometer system.

To detect all metabolites of $\mathrm{CBZ}, \mathrm{CBZ}$ was dissolved in methanol to make stock solution (21.19 mM), a high concentration of CBZ sample was prepared by mixing $62.56 \mu \mathrm{M}(14.8 \mathrm{mg} / \mathrm{L}) \mathrm{CBZ}$ with $0.4 \mathrm{nM}$ CPO, $\mathrm{H}_{2} \mathrm{O}_{2}$ stock solution (41.16 $\mathrm{mM}$ ) was added to reaction system at $56.5 \mu \mathrm{L} /$ minute to make the final 
concentration of $\mathrm{H}_{2} \mathrm{O}_{2}$ up to $316.56 \mu \mathrm{M}$. The total reaction time was 55 minutes. The solution was extracted by ethyl acetate, and the supernatant was evaporated by using nitrogen gas. Metabolites were dissolved in $2.0 \mathrm{~mL} \mathrm{H} \mathrm{H}_{2} \mathrm{O}$ /methanol (95:5 $\mathrm{v} / \mathrm{v}$ ) to make the final concentration approximately $5 \mathrm{mg} / \mathrm{mL}(\mathrm{ppm})$. The sample was centrifuge at $1200 \mathrm{~g}$ for 10 minutes, $1.5 \mathrm{~mL}$ supernatant was removed by syringe. Filtration was applied by using $0.22 \mu \mathrm{M}$ polyethersulfone syringe filter. The sample was stored at $-20{ }^{\circ} \mathrm{C}$ in freezer, detected both in LC-Q-TOF/MS system and Triple-Quadrupole LC/MS/MS system.

To investigate the mechanism of degradation, samples were prepared with low concentration of $\mathrm{H}_{2} \mathrm{O}_{2}$. $6.86 \mu \mathrm{M} \mathrm{H}_{2} \mathrm{O}_{2}$ was added directly to Centriprep ${ }^{\circledR}$ centrifugal filter unit (30,000 Dalton) with $42.28 \mu \mathrm{M} \mathrm{CBZ}$, catalyzed by $1.3 \mathrm{nM}$ CPO in the $100 \mathrm{mM}$ phosphate buffer with $20 \mathrm{mM} \mathrm{KCl}$ for 1 minute, 3 minutes and 5 minutes, filter units were centrifuged at $3000 \mathrm{~g}$ for $1 \mathrm{~min}$ at room temperature, and extracted the filtrate by ethyl acetate, purged the organic phase with nitrogen gas to dryness. The dried metabolites were dissolved in $\mathrm{H}_{2} \mathrm{O} /$ methanol $(95: 5 \mathrm{v} / \mathrm{v})$ to make the final concentration approximate $1 \mathrm{mg} / \mathrm{L}$ (ppm), and detected by LC-Q-TOF-MS system immediately. Experiments were run in duplicate.

3.2.3.2 Instrumentation and chromatographic separation

The instrumentation and chromatographic separation were the same as in section 2.2.3.2.

\subsubsection{Data Mining and Database development}

The data Mining and Database development were the same as in section 
2.2.3.3.

3.3 Result and discussion

3.3.1 UV-Vis study of CPO-catalyzed degradation of carbamazepine

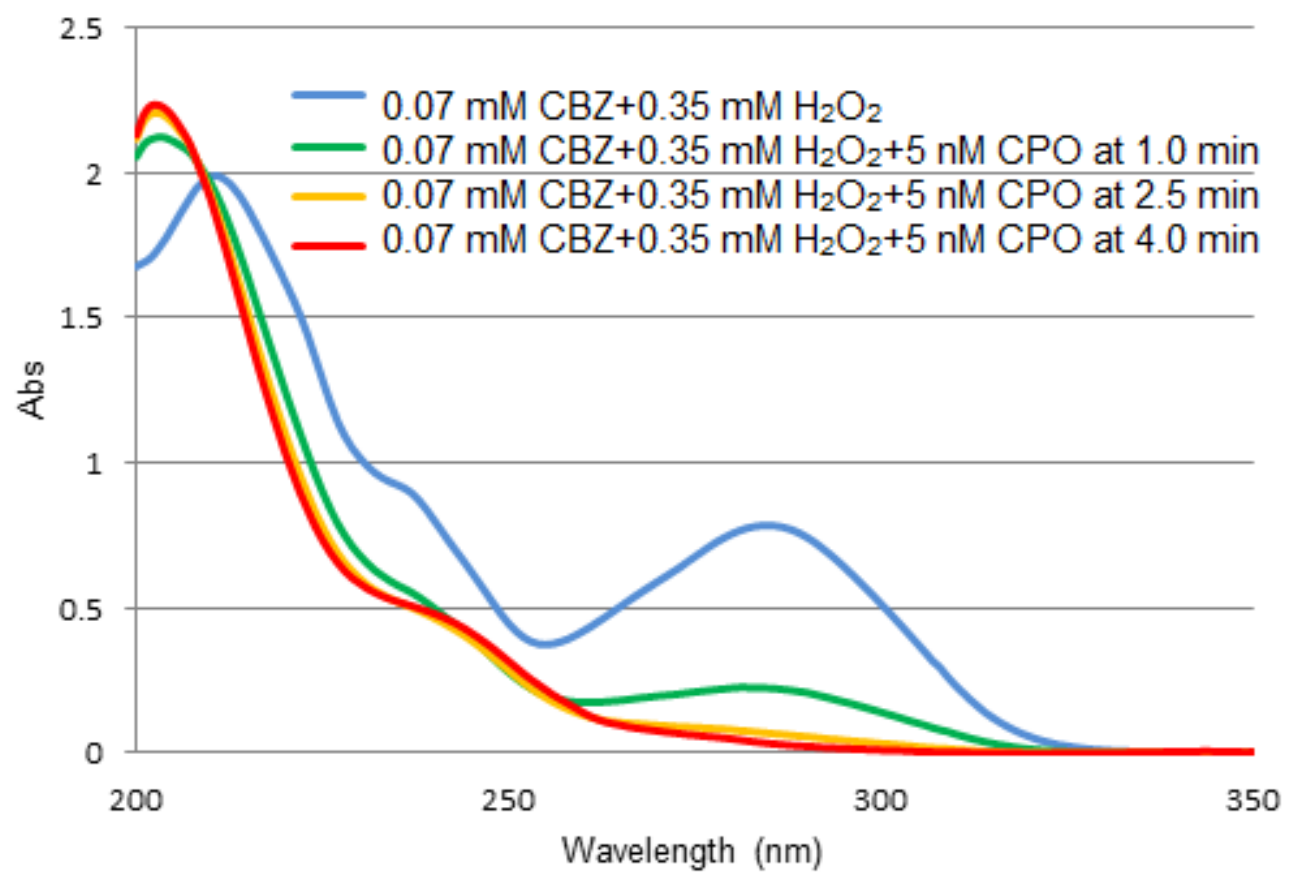

Figure 3.1 UV-Vis Spectra of $\mathrm{CBZ}$ with $\mathrm{H}_{2} \mathrm{O}_{2}$ and its metabolites at $1 \mathrm{~min}, 2.5 \mathrm{~min}$ and $4 \mathrm{~min}$.

UV-Vis Spectra of CBZ (0.07 mM / $16.53 \mathrm{mg} / \mathrm{L})$ and $\mathrm{H}_{2} \mathrm{O}_{2}(0.75 \mathrm{mM})$ were scanned in $100 \mathrm{mM} \mathrm{KH}_{2} \mathrm{PO}_{4}$ buffer, $20 \mathrm{mM} \mathrm{KCl}$ at $\mathrm{pH} 2.75$ (Fig.3.1). The Spectrum of CBZ showed a strong absorption at $285 \mathrm{~nm} .1$ minute after addition of $5 \mathrm{nM} \mathrm{CPO}$, the $285 \mathrm{~nm}$ absorption decreased, and stopped increasing at 4 minutes (Fig. 3.1). Wavelength at $285 \mathrm{~nm}$ was used to measure kinetic parameter of $\mathrm{CBZ}$ degradation catalyzed by CPO.

The same reaction was carried out under the same condition except for the chlorine ion $(\mathrm{KCl})$ in phosphate buffer. Without $\mathrm{KCl}$, the absorbance did not 
change after the addition of CPO. Chlorine ion is necessary in the degradation of $\mathrm{CBZ}$ in $\mathrm{CPO}-\mathrm{H}_{2} \mathrm{O}_{2}-\mathrm{Cl}^{-}$system.

According to Equation (1), The efficiency of degradation catalyze by $5 \mathrm{nM}$ CPO was $96 \%$ within 4 minutes, the efficiency might be more than $96 \%$ since the the tail of the UV peak of product seemed cover the original drug $(285 \mathrm{~nm})$.

3.3.2 The effect of chloride on the degradation of CBZ

Degradation rate was calculated from 0.2-0.6 minute. The degradation rate increased from 0 to $18.89 \mu \mathrm{M} / \mathrm{min}$. The obsevation was consistent as described in section 3.2.1, suggested that chloride participates in the degradation of CBZ. (Fig. 3.2). 


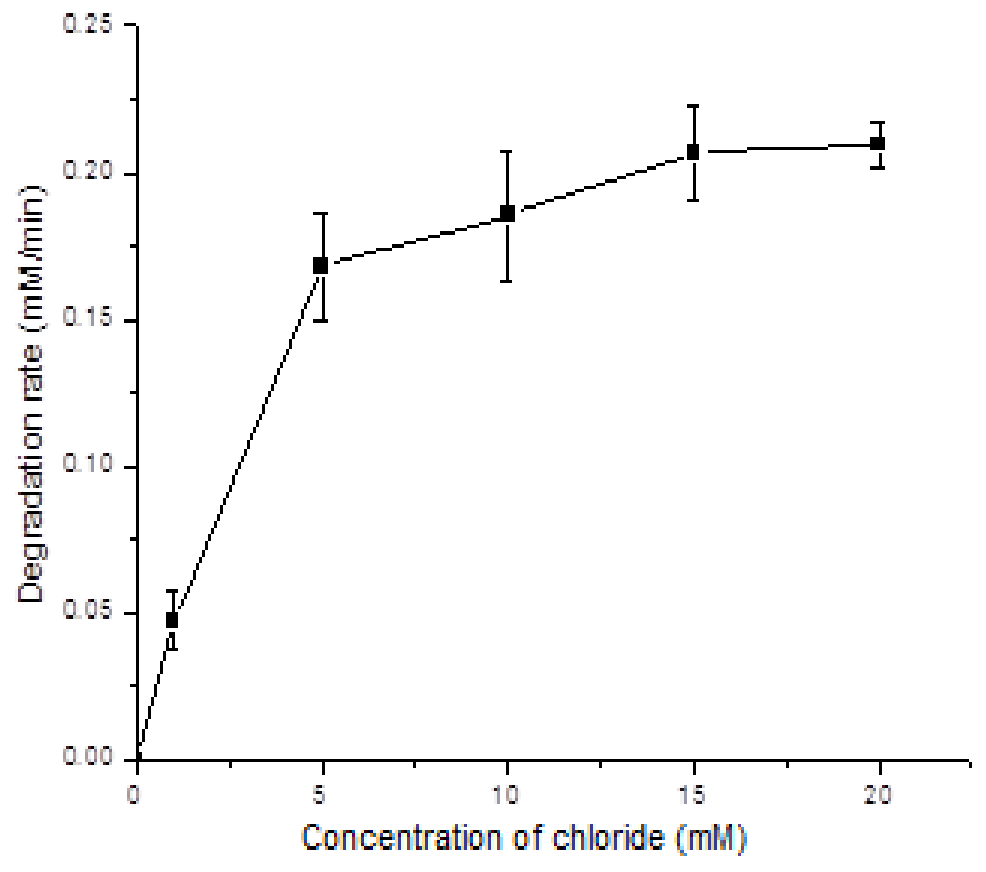

Figure 3.2. The effect of chloride on the degradation of $\mathrm{CBZ}$. Data were collected from triplicate experiment in $100 \mathrm{mM}$ phosphate buffer at $\mathrm{pH} 3.0$, with $0.07 \mathrm{mM} \mathrm{CBZ}, 0.07 \mathrm{mM}$ $\mathrm{H}_{2} \mathrm{O}_{2}$, and $2.5 \mathrm{nM} \mathrm{CPO}$. 
3.3.3 The effect of $\mathrm{pH}$ on the degradation of CBZ

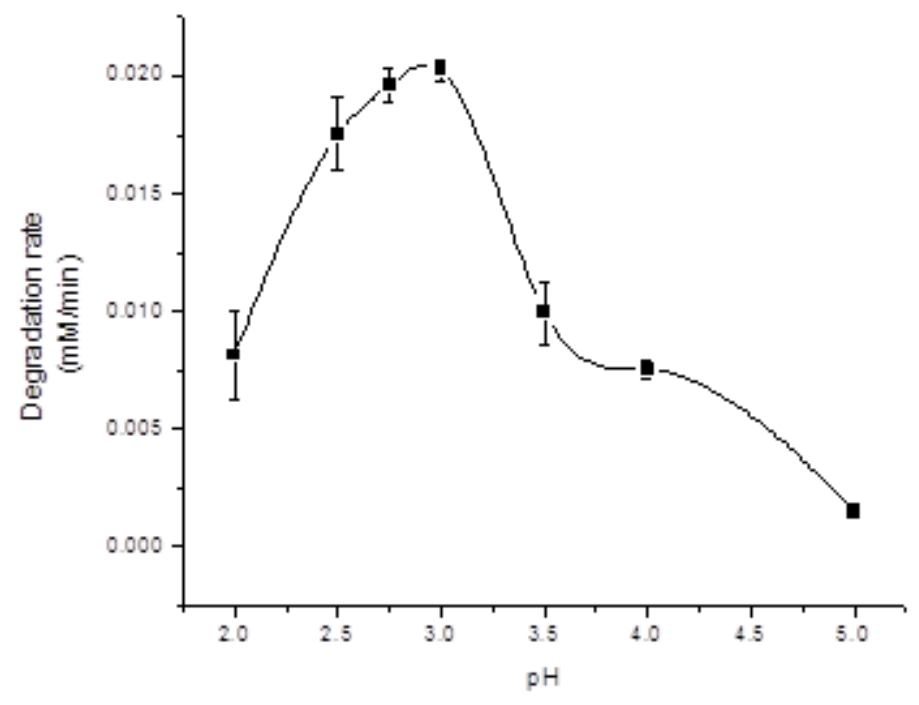

Figure 3.3 The effect of $\mathrm{pH}$ on $\mathrm{CBZ}$ degradation. Data were collected from triplicate experiment in $100 \mathrm{mM}$ phosphate buffer $(20 \mathrm{mM} \mathrm{KCl})$ with $0.07 \mathrm{mM} \mathrm{CBZ,} 0.07 \mathrm{mM} \mathrm{H}_{2} \mathrm{O}_{2}$, and $2.5 \mathrm{nM} \mathrm{CPO}$ at $\mathrm{pH} 3.0$.

The optimum $\mathrm{pH}$ for the degradation of $\mathrm{CBZ}$ is 3.0 in the presence of $20 \mathrm{mM}$ $\mathrm{Cl}^{-}$, the degradation efficiency decreased from $\mathrm{pH} 3.5$ to 5 . This curve was close to the expected chlorination reaction and oxidation reaction, [60] suggested CPO could be applied in the acid wastewater treatment. (Fig. 3.3).

\subsubsection{The effect of $\mathrm{H}_{2} \mathrm{O}_{2}$ concentration}

The degration rate was increased as the concentration of $\mathrm{H}_{2} \mathrm{O}_{2}$ increased to $0.53 \mathrm{mM}$. From 0.53 to $0.71 \mathrm{mM}$, the rate was still stable, only decreased slightly. This could be due to the degradation of CPO by the high concentration of $\mathrm{H}_{2} \mathrm{O}_{2}$. [61] The stability of CPO in the presence of $\mathrm{H}_{2} \mathrm{O}_{2}$ compared with other peroxidase is suggested that CPO has a better prospect of application than the same class enzyme. (Fig. 3.4). 


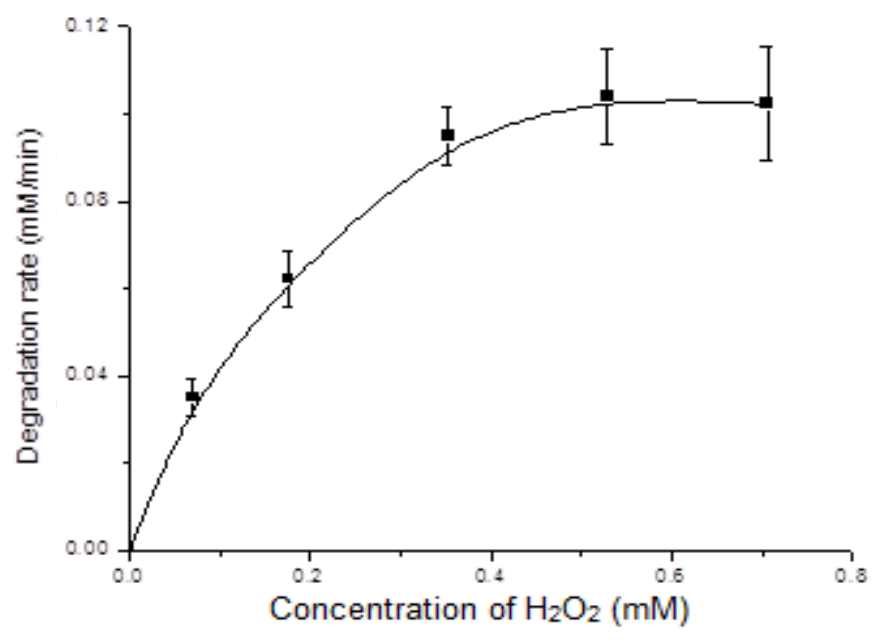

Figure 3.4 The effect of $\mathrm{H}_{2} \mathrm{O}_{2}$ concentration, Data were collected from triplicate experiment in $100 \mathrm{mM}$ phosphate buffer $(20 \mathrm{mM} \mathrm{KCl})$ with $0.07 \mathrm{mM} \mathrm{CBZ}$ and $5 \mathrm{nM}$ CPO at $\mathrm{pH}$ 3.0.

\subsubsection{The kinetic parameters of CBZ degradation catalyzed by CPO}

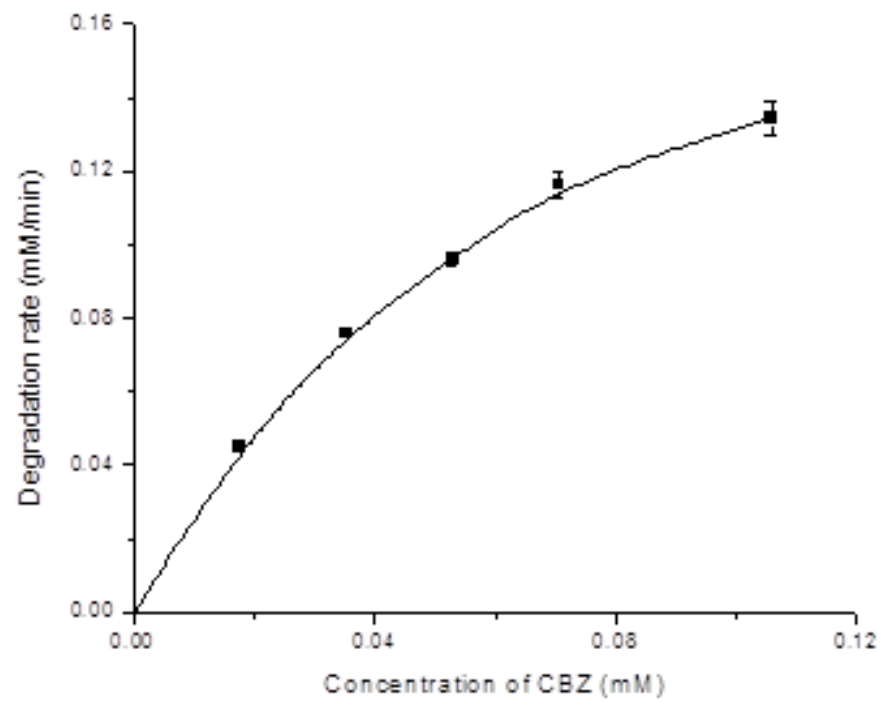

Figure 3.5 The effect of $\mathrm{CBZ}$ concentration. Data were collected from triplicate experiment in $100 \mathrm{mM}$ phosphate buffer $(20 \mathrm{mM} \mathrm{KCl})$ with $0.07 \mathrm{mM} \mathrm{H}_{2} \mathrm{O}_{2}$, and $5 \mathrm{nM}$ $\mathrm{CPO}$ at $\mathrm{pH} 3.0$, concentration of $\mathrm{CBZ}$ was varied from $0.02 \mathrm{mM}$ to $0.11 \mathrm{mM}$.

Different concentrations of $\mathrm{CBZ}$ were reacted with $0.07 \mathrm{mM} \mathrm{H}_{2} \mathrm{O}_{2}$ with $5 \mathrm{nM}$ 
CPO (Fig. 3.5). According to Equation 2, the kinetic parameters of CBZ degradation catalyzed by CPO was calculated (Table 3.1)

Table 3.1 The kinetic parameters of CBZ degradation catalyzed CPO.

\begin{tabular}{|c|c|c|c|c|}
\hline $\begin{array}{c}K_{\mathrm{m}} \\
(\mu \mathrm{M})\end{array}$ & $\begin{array}{c}V_{\max } \\
\left(\mu \mathrm{M} \mathrm{s}^{-1}\right)\end{array}$ & $\begin{array}{c}k_{\text {cat }} \\
\left(\mathrm{s}^{-1}\right)\end{array}$ & $\begin{array}{c}k_{\text {cat }} / K_{\mathrm{m}} \\
\left(\mu \mathrm{M}^{-1} \mathrm{~s}^{-1}\right)\end{array}$ & $\mathrm{R}^{2}$ \\
\hline 73.35 & 3.87 & 733 & 10.54 & 0.9995 \\
\hline
\end{tabular}

\subsubsection{LC-Q-TOF- MS}

To investigate the degradation efficiency of $\mathrm{CBZ}$ in $\mathrm{CPO}-\mathrm{H}_{2} \mathrm{O}_{2}-\mathrm{Cl}^{-}$system, $10.59 \mu \mathrm{M} \mathrm{CBZ}$ was reacted with $107.19 \mu \mathrm{M}$ of $\mathrm{H}_{2} \mathrm{O}_{2}$ and $\mathrm{CPO}(2.9 \mathrm{nM})$ for 10 minutes, the sample was analyzed by LC-Q-TOF-MS, CBZ was not observed, the degradation efficiency by low concentration of CPO could achieved $100 \%$, suggesting the potential of the application of CPO in large-scale waste water treatment.

Samples were detected in Agilent Technologies 6530 Accurate-Mass LC-QTOF-MS in full scan MS mode, the accurate mass data of the molecular ions were processed through the Agilent MassHunter Qualitative Analysis software. There were $15 \mathrm{CBZ}$ metabolites (coded from CM1 to CM15) confirmed by different retention times and accurate mass-to-charge ratios $(\mathrm{m} / \mathrm{z})$. The elemental formula, retention time, the relative mass difference between the observed mass and the mass of the target compound (in parts per million), and the difference between the observed mass and the mass of target compound (in milliDaltons) 
were collected (Table 3.2).

Table 3.2 Accurate-Mass LC-Q-TOF-MS data for the identification of CBZ and its metabolites.

\begin{tabular}{|l|l|c|c|c|r|r|}
\hline \multicolumn{1}{|c|}{ Code } & \multicolumn{1}{|c|}{ Formula } & $\begin{array}{c}\text { Retention time } \\
(\mathrm{min})\end{array}$ & $\begin{array}{c}\text { Experimental mass } \\
(\mathrm{m} / \mathrm{z})\end{array}$ & $\begin{array}{c}\text { Theoretical mass } \\
(\mathrm{m} / \mathrm{z})\end{array}$ & $\begin{array}{c}\text { Diff } \\
(\mathrm{ppm})\end{array}$ & $\begin{array}{c}\text { Diff } \\
(\mathrm{mDa})\end{array}$ \\
\hline $\mathrm{CMZ}$ & $\mathrm{C}_{15} \mathrm{H}_{12} \mathrm{~N}_{2} \mathrm{O}$ & 5.901 & 236.0943 & 236.0950 & -2.73 & -0.64 \\
\hline $\mathrm{CM} 1$ & $\mathrm{C}_{15} \mathrm{H}_{12} \mathrm{~N}_{2} \mathrm{O}_{2}$ & 4.314 & 252.0914 & 252.0899 & 6.21 & 1.56 \\
\hline $\mathrm{CM} 2$ & $\mathrm{C}_{15} \mathrm{H}_{14} \mathrm{~N}_{2} \mathrm{O}_{3}$ & 3.366 & 270.1004 & 270.1004 & -0.08 & -0.02 \\
\hline $\mathrm{CM} 3$ & $\mathrm{C}_{14} \mathrm{H}_{11} \mathrm{NO}_{2}$ & 2.839 & 225.0790 & 225.0790 & -0.06 & -0.01 \\
\hline $\mathrm{CM} 4$ & $\mathrm{C}_{14} \mathrm{H}_{9} \mathrm{NO}$ & 6.776 & 207.0680 & 207.0684 & -1.84 & -0.38 \\
\hline $\mathrm{CM} 5$ & $\mathrm{C}_{13} \mathrm{H}_{9} \mathrm{~N}$ & 3.970 & 179.0728 & 179.0735 & -4.12 & -0.74 \\
\hline $\mathrm{CM} 6$ & $\mathrm{C}_{13} \mathrm{H}_{9} \mathrm{NO}$ & 5.185 & 195.0678 & 195.0684 & -3.23 & -0.63 \\
\hline $\mathrm{CM} 7$ & $\mathrm{C}_{15} \mathrm{H}_{13} \mathrm{NO}_{2}$ & 3.793 & 239.0938 & 239.0946 & -3.64 & -0.87 \\
\hline $\mathrm{CM} 8$ & $\mathrm{C}_{14} \mathrm{H}_{9} \mathrm{NO}_{2}$ & 2.379 & 223.0630 & 223.0633 & -1.64 & -0.37 \\
\hline $\mathrm{CM} 9$ & $\mathrm{C}_{15} \mathrm{H}_{11} \mathrm{NO}_{3}$ & 3.959 & 253.0748 & 253.0739 & 3.53 & 0.89 \\
\hline $\mathrm{CM} 10$ & $\mathrm{C}_{16} \mathrm{H}_{14} \mathrm{~N}_{2} \mathrm{O}_{2}$ & 4.863 & 266.1058 & 266.1055 & 0.88 & 0.23 \\
\hline $\mathrm{CM} 11$ & $\mathrm{C}_{15} \mathrm{H}_{12} \mathrm{CINO}_{2}$ & 6.061 & 273.0559 & 273.0557 & 0.90 & 0.25 \\
\hline $\mathrm{CM12}$ & $\mathrm{C}_{14} \mathrm{H}_{8} \mathrm{CINO}$ & 7.985 & 241.0298 & 241.0294 & 1.36 & 0.33 \\
\hline $\mathrm{CM} 13$ & $\mathrm{C}_{13} \mathrm{H}_{8} \mathrm{CIN}$ & 7.442 & 213.0356 & 213.0345 & 5.14 & 1.10 \\
\hline $\mathrm{CM} 14$ & $\mathrm{C}_{13} \mathrm{H}_{8} \mathrm{CINO}$ & 6.222 & 229.0291 & 229.0294 & -1.48 & -0.34 \\
\hline $\mathrm{CM} 15$ & $\mathrm{C}_{14} \mathrm{H}_{8} \mathrm{CINO} \mathrm{N}_{2}$ & 3.111 & 257.0240 & 257.0244 & -1.46 & -0.38 \\
\hline
\end{tabular}

All the relative mass difference of the standard drug (CBZ) and metabolites were less than $5.0 \mathrm{ppm}$ except for CM1 (6.21 ppm) and CM13 (5.14 ppm).The relative mass difference of metabolite $\mathrm{CM} 1$ and $\mathrm{CM} 13$ in all experiments were between $0.19 \mathrm{ppm}$ and $9.54 \mathrm{ppm}, 0.74 \mathrm{ppm}$ and $5.14 \mathrm{ppm}$, respectively. The mass differences of all compounds were less than $2.0 \mathrm{mDa}$. This method was proved to be efficient for determination of the metabolites of CBZ.

The mass spectra of each individual metabolite were collected in positive mode by MassHunter Workstation software (Appendix I). Since it was in positive 
mode, all the compounds were detected as molecular ion $[\mathrm{M}+\mathrm{H}]^{+}$except for CM9, the detected molecular ion was $\left[\mathrm{M}+\mathrm{NH}_{4}\right]^{+}$adduct $(271.1085 \mathrm{~m} / \mathrm{z})$, the ammonium adduct formation was favored in the ion source probable due to the ion pairing effect on the functional group responsible of ionization.

For chlorinated metabolites, the isotope peaks were detected as the conformation of addition of chlorine atom, the two major peaks of each spectra separated by $2 \mathrm{~m} / \mathrm{z}$ units and peak heights are in the ratio of 3:1, proved these molecules contain one chlorine atom.

The structures of each metabolite were confirmed in targeted MS/MS by retention time and fragment ions (Fig. 3.6). There were 2 types of metabolites based on their structure. The first type contained CM1, CM2, CM9, CM10 were suggestive of oxygen insertion into the CBZ-based structure. The other structures were the second type, structures were based on acridine (CM5), the decarbonylation product of parent compound. All chlorinated metabolites were from acridine-based structures. CM11, CM12, CM13, CM14, CM15 was the chlorinated product of $\mathrm{CM} 7, \mathrm{CM} 4, \mathrm{CM}$, CM6, CM8, respectively. CM7 was generated from CM3 by methylation of hydroxyl group. CM8 was the hydroxylated product of CM4. 
$\mathrm{C}_{15} \mathrm{H}_{12} \mathrm{~N}_{2} \mathrm{O} \quad$ (CBZ)

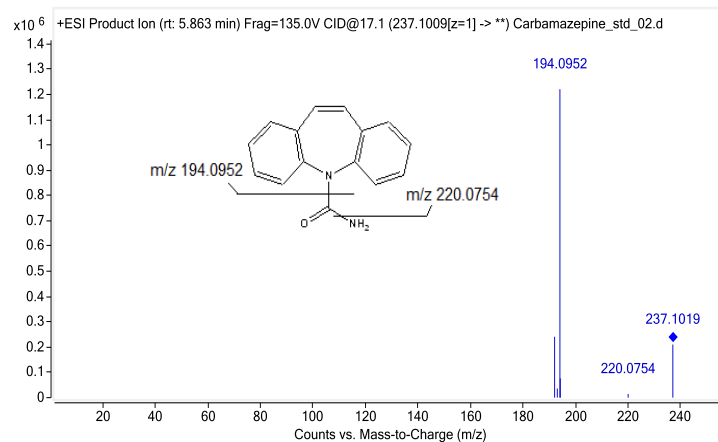

$\mathrm{C}_{15} \mathrm{H}_{14} \mathrm{~N}_{2} \mathrm{O}_{3} \quad$ (CM2)

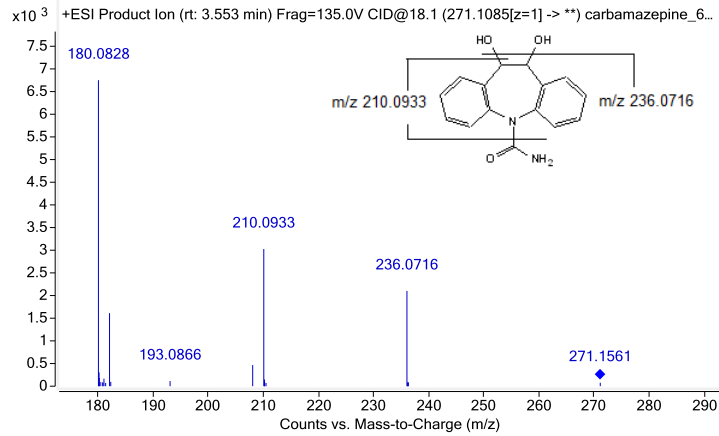

\section{$\mathrm{C}_{14} \mathrm{H}_{9} \mathrm{NO} \quad(\mathrm{CM} 4)$}

x10 4 +ESI Product Ion (rt: $6.817 \mathrm{~min})$ Frag=135.0V CID@16.2 (208.0752[z=1] -> **) carbamazepine_...

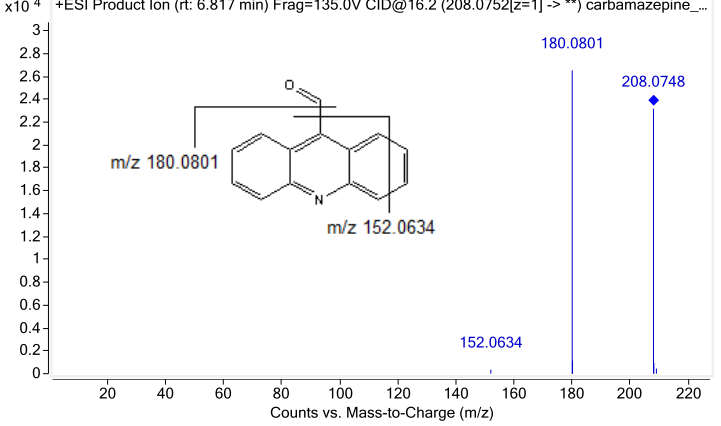

\section{$\mathrm{C}_{13} \mathrm{H}_{9} \mathrm{NO} \quad(\mathrm{CM} 6)$}

x10 5 +ESI Product Ion (rt: 5.508 min) Frag=135.0V CID@15.9 (196.0748[z=1] -> **) carbamazepine_..

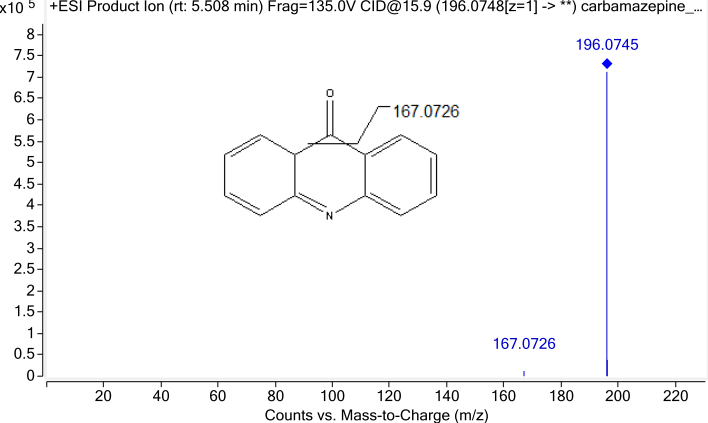

$\mathrm{C}_{15} \mathrm{H}_{12} \mathrm{~N}_{2} \mathrm{O}_{2}(\mathrm{CM} 1)$

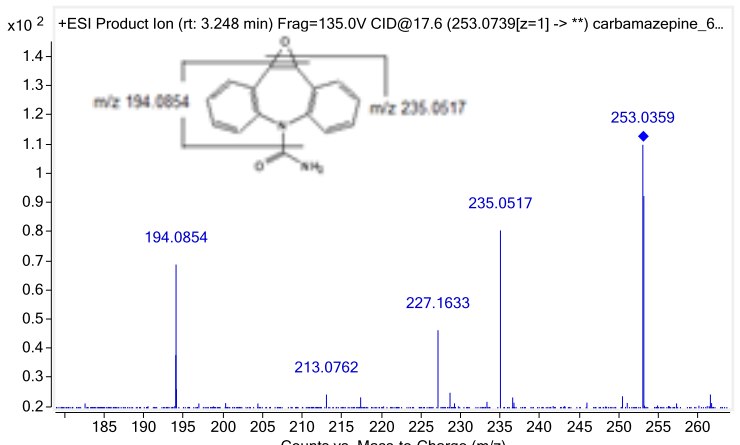

\section{$\mathrm{C}_{14} \mathrm{H}_{11} \mathrm{NO}_{2}(\mathrm{CM} 3)$}

x10 3 Cpd 6: 3.300: +ESI Product lon (rt: 3.139-3.338 min, 7 scans) Frag=135.0V CID@16.8 (226.086...

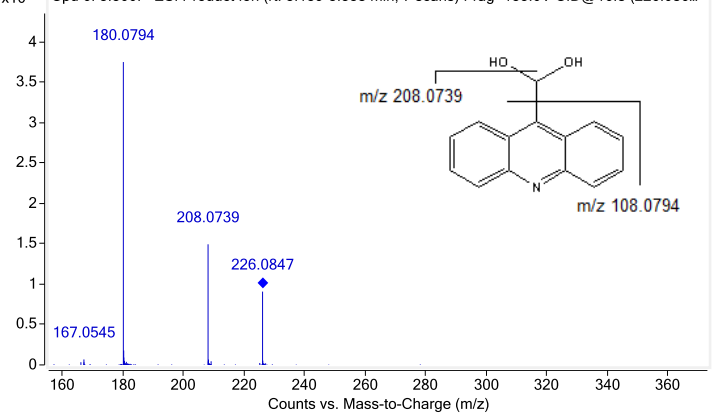

$\mathrm{C}_{13} \mathrm{H}_{9} \mathrm{~N}(\mathrm{CM} 5)$

x10 3 +ESI Product lon (rt: $3.913 \mathrm{~min})$ Frag=135.0V CID@15.4 (180.0799[z=1] -> **) carbamazepine_..

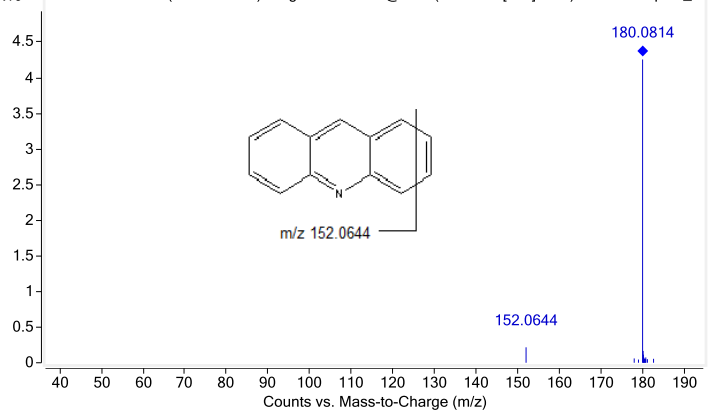

$\mathrm{C}_{15} \mathrm{H}_{13} \mathrm{NO}_{2}$ (CM7)

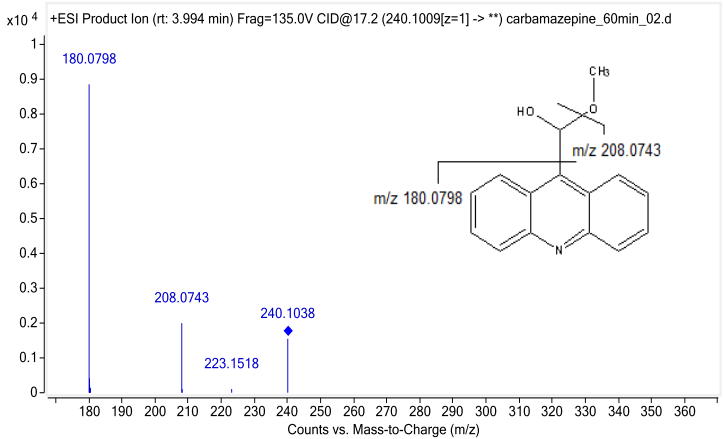

Figure 3.6 The targeted MS/MS spectra of CBZ and its metabolites. 


\section{$\mathrm{C}_{14} \mathrm{H}_{9} \mathrm{NO} 2(\mathrm{CM} 8)$}

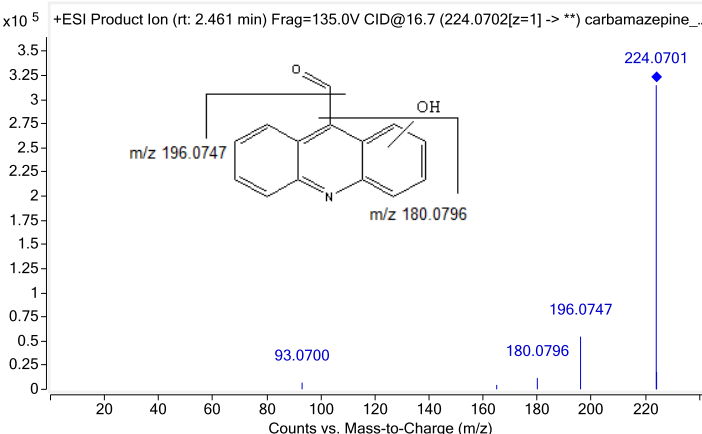

$\mathrm{C}_{16} \mathrm{H}_{14} \mathrm{~N}_{2} \mathrm{O}_{2} \quad(\mathrm{CM} 10)$

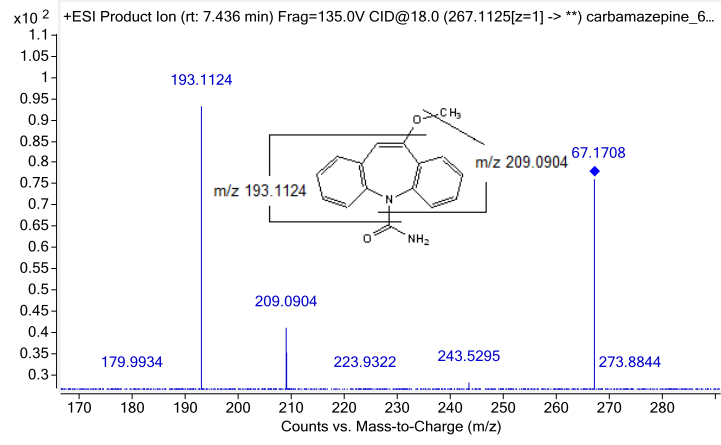

\section{$\mathrm{C}_{14} \mathrm{H}_{8} \mathrm{CINO} \quad(\mathrm{CM} 12)$}

x10 ${ }^{3}$ +ESI Product lon (It: 8.466 min) Frag=135.0V CID@17.3 (242.0367[z=1] - >*) carbamazepine_60min_02.d

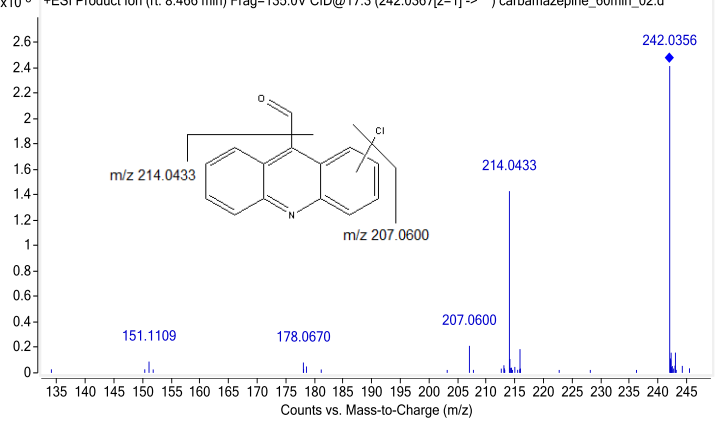

\section{$\mathrm{C}_{13} \mathrm{H}_{8} \mathrm{CINO} \quad(\mathrm{CM} 14)$}

x10 4 +ESI Product lon (rt: 6.654 min) Frag=135.0V CID@16.9 (230.0363[z=1] > **) carbamazepine_60min_02.d

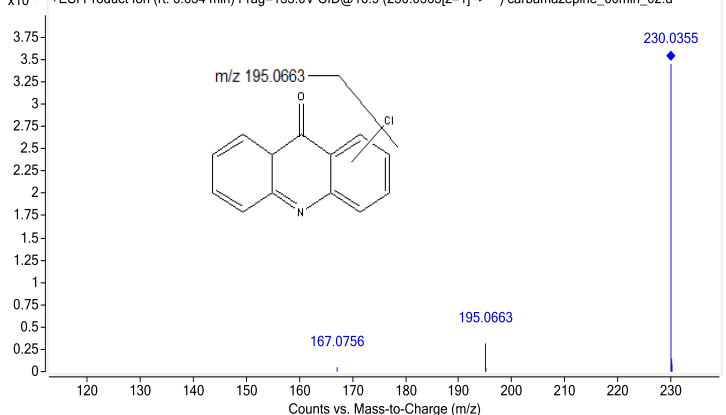

$\mathrm{C}_{15} \mathrm{H}_{11} \mathrm{NO}_{3}$ (CM9)

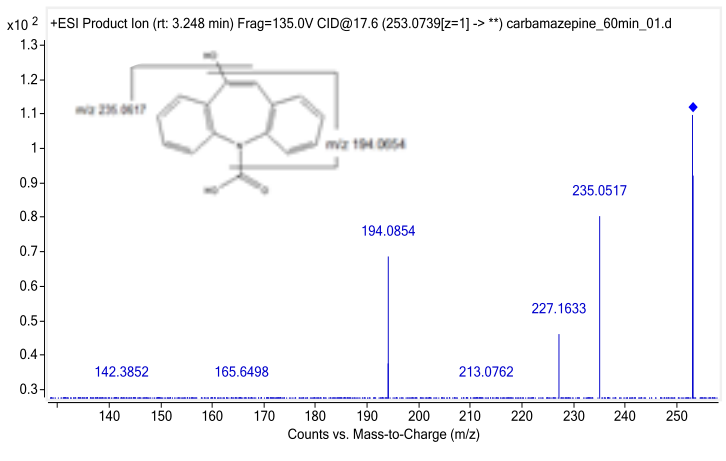

$\mathrm{C}_{15} \mathrm{H}_{12} \mathrm{CINO}_{2} \quad(\mathrm{CM} 11)$

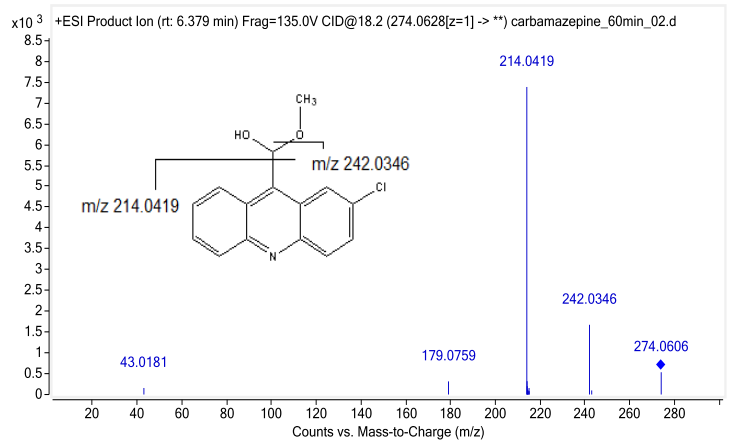

\section{$\mathrm{C}_{13} \mathrm{H}_{8} \mathrm{CIN}(\mathrm{CM} 13)$}

x10 4 +ESI Product lon (rt: 7.834 min) Frag=135.0V CID@16.4 (214.0424[z=1] > **) carbamazepine_60min_02.d

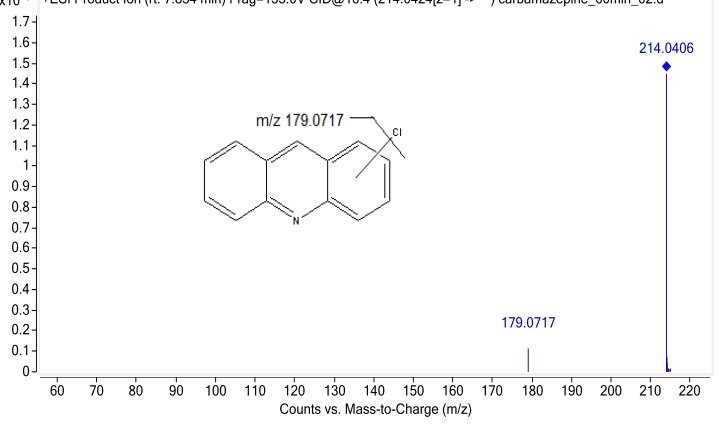

\section{$\mathrm{C}_{14} \mathrm{H}_{8} \mathrm{CINO}_{2} \quad(\mathrm{CM} 15)$}

x10 3 +ESI Product lon (rt: $3.241 \mathrm{~min}$ ) Frag=135.0V CID@17.7 (258.0309[z=1] -> **) carbama...

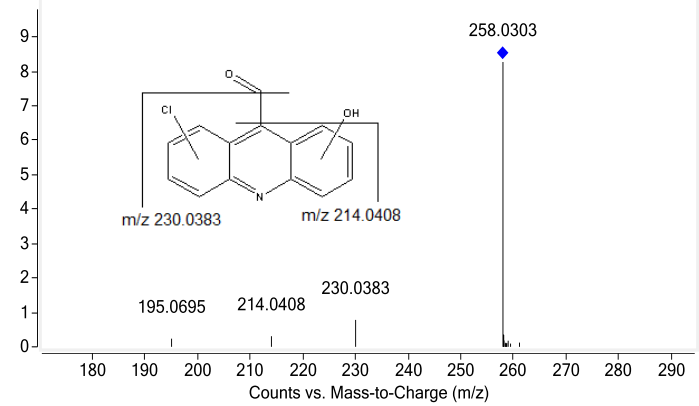

Figure 3.6 (Cont.). The targeted MS/MS spectra of CBZ and its metabolites. 
The concentrations of all metabolites were measured as compound area by MassHunter Workstation software, and presented by percentage of all compounds as pie chart, all chlorinated compounds were showed in the second pie chart at right side (Fig. 3.7)

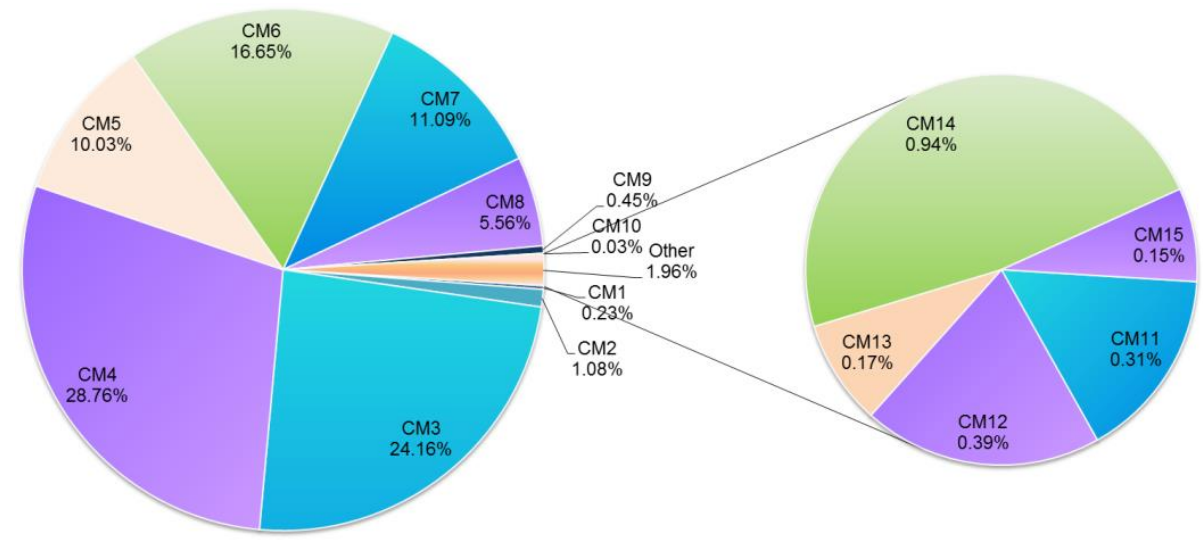

Figure 3.7. The percentage of each metabolites measured by compound area. Metabolites shared the same structure presented by the same color.

To investigate the mechanism of degradation process, the experiment was carried out for limited reaction time (1,3 and 5 minutes) with low concentration of $\mathrm{H}_{2} \mathrm{O}_{2}(6.86 \mu \mathrm{M})$, the ratio of the concentration of $\mathrm{CBZ}$ and $\mathrm{H}_{2} \mathrm{O}_{2}$ was about $7: 1$. Only part of CBZ was degraded, and only several metabolites were detected which could be suggested as the first formed metabolites (Fig 3.8). At the first minute, only CM1, CM2, CM9, CM10 were formed, the four proposed structures were suggestive of oxygen insertion into the CBZ-based structure, produced directly from CBZ without decarbonylation, CM1 was the most abundant metabolite, suggested the first step of degradation was the epoxidation of CBZ. The percentage of these four compounds decreased significantly after reacted with higher concentration of $\mathrm{H}_{2} \mathrm{O}_{2}$ for longer time (Fig. 3.7). From 3 minutes, 
acridine (CM5) was formed, CM7 and CM8, two acridine-based metabolites were detected at 5 minutes. The final concentrations of them were the relatively high. Compared with the CBZ-based structure compounds, acridine-based structure were suggested as the major products, acridine (CM5), the decarbonylation product of parent compound, with $\mathrm{CM} 6, \mathrm{CM} 7$ and $\mathrm{CM} 8$ were the major metabolites of the degradation catalyzed by CPO, CBZ-based structures existed as intermediates of the degradation. $\mathrm{CM} 5, \mathrm{CM} 6, \mathrm{CM} 7$ and $\mathrm{CM} 8$ were the most abundant metabolites, suggested they were the major metabolites of the degradation catalyzed by CPO.

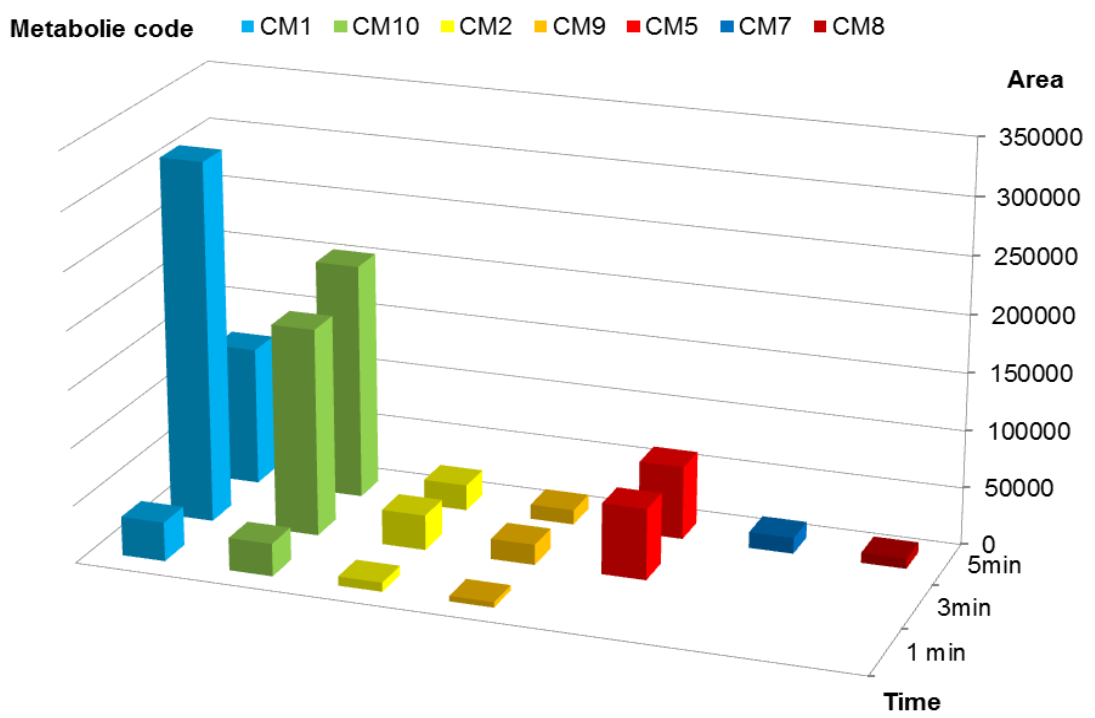

Figure 3.8 The area of metabolites with limited $\mathrm{H}_{2} \mathrm{O}_{2}$ at $1 \mathrm{~min}, 3 \mathrm{~min}$ and $5 \mathrm{~min}$ detected by Accurate-Mass LC-Q-TOF-MS. All experiments were duplicates and data reported were mean values of two independent measurements.

The chlorinated products were observed as CM11-CM15, the concentration of them were relatively low (Fig. 3.7) and they were not observed at the first stage of reaction (Fig. 3.8), these metabolites were not the major product of the 
degradation catalyzed by CPO.

The chromatograms of $\mathrm{CBZ}$ and its metabolites were collected with their proposed structures (Fig. 3.9). In the chromatograms of CM1, CM2, CM9, CM11, CM12, CM13, CM14 and CM15, there were isomers identified by different retention time. For CM1, CM9, CM11 and CM12, metabolites had problem of signal to noise ratio might due to the low concentration, chromatograms of the four compounds were collected by Agilent Technologies 6460 Triple-quadrupole LC/MS/MS in multiply reaction monitoring (MRM) mode.

\subsubsection{Triple-Quadruple LC/MS/MS}

Agilent Technologies 6460 Triple-Quadrupole LC/MS/MS in multiply reaction monitoring (MRM) mode was applied in the investigation of metabolites of CBZ, especially for the 3 compounds (CM1, CM9, CM11 and CM12) which the resolution were low in Q-TOF. Data was analyzed in Agilent MassHunter Qualitative Analysis software. After the formula of metabolites was confirmed by LC-Q-TOF-MS, different retention times of individual metabolites could be recognized by Triple quad with less noise than in Q-TOF. (Fig. 3.9)

The specific parameters, including optimized fragmentor voltage and collision energy (CE) for different MRM transition has been determined by flow injection analysis without column (FIA) with MassHunter Optimizer software (Appendix II). Four transitions were selected to monitor for one compound. 
$\mathrm{C} 15 \mathrm{H} 12 \mathrm{~N} 2 \mathrm{O} \quad(\mathrm{CBZ})$
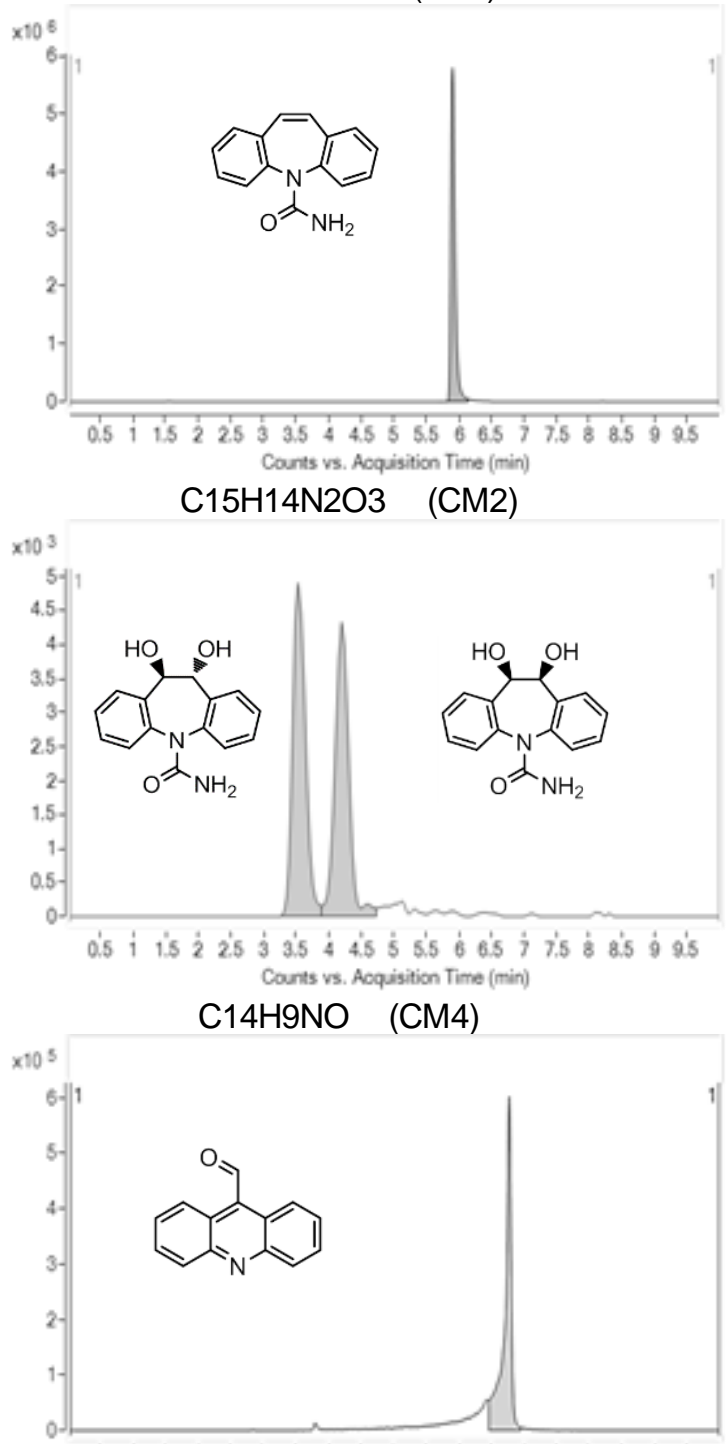

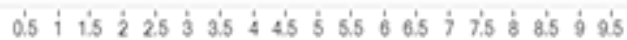
Counts vs. Acquisition Time (min) C13H9NO (CM6)

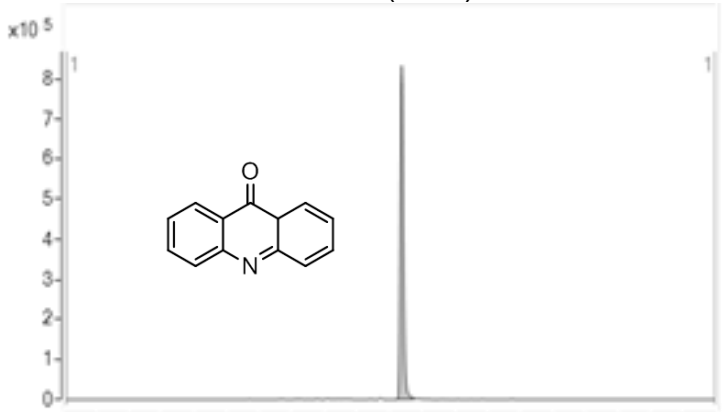

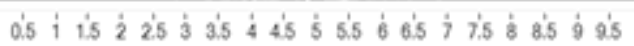
Counts vs. Acquisition Time (min)
C15H12N2O2 (CM1)

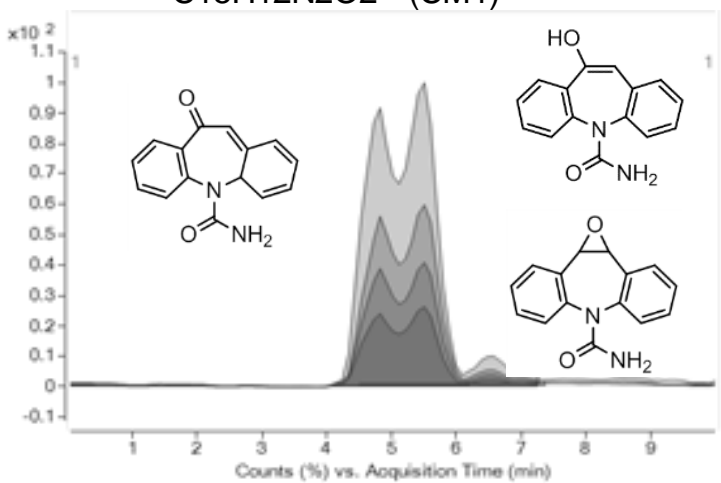

C14H11NO2 (CM3)

$\times 10^{2}$

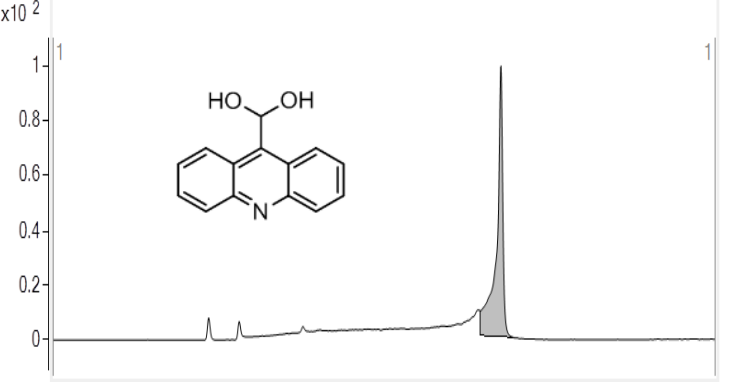

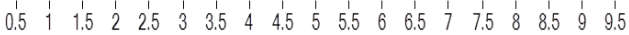
Counts (\%) vs. Acquisition Time (min)

C13H9N (CM5)
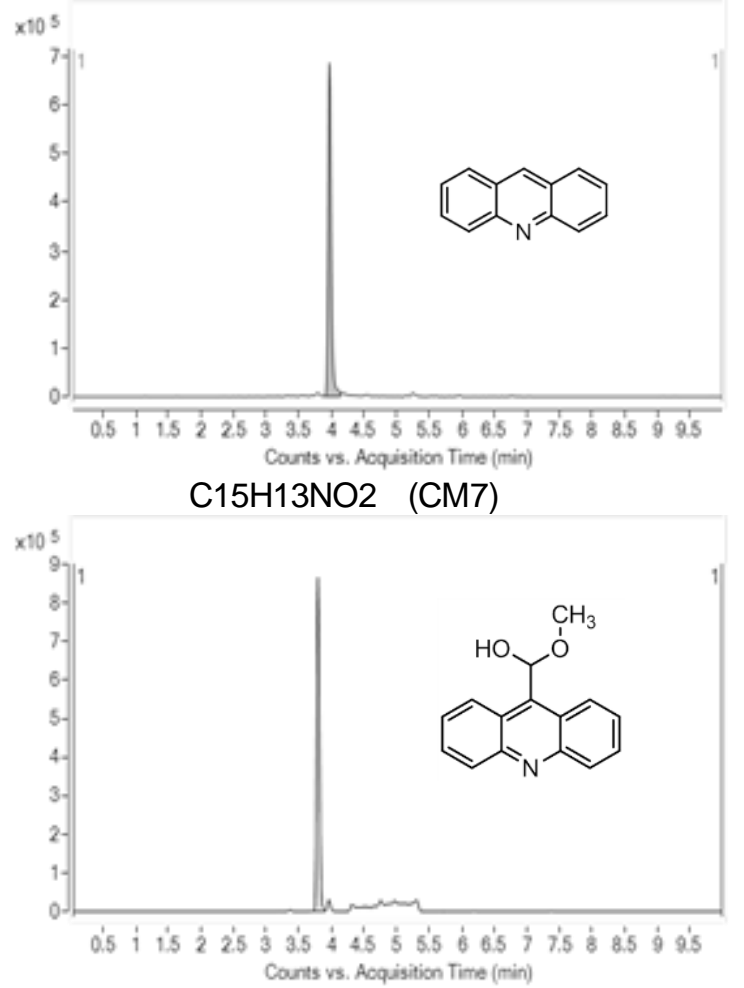

Figure 3.9 The chromatograms of $\mathrm{CBZ}$ and its metabolites. 
C14H9NO2 (CM8)
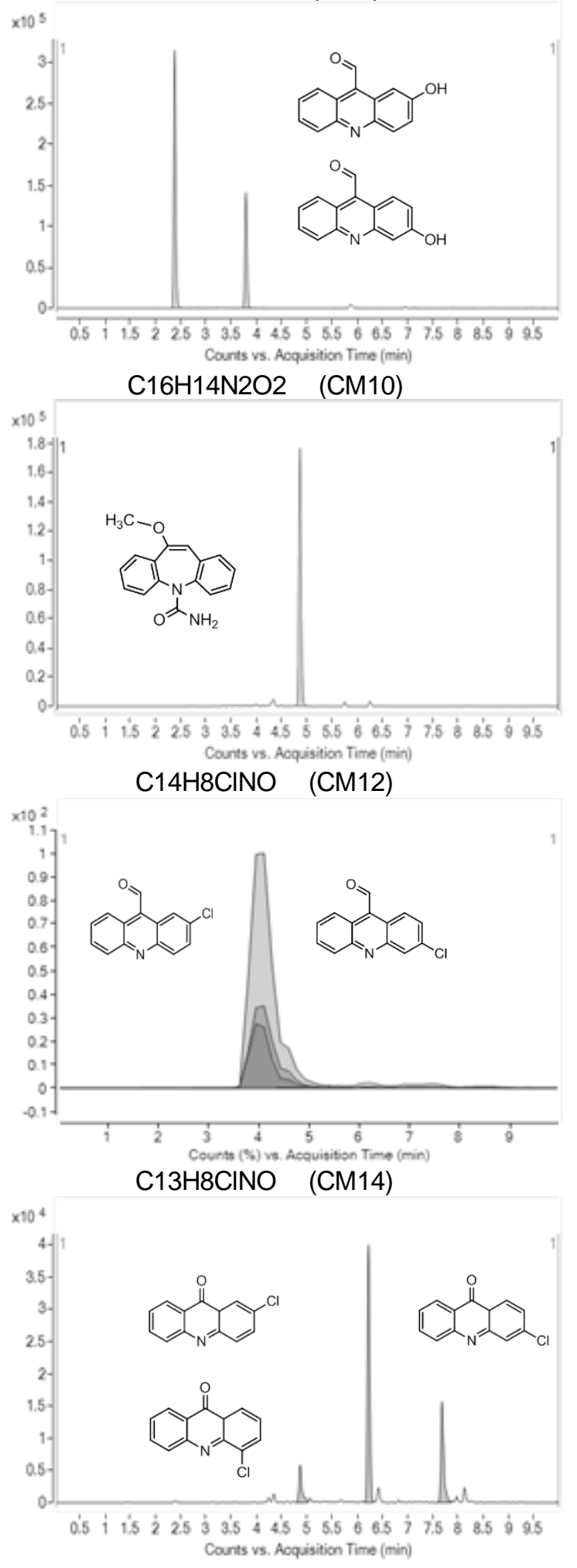

C15H11NO3 (CM9)
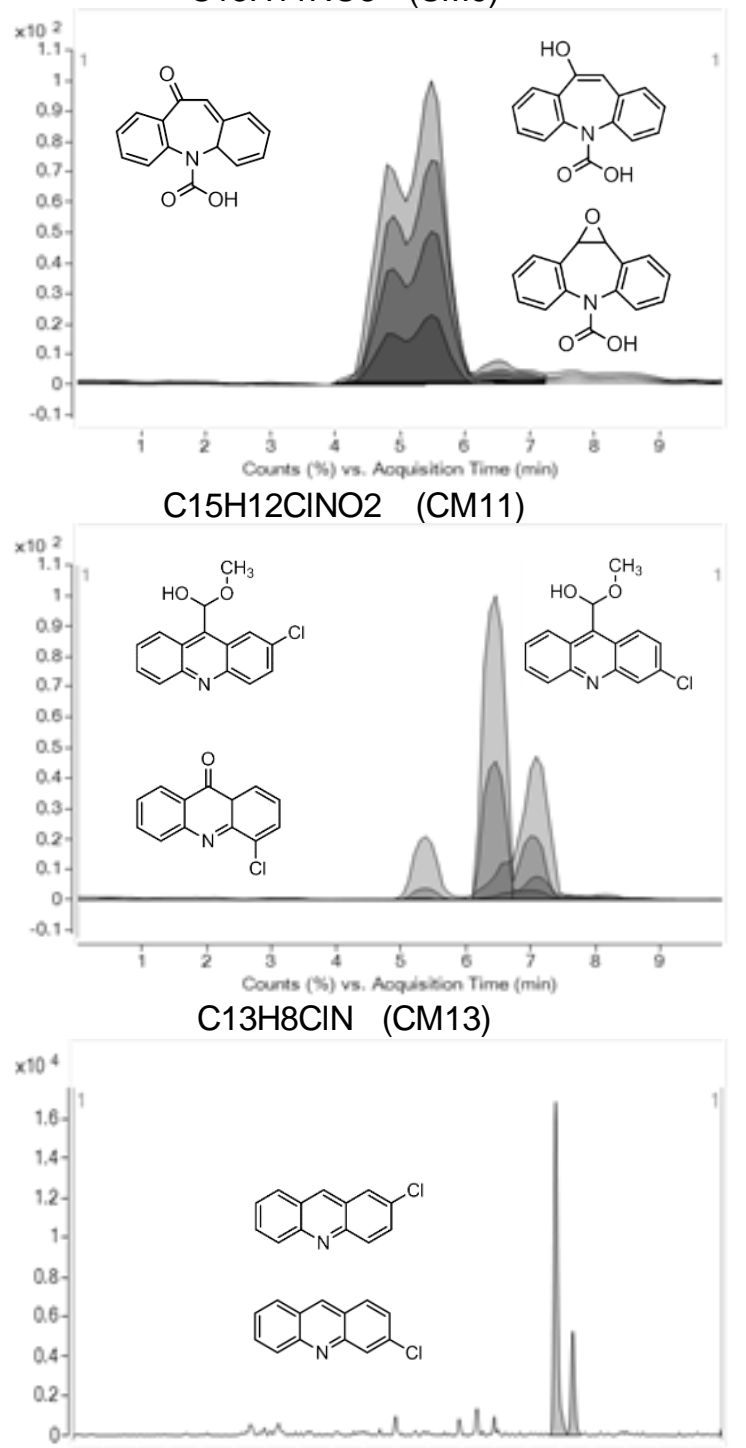

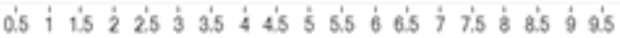
Counts vs. Acquisition Time (min) C14H8CINO2 (CM15)

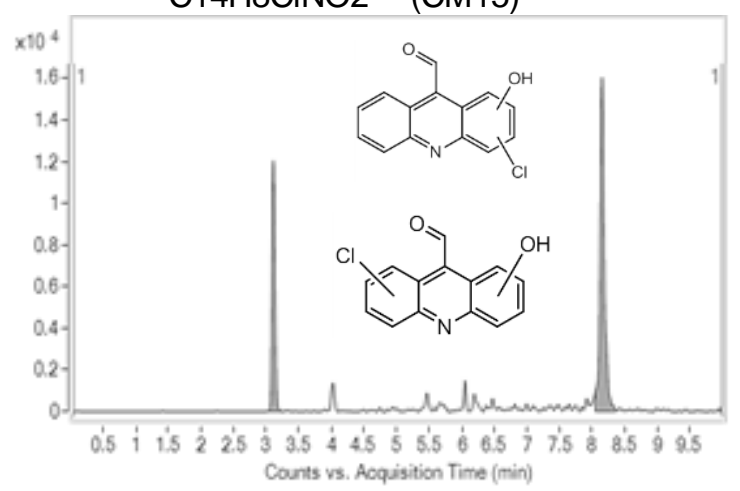

Fiqure 3.9 (Cont.) The chromatograms of CBZ and its metabolites. 
The information of produced ions gave a better understanding of the structure of metabolites than the targeted MS/MS, it provided all the fragment information of parent compound to help to analyze, several same transitions could suggest the structural similarity. For example, CM4, CM5, and CM7 shared most of their product ions (Table 3.3).

Table 3.3 The optimizer data of CM4, CM5 and CM7.

\begin{tabular}{|l|c|c|c|c|}
\hline \multicolumn{2}{|c|}{ Precursor ion } & $\begin{array}{c}\text { Precursor ion } \\
(\mathrm{m} / \mathrm{z})\end{array}$ & $\begin{array}{c}\text { Shared product ions } \\
(\mathrm{m} / \mathrm{z})\end{array}$ & $\begin{array}{c}\text { Independent product ions } \\
(\mathrm{m} / \mathrm{z})\end{array}$ \\
\hline $\mathrm{C}_{14} \mathrm{H}_{9} \mathrm{NO}$ & $(\mathrm{CM} 4)$ & $\mathbf{2 0 8}$ & & $75,102,154$, \\
\hline $\mathrm{C}_{13} \mathrm{H}_{9} \mathrm{~N}$ & $(\mathrm{CM})$ & $\mathbf{1 8 0}$ & $\mathbf{1 8 0 , 1 5 2 , 1 2 8 ,}$ & $\mathbf{7 5 , 1 0 2 , 1 5 3 , 1 4 0}$ \\
\hline $\mathrm{C}_{15} \mathrm{H}_{13} \mathrm{NO}_{2}$ & $(\mathrm{CM})$ & 240 & $127,77,101,51$ & $\mathbf{2 0 8 , 1 5 3 , 1 5 4}$ \\
\hline
\end{tabular}

The bold values were the mass of precursor ions. The italic values were estimated as the same fragments adducted with vary hydrogens.

The different elution times of the same formula was considered as isomers. In addition, the existence of isomers could also be suggested with distinctive product ions by the same fragmentor voltage at different retention time.

\subsubsection{The proposed mechanism of degradation catalyzed by CPO}

With all information above, the pathway for CBZ metabolism catalyzed by CPO was proposed (Fig 3.10.) The main pathway of degradation was to form the 10,11-expoxy carbamazepine (CM1), the $\mathrm{C}_{10^{-}} \mathrm{C}_{11}$ bond was likely the most reactive site. The 10,11-dihydroxy carbamazepine (CM2) produced by addition of $\mathrm{H}_{2} \mathrm{O}$, with both trans and cis isomers. They were major transient intermediates further underwent cleavage of the carbamoyl moiety and rearrangement of heterocycles, from azepine ring to a pyridine structure, to form 9-acridine- 
caboxaldehyde hydrate form (CM3). Hydroxyl group of CM3 was exchanged with methanol in phosphate buffer $(\mathrm{pH} 3.0)$, to generate methylated product CM7. Dehydration was the reaction happened at the same time, 9-acridinecaboxaldehyde (CM4) was generated. CM8 was hydroxylated from CM4. Both CM3 and CM4 were not observed on mass spectra, because they transferred to their product quickly at the beginning of reaction (Fig. 3.8). Acridine (CM5) was formed from CM4 by cleaving aldehyde group of CM4. Further, the derivatives of CM5 was generated as CM6' and CM6. CM6' was the hydroxylated product of CM5, hydroxylation was at 9 position due to its low electron density. The oxidized metabolite, acridone (CM6) was from CM6' by kept oxidizing at hydroxyl group and considered as more abundant than CM6' according to its stable structure.

The minor path way was from CM1'a, hydrolysis of the carbamoyl moiety, to form a carboxylic acid group CM9a, and further CM9a' underwent the oxidation to form CM9b. CM1'a was transformed from CM2 by losing water molecule, by exchanged the carbamoyl moiety, CM9a was also formed. Oxcarbazepine (CM1'b) was oxidation of CM1'a on the hydroxyl group, and CM1'b produced CM9b by the same way as CM1'a to CM9a. The methylation of hydroxyl group of CM1a generated CM10. CM11, CM12, CM13, CM14 and CM15 were the chlorinated metabolites from CM7, CM4, CM5, CM6, respectively. 
<smiles>O=C(O)C1N2C=CC=CC2=CC(=O)N1C(=O)O</smiles><smiles>CC(C)C1(C(C)(C)C)C=C(O)c2ccccc2N1C(=O)O</smiles><smiles>CO</smiles><smiles>CCOC1=Cc2ccccc2N(C(N)=O)c2ccccc21</smiles><smiles>C1C2CC1C2</smiles><smiles>COC(O)c1c2ccccc2nc2cc(I)ccc12</smiles><smiles>NC(=O)n1c2cccc-2cc(=O)c2ccccc21</smiles><smiles>C=[V]C</smiles><smiles>CC(C)(N)C(=O)N1c2ccccc2C=Cc2ccccc21</smiles><smiles>NC(=O)N1c2ccccc2C=C(O)c2ccccc21</smiles><smiles>NC(=O)N1c2ccccc2C2OC2c2ccccc21</smiles><smiles>COC(O)c1c2ccccc2nc2ccccc12</smiles><smiles>C=CC</smiles><smiles>NC(=O)N1c2ccccc2C(O)C(O)c2ccccc21</smiles><smiles></smiles>
(CM3)

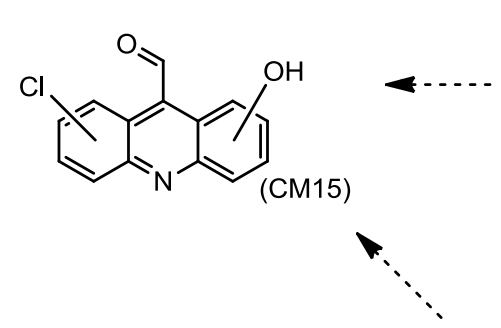

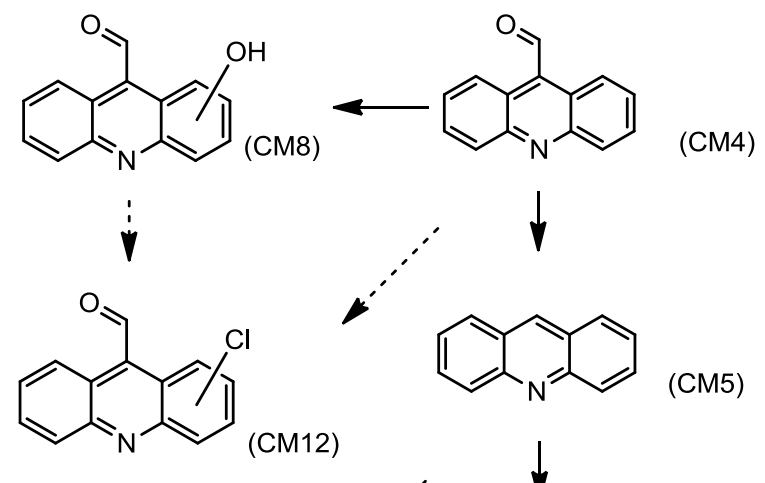<smiles>CC(C)(C)c1ccc2nc3ccccc3c(O)c2c1</smiles><smiles>CC(C)CC(C)C(C)(C)C</smiles>

Figure 3.10 The proposed mechanism of the degradation of CBZ catalyzed by CPO. 


\subsection{Discussion}

The process of CBZ degradation catalyzed by CPO was efficient, $100 \%$ CBZ was depleted at the concentration from $2.5 \mathrm{mg}$ to $14.8 \mathrm{mg} / \mathrm{L}$ for minutes, or $\geq 96 \%$ with $16.5 \mathrm{mg} / \mathrm{L}$ for 4 minutes, all in nanomolar level CPO. The degradation rate and concentrations were conservative, removal ability are mostly likely more than parameters used in the experiment due to the LC samples were not monitored by shorter time period.

Compared with some biological treatment in water, such as white rot fungus, the efficiency of CPO-catalyzed reaction was dramatically improved. For example, it was reported that $57 \%$ to about $70 \%$ of CBZ was removed by Trametes versicolor, and $46 \%$ was degraded by Ganoderma. Lucidum for 7 days, at the original concentration of $10 \mathrm{mg} / \mathrm{L}$ (ppm). [58]

The UV treatment, the most efficient common water treatment in degrading CBZ, compared with $\mathrm{ClO}_{2}$ oxidation and active sludge treatment. The UV

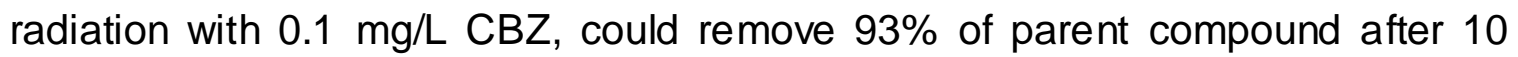
minutes. The concentration of $\mathrm{CBZ}$ was $0.1 \mathrm{mg} / \mathrm{L}$ in $\mathrm{ClO}_{2}$ to remove $54 \% \mathrm{CBZ}$; in active sludge treatment with $0.2 \mathrm{mg} / \mathrm{L} \mathrm{CBZ,16 \%}$ of drug was removed. [62] For the other active sludge degradation experiment with $30 \mu \mathrm{g} / \mathrm{L} \mathrm{CBZ}$, the removal of CBZ was not observed.[63] $\mathrm{TiO}_{2} / \mathrm{UV}$ method could reach $74 \% \mathrm{CBZ}$ conversion for 2 hours with $\mathrm{TiO}_{2}$ at $100 \mathrm{mg} / \mathrm{L}$.[59] The complete CBZ degradation (10mg/L) by Fenton-like oxidation was achieved at $2 \mathrm{mg} / \mathrm{L}$ iron for 1 hour, at $50{ }^{\circ} \mathrm{C}$.[64] The new CBZ biodegradation was investigated by using freshwater microalgae for 10 days the percentage of degradation was $30 \%-37 \%$, with initial CBZ 
concentration at $1 \mathrm{mg} / \mathrm{L}(\mathrm{ppm})$. With the increased of CBZ concentration, the degradation rate was decreased.[57] Ozonation of CBZ was likely the rapidest degradation treatment to $\mathrm{CBZ}$ in drinking water treatment system by ppm level ozone.[65] However, to consider about the application in large scale environment, CPO showed the stronger degradation ability to high concentration of CBZ at simple conditions (low concentration of catalyst, easy operation and proper reaction time), which was a potential choice industrial wastewater treatment.

Most of $\mathrm{CBZ}$ metabolites generated by $\mathrm{CPO}-\mathrm{H}_{2} \mathrm{O}_{2}-\mathrm{Cl}^{-}$system were the same as products in the common water treatment and in environment.[58, 59, 62, 63, 66] The $\mathrm{CPO}-\mathrm{H}_{2} \mathrm{O}_{2}-\mathrm{Cl}^{-}$system could be used as the environmental model to learn the chlorinated and oxidized reaction of specific pollutants.

To consider the toxicity and the persistence of CBZ products, the possible environmental impact of metabolites should be emphasized. Although simple acridines were not carcinogens, acridine and its derivatives were suggestive of mutagenic activities.[67] Acridine and aridone showed more toxic than CMZ itself in different ecotoxicity assays.[53]

There are still abundant acridine, acridone, and their derivatives after degradation catalyzed by CPO. The acridine and acridone are more susceptible to biological treatments. CPO might be applied in active sludge or with other microorganism to digest the major metabolites. The UV treatment showed a outstanding removal of acridine and acridone. CPO catalyzed degradation could be coupled with UV-treatment to increase the degradation efficiency. The 
investigation of improving the depletion of toxicologically relevant metabolites of CBZ, such as by coupling CPO catalyzed degradation with other treatment should be considered in the future experiments 


\section{CHATPER IV.}

\section{CPO-CATALYZED DEGRADTION OF SULFAMETHAZINE}

\subsection{Background}

Over 10,000 tons level of antibiotics are estimated to be used in the U.S.A per year. [68] Sulfonamide pharmaceutical substances are widely used in human and veterinary antibacterial treatments and they are frequently detected in wastewater and surface water with the active sulfonamide concentration detected as $20 \mathrm{mg} / \mathrm{L}$.[69] Sulfamethazine or sulfadimidine (SMZ) belongs to heterocyclic sulfonamides, and the concentration of SMZ has been detected to $8.7 \mathrm{mg} / \mathrm{kg}$ in manure.[70] Nine sulfonamide antibiotics were detected in surface water with SMZ as the highest one with concentration of $78.3 \mathrm{ng} / \mathrm{L}, \mathrm{SMZ}$ resistant bacteria was found in the sample.[8] The detection of SMZ resistant bacteria implied the extensive use of SMZ increased the risk of antibacterial resistance..

CPO showed its ability to degrade/ detoxicate drugs in our previous study, and the aim of this experiment was to investigate the potential application of CPO in degradation of antibiotics. To evaluate $\mathrm{CPO}-\mathrm{H}_{2} \mathrm{O}_{2}-\mathrm{Cl}^{-}$system, the reaction efficiency of CPO in the degradation of SMZ would be investigated and the structures of metabolites and degradation pathway would be proposed.

4.2 Experimental Procedure

4.2.1 Material

All material and chemicals used were the same as described in section 2.2.1.

4.2.2 UV-Visible spectrophotometry

A VARIAN UV-Vis spectrophotometer (Cary 200 Bio) was used to collect the 61 
UV spectra of the degradation products. SMZ was dissolved in methanol to make $3.59 \mathrm{mM}$ stock solution. The drug solution was scanned by dissolving $0.06 \mathrm{mM}$

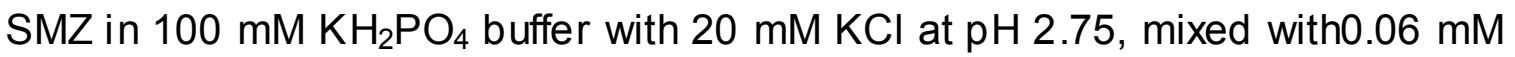
$\mathrm{H}_{2} \mathrm{O}_{2}$. UV spectra were recorded after the addition of $5 \mathrm{nM}$ CPO for 1 minute, 2.5 minutes and 4 minutes.

\subsubsection{Liquid chromatography and mass spectrometry}

\subsubsection{Sample preparation}

To investigate the degradation efficiency, SMZ was dissolved in methanol to make a stock solution (3.59 mM), $62.45 \mu \mathrm{M}(17.38 \mathrm{mg})$ of $\mathrm{SMZ}$ was mixed with $1.3 \mathrm{nM}$ CPO for 30 minutes at room temperature. $\mathrm{H}_{2} \mathrm{O}_{2}$ stock solution $(41.16 \mathrm{mM})$ was added to reaction system at $56.5 \mu \mathrm{L} /$ minute to make the final concentration of $\mathrm{H}_{2} \mathrm{O}_{2}$ achieved $314 \mu \mathrm{M}$. Mixture was centrifuged at $3,000 \mathrm{~g}$ in Centriprep ${ }^{\circledR}$ centrifugal filter unit with a 30,000 Dalton cut-off membrane (EMD Millipore, Billerica, MA, USA). The filtrate was collect after centrifuged for 1 min. Ethyl acetate was used to extract the filtrate while shaking vigorously. The get rid of the organic solvent, The supernatant was evaporated to dryness. The dried residues were dissolved in $\mathrm{H}_{2} \mathrm{O}$ /methanol $(95: 5 \mathrm{v} / \mathrm{v})$ to make the final concentration approximate $1 \mathrm{mg} / \mathrm{L}(\mathrm{ppm})$. Sample was stored at $-20{ }^{\circ} \mathrm{C}$ in a freezer or immediately detected by LC-Q-TOF-MS mass spectrometer system.

To detect all metabolites of SMZ, the same experiment above was carried out (3.59 mM SMZ, $314 \mu \mathrm{M} \mathrm{H}_{2} \mathrm{O}_{2}$ and $1.3 \mathrm{nM}$ ) for 1.5 hour, extracted directly by ethyl acetate. And nitrogen gas purge was used to get sample dried. The dried metabolites were dissolved in $2.0 \mathrm{~mL} \mathrm{H} \mathrm{H}_{2} \mathrm{O}$ /methanol $(95: 5 \mathrm{v} / \mathrm{v})$ to make the final 
concentration approximate $5 \mathrm{mg} / \mathrm{L}$ (ppm). Centrifuge the sample with $1200 \mathrm{~g}$ for 10 minutes, $1.5 \mathrm{~mL}$ supernatant was removed by syringe. Filtration was applied by using $0.22 \mu \mathrm{M}$ polyethersulfone syringe filter. The sample was stored at $-20^{\circ} \mathrm{C}$ in a freezer and detected both in LC-Q-TOF-MS.

To investigate the mechanism of degradation in $\mathrm{CPO}-\mathrm{H}_{2} \mathrm{O}_{2}-\mathrm{Cl}^{-}$system, the sample reacted with low concentration of $\mathrm{H}_{2} \mathrm{O}_{2}$ was prepared. $6.86 \mu \mathrm{M} \mathrm{H}_{2} \mathrm{O}_{2}$ was added directly to Centriprep ${ }^{\circledR}$ centrifugal filter unit (30,000 Dalton cut-off) with $35.90 \mu \mathrm{M} \mathrm{SMZ}$, catalyzed by $1.3 \mathrm{nM}$ CPO in the $100 \mathrm{mM}$ phosphate buffer with $20 \mathrm{mM} \mathrm{KCl}$ for 1 minute, 3 minutes and 5 minutes, filter units were centrifuged at $3000 \mathrm{~g}$ for $1 \mathrm{~min}$ at room temperature, and extracted the filtrate by ethyl acetate, purged the organic phase with nitrogen gas to dryness. The dried metabolites were dissolved in $\mathrm{H}_{2} \mathrm{O}$ /methanol $(95: 5 \mathrm{v} / \mathrm{v})$ to make the final concentration approximate $1 \mathrm{mg} / \mathrm{L}$ (ppm), and detected by LC-Q-TOF-MS system immediately. Experiments ran in triplicate.

To investigate the brominated products, the reaction was also carried out in the buffer contained $\mathrm{KBr}$ instead of $\mathrm{KCl}, 62.45 \mu \mathrm{M} \mathrm{SMZ}, 2 \mathrm{mM} \mathrm{H} \mathrm{O}_{2}$, catalyzed by $2 \mathrm{nM}$ CPO for 30 minutes. After extraction and purge procedure, the final concentration dissolved in the $\mathrm{H}_{2} \mathrm{O} /$ methanol $(95: 5 \mathrm{v} / \mathrm{v})$ was approximate $1 \mathrm{mg} / \mathrm{L}$ (ppm).

4.2.3.2 Instrumentation and chromatographic separation

Instrumentation and chromatographic separation were the same as in section 2.2.3.2. without the application of Triple-Quandrupole LC/MS/MS mass spectrometry. 


\subsubsection{Data Mining and Database development}

The data Mining and Database development were the same as in section 2.2.3.3 without the application of FIA.

\subsection{Result and discussion}

4.3.1 UV-Vis study of CPO-catalyzed degradation of carbamazepine

UV-Vis Spectra of SMZ $(0.06 \mathrm{mM})$ and $\mathrm{H}_{2} \mathrm{O}_{2}(0.06 \mathrm{mM})$ were scanned in 100 mM KH${ }_{2} \mathrm{PO}_{4}$ buffer with $20 \mathrm{mM} \mathrm{KCl}$ at pH 2.75 (Fig.4.1). The Spectrum of SMZ showed the absorption at $241 \mathrm{~nm}, 263 \mathrm{~nm}$ and $306 \mathrm{~nm}$. 1 minute after addition of $5 \mathrm{nM}$ CPO, the $241 \mathrm{~nm}$ absorption increased, and stopped increasing at 2.5 minutes, the $263 \mathrm{~nm}$ peak kept decreasing. And the wavelength at $306 \mathrm{~nm}$ increased from 1 minute to 2.5 minutes. The UV spectrum at 4 minutes was monitored, the line was the same as the wavelength at 2.5 minutes. $\mathrm{H}_{2} \mathrm{O}_{2}$ was added to the mixture solution, to make the total concentration of $\mathrm{H}_{2} \mathrm{O}_{2}$ increase to $0.30 \mathrm{mM}$, after 1 minute, the $241 \mathrm{~nm}$ peak decreased and a strong absorption was observed at $273 \mathrm{~nm}$ (Fig. 4.1). There was no wavelength could be used to measure kinetic parameter of SMZ degradation catalyzed by CPO.

The same reaction was carried out under the same condition except for the chlorine ion $(\mathrm{KCl})$ in phosphate buffer. Without $\mathrm{KCl}$, the absorbance did not change after the addition of CPO. Chlorine ion is imperative in the degradation of $\mathrm{SMZ}$ in $\mathrm{CPO}-\mathrm{H}_{2} \mathrm{O}_{2}-\mathrm{Cl}^{-}$system.

\subsubsection{1 $\mathrm{CPO}-\mathrm{H}_{2} \mathrm{O}_{2}-\mathrm{Cl}^{-}$system}

To investigate the degradation efficiency of $\mathrm{SMZ}$ in $\mathrm{CPO}-\mathrm{H}_{2} \mathrm{O}_{2}-\mathrm{Cl}^{-}$system, $62.45 \mu \mathrm{M} \mathrm{SMZ}$ was reacted with $314 \mu \mathrm{M}$ of $\mathrm{H}_{2} \mathrm{O}_{2}$ and CPO (1.3 nM) for 30 


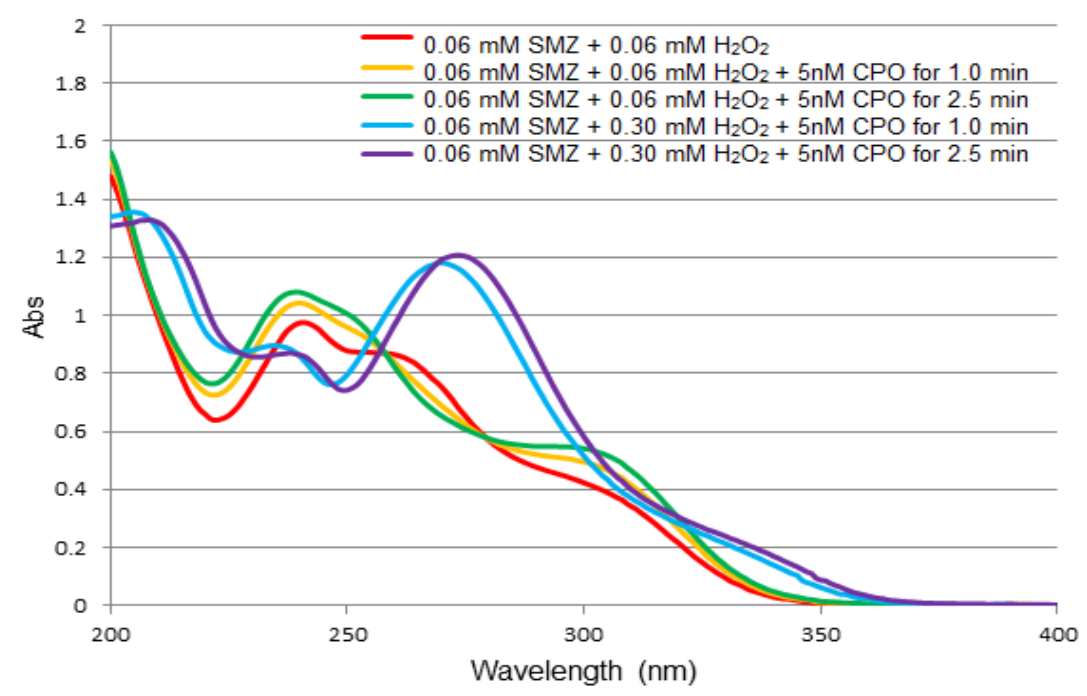

Figure 4.1 UV spectrum of SMZ degradation catalyzed by CPO

minutes, the sample was detected by LC-Q-TOF-MS, SMZ was not observed, the

\subsubsection{LC-Q-TOF- MS}

Degradation efficiency by nanomolar level of CPO could achieved 100\%, suggesting the potential of the application of CPO in large-scale waste water treatment.

Samples were detected in Agilent Technologies 6530 Accurate-Mass LC-QTOF-MS in full scan MS mode, the accurate mass data of the molecular ions were processed through the Agilent MassHunter Qualitative Analysis software. To detected all metabolites, samples were concentrated 5 folds, there were 8 SMZ metabolites (coded from SM1 to SM8) confirmed by different retention times and accurate mass-to-charge ratios $(\mathrm{m} / \mathrm{z})$. SM9 was detected only in the reaction with limited $\mathrm{H}_{2} \mathrm{O}_{2}$ within 5 minutes as an intermediate product. The elemental formula, retention time, the relative mass difference between the observed mass and the mass of the target compound (in parts per million), and the difference 
between the observed mass and the mass of target compound (in milliDaltons) were collected (Table 4.1).

Table 4.1 Accurate-Mass QTOF-LC/MS data for the identification of SMZ and its metabolites catalyzed in $\mathrm{CPO}-\mathrm{H}_{2} \mathrm{O}_{2}-\mathrm{Cl}$ - system.

\begin{tabular}{|c|l|c|c|c|c|c|}
\hline Code & \multicolumn{1}{|c|}{ Formula } & $\begin{array}{c}\text { Retention time } \\
(\mathrm{min})\end{array}$ & $\begin{array}{c}\text { Experimental mass } \\
(\mathrm{m} / \mathrm{z})\end{array}$ & $\begin{array}{c}\text { Theoretical mass } \\
(\mathrm{m} / \mathrm{z})\end{array}$ & $\begin{array}{c}\text { Diff } \\
(\mathrm{ppm})\end{array}$ & $\begin{array}{c}\text { Diff } \\
(\mathrm{mDa})\end{array}$ \\
\hline $\mathrm{SMZ}$ & $\mathrm{C}_{12} \mathrm{H}_{14} \mathrm{~N}_{4} \mathrm{O}_{2} \mathrm{~S}$ & 4.245 & 278.0832 & 278.0837 & -1.93 & -0.54 \\
\hline $\mathrm{SM} 1$ & $\mathrm{C}_{12} \mathrm{H}_{14} \mathrm{~N}_{4}$ & 3.219 & 214.1211 & 214.1218 & -3.27 & -0.70 \\
\hline $\mathrm{SM} 2$ & $\mathrm{C}_{12} \mathrm{H}_{13} \mathrm{ClN}_{4}$ & 4.106 & 248.0829 & 248.0829 & 0.00 & 0.00 \\
\hline $\mathrm{SM} 3$ & $\mathrm{C}_{12} \mathrm{H}_{12} \mathrm{Cl}_{2} \mathrm{~N}_{4}$ & 7.295 & 282.0440 & 282.0439 & 0.23 & 0.07 \\
\hline $\mathrm{SM} 4$ & $\mathrm{C}_{12} \mathrm{H}_{11} \mathrm{Cl}_{3} \mathrm{~N}_{4}$ & 7.400 & 316.0044 & 316.0049 & -1.71 & -0.54 \\
\hline $\mathrm{SM} 5$ & $\mathrm{C}_{12} \mathrm{H}_{13} \mathrm{ClN}_{4} \mathrm{O}_{2} \mathrm{~S}$ & 4.894 & 312.0447 & 312.0448 & -0.13 & -0.04 \\
\hline $\mathrm{SM} 6$ & $\mathrm{C}_{12} \mathrm{H}_{12} \mathrm{Cl}_{2} \mathrm{~N}_{4} \mathrm{O}_{2} \mathrm{~S}$ & 5.414 & 346.0054 & 346.0058 & -1.04 & -0.36 \\
\hline $\mathrm{SM} 7$ & $\mathrm{C}_{12} \mathrm{H}_{13} \mathrm{ClN}_{4} \mathrm{O}_{3} \mathrm{~S}$ & 2.980 & 328.0398 & 328.0397 & 0.25 & 0.08 \\
\hline $\mathrm{SM} 8$ & $\mathrm{C}_{12} \mathrm{H}_{11} \mathrm{Cl}_{3} \mathrm{~N}_{4} \mathrm{O} \mathrm{O}$ & 7.267 & 379.9668 & 379.9668 & -0.16 & -0.06 \\
\hline $\mathrm{SM} 9$ & $\mathrm{C}_{12} \mathrm{H}_{14} \mathrm{~N}_{4} \mathrm{O}_{3} \mathrm{~S}$ & 1.020 & 294.0790 & 294.0787 & 1.17 & 0.34 \\
\hline
\end{tabular}

All the relative mass difference of the standard drug (SMZ) and metabolites were less than $4.0 \mathrm{ppm}$. The mass differences of all compounds were less than 1.0 $\mathrm{mDa}$. This method was proved to be efficient for determination of the metabolites of SMZ.

The mass spectra of each individual metabolite were collected in positive mode by MassHunter Workstation software (Appendix I). Since it was in positive mode, all the compounds were detected as molecular ion $[\mathrm{M}+\mathrm{H}]^{+}$. SM7 and SM9 were detected as molecular ion $[\mathrm{M}+\mathrm{Na}]^{+}$adduct $(351.0287 \mathrm{~m} / \mathrm{z}$ and $317.0677 \mathrm{~m} / \mathrm{z}$, respectively), the sodium adduct formation was favored in the ion source probable due to the ion pairing effect on the functional group responsible of ionization.

For chlorinated metabolites with one chlorine atom in compound (SM2, SM5 and SM7), the isotope peaks were detected as the conformation of addition of 66 
chlorine atom, the two major peaks of each spectrum separated by $2 \mathrm{~m} / \mathrm{z}$ units and peak heights are in the ratio of $3: 1$, proved these molecules contain one chlorine atom. For SM3 and SM6, there were 3 lines in the molecular ion region $(M+, M+2$ and $M+4)$ with gaps of $2 \mathrm{~m} / \mathrm{z}$ units between them, and with peak heights in the ratio of 9:6:1, it was confirmed that both compounds contain 2 chlorines. For SM4 and SM8, compounds had the pattern 27:27:9:1.[71]

The structures of each metabolite were confirmed in targeted MS/MS by retention time and fragment ions (Fig. 4.2). There were 2 types of metabolites based on their structures. The first type products were $\mathrm{SO}_{2}$ extrusion structures. (SM1, SM2, SM3 and SM4). SM1 was the product lost the sulfonyl group of SMZ, SM2, SM3 and SM4 were the chlorinated metabolites of SM1. The other structures were directly chlorination of SMZ (SM5, SM6 and SM8), and the hydroxylation product of SM5 was SM7. SM9 was the metabolic intermediate of SM7, the hydroxylated product of SMZ, it could only be detected at the beginning of the reaction.

The concentrations of all metabolites were measured as compound area by MassHunter Workstation software, and presented by percentage of all compounds as pie chart, percentage less than $1 \%$ were showed in the second pie chart at right side (Fig. 4.3)

To investigate the mechanism of degradation process, a experiment was carried out for limited reaction time (1,3 and 5 minutes) with low concentration of $\mathrm{H}_{2} \mathrm{O}_{2}(6.86 \mu \mathrm{M})$, the ratio of the concentration of drug and $\mathrm{H}_{2} \mathrm{O}_{2}$ was about 5:1. Only part of SMZ was degraded, and 3 metabolites were detected which could 


\section{$\mathrm{C}_{12} \mathrm{H}_{14} \mathrm{~N}_{4} \mathrm{O}_{2} \mathrm{~S}(\mathrm{SMZ})$}

x10 5 +ESI Product Ion (rt: $4.199 \mathrm{~min})$ Frag=135.0V CID@18.4 (279.0925[z=1] -> **) Sulfam...

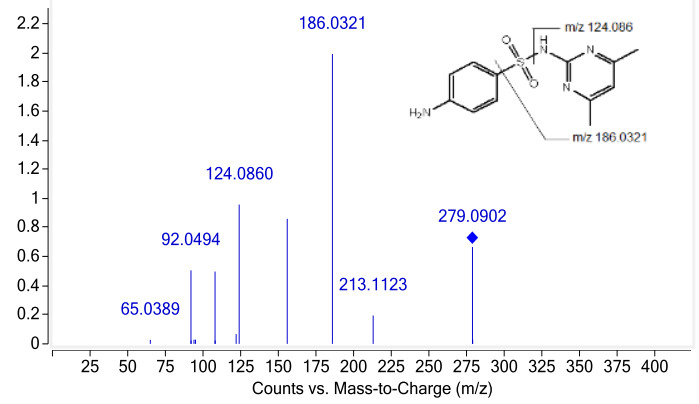

\section{$\mathrm{C}_{12} \mathrm{H}_{13} \mathrm{CIN}_{4}(\mathrm{SM} 2)$}

x10 4 +ESI Product lon (rt: $5.728 \mathrm{~min}$ ) Frag=135.0V CID@17.5 (249.0890[z=1] -> **) Sulfamethazi...

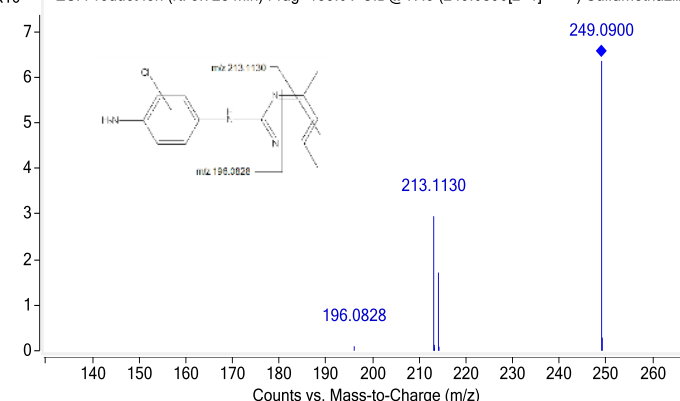

\section{$\mathrm{C}_{12} \mathrm{H}_{11} \mathrm{C}_{13} \mathrm{~N}_{4}$ (SM4)}

x10 3 +ESI Product Ion (rt: $2.442 \mathrm{~min}$ ) Frag=135.0V CID@19.5 (317.0675[z=1] -> **) Sulfamethazi...

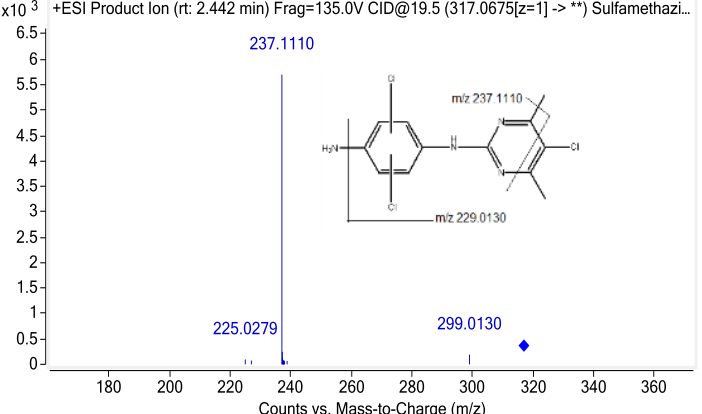

\section{$\mathrm{C}_{12} \mathrm{H}_{12} \mathrm{Cl}_{2} \mathrm{~N}_{4} \mathrm{O}_{2} \mathrm{~S}(\mathrm{SM} 6)$}
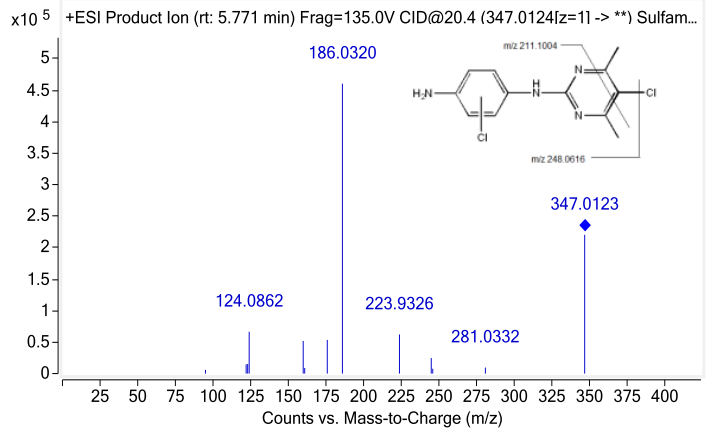

\section{$\mathrm{C}_{12} \mathrm{H}_{14} \mathrm{~N}_{4}(\mathrm{SM} 1)$}

x10 4 +ESI Product lon (rt: 3.432 min) Frag=135.0V CID@16.5 (215.1283[z=1] -> **) Sulfam..

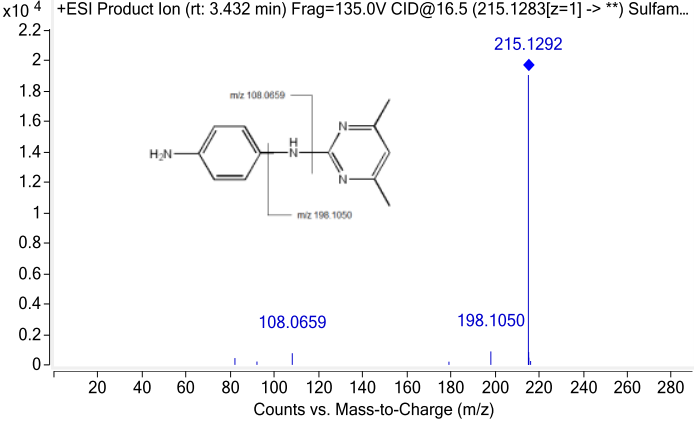

\section{$\mathrm{C}_{12} \mathrm{H}_{12} \mathrm{C}_{12} \mathrm{~N}_{4}(\mathrm{SM} 3)$}

x10 3 +ESI Product Ion (rt: 6.810 min) Frag=135.0V CID@18.5 (283.0511 [z=1] ->**) Sulfamethazi...

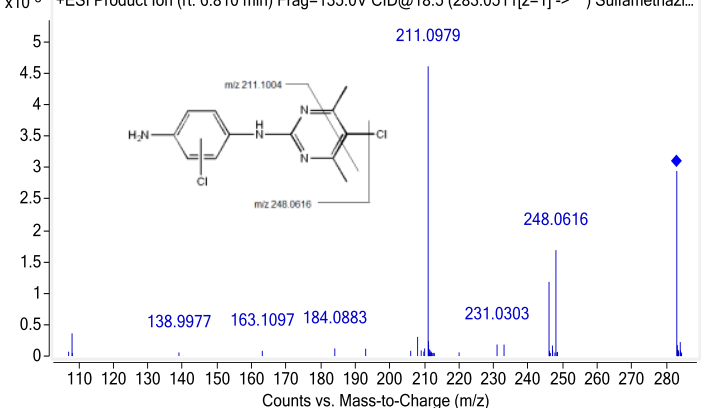

$\mathrm{C}_{12} \mathrm{H}_{13} \mathrm{ClN}_{4} \mathrm{O}_{2} \mathrm{~S}$ (SM5)
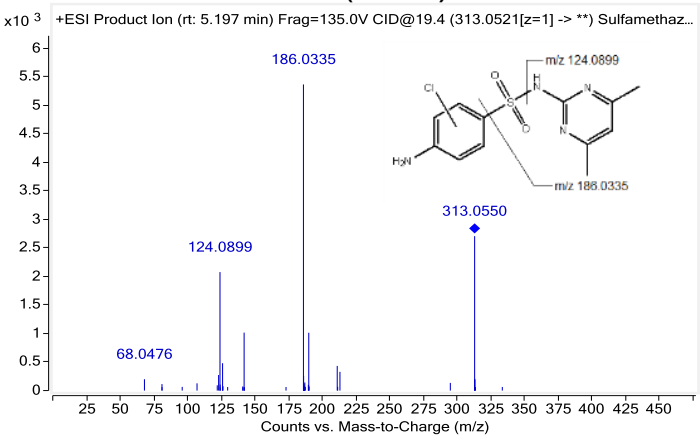

$\mathrm{C}_{12} \mathrm{H}_{13} \mathrm{ClN}_{4} \mathrm{O}_{3} \mathrm{~S}(\mathrm{SM} 7)$

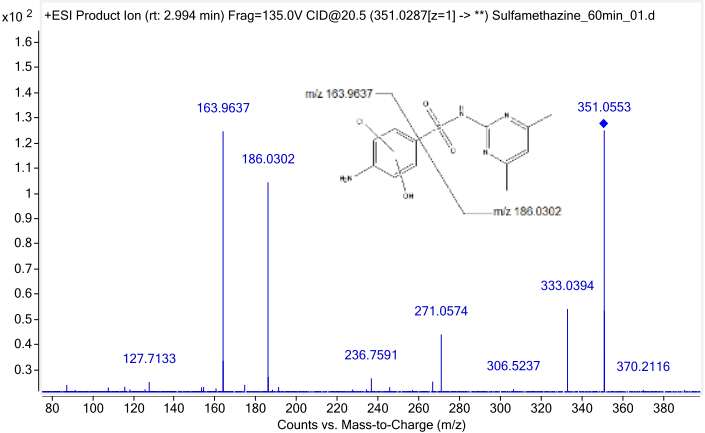

Figure 4.2 The targeted MS/MS spectra of APAP and its metabolites. 


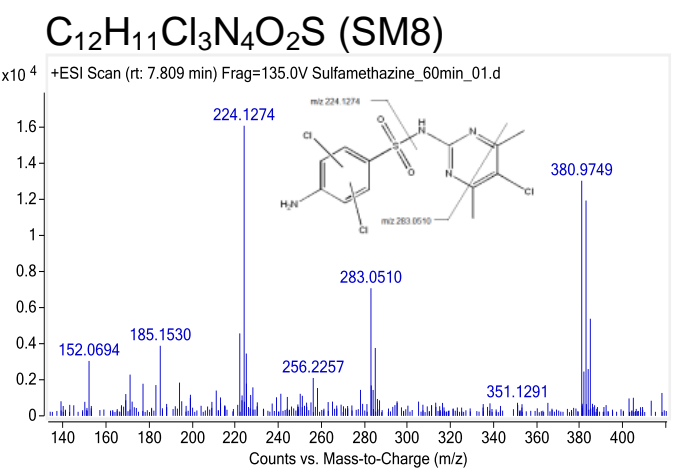

\section{$\mathrm{C}_{12} \mathrm{H}_{14} \mathrm{~N}_{4} \mathrm{O}_{3} \mathrm{~S}$ (SM9)}

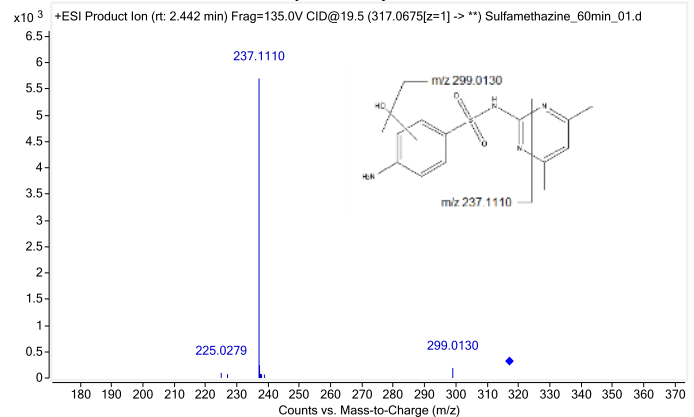

Figure 4.2 (cont.) The targeted MS/MS spectra of APAP and its metabolites.

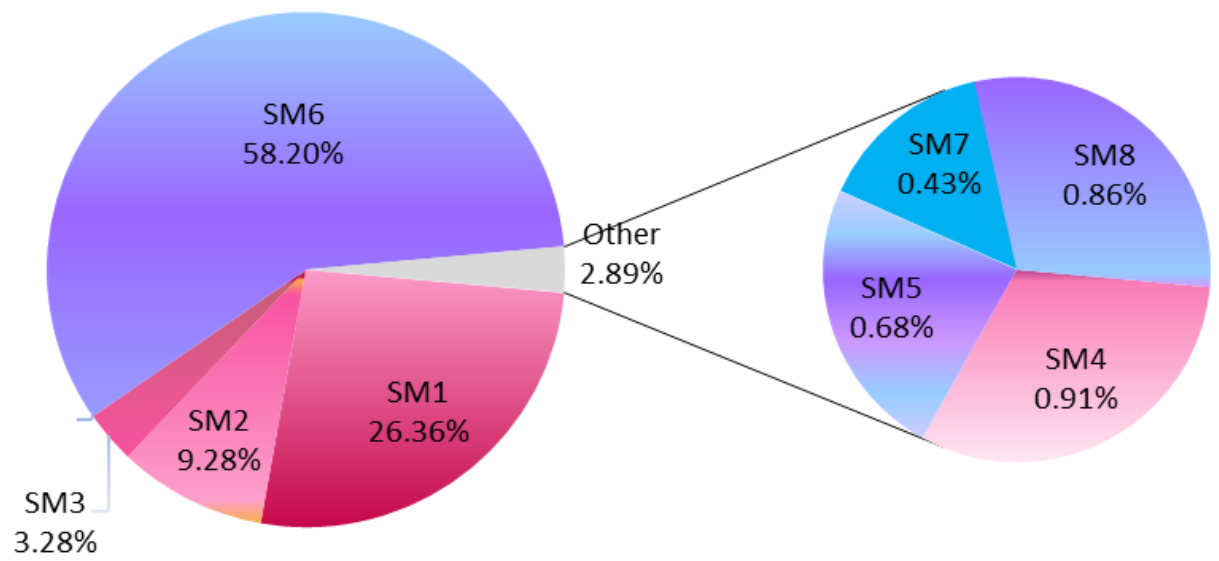

Figure 4.3 The percentage of each metabolites measured by compound area. Metabolites shared the same structure presented by the same color (pink color represent the desulnonated structure, purple represent the SMZ-based group and blue presents the hydroxylated group).

suggested as the first formed metabolites (Fig 4.4). SM1 was the most abundant metabolite within 5 minutes, and SM5, SM9 generated at the same time in lower amounts, suggested that the first step of degradation was the oxidation, chlorination and the loss of sulfonyl group, SM1 formed preferentially.

The area of SM1 kept stable at first 3 minutes and showed decreased tendency at 5 minutes, it might due to the transformation of SM1 to chlorinated metabolites which under the limit of detection. The percentage of SM1 was $26.35 \%$ in the reaction with higher concentration of $\mathrm{H}_{2} \mathrm{O}_{2}$ for longer reaction time, 
whereas SM6 was the primary product finally, suggested that the desulfonylation reaction was predominant at the first reaction stage, and then the rate of chlorination significantly increased.

SM5 had the increased tendency form 1 minute to 5 minute, the finally concentration of SM5 was low but its chlorinated product SM6 was the major metabolites, SM5 was suggested as the major intermediate metabolite. SM9 was not observed after reaction with high concentration $\mathrm{H}_{2} \mathrm{O}_{2}$ for 30 minutes, but its chlorinated product was detected as $0.43 \%$ of all metabolites, it was suggested that hydroxylated metabolites were the byproducts in the reaction. Chlorination and desulfonylation were the major reactions, hydroxylation was the minor reaction. (Fig.4.3).

For desulfonylated metabolite SM1 and its chlorinated products SM2, SM3 and SM4, the total concentration of them was $39.83 \%$ and the 3 chlorine atom addition structure (SM4) was only $0.91 \%$. Chlorination of the desufonylated structure by 3 chlorine atoms was not favored in the reaction which may due to the structure of CPO binding pocket and the polarity in the pocket. The same limitation of chlorine atoms addition also applied in SMZ based structure, the total concentration of them was $60.17 \%$, SM8 $(0.86 \%)$ were the minor product of the degradation catalyzed by CPO. Two chlorine atoms were preferentially inserted to SMZ molecule (SM6, 58.20\%) in contrast to the three chlorine atoms addition. (Fig 4.4)

The chromatograms of SMZ and its metabolites were collected with their proposed structures (Fig. 4.5). In the chromatograms of SM2, SM3, SM4, SM5, 


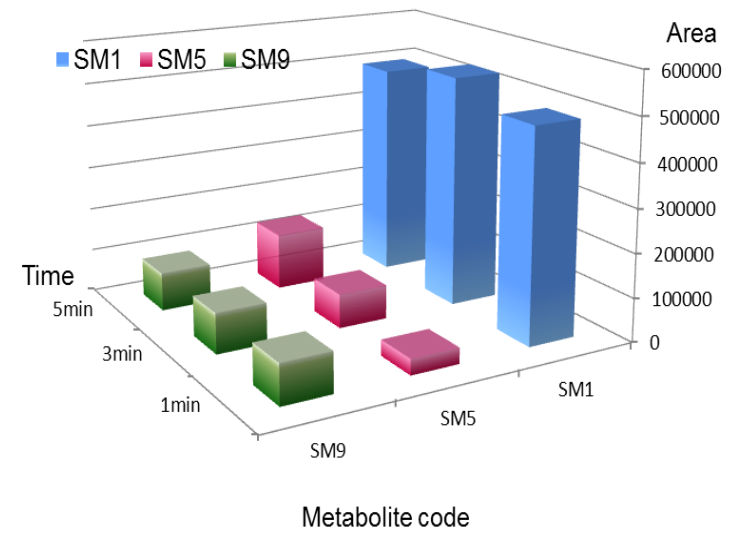

Figure 4.4 The area of metabolites with limited $\mathrm{H}_{2} \mathrm{O}_{2}$ at 1 minute, 3 minutes and 5 minutes detected by Accurate-Mass LC-Q-TOF-MS. All experiments were duplicates and data reported were mean values of two independent measurements.

SM7, SM8 and SM9, there were isomers identified by different retention times.

The extrusion of $\mathrm{SO}_{2}$ structure (SM1) was reported previously with structural rearrangement. There were two structures proposed for SM1 (Table 4.2). One is N1-(4,6-dimethylpyrimidin-2-yl)benzene-1 (a), 4-diamine, another is 4-(2-imino4,6-dimethylpyrimidin-1(2H)-yl)aniline (b). Proposed structures were presented by form (a) in all the spectra and chromatograms, form (a) was probably the actual structure of metabolite in the reaction catalyzed by CPO because of its less rearrangement than form Table 4.2 Possible identities of $\mathrm{C}_{12} \mathrm{H}_{14} \mathrm{~N}_{4}$ (SM1).

(b). SM2-SM4 were the chlorinated products of SM1.In $\mathrm{SM} 2$, there were 5 isomers according to the 5 different retention times. The two major isomers were chlorinated on

\begin{tabular}{|l|l|}
\hline Structure & Reference \\
\hline [(a)
\end{tabular}


position 1 and 2 because of the high electron density of aniline group and the metabolite chlorinated at position 1 (Fig. 4.5) was assumed as the most abundant product because of its electron density, $-\mathrm{NH}_{2}$ group on benzene ring was an electron donating group (EDG), whereas sulfonyl group was electron withdrawing group. Other isomers were also suggested first be chlorinated or hydroxylated on the aniline group at the carbon atoms which located close to amine.

SM5 had 5 different chlorinated sites which corresponded to 5 different retention time, major metabolites were chlorinated at position 1,2 and 3 , the $3^{\text {rd }}$ position was on the dimethylpyrimidine group (Fig 4.5). The other two were proposed to assign to the two amine groups. SM6 only showed one retention time, there was one structure was stable, other structures may exist but with the amount under the limit of detection. The chlorine atoms probably added to the aniline group near primary amine due to the high electron density and it was a typical chlorination catalyzed by CPO.[39] SM8 was the byproduct with one more chlorine atom addition based on SM7, the two retention times suggested 2 isomer structures, one additional chloride sites were on the aniline group near $\mathrm{NH}_{2}$ or on the dimethylpyrimidine.

SM7 and SM9 were the hydroxylated products of SMZ, although in $\mathrm{TiO}_{2} / \mathrm{UV}$ method, the pyrimidinyl moiety of SMZ was suggested to be hydroxylated, in CPO reaction, phenyl portion were proposed to be hydroxylated according to the MSMS spectrum. [81] The hydroxylation of aromatic amine in SMZ was also reported in the biodegradation catalyzed by white rot fungus.[72] However, 


\section{$\mathrm{C}_{12} \mathrm{H}_{14} \mathrm{~N}_{4} \mathrm{O}_{2} \mathrm{~S}(\mathrm{SMZ})$}

x10 ${ }^{6}$ Cpd 1: C12 H14 N4 O2 S: +ESI EIC(279.0910, 290.0832, 292.0863, 296....

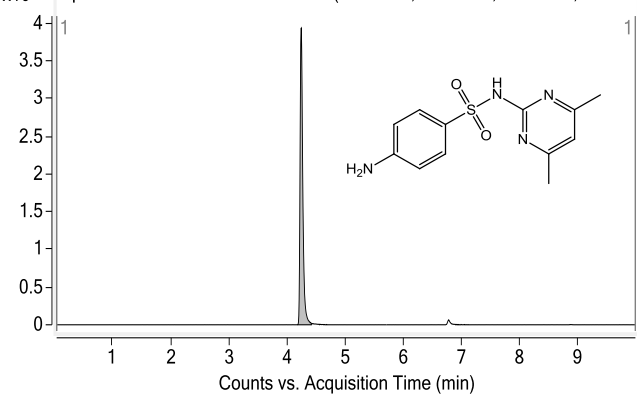

\section{$\mathrm{C}_{12} \mathrm{H}_{13} \mathrm{ClN}_{4}(\mathrm{SM} 2)$}

x10 ${ }^{2} \mathrm{Cpd} 2 \mathrm{C} 12 \mathrm{H} 13 \mathrm{Cl} \mathrm{N} 4:+\mathrm{EIC}(249.0902,251.0875,266.1167,268.1140$...) Scan S.

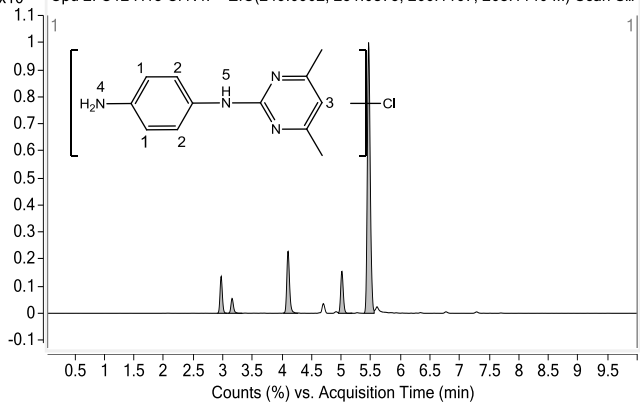

$\mathrm{C}_{12} \mathrm{H}_{11} \mathrm{Cl}_{3} \mathrm{~N}_{4}(\mathrm{SM} 4)$

$\times 10^{2}$ Cpd 4: C12 H11 Cl3 N4: + ElC(317.0122, 319.0093, 321.0066, 334.0388 ...)...

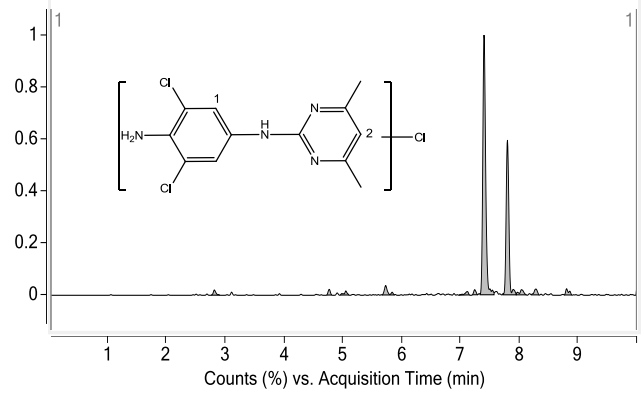

\section{$\mathrm{C}_{12} \mathrm{H}_{12} \mathrm{Cl}_{2} \mathrm{~N}_{4} \mathrm{O}_{2} \mathrm{~S}(\mathrm{SM} 6)$}

x10 2 Cpd 6: C12 H12 Cl2 N4 O2 S: + EIC(347.0131, 349.0102, 364.0396, 366.03...

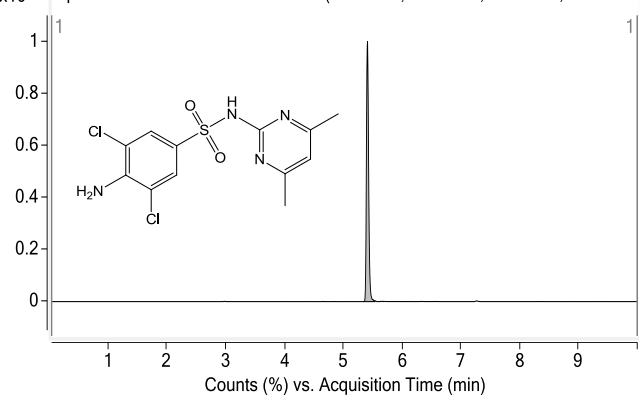

$\mathrm{C}_{12} \mathrm{H}_{14} \mathrm{~N}_{4}(\mathrm{SM} 1)$

x10 2 Cpd 1: C12 H14 N4: + EIC(215.1291, 232.1557, 237.1111, 253.0850) Scan Su...

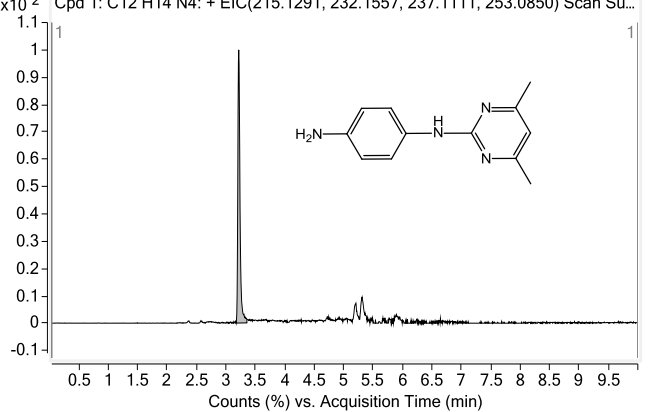

$\mathrm{C}_{12} \mathrm{H}_{12} \mathrm{Cl}_{2} \mathrm{~N}_{4}(\mathrm{SM} 3)$

$\times 102$ Cpd 1: $\mathrm{C} 12 \mathrm{H} 12 \mathrm{Cl} 2 \mathrm{~N} 4$ : + EIC $(283.0512,285.0484,300.0777,302.0749 \ldots$.$) Scan...$

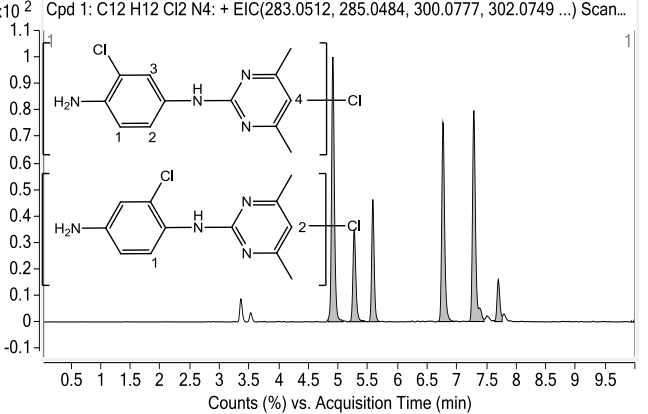

$\mathrm{C}_{12} \mathrm{H}_{13} \mathrm{ClN}_{4} \mathrm{O}_{2} \mathrm{~S}$ (SM5)

x10 2 Cpd 5: C12 H13 CI N4 O2 S: + EIC(313.0521, 315.0493, 330.0786, 332.075.

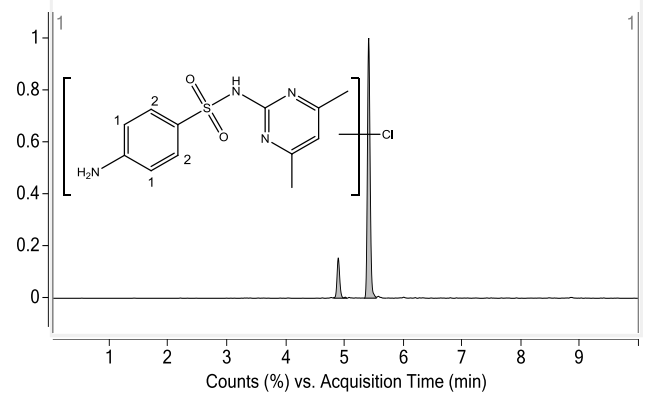

$\mathrm{C}_{12} \mathrm{H}_{13} \mathrm{ClN}_{4} \mathrm{O}_{3} \mathrm{~S}$ (SM7)

x10 2 Cpd 6: C12 H13 Cl N4 O3 S: + EIC(329.0470, 331.0442, 346.0735, 348.070

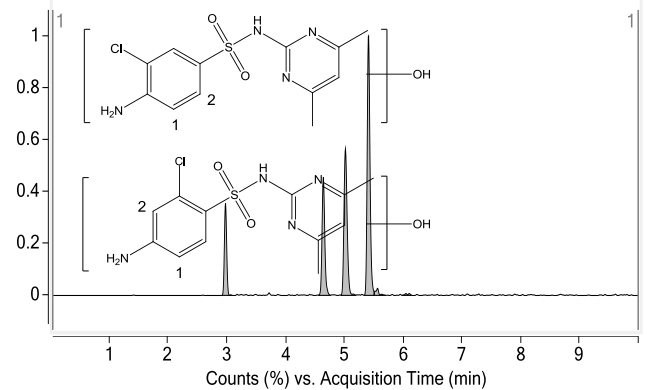

Figure 4.5. The chromatograms of CBZ and its metabolites. 

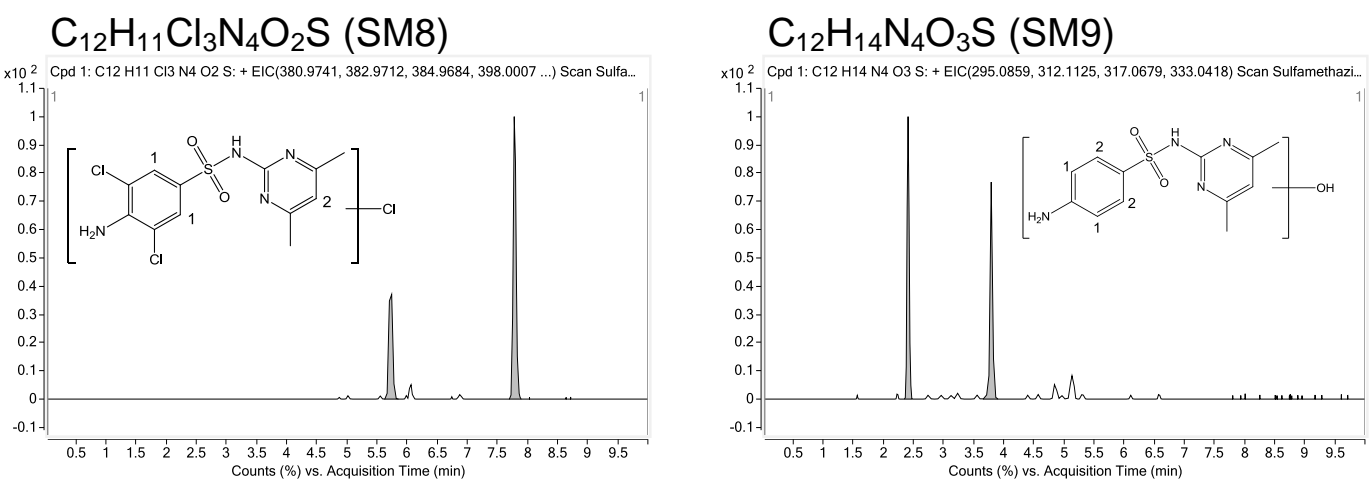

Figure 4.5. (cont.) The chromatograms of CBZ and its metabolites.

according to CPO chlorination preference, the hydroxylation was recommended mainly at phenyl portion.

The mechanism of degradation catalyzed by CPO was proposed considering all information above, the pathway for SMZ metabolism catalyzed by CPO was proposed, each metabolite showed by one of its proposed chemical structures instead of all isomers. For $\mathrm{CPO}-\mathrm{H}_{2} \mathrm{O}_{2}-\mathrm{Cl}^{-}$system (Fig 4.6), the chlorinated steps with one and two chlorine atoms addition and desulfonylation of SMZ were the major pathways. The minor path way was hydroxylation and chlorination with three chlorine atoms.

\subsubsection{2 $\mathrm{CPO}-\mathrm{H}_{2} \mathrm{O}_{2}-\mathrm{Br}^{-}$system}

To investigate the halogenation of SMZ catalyzed by $\mathrm{CPO}, 20 \mathrm{mM} \mathrm{KBr}$ was applied in the buffer instead of $\mathrm{KCl}$, the $\mathrm{CPO}-\mathrm{H}_{2} \mathrm{O}_{2}-\mathrm{Br}$ system reaction was carried out at the room temperature, and the product spectrum was obtained (Appendix I) There were only 3 metabolites detected. All of them were brominated products. (Table 4.3) [71] There were two peaks $(357.0027 \mathrm{~m} / \mathrm{z}$ and 

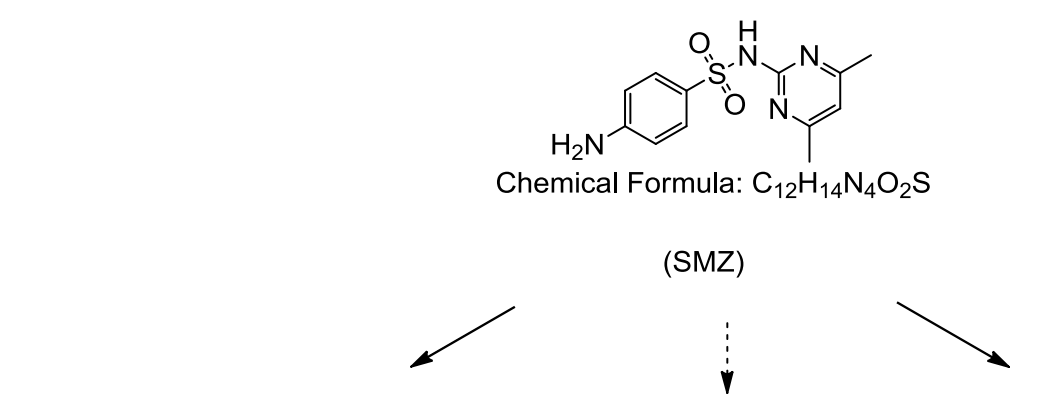<smiles>Cc1cc(C)nc(NS(=O)(=O)c2ccc(N)c(Cl)c2)n1</smiles><smiles>Cc1cc(C)nc(NS(=O)(=O)c2ccc(N)c(Cl)c2)n1</smiles>
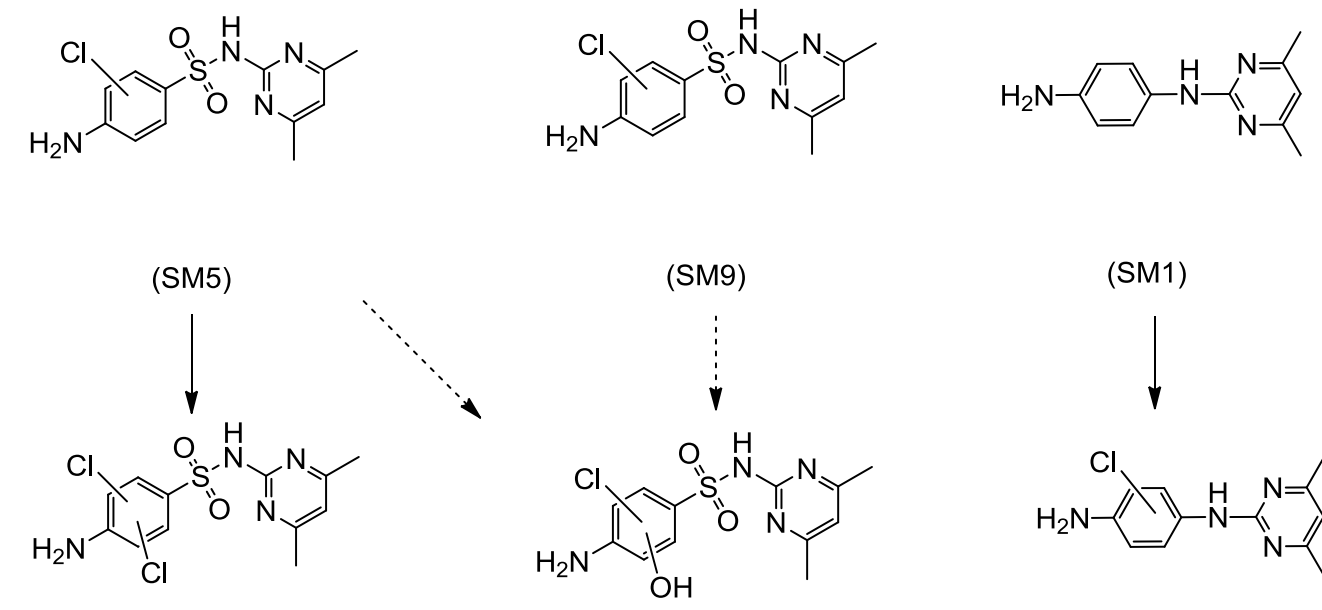

(SM1)

(SM6)

(SM7)
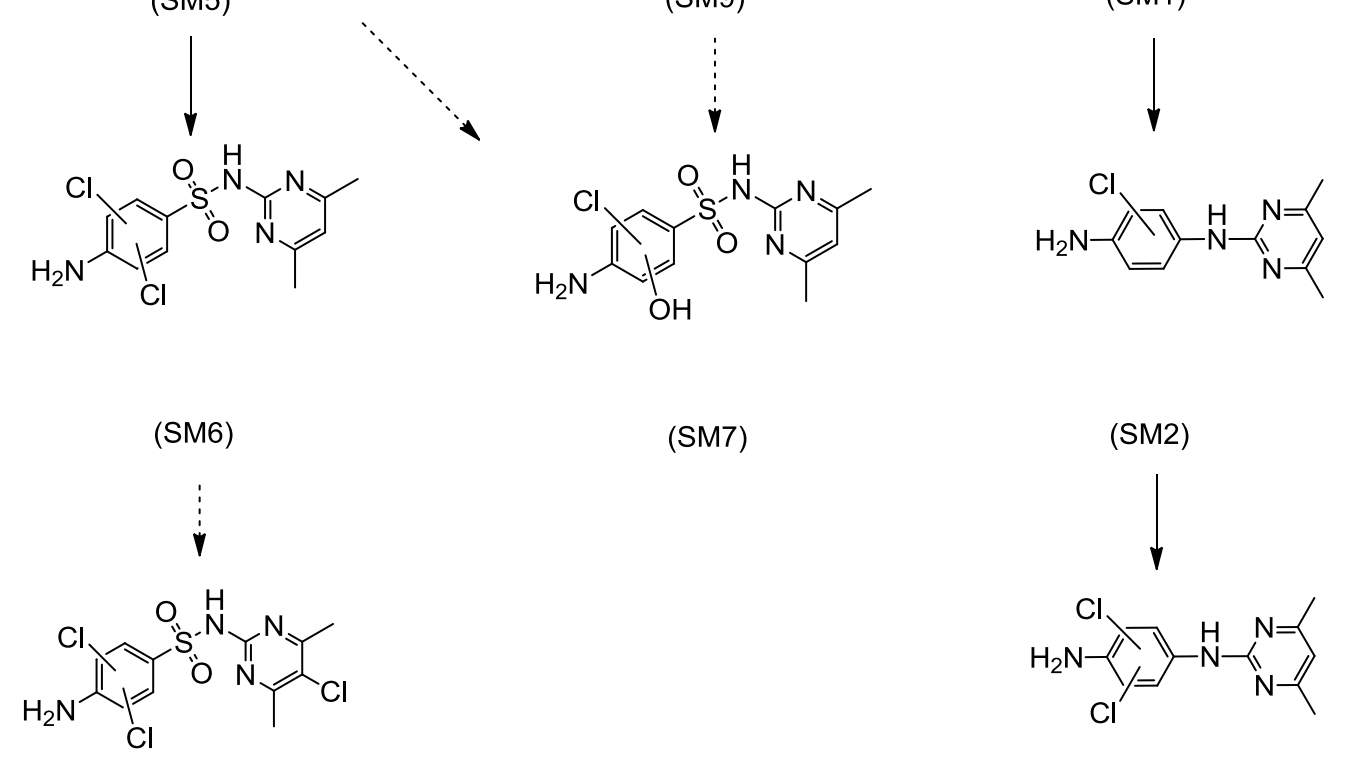

(SM8)

(SM3)

major pathway

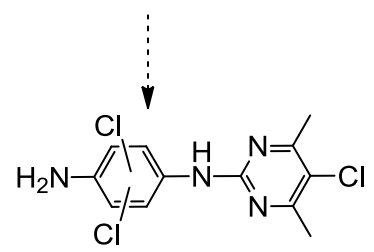

(............. minor pathway

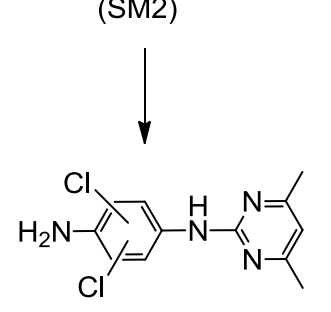

(SM4)

Figure 4.6. The proposed mechanism of the degradation of $\mathrm{SMZ}$ catalyzed by $\mathrm{CPO}-\mathrm{H}_{2} \mathrm{O}_{2}-\mathrm{Cl}-$ system presented by primary structure of each metabolite. 
Table 4.3 Accurate-Mass LC-Q-TOF-MS data for the identification of SMZ and its metabolites catalyzed in $\mathrm{CPO}-\mathrm{H}_{2} \mathrm{O}_{2}-\mathrm{Br}^{-}$system.

\begin{tabular}{|c|c|c|c|c|c|c|}
\hline Code & \multicolumn{1}{|c|}{ Formula } & $\begin{array}{c}\text { Retention time } \\
(\mathrm{min})\end{array}$ & $\begin{array}{c}\text { Experimental mass } \\
(\mathrm{m} / \mathrm{z})\end{array}$ & $\begin{array}{c}\text { Theoretical mass } \\
(\mathrm{m} / \mathrm{z})\end{array}$ & $\begin{array}{c}\text { Diff } \\
(\mathrm{ppm})\end{array}$ & $\begin{array}{c}\text { Diff } \\
(\mathrm{mDa})\end{array}$ \\
\hline $\mathrm{SM} 5-\mathrm{Br}$ & $\mathrm{C}_{12} \mathrm{H}_{13} \mathrm{BrN}_{4} \mathrm{O}_{2} \mathrm{~S}$ & 5.390 & 355.9948 & 355.9943 & 1.65 & 0.59 \\
\hline $\mathrm{SM6}-\mathrm{Br}$ & $\mathrm{C}_{12} \mathrm{H}_{12} \mathrm{Br}_{2} \mathrm{~N}_{4} \mathrm{O}_{2} \mathrm{~S}$ & 6.095 & 433.9042 & 433.9048 & -1.28 & -0.55 \\
\hline $\mathrm{SM} 8-\mathrm{Br}$ & $\mathrm{C}_{12} \mathrm{H}_{11} \mathrm{Br}_{3} \mathrm{~N}_{4} \mathrm{O}_{2} \mathrm{~S}$ & 8.258 & 511.8144 & 511.8153 & -1.66 & -0.85 \\
\hline
\end{tabular}

$368.9995 \mathrm{~m} / \mathrm{z}$ ) in approximately $1: 1$ ratio in the mass spectrum of $\mathrm{SM} 5-\mathrm{Br}$, confirming compound contained 1 bromine atom. For SM6-Br, there were three peaks $(434.9117 \mathrm{~m} / \mathrm{z}, 436.9090 \mathrm{~m} / \mathrm{z}$ and 438.9074$)$ in $1: 2: 1$ ratio, suggested 2 bromines addition to the parent compound. The ratios of 3 bromine atoms contained molecule are 1:3:3:1, which was observed in the mass spectrum of $\mathrm{SM} 8-\mathrm{Br}$, suggested the number of bromine in this metabolite.

In the $\mathrm{CPO}-\mathrm{H}_{2} \mathrm{O}_{2}-\mathrm{Br}^{-}$system, neither the loss of sulfonyl group, nor the

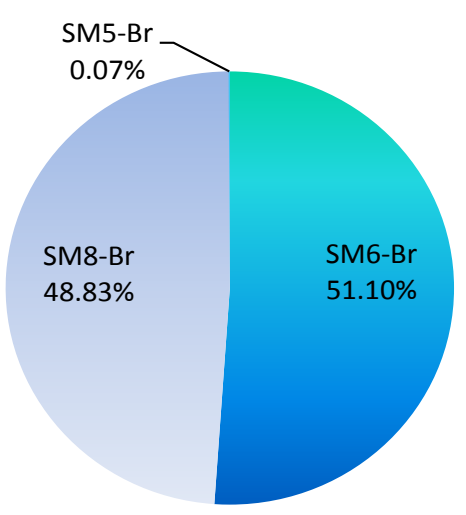

Figure 4.7 The percentage of the three metabolites measured by compound area (catalyzed by $\mathrm{CPO}-\mathrm{H}_{2} \mathrm{O}_{2}-\mathrm{Br}-$ system). hydroxylation was observed (Fig 4.7). Compared with the chlorination of SMZ, bromination was favorable to form the product with 3 halogen atoms addition (48.83\%).

Halogenation, hydroxylation and desulfonylation were suggested as competitive reactions in the SMZ degradation catalyzed by CPO. When buffer contained bromide, with competitive pathway was predominantly changed to halogenation. This

result was consistent with our previous result that the rate of halogenation in the presence of bromide was higher than chloride.[28] 
$\mathrm{C}_{12} \mathrm{H}_{13} \mathrm{BrN}_{4} \mathrm{O}_{2} \mathrm{~S}$ (SM5-Br) MSMS spectra

x10 2 +ESI Product lon (rt: 5.365 min) Frag=135.0V CID@20.8 (358.9994[z=1]...

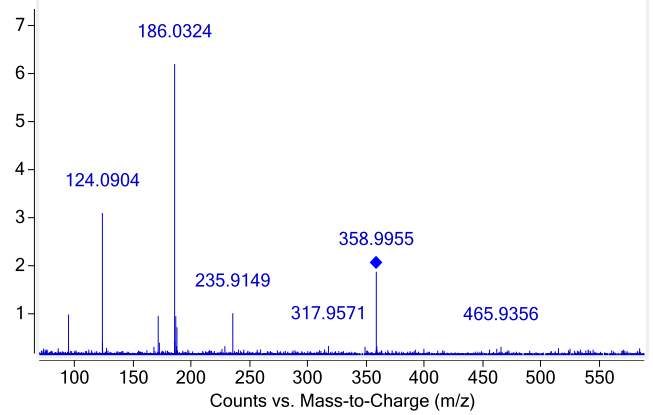

$\mathrm{C}_{12} \mathrm{H}_{12} \mathrm{Br}_{2} \mathrm{~N}_{4} \mathrm{O}_{2} \mathrm{~S}$ (SM6-Br) MSMS spectra
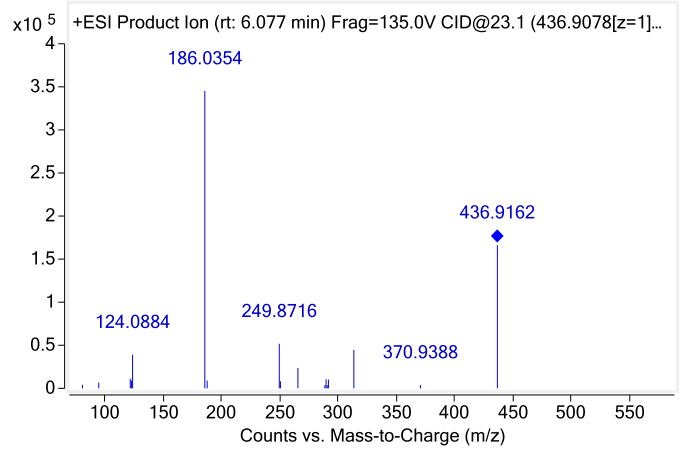

$\mathrm{C}_{12} \mathrm{H}_{11} \mathrm{Br}_{3} \mathrm{~N}_{4} \mathrm{O}_{2} \mathrm{~S}$ (SM8-Br) MSMS spectra x10 5 +ESI Product lon (rt: 8.249 min) Frag=135.0V CID@25.5 (516.8105[z=1]...

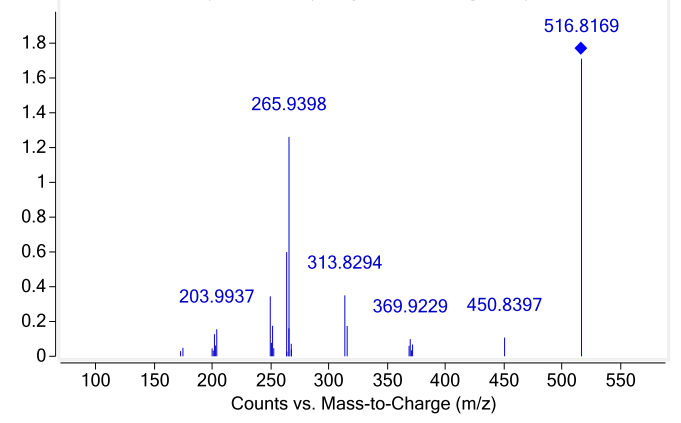

$\mathrm{C}_{12} \mathrm{H}_{13} \mathrm{BrN}_{4} \mathrm{O}_{2} \mathrm{~S}$ (SM5-Br) chromatogram x10 2 Cpd 3: C12 H13 Br N4 O2 S: + EIC(357.0015, 358.9995, 374.0281, 376.026...

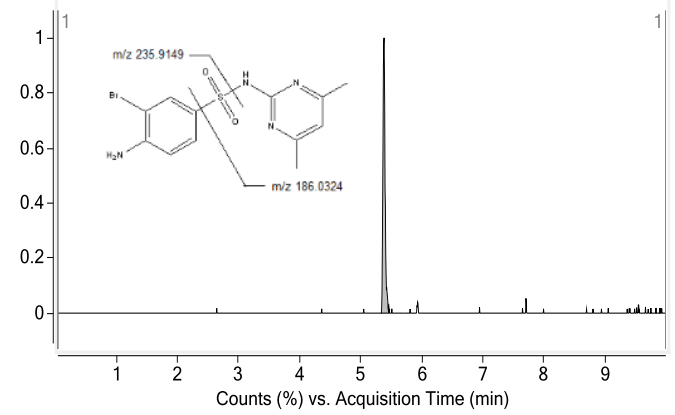

$\mathrm{C}_{12} \mathrm{H}_{12} \mathrm{Br}_{2} \mathrm{~N}_{4} \mathrm{O}_{2} \mathrm{~S}$ (SM6-Br) chromatogram x10 2 Cpd 1: C12 H12 Br2 N4 O2 S: + EIC(434.9120, 436.9100, 438.9080, 451.93...

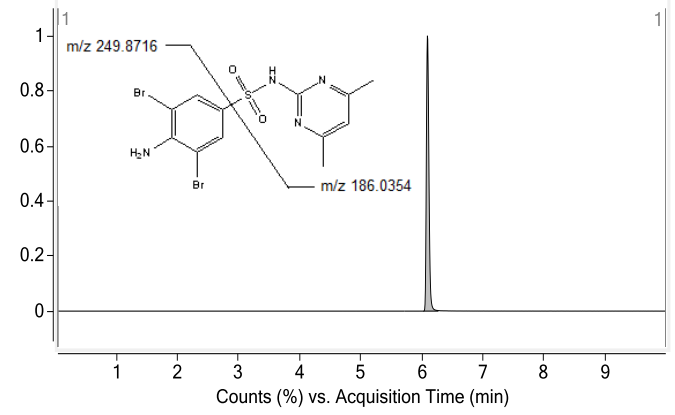

$\mathrm{C}_{12} \mathrm{H}_{11} \mathrm{Br}_{3} \mathrm{~N}_{4} \mathrm{O}_{2} \mathrm{~S}$ (SM8-Br) chromatogram x10 2 Cpd 2: C12 H11 Br3 N4 O2 S: + EIC(514.8205, 516.8185, 518.8165, 531.84...

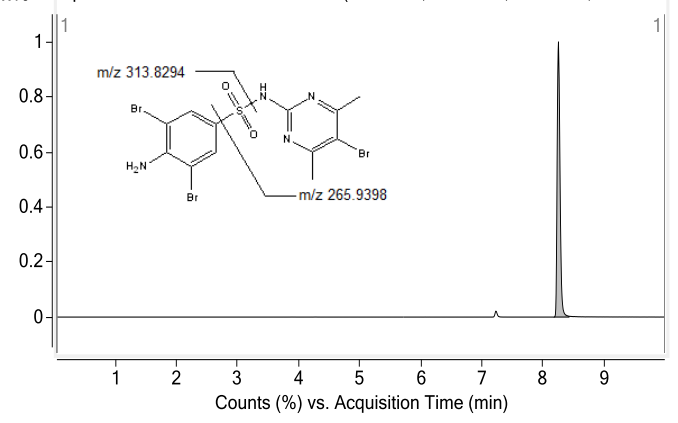

Figure 4.8 The mass spectra and chromatograms of SMZ brominated metabolites.

The structures were confirmed by targeted MSMS, and the chromatograms of each metabolite were collected. (Fig 4.8).

There was only one peak in each chromatogram, demonstrated that there was no isomer of brominated product. Bromination showed higher halogenated selectivity in the $S M Z$, it was presumably due to the formation of $\mathrm{Br}_{2}$ during the CPO catalyzation. The halogenation might occur in the solution or the wide 
channel of CPO, reacted with the free bromine. This assumption also consistent with the only one retention time of $\mathrm{SM} 6, \mathrm{Cl}_{2}$ might release and reacted with $S M Z$ directly by two chlorinated sites. It was suggested that $\mathrm{HClO}$ formed in the catalyzation to chlorinate substrate, however in chlorination of SMZ by hypochlorite, the product was only reported as $\mathrm{SM} 5, \mathrm{HClO}$ would not be the only crucial intermediate involved in the chlorination.[82]

For $\mathrm{CPO}-\mathrm{H}_{2} \mathrm{O}_{2}-\mathrm{Br}^{-}$system, there was only one pathway to elucidate the mechanism of SMZ halogenation. (Figure

\subsection{Discussion}

The process of SMZ degradation catalyzed by CPO was efficient, $100 \%$

SMZ was depleted at the concentration from $17.38 \mathrm{mg} / \mathrm{L}$ for minutes by the

Chemical Formula: $\mathrm{C}_{12} \mathrm{H}_{11} \mathrm{Br}_{3} \mathrm{~N}_{4} \mathrm{O}_{2} \mathrm{~S}$

(SM8-Br)<smiles>Cc1nc(NS(=O)(=O)c2cc(Br)c(N)c(Br)c2)nc(C)c1Br</smiles>

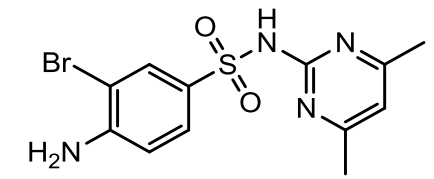

Chemical Formula: $\mathrm{C}_{12} \mathrm{H}_{13} \mathrm{BrN}_{4} \mathrm{O}_{2} \mathrm{~S}$

(SM5-Br)

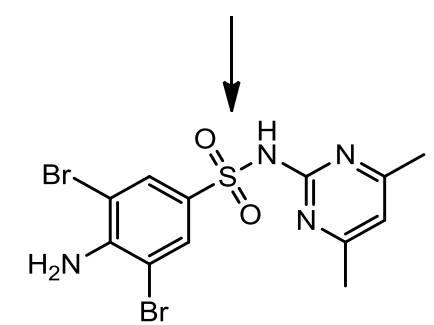

Chemical Formula: $\mathrm{C}_{12} \mathrm{H}_{12} \mathrm{Br}_{2} \mathrm{~N}_{4} \mathrm{O}_{2} \mathrm{~S}$

(SM6-Br)<smiles>[Te][Te]</smiles>

Figure 4.9. The mechanism of SMZ bromination catalyzed by $\mathrm{CPO}$

nanomolar level CPO. The degradation rate and substrate concentrations were conservative, removal ability are mostly likely more than parameters used in the experiment due to the LC samples were not monitored by shorter time period. 
The major metabolite in environment was $\mathrm{N}^{4}$-acetyl-sulfamethazine.The desulfonylated products generated by $\mathrm{CPO}-\mathrm{H}_{2} \mathrm{O}_{2}-\mathrm{Cl}^{-}$system are more susceptible to future biological degradation.[70]

Compared with some biodegradation treatment in water, such as white rot fungus, the efficiency of CPO-catalyzed reaction was dramatically improved. For example, it was reported $9 \mathrm{mg} / \mathrm{L} \mathrm{SMZ}$ was removed by Trametes versicolor for 20 hours.[72] The $62 \% \pm 4 \% \mathrm{SMZ}$ was removed within 8 minutes when $36 \mu \mathrm{M}$ $\mathrm{SMZ}$ reacted with $360 \mu \mathrm{M} \mathrm{MnO}$.[8]

It was reported that in different types of treatments (photolysis, $U V / \mathrm{H}_{2} \mathrm{O}_{2}$, UV/persulfate and persulfate oxidation) with $20 \mu \mathrm{M} \mathrm{SMZ}$ for 45 minutes, the removal rate of $\mathrm{SMZ}$ achieved $15.1 \%$ to $96.5 \%$. The $\mathrm{UV} / \mathrm{H}_{2} \mathrm{O}_{2}$ achieved $87.5 \%$, the most effective method was UV/persulfate, however this reaction required 200 $\mu \mathrm{M}$ sulfate to accomplish $96.5 \%$ degradation, $500 \mu \mathrm{M}$ sulfate to accomplish $100 \%$ degradation. As it stated by the author, the persulfate addition may cause environmental problem.[79]

The degradation of SMZ was not significantly observed after 8 hours when treated by sodium hypochlorite, and used more than one month to degrade substrate.[83]

CPO catalyzed degradation has the potential to apply in large scale wastewater treatment considering about the nanomolar level enzyme and the rapid sample preparation.

The oxidation and chlorination products of $\mathrm{SMZ}$ generated in $\mathrm{CPO}-\mathrm{H}_{2} \mathrm{O}_{2}-\mathrm{Cl}^{-}$ system could be found in most of the water chlorination treatment and 
biodegradation process.[72, 75,83$] \mathrm{CPO}-\mathrm{H}_{2} \mathrm{O}_{2}-\mathrm{Cl}^{-}$system might be used as the environmental model to learn the chlorinated and oxidized reaction of specific pollutants. 


\section{CHAPTER V.}

\section{ENGINEERING THE HYDROGEN BOND OF CPO BY MUTANT H105R}

\subsection{Introduction}

Glutamic acid 183 (Glu 183) of CPO located closely to the heme iron in the distal pocket, suggested its function to in the cleavage of the peroxide $\mathrm{O}-\mathrm{O}$ bond. [20] It is an important acid-base catalyst in the formation of compound I. In a mutagenensis study, Glu 183 was replaced by histidine residue, the mutant's chlorination and dismutation activity were decreased to $15 \%$ and $50 \%$, respectively.[23] The result implied that the Glu 183 affects predominately

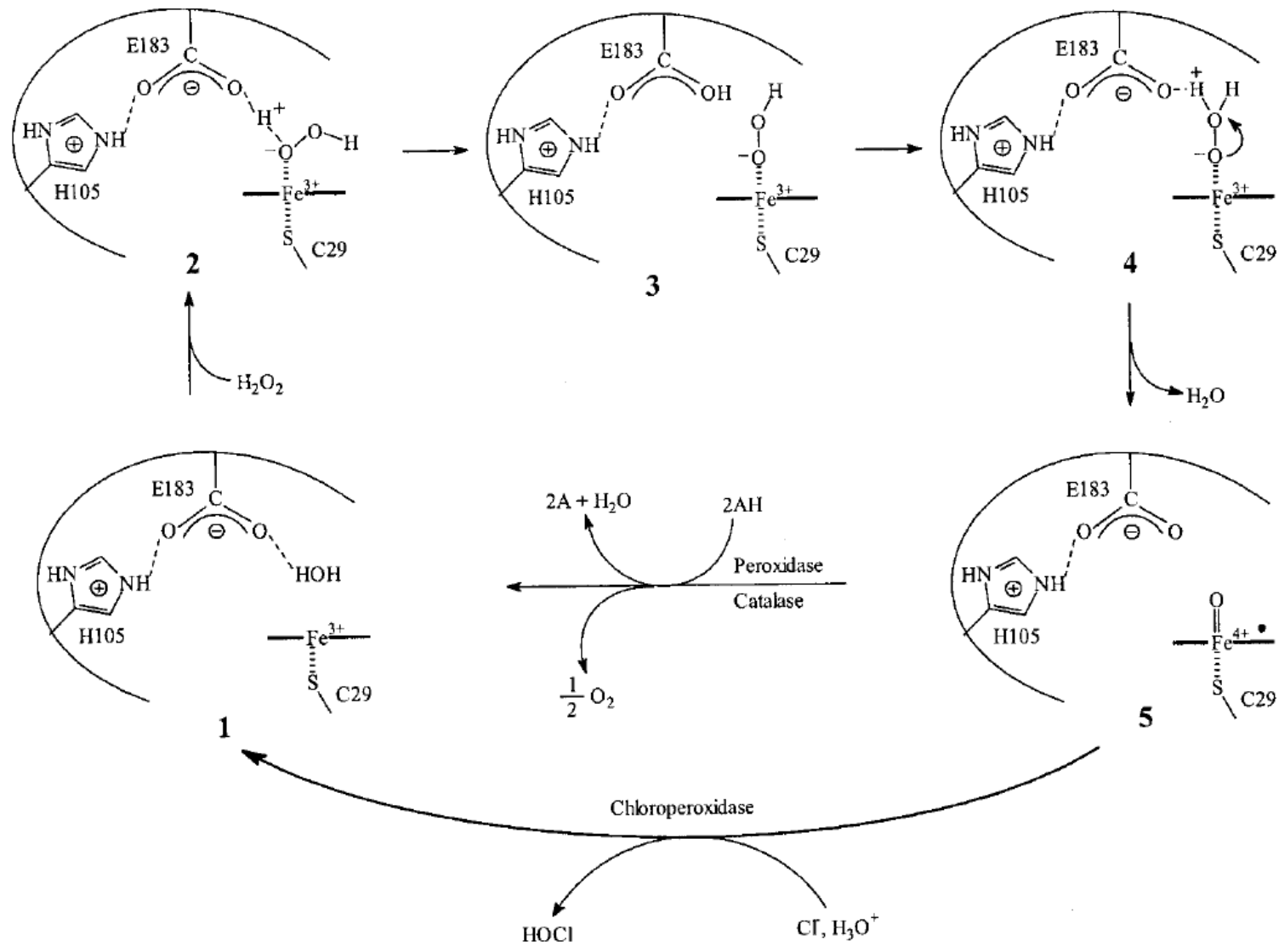

Figure 5.1 The Proposed mechanism of His 105 in the cleavage of the peroxide O-O bond. 
chlorination activity, but not essential for it. The hydrogen bond linked to 183 and the distal pocket structure might affect the enzyme activity, mutant $\mathrm{E} 183 \mathrm{H}$ could still form hydrogen bond with histidine 105 (His 105) to facilitate the cleavage of peroxide O-O bond.

His 105 was located in the heme distal pocket, formed hydrogen bond with glutamic acid 183. His 105 is $3.5 \AA$ form the propionate carboxyl group, it might be critical in peroxide O-O cleavage by forming a hydrogen bond with Glu183 which position the carboxyl group toward the heme iron. The hydrogen bond between $\mathrm{H} 105$ and E183 was suggested to play an essential role in modulating the chlorination activity. (Fig. 5.1) [1, 21] When H105 was replaced by a small and nonpolar amino acid alanine (H105A) to decrease the polarity and destroyed chlorination decreased. [85]

To investigate the function of the hydrogen bond between histidine and glutamic acid, mutant $\mathrm{H} 105 \mathrm{R}$ was created by changing histidine 105 to arginine to increase the hydrogen bonding strength.

\subsection{Experimental Procedure}

\subsubsection{Materials}

A filamentous fungus Aspergillus niger (A. niger, MGG029) were purchased from American Type Culture Collection (Manassas, VA). Gene expression vector pCPO3.I-Amds which is coding for WT CPO and co-transformation plasmid pAB4.1 with PyrG selection marker (GenBank accession no. AJ300448) were obtained TNO Microbiology and Systems Biology, Netherlands. Ultra-Pfu DNA 
polymerase and The QuikChange II XL sitedirected mutagenesis kit were purchased from Stratagene (La Jolla, CA). Lysing enzyme (L1412) was from Sigma- Aldrich (St. Louis, MO) Purified oligonucleotide primers were obtained from Eurofins MWG Operon (Huntsville, AL). All other chemicals were purchased from Thermo Fisher scientific (Waltham, MA). De-ionized water was produced by using a Milli-Q® Biocel $^{\mathrm{TM}}$ Ultra-Pure water purifier system equipped with 0.22 $\mu \mathrm{M}$ membrane filter cartridge (EMD Millipore, Billerica, MA, USA), purification cartridge and an organic removal cartridge (Evoqua Water Technologies, Lowell, MA, USA).

\subsubsection{Construction of H105R mutant and plasmid propagation}

To investigate the function of His 105 and the relation between His 105 and Glu183, the H105R mutation was created by site-directed mutagenesis. Vector pCPO3.I-Amds, a $14 \mathrm{~kb}$ plasmid was used as template. A.nidulans acetamidase gene (AmdS) was inserted into Notl restriction enzeme digestion site as a selection marker, to allow the mutant contains Amds to grow on acetamide plate, consuming acetamide as the sole source of nitrogen. The full encoded CPO gene, pCPO3.I is placed under control of the A. niger glucoamylase promoter 
(PglaA) and A. nidulans anthranilate synthetase terminator (TtrpC). (Fig. 5.2)

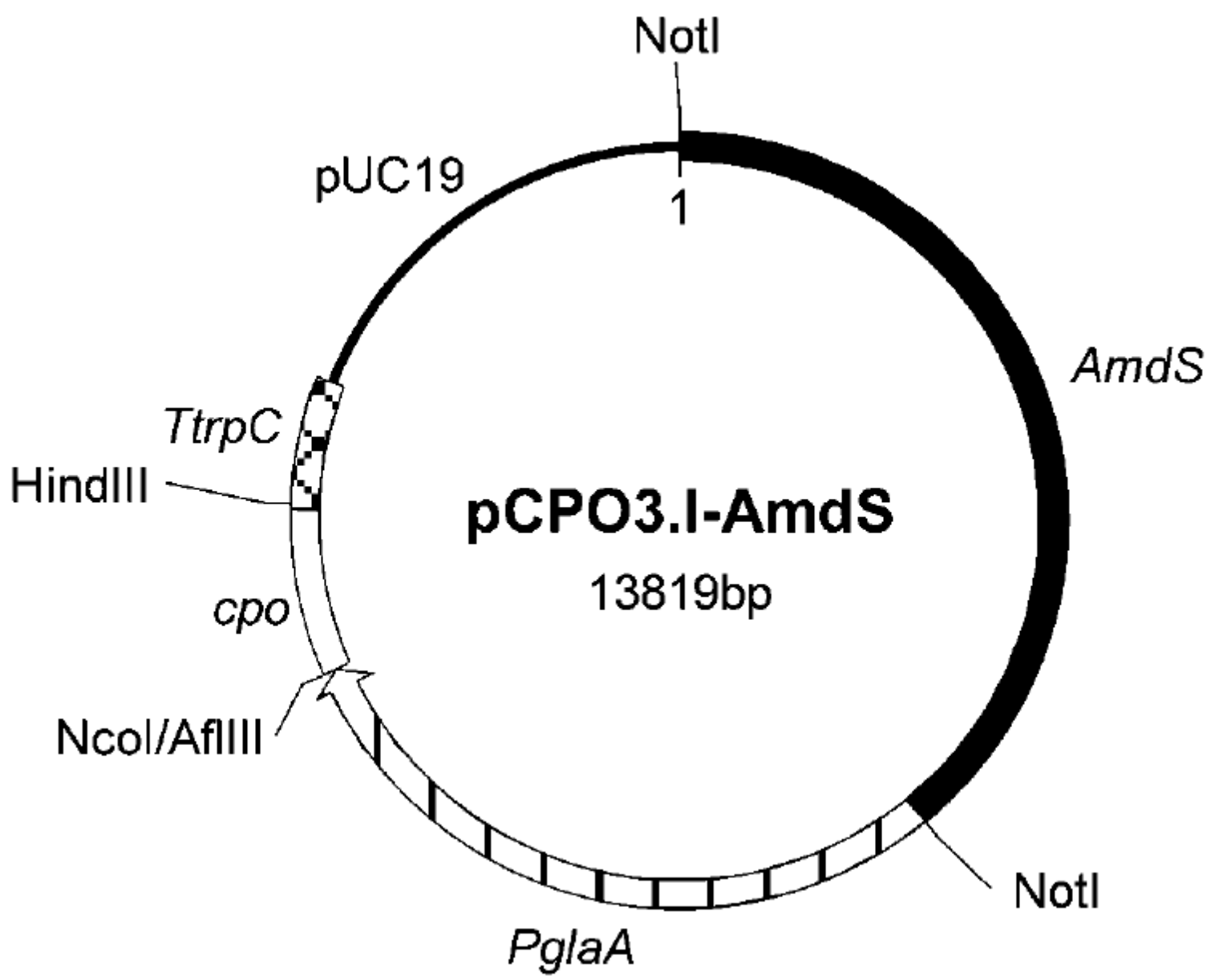

Figure 5.2 The CPO expression vector pCPO3.1-AmdS for transformation of A.niger strain.[2]

Encoded primers for H105R mutant was 5'-gag ccc cac get ttc gag cgc gac c-3'(primer 1) and 5'-gcg gga gaa gga gtg gtc gcg ctc g-3'(primer 2), both with the melting temperature of $74.42^{\circ} \mathrm{C}$. The PCR was carried out by QuikChange II XL sitedirected mutagenesis kit and Eppendorf thermal cycler (Mastercycler gradient) , PfuUltra HF DNA polymerase was added to reaction.The PCR reaction was set up at $98{ }^{\circ} \mathrm{C}$ for 50 seconds, followed by 18 cycles of $98^{\circ} \mathrm{C}$ for 30 
seconds for denaturation, $63{ }^{\circ} \mathrm{C}$ for 30 seconds for annealing, $72{ }^{\circ} \mathrm{C}$ for 14 minutes for extension, the last cycle was hold at $72{ }^{\circ} \mathrm{C}$ for 10 minutes.

DPN I restriction endonuclease was applied to digest the templates. PCR product was propagated in E. coli strain (H105R). Plasmids from E. coli was extracted by QIAGEN DNA extraction mini kit (QIAGEN, CA). The extracted DNA was examined by DNA electrophoresis and confirmed by DNA sequencing (Fig. 5.3)

5.2.3 Transformation into A. niger and selection for expression

The A. niger MGG029 strain was inoculated in $50 \mathrm{~mL}$ minimal medium (MM) containing maltose $(5 \%)$, glucose $(1 \%)$, casamino acids $(0.5 \%)$, yeast extract (0.5\%), $\mathrm{NaNO}_{3}(70 \mathrm{mM}), \mathrm{KCl}(7 \mathrm{mM}), \mathrm{K}_{2} \mathrm{HPO}_{4}(6 \mathrm{mM}), \mathrm{MgSO}_{4}(2 \mathrm{mM})$, uridine (10 $\mathrm{mM})$, carbenicillin $(50 \mathrm{mg} / \mathrm{L})$, the Hutner trace elements solution $(50 \mu \mathrm{L})$.[84] The culture was incubated for $37{ }^{\circ} \mathrm{C}$ at $250 \mathrm{rpm}$ for 1 day and change to $30{ }^{\circ} \mathrm{C}$ for $2-5$ days, homogenizer was used to disrupted mycelia for 20 seconds, repeated 3 times. Then the culture was transferred to $1 \mathrm{~L}$ media with the same compositions as in $50 \mathrm{~mL} \mathrm{MM}$, incubated at $30{ }^{\circ} \mathrm{C}$ for 20 hours at $250 \mathrm{rpm}$.

Mycelia was resuspended in 1.7 Osm solution $\left(0.27 \mathrm{M} \mathrm{CaCl}_{2}\right.$ and $\left.0.6 \mathrm{M} \mathrm{NaCl}\right)$ after filtered through sterile myracloth. Protoplasts were incubated with lysing enzyme $(\mathrm{L} 1412)$ at $37{ }^{\circ} \mathrm{C}$ for 4 hours at $150 \mathrm{rpm}$, resuspended protolasts and incubated on ice for 20 minutes, then centrifuged at $3500 \mathrm{rpm}$ for 15-30 minutes at $0{ }^{\circ} \mathrm{C}$ to get precipitate. The supernatant was decanted, precipitate was 
washed twice by STC 1700 buffer (1.2 M sorbitol, $10 \mathrm{mM}$ Tris- $\mathrm{HCl}, 50 \mathrm{mM} \mathrm{CaCl} 2$ and $35 \mathrm{mM} \mathrm{NaCl}$ at $\mathrm{pH}$ 7.5), resuspended by STC 1700 and incubated with10 $\mu \mathrm{g}$ mutant plasmid and $1 \mathrm{\mu g}$ pAB4.1 co-transformation plasmid at $25{ }^{\circ} \mathrm{C}$ for 25 minutes. The incubated protoplast was mixed with 60\% PEG 4000 in 10 mM Tris$\mathrm{HCl}$ buffer at $\mathrm{pH} 7.5$ and $50 \mathrm{mM} \mathrm{CaCl}_{2}$ carefully in three steps. The PEG-treated protoplast was diluted to $10 \mathrm{~mL}$ with STC 1700 and collected through centrifugation. The protoplast was resuspended in the leftover of STC1700 and spread onto 1.2 M sorbitol selective agar medium plate, incubate for 3-5 days at $22{ }^{\circ} \mathrm{C}$.

\subsubsection{Expression of the H105R mutant protein}

Mutant colonies on the selective plates were inoculated in MM (without uridine and yeast extract, addition of $0.1 \mathrm{mM} 5$-Aminolevulinic acid hydrochloride (heme precursor) for $22{ }^{\circ} \mathrm{C}$ at $250 \mathrm{rpm}$ for 7 days.

MCD assay and ABTS assay of the culturing medium were used to determine the protein yield by its chlorination and peroxidation activity, respectively.

MCD assay was measured at $278 \mathrm{~nm}$ by UV-Vis spectroscopy. $0.17 \mathrm{mM}$ monochlorodimedone (MCD) was mixed with 50-500 uL culture medium in 100 $\mathrm{mM} \mathrm{KH} \mathrm{PO}_{4}$ buffer with $20 \mathrm{mM} \mathrm{KCl}$ at $\mathrm{pH} 2.75$, after addition of $2 \mathrm{mM} \mathrm{H}_{2} \mathrm{O}_{2}$, absorbance at $278 \mathrm{~nm}$ was monitored for 1 minute.

$1.7 \mathrm{mM} \mathrm{2,} \mathrm{2'-azino-bis-3-ethy-benzthiazoline-6-sulfonic} \mathrm{acid} \mathrm{(ABTS)} \mathrm{was}$ mixed with $50 \mu \mathrm{L}$ clear culture medium in $100 \mathrm{mM} \mathrm{KH}_{2} \mathrm{PO}_{4}$ buffer with $25 \mathrm{mM}$ 
citric acid at $\mathrm{pH} 3.0$, after addition of $2 \mathrm{mM} \mathrm{H}_{2} \mathrm{O}_{2}$, the UV started to collect the absorbance at $405 \mathrm{~nm}$ for 1 minutes.

Due to decreased tendency of ABTS activity after 2-3 days since inoculation, and totally destroyed activity after Amicon stirring pressure cell, $0.05 \mathrm{mM}$ ferriprotoporphyrin IX chloride (hemin) was added to culture to stabilized the mutant.

\subsubsection{Purification of the mutant protein}

After 7 days, the 12 Liter medium was filtered through myracloth and glass fiber filter circles $\mathrm{G} 6$ to remove fungus, concentrated to $50 \mathrm{~mL}$ in the Amicon ultrafiltration cell. $50 \mathrm{~mL}$ crude sample was dialyzed in 4 liters $25 \mathrm{mM}$ phosphate buffer at $\mathrm{pH} 5.9$ for 12 hours, and repeat dialysis again with fresh buffer. The sample was filtered by $0.45 \mu \mathrm{M}$ membrane.

lon exchange chromatography was applied by diethylaminoethyl (DEAE) sepharose fast flow column with $50 \mathrm{~mL}$ DEAE resin. $25 \mathrm{mM}$ phosphate buffer at $\mathrm{pH} 5.9$ with ionic strength gradient was used to wash the colunm, gradually increase the concentration of $\mathrm{NaCl}$ from 0.0 to $0.5 \mathrm{M}$. Different eluted portions were collected and concentrated by Centriprep ${ }^{\circledR}$ centrifugal filter unit $(30,000$ Dalton). Absorption spectrum was scanned and SDS-PAGE was used to check the existence of mutant.

All buffers used in column were filtered through $0.45 \mu \mathrm{M}$ membrane and degassed for 15 minutes to remove solid and gas particles. Purification by columns was carried out in $4{ }^{\circ} \mathrm{C}$ to keep protein stable. 
Sodium dodecyl sulfate polyacrylamide gel electrophoresis (SDS-PAGE) was used to check the molecular size of eluted products.

5.3 Result and discussion

5.3.1 Mutant DNA sequencing

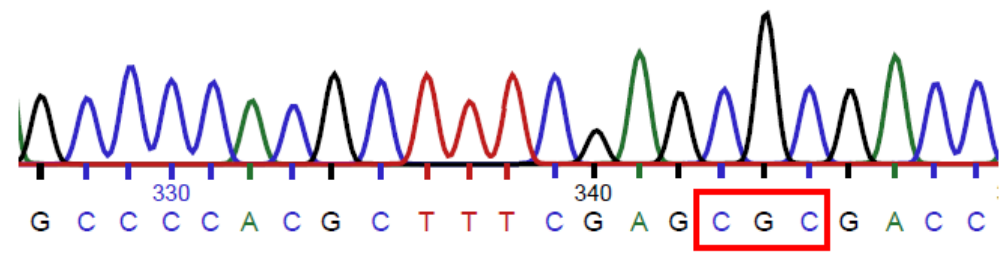

Figure 5.3 DNA sequence of H105R mutant.

In the sequencing result, the Histidine codon CAC was replaced by Arginine codon CGC successfully. The GC content was as high as $72 \%$, but PCR protocol still work effectively.

5.3.2 Transformaiton and expression result

H105R mutant grown on $1.2 \mathrm{M}$ sorbitol selective agar plate after transformation suggested the transformation was successful. The colonies were inoculated to $12 \mathrm{~L}$ medium and monitored the expression of protein by MCD and ABTS assays. There was no MCD activity showed in mutant medium, only ABTS assay could be used to evaluate the expression. The ABTS activity was high at the second day of inoculation, and

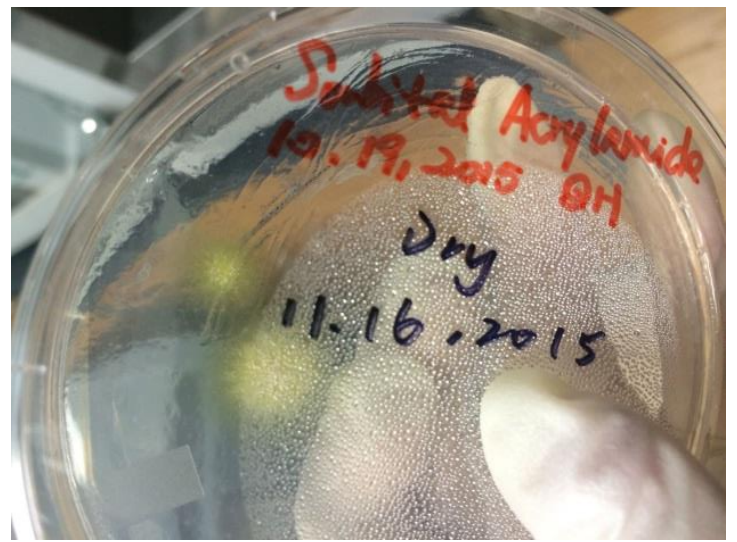

Figure 5.4 H105R mutant grown on 1.2 sorbitol selective agar plate after 24 hours. 
quickly decreased. (Fig. 5.5).

$50 \mu \mathrm{M}$ hemin was added to culture to stabilized the protein, repeated the same protocol to 12 liters culture.

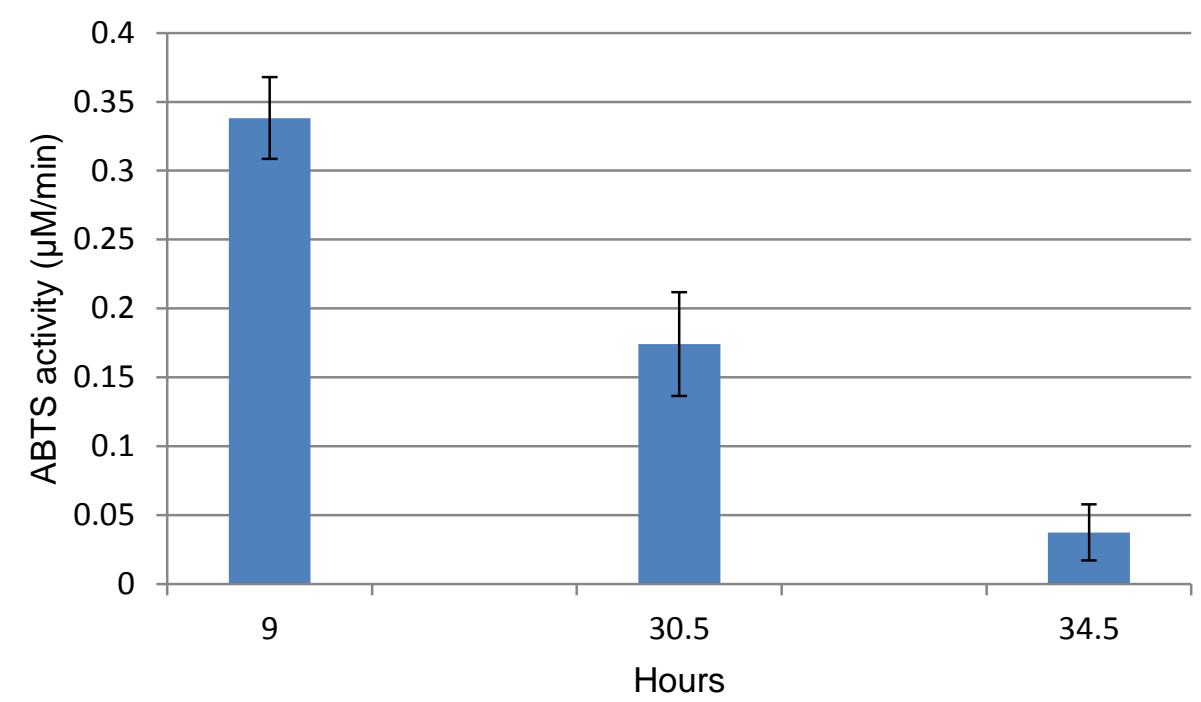

Figure 5.5 The ABTS activity of $\mathrm{H} 105 \mathrm{R}$ cultures since the second day of inoculation. Samples were run in triplicate.

\subsubsection{Purification}

The purification of concentrated sample was collected to run SDS-PAGE with samples from the crude medium and other portion of elution product. (Fig. 5.6) The band of mutant was presented in SDS-PAGE, the concentrated sample (lane2) was of transparent color, implying the heme was not incorporated into protein.

In UV-Vis spectrum of concentrated sample (lane 2), the low-spin ferric heme protein typically with a Soret band around $420 \mathrm{~nm}$ was not observed (Fig. 5.7), indicating the heme incorporation was not efficient in $\mathrm{H} 105 \mathrm{R}$ mutant, the recombinant H105R mutant was apoprotein. 


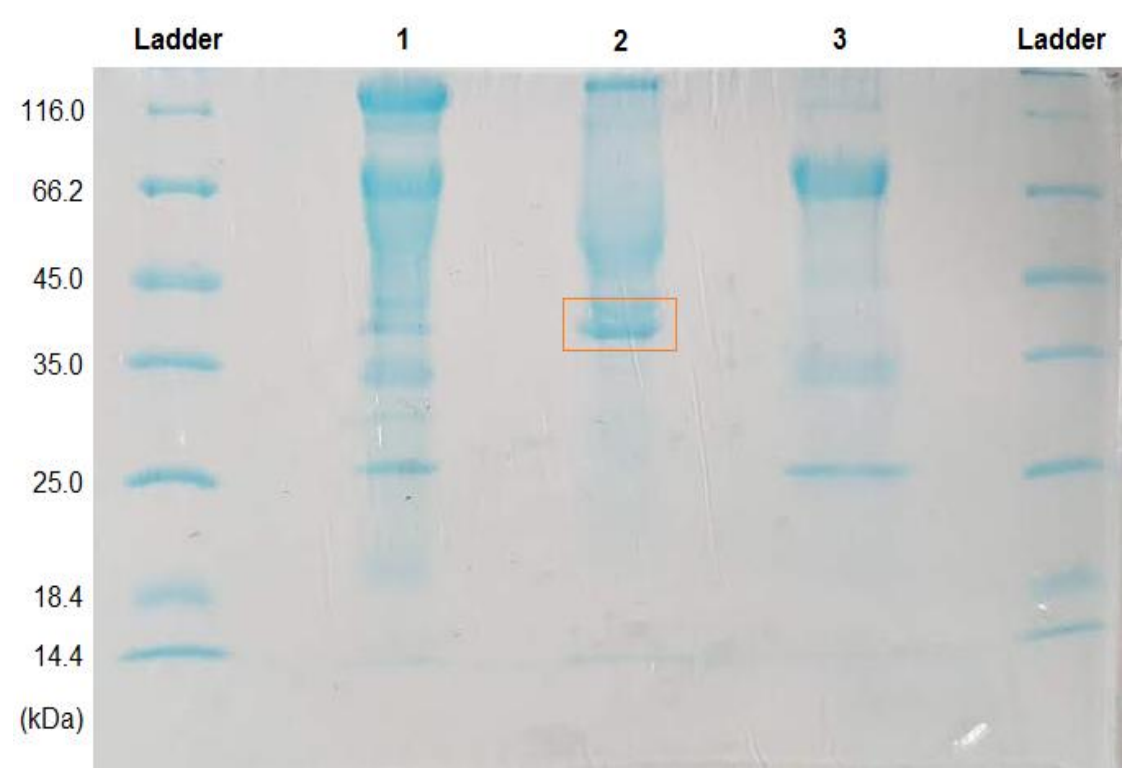

Figure 5.6 SDS-PAGE of mutated protein. Lane 1-the crude sample before ion exchange; lane 2-ion exchange eluted products (band of $\mathrm{H} 105 \mathrm{R}$ in red rectangle); lane 3-products eluted by buffer with $1 \mathrm{M} \mathrm{NaCl}$.

\subsection{Discussion}

The apoprotein H105R was suggested that arginine might change the distal pocket due to its charge or structure, and even result in the instability of heme

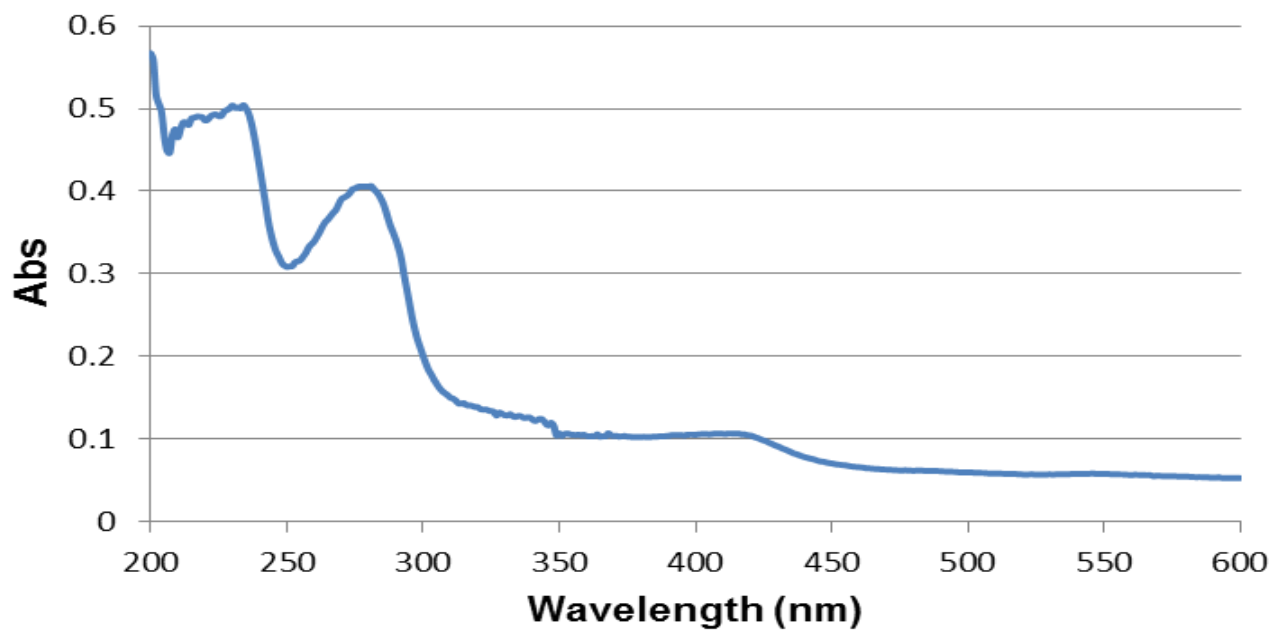

Figure 5.7 UV-Vis spectra of H105R mutant. 
porphyrin. Although $\mathrm{H} 105$ could be changed to alanine $(A)$, the structure of CPO would not change much due to the smaller size of alanine.

The chlorination activity was not found during all the process, suggested that the chlorination active site in CPO was not formed. The change of distal pocket affected the chlorination dramatically and the role of $\mathrm{H} 105$ site was crucial in supporting the CPO construction near the heme center.

The peroxidation decreased during culturing and amicon concentration, implied that mutated protein was easy to be denatured. The H105 has the ability to stabilize E183 by hydrogen bond, changing it to a larger and more polar amino acid might destroy the structure and function of CPO by affected E183.

There is also possibility that the change from histidine to arginine might directly change the tertiary structure of mutant protein. In conclusion, the amino acid at 105 site could be changed to arginine but could not express active protein due to heme incorporation failure. 


\section{CHAPTER VI}

\section{DEGRADATION OF NON-STEROIDAL ANTI-INFLAMMATORY DRUGS DiClOFENAC AND NAPROXEN BY CHLOROPEROXIDASE}

THIS PAPER IS SUBMITTED AND ITS FORMAT IS KEPT 


\title{
Degradation of Non-steroidal Anti-inflammatory Drugs Diclofenac and Naproxen by Chloroperoxidase
}

\author{
Xiaohong $\mathrm{Li}^{\mathrm{a}, \dagger}$, Qinghao $\mathrm{He}^{\mathrm{b}, \dagger}$, Haiyun $\mathrm{Li}^{\mathrm{a}}$, Mancheng $\mathrm{Hu}^{\mathrm{a}, \mathrm{c}}$, Shuni $\mathrm{Li}^{\mathrm{a}, \mathrm{c}}$, Quanguo \\ Zhai $^{\text {a,c }}$, Yucheng Jiang ${ }^{\text {a.c*}}$, Xiaotang Wang ${ }^{\text {b* }}$ \\ a School of Chemistry \& Chemical Engineering, Shaanxi Nomal University, Xi'an, \\ 710062, P.R. China \\ b Department of Chemistry and Biochemistry, Florida International University, \\ Miami, Florida 33199,USA \\ c Key Laboratory of Macromolecular Science of Shaanxi Province, Shaanxi \\ Normal University, Xi'an, 710062, \\ P.R. China
}

†These authors contributed equally to this work ${ }^{*}$ Corresponding authors

Dr. Yucheng Jiang

Mailing Address: School of Chemistry\& Chemical Engineering

Xi'an, No. 620 West Chang'an Road, Chang'an District 710119, P.R. China

E-mail: jyc@snnu.edu.cn

Phone: +86 2981530763

Dr. Xiaotang Wang

Mailing Address: Department of Chemistry and Biochemistry

Florida International University

11200 S.W. 8th Street, Miami, Florida 33199. USA

E-mail:wangx@fiu.edu

Phone: (305) 348-7544 


\section{Abstract}

Non-steroidal anti-inflammatory drugs (NSAIDs), such as diclofenac and naproxen, are widely used for the treatment of arthritis, ankylosing spondylitis, and acute muscle pain. However, most NSAIDs are usually not metabolized and simply pass through human body. These drugs are difficult to be decomposed by general waste treatment strategies and have caused serious environmental concerns. Here we report a rapid and efficient enzymatic degradation of diclofenac and naproxen by chloroperoxidase (CPO), a heme protein isolated from Caldarimyces fumago (C. fumago). Complete dagradation of diclofenac and naproxen was achieved in only 9 and 7 min for diclofenac and naproxen, respectively, under mild conditions with nanomolar enzyme concentration. The degraded products were identified by both HPLC-MS and NMR, suggesting the involvement of multiple steps in CPO catalyzed degradation of the two drug molecules. Moreover, our work demonstrated that CPO treatment followed by existing bioremediation technologies (activated sludge) greatly improved the efficiency and completeness of decontaminating these two drugs from waste water. Most significantly, our eco-toxicity test using green algae, Chlorella Pyrenoidos, showed that the products had noticeably lower toxicity than the parent drugs, demonstrating the potential of CPO in large-scale treatment of sewage contaminated with diclofenac and naproxen.

Keywords: enzymatic degradation; diclofenac; naproxen; chloroperoxidase; eco-toxicity

\section{Introduction}

Both diclofenac (2-[(2,6-dichlorophenyl)amino]benzeneacetic acid; sodium salt) and naproxen (2-(6-methoxynaphthalen-2-yl)propionic acid) (Fig. 1) are non-steroidal antiinflammatory drugs (NSAIDs). They are widely used in the treatment of arthritis, ankylosing spondylitis, acute muscle pain, and other symptoms associated with inflammation (Grenni et al., 2013; Sathishkumar et al., 2012). The widespread 
application of these drugs coupled with their resistance toward metabolic breakdown in human body inevitably resulted in the release of large amount of these drugs into the aquatic environment. In recent years, diclofenac and naproxen has been detected in surface water, groundwater, wastewater, and even in drinking water at concentrations ranging from $\mathrm{ng} \cdot \mathrm{L}^{-1}$ to $\mu \mathrm{g} \cdot \mathrm{L}^{-1}$ (Zhang et al., 2008; Zhao et al., 2009). It has been reported that naproxen has adverse effects on biota, such as impairing the lipid peroxidation system of bivalves and altering microbial community structure to yield antibiotic resistance in environmental microbial communities (Gagné et al., 2006). Diclofenac was recently designated as a devastating environmental pollutant because of its bioaccumulation in the food chain (llic et al., 2011). Therefore, effective degradation of these drugs is of paramount significance for reducing their accumulation in the environment.

Unfortunately, conventional sewage treatment is inefficient in removing or degrading diclofenac and naproxen (Hartmann et al., 2008; Nakada et al., 2006). For example, no noticeable breakdown of diclofenac was observed over a period of 28 days either when it was the sole source of carbon or when an external carbon source was added for cometabolic degradation (Quintana et al., 2005). Batch tests using an activated sludge system and membrane bioreactors also revealed very poor degradability of diclofenac in comparison with other pharmaceuticals (Samaras et al., 2013). Other conventional water treatment processes such as coagulation, sedimentation and filtration have all been proven to be ineffective to remove these two drugs (Brillas et al., 2010; Westerhoff et al., 2005). Consequently, physicochemical approaches including ultrasonic (Naddeo et al., 2010), electrochemical oxidation (Faber et al., 2012), photocatalytic (Arriaga et al., 2008), potassium permanganate oxidation (Álvarez et al., 2013) and ozone oxidation (Naddeo et al., 2009) have been adopted to improve the removal of these drugs from 
drinking water or wastewater. However, limitations of these methods, such as cost, efficiency, and secondary pollution from use of chemicals, warrant further investigations on the removal/breakdown of these widely used drugs from environment.

Little evidence of diclofenac transformation by microbial communities is documented in the literature. White-rot fungi (WRF) were found to be efficient in degrading both diclofenac (Urrea et al., 2010) and naproxen (Urrea et al., 2010), but long treatment time ( $1 \mathrm{~h}$ and $5 \mathrm{~h}$, respectively) was needed. Enzymatic degradation is an ideal approach because of the mild and environmentally friendly conditions employed. Thus, crude lignin peroxidase (LiP, a heme-imidazole peroxidase) from Phanerochaete chrysosporium ( $P$. chrysosporium) has been used to convert diclofenac in various conditions and was found to be highly effective (Zhang et al., 2010). In addition, fungal unspecific peroxygenases (UPOs) have been shown to be able to hydroxylate/O-demethylate a diverse array of pharmaceuticals (including diclofenac and naproxen)(Hofrichter et al., 2014; Kinne et al., 2009; Piontek et al., 2013; Poraj-Kobielska et al., 2011; Wang et al., 2013). Inspired by the results of LiP and UPOs, we studied the degradation of diclofenac and naproxen by chloroperoxidase (CPO), a heme containing glycoprotein that is phylogenetically (hemethiolate proteins) and functionally (haloperoxidases) related to UPOs with higher oxidation potential and thermal/chemical stability than LiP (Makino et al., 1976; Millis et al., 1989). High performance liquid chromatography-mass spectrometry (HPLC-MS) and nuclear magnetic resonance (NMR) spectroscopy were employed to identify the major degradation products. Based on the products identified, reaction pathways are postulated. Our results demonstrated that CPO can effectively convert both diclofenac and naproxen into compounds that are significantly less toxic based on their inhibitory effects and $E C_{50}$ value on the growth of a freshwater green alga, Chlorella pyrenoidos. 


\section{Experimental}

\subsection{Enzyme preparation}

Chloroperoxidase was isolated from the growth medium of $C$. fumago according to the method of Morris and Hager (Morris et al., 1966) with minor modifications, using acetone rather than ethanol in the solvent fractionation step. CPO with $R z=1.03\left(A_{398} / A_{280}, 1.44\right.$ for pure enzyme) was prepared and stored in $100 \mathrm{mM}$ phosphate buffer $(\mathrm{pH} 5.0)$ at $4{ }^{\circ} \mathrm{C}$. The halogenation activity of CPO used in this study was $4232 \mathrm{U} \cdot \mathrm{mL}^{-1}$ based on the standard monochlorodimedon (MCD) assay (Hager et al., 1966). The aromatic hydroxylation activity $\left(3563 \mathrm{U} \cdot \mathrm{mL}^{-1}\right)$ of the enzyme was determined by monitoring the hydroxylation of naphthalene into 1-naphthol (Kluge et al., 2007). The classic peroxidase activity of the enzyme determined using ABTS (2,2'-azino-bis(3-ethylbenzothiazoline-6sulphonic acid)) as substrate was $3071 \mathrm{U} \cdot \mathrm{mL}^{-1}$ (Manoj et al., 2008).

\subsection{Reagents and buffers}

All reagents used in this study, including diclofenac, naproxen, dipotassium hydrogen phosphate, potassium dihydrogen phosphate, hydrogen peroxide $(30 \%$ in aqueous solution), ethyl acetate, and inorganic reagents for cultivating the green alga were obtained from Xi'an Chemical Co. Ltd (Xi'an, China) with highest purity ( $\geq 98 \%)$. Other chemicals such as methanol and acetonitrile (chromatography grade) as well as standard degradation product of the two drugs, o-desmethylnaproxen and 4'hydroxydiclofenac (chromatography grade) were purchased from Sigma Aldrich (St. Louis, MO USA).

Phosphate buffer $\left(0.1 \mathrm{~mol} \cdot \mathrm{L}^{-1}\right)$ was prepared by mixing appropriate volumes of 1 $\mathrm{mol} \cdot \mathrm{L}^{-1} \mathrm{KH}_{2} \mathrm{PO}_{4}$ and $\mathrm{K}_{2} \mathrm{HPO}_{4}$ stock solutions and diluting the combined solutions to $1 \mathrm{~L}$. Then the solution was adjusted to various $\mathrm{pH}$ with $1 \mathrm{~mol} \cdot \mathrm{L}^{-1} \mathrm{H}_{3} \mathrm{PO}_{4}$. All solutions were prepared using deionized water with a conductivity of $5.6 \times 10^{-8} \mathrm{~s} \cdot \mathrm{cm}^{-1}$. 


\subsection{Degradation of diclofenac and naproxen}

Enzymatic degradation of both drugs was carried out in $0.1 \mathrm{~mol} \cdot \mathrm{L}^{-1}$ phosphate buffer in a centrifugal tube with a total volume of $3.0 \mathrm{~mL}$ containing $\mathrm{CPO}\left(0.25-23 \mathrm{nmol} \cdot \mathrm{L}^{-1}\right), 20$ $\mathrm{mmol} \cdot \mathrm{L}^{-1} \mathrm{KCl}$, and drugs $\left(15 \mu \mathrm{mol} \cdot \mathrm{L}^{-1}\right)$ at $\mathrm{pH} 2 \sim 6$ at $298 \mathrm{~K}$. The reaction was started by adding $\mathrm{H}_{2} \mathrm{O}_{2}\left(0.015-0.3 \mathrm{mmol} \cdot \mathrm{L}^{-1}\right)$ in the absence of light under magnetic stirring and was continued for $20 \mathrm{~min}$. The supernatant of the reaction mixture was extracted 3 times using ethyl acetate. The combined organic extract was concentrated by rotary evaporation $(0.09 \mathrm{MPa}, 308 \mathrm{~K})$ to remove the solvent. The extracts were then dissolved in acetonitrile and methanol, respectively, for HPLC (LC-20AT, Shimadzu) analysis. The mobile phase consisted of 80:20 (v/v) acetonitrile and water for diclofenac and 90:10 $(\mathrm{v} / \mathrm{v})$ methanol and water for naproxen, and the flow rate was $0.5 \mathrm{ml} \cdot \mathrm{min}^{-1}$. The detector was set at $274 \mathrm{~nm}$ and $235 \mathrm{~nm}$ for diclofenac and naproxen, respectively. The quantitative analysis of the target compounds was based on the standard curve (correlation coefficients were $>0.999$ ).

$$
\text { Degradation efficiency } \eta=\left(\left(C_{0}-C_{t}\right) / C_{0}\right) \times 100 \%
$$

The effect of reaction parameters $\left(\mathrm{pH}\right.$, concentration of enzyme $/ \mathrm{H}_{2} \mathrm{O}_{2}$, and reaction time) on degradation efficiency was investigated and optimized.

All experiments were triplicated and data reported were mean values of three independent measurements.

\subsection{Determination of products}

Samples were treated as above for HPLC-MS analysis. An Esquire LC-ion trap mass spectrometer (Bruker Daltonics, Germany) equipped with an orthogonal geometry Electrospray lonization (ESI) source was employed to determine the formulae of the products. Nitrogen was used as the drying $\left(8 \mathrm{~L} \cdot \mathrm{min}^{-1}\right)$ and nebulizing $(0.8 \mathrm{bar})$ gas at $180^{\circ} \mathrm{C}$. Scanning was performed from $\mathrm{m} / \mathrm{z} 100$ to 1000 in the standard resolution mode. 
To establish the structure of the degradation products, the reaction was carried out using the same condition as stated above except a larger volume $(300 \mathrm{~mL})$ was used. Upon completion of the reaction, the reaction mixture was extracted with either ethyl acetate or chloroform. After removal of the solvent by rotary evaporation $(0.09 \mathrm{MPa}$, $308 \mathrm{~K}$ ) the extracts were dissolved in either deuterated chloroform or methanol and transferred to $5 \mathrm{~mm}$ NMR tubes. NMR experiments were carried out on a Bruker 600 $\mathrm{MHz}$ NMR spectrometer operating at a proton frequency of $599.73 \mathrm{MHz}$. All spectra were recorded at $298 \mathrm{~K}$ using standard pulse programs from the manufacturer.

\subsection{Elimination of COD and TOC}

Total organic carbon (TOC) measurement was conducted on a TOC-VCPA analyzer (Shimadzu Corp.). The feed speed was $150 \mathrm{ml} \cdot \mathrm{min}^{-1}$. Chemical oxygen demand (COD) was measured by a quick method on a Rapid Autoanalyzer (5B-1(F), Lian-hua Tech.Co., Ltd). A solution containing $2.5 \mathrm{ml}$ sample, $0.7 \mathrm{ml}$ reagent $\mathrm{D}$ (potassium dichromate) and $4.8 \mathrm{ml}$ reagent $\mathrm{E}$ (catalysts) in a $20.0 \mathrm{ml}$ glass tube was heated to $438 \mathrm{~K}$ and kept for 10 min together with a blank sample and a standard sample. After 2 min of air cooling, the heated solution was cooled by water for another $2 \mathrm{~min}$. Then the absorbency of the samples was measured at $610 \mathrm{~nm}$.

\subsection{Treatment of drug effluent by activated sludge}

A mixed population of activated sludge microorganisms was collected from Xi'an second sewage treatment plant (X'an, China). The sample of activated sludge was filtered on a

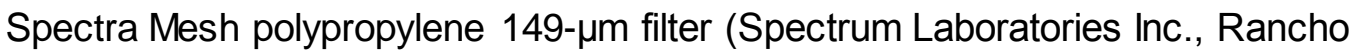
Dominguez, CA, USA) to remove aggregates. The sample was then washed three times by centrifugation and suspended in the same volume of culture medium. To remove any excessive amounts of dissolved organic carbon, the suspension was stirred and maintained under oxygen at $298 \mathrm{~K}$ for at least $24 \mathrm{~h}$ without exposure to the test materials. 
The volatile ratio $f$ of activated sludge was 0.74 .

$90 \mathrm{~mL}$ of $15 \mu \mathrm{mol} \cdot \mathrm{L}^{-1}$ drug effluent was put into the activated sludge suspension before /after enzymatic treatment (to ensure a final drug concentration of $7.5 \mu \mathrm{mol} \cdot \mathrm{L}^{-1}$ ). The samples were stirred for the duration of the study with a magnetically coupled stirrer when air was used as the aerated gas. The sample was then left to stand for $1-2 \mathrm{~h}$. The supernatant was taken for determination of COD.

\subsection{Toxicity Tests}

Freshwater unicellular green alga, $C$. pyrenoidosa (provided by the Institute of Wuhan Hydrobiology, Chinese Academic of Science), was cultivated in nutrient media of blue green medium (BG11) at $298 \mathrm{~K}$ and illuminated with cool-white fluorescent lights at a continuous light intensity of 2000 Lx. For cell experiments, C. Pyrenoidosa was exposed, during its log growth phase, to the toxicant at five different concentrations (maintain final concentration ranging from 0.01 to $0.36 \mathrm{mg} / \mathrm{L}$ ) for $3-4$ days at $298 \mathrm{~K}$. The concentration of the alga was determined by monitoring the change of absorption at $680 \mathrm{~nm}$ ( $\mathrm{Ma}$ et al., 2006). The toxicity tests for each drug concentration were conducted in triplicate.

The growth inhibition rate $i$ for each sample was calculated from Equation (2) and (3) (Lange et al., 2006),

$$
\begin{aligned}
\mu & =\left(\ln O D_{t}-\ln O D_{t 0}\right) /\left(t-t_{0}\right) \\
i & =\left(\mu_{\mathrm{c}}-\mu_{t}\right) / \mu_{c} \times 100 \%
\end{aligned}
$$

where $t-t_{0}$ is incubation time $(\min ) ; O D_{t 0}$ is absorbance at $t_{0} ; O D_{t}$ is absorbance at $t ; \mu$ is growth rate of all life $\left(\mathrm{min}^{-1}\right) ; \mu_{\mathrm{c}}$ is growth rates of control culture without toxin addition $\left(\mathrm{min}^{-1}\right)$; and $\mu_{\mathrm{t}}$ is growth rates of cultures in the presence of drugs $\left(\mathrm{min}^{-1}\right) . E C_{50}($ drug concentration required to cause $50 \%$ reduction in growth) values were calculated using linear regression analysis of drug concentration as natural logarithm versus percentage 
inhibition. All correlation coefficients were $>0.99$.

\section{Results and discussion}

\subsection{Effect of reaction parameters on drug Degradation}

Since various physicochemical parameters influence the degradation efficiency, it is essential to optimize these factors in order to make the process more efficient and practically applicable.

The $\mathrm{pH}$ range investigated was 2-6 due to poor stability and activity of CPO at higher pH. Fig. S1 (A) showed that the degradation efficiency of naproxen and diclofenac increased rapidly with increasing $\mathrm{pH}$, and reached maximum around $\mathrm{pH} 3.2$. The degradation efficiency decreased sharply when $\mathrm{pH}$ was increased above 3.2. The preference for such a low reaction $\mathrm{pH}$ has been observed for most $\mathrm{CPO}$ catalyzed reactions and has been attributed to the protein's unique active site structure and catalytic mechanism (Liu et al., 2014; Zhang et al., 2012). CPO uses a glutamic acid (Glu 183) as the acid-base catalyst to aid the formation of compound I (Sundaramoorthy et al., 1995; Wang et al., 2003). The protonation of Glu183 is necessary for both the formation of compound I and the binding of negatively charged substrates to avoid unfavorable electrostatic interactions. Acidic environment is also needed to protonate compound $\mathrm{X}$ involved in most CPO catalyzed halide dependent reactions (Chiang et al., 1976; Dawson et al., 1988).

It is well known that high concentration of $\mathrm{H}_{2} \mathrm{O}_{2}$ (oxidant) inactivates most heme containing enzymes due to internal oxidative destruction of the porphyrin prosthetic group (Grey et al., 2007). Thus low concentrations of $\mathrm{H}_{2} \mathrm{O}_{2}$ are employed for reactions catalyzed by most heme peroxidases. This strategy cannot be simply applied to CPO because of its ability to disproportionate hydrogen peroxide. Therefore, the optimum concentration of hydrogen peroxide needs to be determined based on the actual 
substrate. The effect of $\mathrm{H}_{2} \mathrm{O}_{2}$ concentration on $\mathrm{CPO}$ catalyzed degradation of diclofenac and naproxen is shown in Fig. S1B. As expected for all peroxidases, no degradation of either drug was observed before the addition of $\mathrm{H}_{2} \mathrm{O}_{2}$. The degradation efficiency of both drugs increased as $\mathrm{H}_{2} \mathrm{O}_{2}$ concentration is increased. Maximum rate is achieved when total $\mathrm{H}_{2} \mathrm{O}_{2}$ concentration reached $0.1 \mathrm{mmol} \cdot \mathrm{L}^{-1}$. Further addition of $\mathrm{H}_{2} \mathrm{O}_{2}$, however, repressed the degradation of both drugs possibly due to formation of compound III caused by high concentrations of $\mathrm{H}_{2} \mathrm{O}_{2}$ (Ayala et al., 2011). Therefore, $0.1 \mathrm{mmol} \cdot \mathrm{L}^{-1}$ of $\mathrm{H}_{2} \mathrm{O}_{2}$ was chosen in the degradation of both diclofenac and naproxen in all subsequent experiments.

Optimizing CPO concentration not only improves degradation efficiency but also saves cost of operation. The range of CPO concentration tested was $0.25-6.0 \mathrm{nmol} \cdot \mathrm{L}^{-1}$ for diclofenac and 1-23.0 $\mathrm{nmol} \cdot \mathrm{L}^{-1}$ for naproxen. Fig. $\mathrm{S} 1(\mathrm{C})$ showed that degradation efficiency of both drugs increased rapidly as CPO concentration was increased. Complete degradation of the drugs was achieved when CPO concentration was above $5.0 \mathrm{nmol} \cdot \mathrm{L}^{-1}$ for diclofenac, and $20.0 \mathrm{nmol} \cdot \mathrm{L}^{-1}$ for naproxen, indicating that $\mathrm{CPO}$ is extremely efficient in the degradation of the subject drugs.

It is remarkable to note that CPO degrades both diclofenac and naproxen with a remarkable rate. As shown in Fig. S1 (D), about $70 \%$ of diclofenac and $75 \%$ of naproxen is degraded within $1 \mathrm{~min}$. The complete degradation was achieved in only 9 and $7 \mathrm{~min}$ for diclofenac and naproxen, respectively, at optimum reaction condition.

\subsection{Determination of products by HPLC-MS and NMR}

Tremendous efforts have been made to characterize the intermediates and final products generated from diclofenac and naproxen degradation (Faber et al., 2012; Urrea et al., 2010). Plausible mechanisms have been proposed for both drugs based on the intermediates and final products identified from different processes. To understand the 
mechanisms of CPO catalyzed degradation and to evaluate the potential of this enzymatic method in environmental and industrial applications, both HPLC-MS and NMR analyses are employed to establish the structures of the putative products from the two drugs.

The hydroxylation of aromatic rings and O-demethylation of esters have been reported for several unspecific peroxygenase (UPOs) (Hofrichter et al., 2014; Kinne et al., 2009; Piontek et al., 2013; Poraj-Kobielska et al., 2011; Wang et al., 2013), a class of hemethiolate proteins related to $\mathrm{CPO}$ and cytochromes P450. However, these two activities have not been reported for CPO. In this work, CPO catalyzed hydroxylation of diclofenac and O-demethylation of naproxen were observed. The degradation of both diclofenac and naproxen was confirmed by HPLC analysis of the reaction product as shown in Fig. 2. The MS spectra of samples from diclofenac degradation (Fig.2) suggested the formation of six putative products. The peak that eluted at $2.6 \mathrm{~min}$ (Fig.2A) shows a molecular ion $[\mathrm{M}-\mathrm{H}]^{-}$at $\mathrm{m} / \mathrm{z} 311$, indicating the addition of an oxygen atom to the parent compound. Multiple possibilities exist as oxygen can be added at all possible positions of the two benzene rings. However, NMR analysis (Fig.3) suggested compound [II] as the major product corresponding to this molecular ion. Since the coupling pattern of the chloride bearing ring remained in the product, the oxygen must have been added to the acetate bearing ring with oxygen added at the para-carbon of the imino group. The NOE between peak "a" at 3.77 ppm (singlet, $2 \mathrm{H}$ ) and peak "b" at 7.25 ppm (Fig.S3), the COSY correlation and splitting pattern confirm the structure of compound [II] as reported previously (Blum et al., 1996; Calza et al., 2006; Coelho et al., 2009; Osorio et al., 2014; Sparidans et al., 2008). Product [l], 4'-hydroxydiclofenac, is commercially available and displays a quite different NMR spectral pattern as shown in Fig. S4 and Fig. S5). The peak eluted at $3.1 \mathrm{~min}$ (Fig.2B) displayed a molecular ion [M-H] at $\mathrm{m} / \mathrm{z} 328$, indicating 
the addition of two oxygen atoms to the parent compound or the addition of one oxygen atom to compound [II]. This product also showed a major fragmentation ion at $\mathrm{m} / \mathrm{z} 284$ (Fig.2B), assignable to the decarboxylation of the major product. Decarboxylation was also observed for diclofenac itself (Fig.S6). The NMR spectrum (Fig.S7) of this product showed the absence of a three proton coupling pattern in the aromatic region as displayed by both the parent compound and compound [II], suggesting the oxygen atom is added to the chloride bearing ring as shown in compound IV. This is in good agreement with observations made with other methods (Blum et al., 1996; Calza et al., 2006; Osorio et al., 2014). The peak eluted at 2.7 min showed a molecular ion [M-H] at $\mathrm{m} / \mathrm{z} 325$ (Fig.2C), assignable to compound [V] or [VI] due to further oxidation of product [II] or [IV]. However, neither compound V nor VI was detected in NMR experiments, implicating that these products might form only in the ionization process within mass spectrometer.

Based on the products identified from our LC-MS and NMR analysis, the sequence of diclofenac degradation catalyzed by CPO is proposed (Fig.4). The diverse catalytic activity of CPO makes it possible to produce a broad array of products from diclofenac degradation, however, under the conditions employed in our study, only hydroxylation activity is observed. This can be appreciated by the similarity between CPO and cytochromes P450 that metabolize most xenobiotics via hydroxylation. Thus CPO converts diclofenac to either monohydroxylated or dihydroxylated products, the same as the major products observed in the metabolism of diclofenac (Blum et al., 1996; Osorio et al., 2014). The close similarity among possible hydroxylation products makes it difficult to isolate and purify individual product. This drawback does not comprise the aim of this study.

The identification of products from CPO catalyzed degradation of naproxen is 
achieved by detailed NMR analysis of the products with the aid of MS. The most noticeable difference between proton NMR spectra of the products and the parent drug, naproxen, is the absence of the methoxy signal (peak "i" around 3.9 ppm, Fig.S8 and S9) in the products as shown in Fig.5. This suggests the demethylation of naproxen as reported previously (Sidelmann et al., 2001; Urrea et al., 2010). Although CPO catalyzed N-demethylation has been reported (Kedderis et al., 1980), the observed Odemethylation represents a novel activity of CPO. This is reminiscent of the activity displayed by P450 (Meunier et al., 2004) and UPOs (Hofrichter et al., 2014; Kinne et al., 2009) that are structurally related to CPO. The methyl (peak "a" at 1.53 ppm, doublet, $\mathrm{J}=6.56,3 \mathrm{H}$ ) and the methine (peak "b" at $4.99 \mathrm{ppm}$, quartets, $\mathrm{J}=6.56,1 \mathrm{H}$ ) signals from the product are indicative of the propionic acid part of naproxen. These signals are downfield shifted compared to the corresponding signals in the parent drug molecule, consistent with observations reported previously(Sidelmann et al., 2001; Urrea et al., 2010). Both the methyl and the methine signals displayed NOE to a peak at $7.42 \mathrm{ppm}$ (peak "h", doublet, $\mathrm{J}=1.18,1 \mathrm{H}$ ) and a peak at 7.48 ppm (signal "c", doublet of doublet, $\mathrm{J}=8.03$ and $1.18,1 \mathrm{H}$ ) as shown in Fig.5 (A). The peak at $7.48 \mathrm{ppm}$ is strongly coupled to a peak at 8.09 ppm (resonance "d", doublet, J=8.03, 1H) as shown in Fig.5 (B). The NOE and coupling pattern of this product suggests no modification occurred to the propionic group bearing ring of naproxen during degradation. The remaining aromatic signals, peak "g" at 7.44 ppm (doublet, $\mathrm{J}=10.11,1 \mathrm{H}$ ) and peak "f" at 6.44 ppm (doublet, $\mathrm{J}=10.18,1 \mathrm{H})$ are strongly coupled (Fig.5 (B)), demonstrating their vicinal relationship. Based on the above NMR spectral property, this product is proposed to be $2-(5,6-$ dihydroxynaphthalen-2-yl)propanoic acid due to modification at 5-C of naproxen. However, the NMR spectra of commercially available desmethylnaproxen (Fig. S10 and Fig. S11) do not support the proposed structure of this degradation product. 
Furthermore, the MS of this product shows a molecular ion $[\mathrm{M}-\mathrm{H}]^{-}$at $\mathrm{m} / \mathrm{z} 311$, also inconsistent with the structure proposed (expected $\mathrm{m} / \mathrm{z}$ at 231). The difference of a mass of 80 between the expected and the observed mass, suggests the phosphorylation of one of the hydroxyl groups. Esterification of desmethylnaproxen has been reported previously (Sidelmann et al., 2001). The high phosphate concentration and the extremely low $\mathrm{pH}$ used in our degradation study make it feasible to phosphorylate 2-(5,6dihydroxynaphthalen-2-yl)propanoic acid and give product (I) as shown in Figure 6. Product (I) can be further degraded to 2-(5,8-dihydroxy-6-(phosphonooxy)naphthalen-2yl)propanoic acid via hydroxylation at the 8-C. However, this product is not observed in either NMR or MS experiments. The observation of a molecular ion $[\mathrm{M}-\mathrm{H}]^{-}$at $\mathrm{m} / \mathrm{z} 325$ suggests the formation of product (II) as shown in Fig.6.

Based on the major products identified from our study, the reaction sequence of naproxen degradation catalyzed by CPO is proposed (Fig.7). Similar as the degradation of diclofenac, CPO catalyzed degradation of naproxen is achieved primarily via CPO's monooxygenase activity. Thus CPO degrades naproxen to either monohydroxylated or dihydroxylated products, similar as the major products observed in bacterial degradation of naproxen (Wojcieszyńska et al., 2014). Initially, naproxen was degraded to desmethylnaproxen (Aresta et al., 2006; Urrea et al., 2010). The desmethylnaproxen is then phosphorylated to [(2-(6-(phosphonooxy)naphthalen-2-yl)acetic acid [a], not observed)] in the presence of high concentrations of phosphate and under low $\mathrm{pH}$ condition employed. Esterification of desmethylnaproxen has been reported in the literature (Sidelmann et al., 2001). Next, [a] was hydroxylated to 2-(5-hydroxy-6(phosphonooxy)naphthalen-2-yl)propanoic acid [] corresponding to m/z 311 observed in Figure 6. Product (I) was then degraded to 2-(5,8-dihydroxy-6(phosphonooxy)naphthalen-2-yl)propanoic acid [b, expected $\mathrm{m} / \mathrm{z}=327]$ which is instantly 
oxidized to 2-(5,8-dioxo-6-(phosphonooxy)-5,8-dihydronaphthalen-2-yl)propanoic acid (II, $\mathrm{m} / \mathrm{z}=325)$ as shown in Fig.6.

The products identified in our NMR and MS analysis are subjected to further oxidative transformation as supported by the results from activated sludge experiment as well as eco-toxicity test.

3.3 Reduction in chemical oxygen demand (COD) and total organic carbon (TOC)

Table 1 showed that only $4.9 \%, 9.1 \%$ of COD and $25 \%, 7.6 \%$ of TOC removal was achieved for diclofenac and naproxen, respectively. It is therefore proposed that CPO catalyzed degradation can serve as an efficient pre-treatment step in waste water treatment. This can be combined with subsequent bioremediation technologies (activated sludge) for complete decontamination of the two drugs in waste water. 3.4 Combined treatment of drug effluent by enzymatic oxidation and activated sludge As indicated in Table 1, the COD value of drug effluent did not decrease noticeably after CPO-treatment. However, compared with the parent drugs, the products from CPO catalyzed degradation have improved solubility in aqueous media and are more vulnerable to further biodegradation. This conclusion was confirmed by the observation that treatment of CPO-catalyzed reaction mixture with activated sludge increased COD removal from $4.9 \%$ and $9.1 \%$ to $85 \%$ and $86 \%$ for diclofenac and naproxen, respectively. On the other hand, treatment by activated sludge alone only removes $49 \%$ and $54 \%$, of the COD for diclofenac and naproxen, respectively, suggesting that more effective decontamination of the two drugs can be achieved through CPO pre-treatment followed by existing bioremediation technologies (activated sludge).

\subsection{Evaluation of the eco-toxicity of the products}

In some cases simple destruction of a drug is inadequate, since the resulting products may also be highly toxic, and special attention must therefore be paid to toxicity 
assessment of products to ensure that the agent has been effectively detoxified. However, toxicity evaluation about the products from diclofenac and naproxen are not readily available. Biological assays offer a direct measure to evaluate the magnitude of the potential health risk of chemicals. Therefore, a growth-inhibitory test was carried out using C. Pyrenoidosa.

Fig.S10 showed that the $72-\mathrm{h} E C_{50}$ increased with the increase in degradation efficiency. The value was $0.25 \mathrm{mg} \cdot \mathrm{L}^{-1}$ for diclofenac and $0.33 \mathrm{mg} \cdot \mathrm{L}^{-1}$ for naproxen at the end of degradation. These results demonstrated that the products had lower toxicity compared with the parent drugs, suggesting the great potential of using CPO as an efficient catalyst in the safe removal of these drugs from environmental.

\section{Conclusion}

In summary, our study demonstrated that CPO catalyzed oxidative degradation is a promising alternative for treatment of waste water containing non-steroidal antiinflammatory drugs. Complete degradation of diclofenac and naproxen is reached in only 9 and 7 min, respectively, under mild conditions.

The products identified by HPLC-MS suggested the initial hydroxylation of the drug molecules followed by further oxidative transformation. The biodegradability of the decomposition products was significantly increased as confirmed by COD measurement after combining the enzymatic oxidation with activated sludge treatment. Most significantly, the products of both diclofenac and naproxen had dramatically lower toxicity than the original drugs as judged by the $72-\mathrm{h} E C_{50}$ value of $C$. Pyrenoidos. Our results demonstrates that $\mathrm{CPO}$ can serve as an efficient, cost-effective, and 
environmentally friendly catalyst for large-scale treatment of waste water contaminated with the two drugs studied in this work..

\section{Acknowledgments}

This work is supported by the National Natural Science Foundation of China (21176150) and the Fundamental Research Funds for the Central Universities (GK201505007) to YJ and the National Science Foundation via Grant CHE-0540763 to X.W. (CAREER Award).

\section{Nomenclature}

NSAID, non-steroidal anti-inflammatory drugs; WRF, white-rot fungus; LiP, lignin peroxidase; CPO, chloroperoxidase; HPLC-MS, high performance liquid chromatography-mass spectrometry; NMR, nuclear magnetic resonance; NOE, nuclear overhauser effect; COSY, ( homonuclear chemical shift ) correlation spectroscopy; MCD, monochlorodimedon; ESI, electrospray ionization; TOC, total organic carbon; COD, chemical oxygen demand; $B G$, blue green medium; $E C_{50}$, median effective concentrations; 


\section{References}

Álvarez TR, Rodil R, Quintana JB, Triñanes S, Cela R. 2013. Oxidation of non-steroidal anti-inflammatory drugs with aqueous permanganate. Water Res 47: 3220-3230.

Aresta A, Carbonara T, Palmisano F, Zambonin CG. 2006. Profiling urinary metabolites of naproxen by liquid chromatography-electrospray mass spectrometry. J Pharmaceut Biomed 41: 1312-1316.

Arriaga FM, Esplugas S, Giménez J. 2008. Photocatalytic degradation of non-steroidal anti-inflammatory drugs with $\mathrm{TiO}_{2}$ and simulated solar irradiation. Water Res. 42: 585-594.

Ayala M, Batista CV, Vazquez-Duhalt R. 2011. Heme destruction, the main molecular event during the peroxide-mediated inactivation of chloroperoxidase from Caldariomyces fumago. J Biol Inorg Chem 16: 63-68.

Blum W, Faigle JW, faar P U, Sallmann A. 1996. Characterization of a novel diclofenac metabolite in human urine by capillary gas chromatography-negative chemical ionization mass spectrometry. J Chromatogr B 685: 251-263.

Brillas E, Segura SG, Skoumal M, Arias C. 2010. Electrochemical incineration of diclofenac in neutral aqueous medium by anodic oxidation using Pt and borondoped diamond anodes. Chemosphere 79: 605-612.

Calza P, Sakkas VA, Medana C, Baiocchi C, Dimou A, Pelizzetti E, Albanis T. 2006 Photocatalytic degradation study of diclofenac over aqueous $\mathrm{TiO}_{2}$ suspensions. Appl Catal B-Environ 67: 197-205.

Chiang R, Rand-Meir T, Makino R, Hager LP. 1976. Compound X an intermediate in enzymatic halogenations. J Biol Chem 251: 6340-6346.

Coelho AD, Sans C, Agüera A, Gómez MJ, Esplugas S, Dezotti M. 2009. Effects of ozone pre-treatment on diclofenac: intermediates, biodegradability and toxicity assessment. Sci Total Environ 407: 3572-3578.

Dawson JH. 1988 Probing structure-function relations in heme-containing oxygenases and peroxidases. Science 240: 433-439. 
Faber H, Melles D, Brauckmann C, Wehe CA, Wentker K, Karst U. 2012. Simulation of the oxidative metabolism of diclofenac by electrochemistry/(liquid chromatography) mass spectrometry. Anal Bioanal Chem 403: 345-354.

Gagné F, Blaise C, Fournier M, Hansen PD. 2006. Effects of selected pharmaceutical products on phagocytic activity in Elliptio complanata mussels. Comp Biochem Phys C 143:179-186.

Grenni P, Patrolecco L, Ademollo N, Tolomei A, Caracciolo AB. 2013. Degradation of Gemfibrozil and Naproxen in a river water ecosystem. Microchem J 107:158-164. Grey CE, Hedström M, Adlercreutz P. 2007. A mass spectrometric investigation of native and oxidatively inactivated chloroperoxidase. Chembiochem 8: 1055-1062.

Hager LP, Morris DR, Brown FS, Eberwein H. 1966. Chloroperoxidase: Il. Utilization of halogen anions. J Biol Chem 241: 1769-1777.

Hartmann J, Bartels P, Mau U, Witter M, Tümpling WV, Hofmann J, Nietzschmann E. 2008. Degradation of the drug diclofenac in water by sonolysis in presence of catalysts. Chemosphere 70: 453-461.

Hofrichter M, Ullrich R. 2014. Oxidations catalyzed by fungal peroxygenases. Curr Opin Chem Biol 19: 116-125.

llic S, Drmic D, Franjic S, Kolenc D, Coric M, Brcic L, Klicek R, Radic B, Sever M, Djuzel V, Filipovic M, Djakovic Z, Stambolija V, Blagaic AB, Zoricic I, Gjurasin M, Stupnisek M, Romic Z, Zarkovic K, Dzidic S, Seiwerth S, Sikiric P. 2011. Pentadecapeptide BPC 157 and its effects on a NSAID toxicity model: Diclofenac-induced gastrointestinal, liver, and encephalopathy lesions Life Sci 88: 535-542.

Kedderis GL, Koop DR, Hollenberg PF. 1980. N-Demethylation reactions catalyzed by chloroperoxidase. J Biol Chem 255: 10174-10182.

Kinne M, Poraj-Kobielska M, Aranda E, Ullrich R, Hammel KE, Scheibner K, Hofrichter M. 2009. Regioselective preparation of 5-hydroxypropranolol and 4hydroxydiclofenac with a fungal peroxygenase Bioorg. Med Chem Lett 19: 30853087. 
Kinne M, Poraj-Kobielska M, Ralph SA, Ullrich R, Hofrichter M, Hammel KE. 2009.

Oxidative cleavage of diverse ethers by an extracellular fungal peroxygenase. J Biol Chem 284: 29343-29349.

Kluge MG, Ullrich R, Scheibner K, Hofrichte M. 2007. Spectrophotometric assay for detection of aromatic hydroxylation catalyzed by fungal haloperoxidaseperoxygenase. Appl Microbiol Biot 75: 1473-1478.

Lange F, Cornelissen S, Kubac D, Sein MM, Sonntag JV, Hannich CB, Golloch A, Heipieper HJ, Möder M, Sonntag CV. 2006. Degradation of macrolide antibiotics by ozone: A mechanistic case study with clarithromycin. Chemosphere 65: 17-23.

Liu LX, Zhang J, Tan Y, Jiang YC, Hu MC, Li SN, Zhai QG. 2014. Rapid decolorization of anthraquinone and triphenylmethane dye using chloroperoxidase: Catalytic mechanism, analysis of products and degradation route. Chem Eng J 244: 9-18. Makino R, Chiang R, Hager LP. 1976. Oxidation-Reduction potential measurements on chloroperoxidase and its complexes. Biochemistry 15: 4748-4754.

Manoj KM, Hager LP. 2008. Chloroperoxidase, a janus enzyme. Biochem 47: 29973003.

Ma JY, Lu NH, Qin WD, Xu RF, Wang YB, Chen XN. 2006 Differential responses of eight cyanobacterial and green algal species, to carbamate insecticides. Ecotox Environ Safe 63: 268-274.

Meunier B, de Visser SP, Shaik S. 2004. Mechanism of oxidation reactions catalyzed by cytochrome p450 enzymes. Chem Rev 104: 3947-3980.

Millis CD, Cai D, Stankovich MT, Tien M. 1989. Oxidation-reduction potentials and ionization states of extracellular peroxidases from the lignin-degrading fungus phanerochaete chrysosporium. Biochemistry 28: 8484-8489.

Morris DR, Hager LP. 1966. Chloroperoxidase: I. Isolation and properties of the crystalline glycoprotein. J Biol Chem 241: 1763-1768.

Naddeo V, Belgiorno V, Ricco D, Kassinos D. 2009. Degradation of diclofenac during sonolysis, ozonation and their simultaneous application, Ultrason. Sonochem 16: 
790-794.

Naddeo V, Belgiorno V, Kassinos D, Mantzavinos D, Meric S. 2010. Ultrasonic

degradation, mineralization and detoxification of diclofenac in water: optimization of operating parameters. Ultrason Sonochem 17: 179-185.

Nakada N, Tanishima T, Shinohara H, Kiri K, Takada H. 2006. Pharmaceutical chemicals and endocrine disrupters in municipal wastewater in Tokyo and their removal during activated sludge treatment. Water Res 40: 3297-3303.

Osorio V, Imbert-Bouchard M, Zonjia B, Aband JL, Pérez S, Varceló D. 2014.

Simultaneous determination of diclofenac, its human metabolites and microbial nitration/nitrosation transformation products in wastewaters by liquid chromatography / quadrupole-linear ion trap mass spectrometry. J Chromatogr A 1347: 63-71.

Piontek K, Strittmatter E, Ullrich R, Gröbe G, Pecyna MJ, Kluge M, Scheibner K, Hofrichter M, Plattner DA. 2013. Structural basis of substrate conversion in a new aromatic peroxygenase: cytochrome P450 functionality with benefits. J Biol Chem 288: $34767-34776$.

Poraj-Kobielska M, Kinne M, Ullrich R, Scheibner K, Kayser G, Hammel KE, Hofrichter M. 2011. Preparation of human drug metabolites using fungal peroxygenases. Biochem Pharmacol 82: 789-796.

Quintana JB, Weiss S, Reemtsma T. 2005. Pathways and metabolites of microbial degradation of selected acidic pharmaceutical and their occurrence in municipal wastewater treated by a membrane bioreactor. Water Res 39: 2654-2664.

Samaras VG, Stasinakis AS, Mamais D, Thomaidis NS, Lekkas TD. 2013. Fate of selected pharmaceuticals and synthetic endocrine disrupting compounds during wastewater treatment and sludge anaerobic digestion. J Hazard Mater 244-245: 259-267.

Sathishkumar P, Chae JC, Unnithan AR, Palvannan T, Kim HY, Lee KJ, Cho M, Kannan S K, Oh BT. 2012. Laccase-poly(lactic-co-glycolic acid) (PLGA) nanofiber: highly 
stable, reusable, and efficacious for the transformation of diclofenac. Enzyme Microb Tech 51:113-118.

Sidelmann UG, Bjørnsdottir I, Shockcor JP, Hansen SH, Lindon JC, Nicholson JK. 2001.

Directly coupled HPLC-NMR and HPLC-MS approaches for the rapid characterisation of drug metabolites in urine: application to the human metabolism of naproxen. J Pharmaceut Biomed Anal 24: 569-579.

Sparidans RW, Lagas JS, Schinkel AH, Schellens JHM, Beijnen JH. 2008. Liquid chromatography-tandem mass spectrometric assay for diclofenac and three primary metabolites in mouse plasma. J Chromatogr B 872: 77-82.

Sundaramoorthy M, Terner J, PoulosI TL. 1995. The crystal structure of chloroperpxidase: a heme peroxidase-cytochrome P450 functional hybrid. Structure 3: $1367-1377$.

Urrea EM, Trujillo MP, Blánquez P, Vicent T, Caminal G. 2010. Biodegradation of the analgesic naproxen by Trametes versicolor and identification of intermediates using HPLC-DAD-MS and NMR. Bioresource Technol 101: 2159-2166.

Urrea EM, Trujillo MP, Morató CC, Caminal G, Vicent T. 2010. Degradation of the drug sodium diclofenac by Trametes versicolor pellets and identification of some intermediates by NMR. J Hazard Mater 176: 836-842.

Wang XS, Peter S, Ullrich R, Hofrichter M, Groves JT. 2013. Driving force for oxygenatom transfer by heme-thiolate enzymes. Angew Chem Int Ed 52: 9238-9241.

Wang XT, Tachikawa H, Yi XW, Manoj KM, Hager LP. 2003. Two-dimensional NMR study of the heme active site structure of chloroperoxidase. J Biol Chem 278: 7765-7774.

Westerhoff P, Yoon Y, Snyder S, Wert E. 2005. Fate of endocrine-disruptor, pharmaceutical, and personal care product chemicals during simulated drinking water treatment processes. Environ Sci Technol 39: 6649-6663.

Wojcieszyńska D, Domaradzka D, Hupert-Kocurek K, Guzik U. 2014. Bacterial degradation of naproxene-Undisclosed pollutant in the environment. J Environ Manage 145: 157-161. 
Zhang J, Feng MY, Jiang YC, Hu MC, Li SN, Zhai QG. 2012. Efficient ecolorization / degradation of aqueous azo dyes using buffered $\mathrm{H}_{2} \mathrm{O}_{2}$ oxidation catalyzed by a dosage below ppm level of chloroperoxidase. Chem Eng J 191: 236-242.

Zhang YJ, Geißen SU, Gal C. 2008. Carbamazepine and diclofenac: removal in wastewater treatment plants and occurrence in water bodies. Chemosphere 73:11511161.

Zhang YJ, Geißen SU. 2010. In vitro degradation of carbamazepine and diclofenac by crude lignin peroxidase. J Hazard Mater 176: 1089-1092.

Zhao JL, Ying GG, Wang L, Yang JF, Yang XB, Yang LH, Li X. 2009. Determination of phenolic endocrine disrupting chemicals and acidic pharmaceuticals in surface water of the Pearl Rivers in South China by gas chromatography-negative chemical ionization-mass spectrometry. Sci Total Environ 407: 962-974. 
Figure captions:

Fig. 1 Chemical structures of diclofenac (a) and naproxen (b)

Fig. 2 ESI-ion trap mass spectra of the degradation products from CPO catalyzed oxidation of diclofenac recorded in negative mode.

Fig. 3 COSY of diclofenac product [II] in chloroform-d.

Fig. 4 Proposed degradation pathway of diclofenac during CPO-catalytic oxidative process.

Fig. 5 Proton NMR (A) NOESY and (B) COSY spectra of naproxen product [l]. The week NOEs between peaks "a" and "c" and between peaks "b" and "c" can only be observed at lower contour levels. The NOE and coupling patterns unequivocally define the structure of this degradation product.

Fig. 6 ESI-ion trap mass spectra of the degradation products from CPO catalyzed oxidation of naproxen recorded in negative mode.

Fig. 7 Proposed degradation pathway of naproxen during CPO-catalytic oxidative process.

Table 1 Elimination of COD and TOC by CPO catalyzed oxidative degradation. 


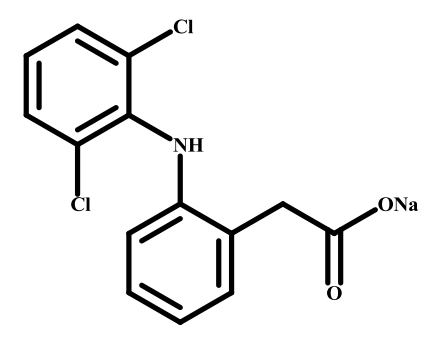

a<smiles>COc1ccc2cc([C@@H](C)C(=O)O)ccc2c1</smiles>

b

Fig. 1 Chemical structures of diclofenac (a) and naproxen (b) 
(A)

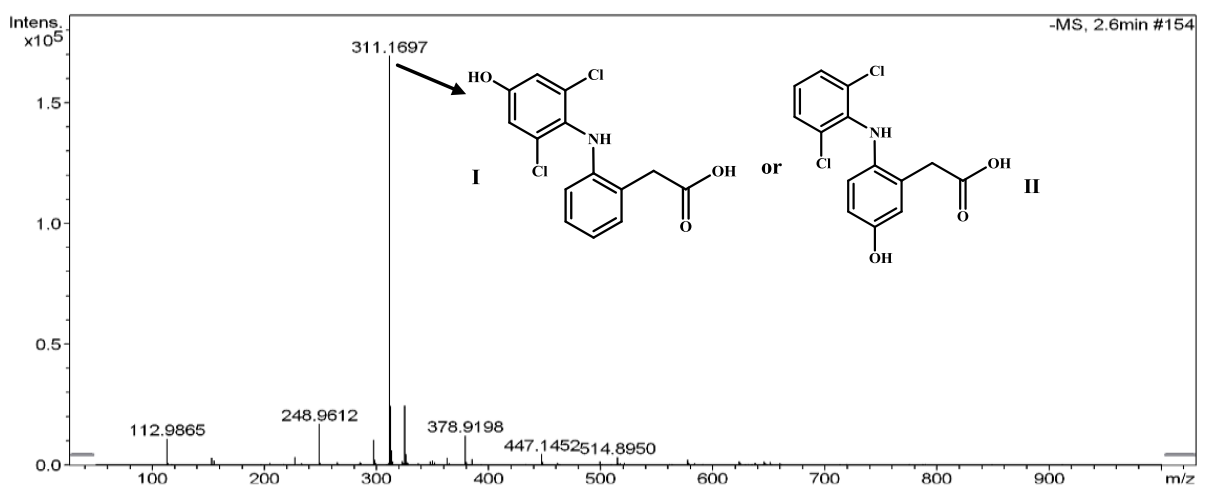

(C)
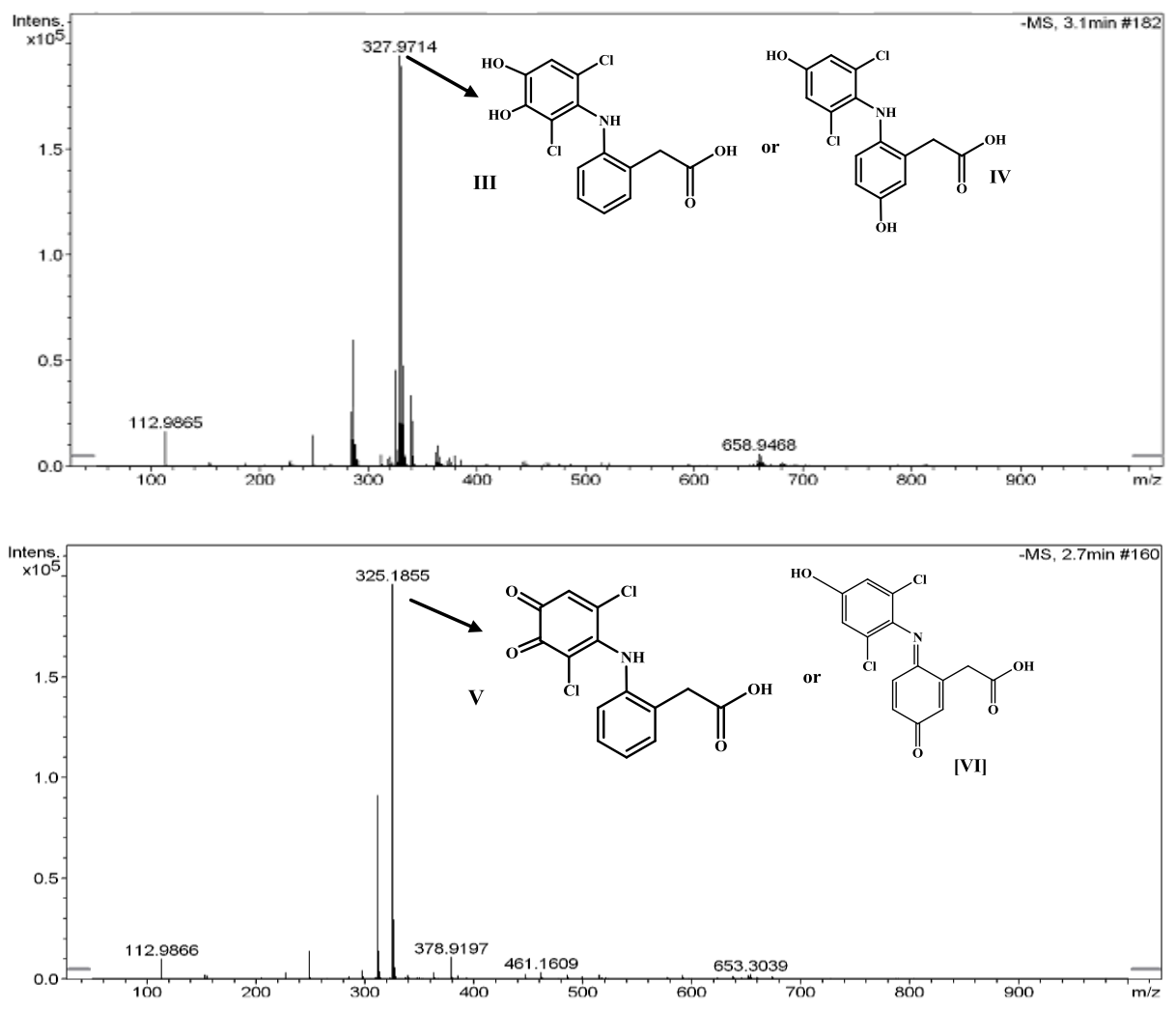

Fig. 2 ESI-ion trap mass spectra of the degradation products from CPO catalyzed oxidation of diclofenac recorded in negative mode. 


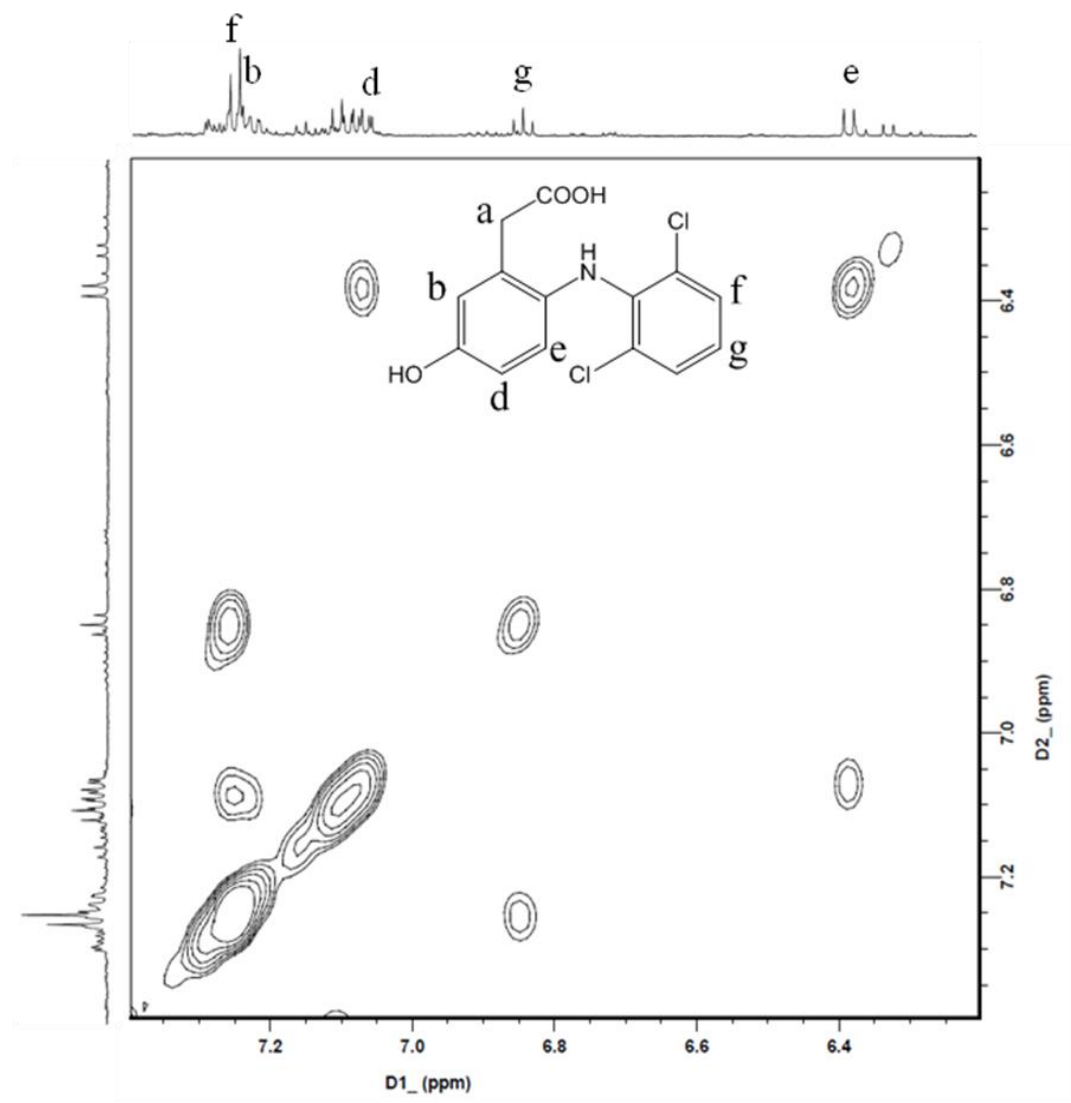

Fig. 3 COSY of diclofenac product [II] in chloroform-d. 


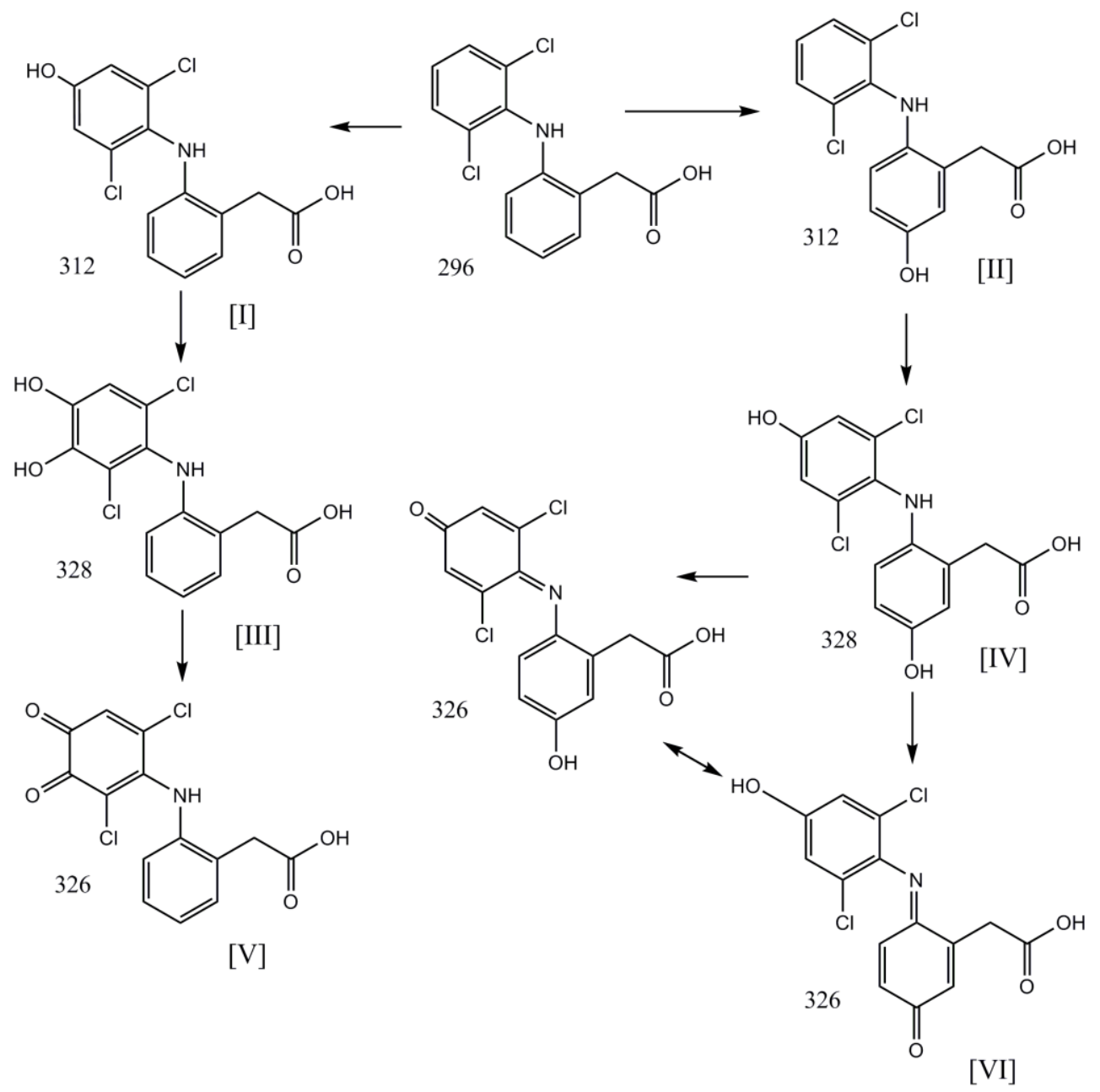

Fig. 4 Proposed degradation pathway of diclofenac during CPO-catalytic oxidative process. 
(A)

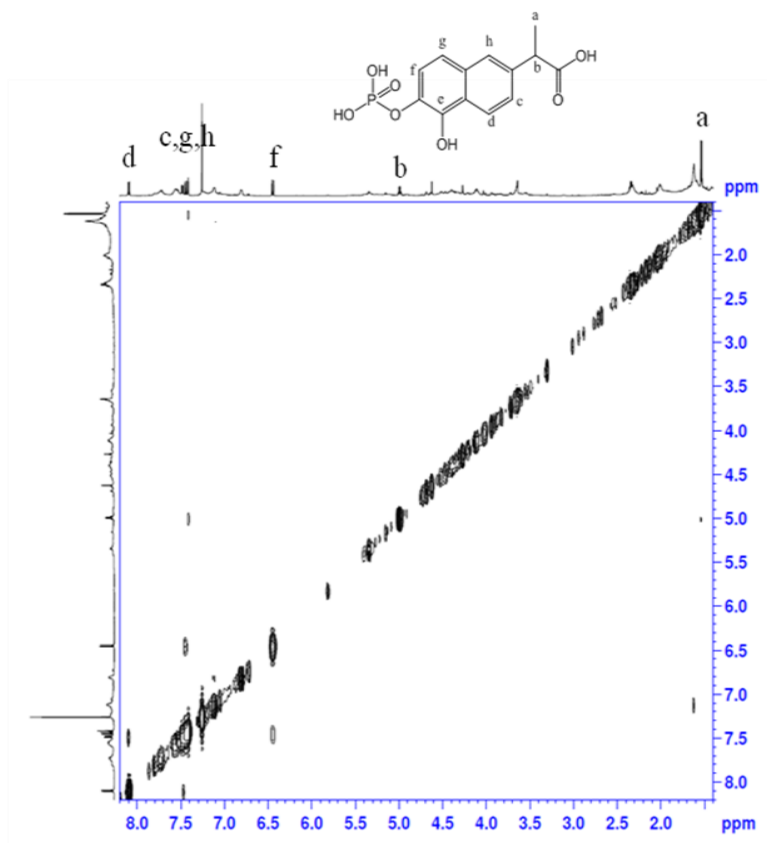

(B)

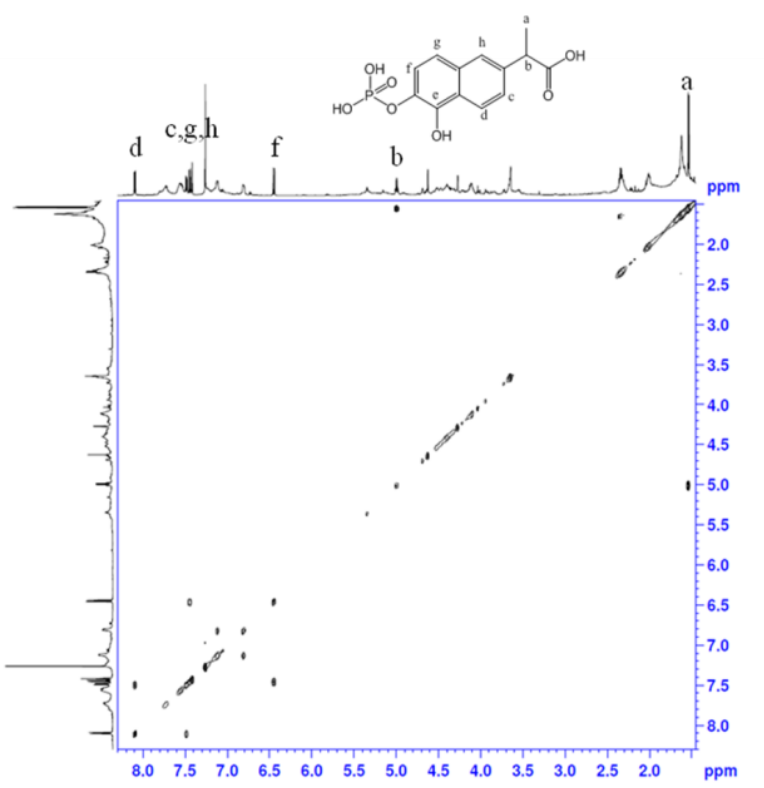

Fig. 5 Proton NMR (A) NOESY and (B) COSY spectra of naproxen product [l]. The week NOEs between peaks "a" and "c" and between peaks "b" and "c" can only be observed at lower contour levels. The NOE and coupling patterns unequivocally define the structure of this degradation product. 


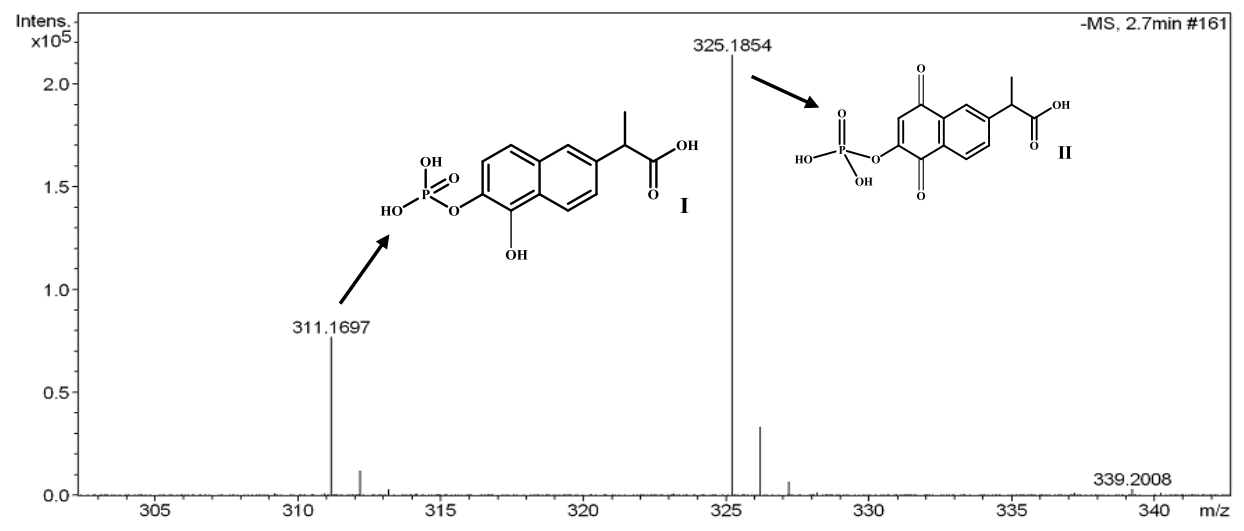

Fig. 6 ESI-ion trap mass spectra of the degradation products from CPO catalyzed oxidation of naproxen recorded in negative mode. 


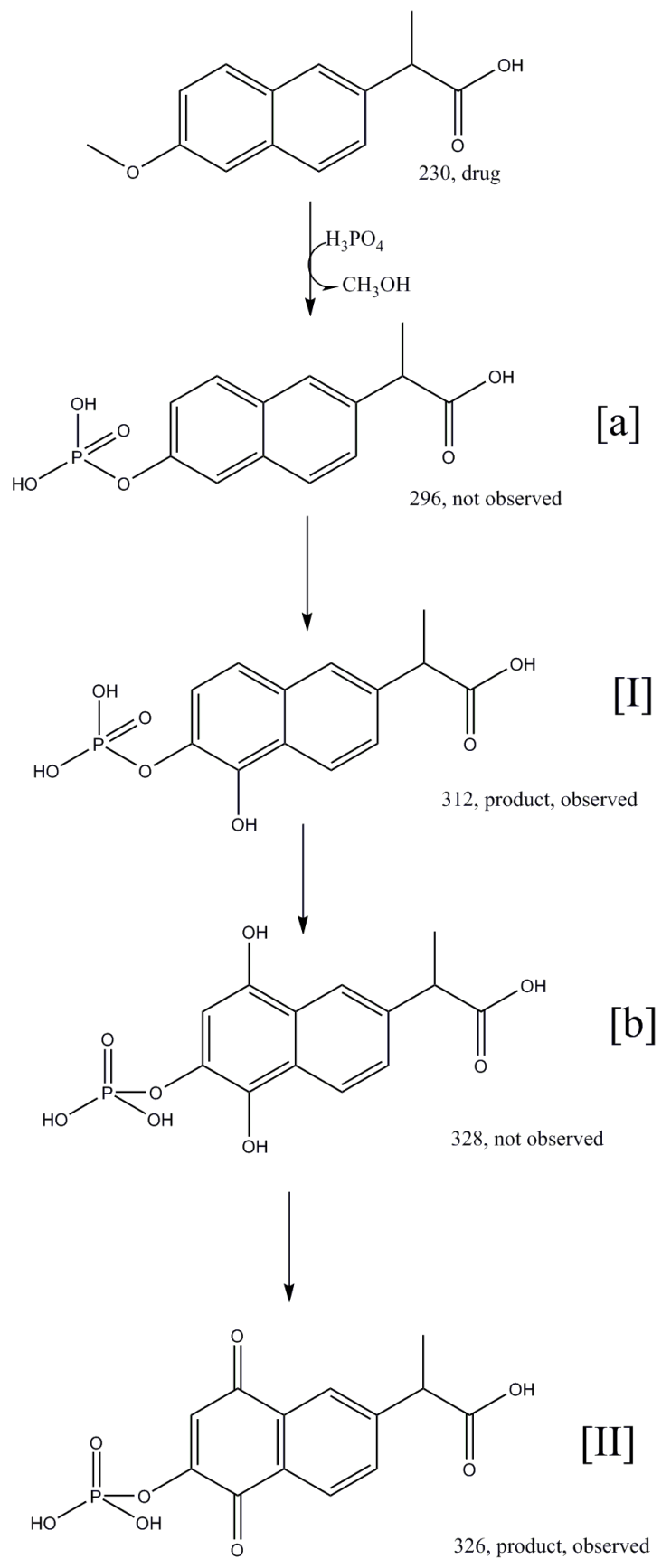

Fig. 7 Proposed degradation pathway of naproxen during CPO-catalytic oxidative process 
Table 1 Elimination of COD and TOC by CPO catalyzed oxidative degradation

\begin{tabular}{ccccc}
\hline substance & COD & COD removal & TOC & TOC removal \\
& $\left(\mathrm{mg} \cdot \mathrm{L}^{-1}\right)$ & $(\%)$ & $\left(\mathrm{mg} \cdot \mathrm{L}^{-1}\right)$ & $(\%)$ \\
\hline diclofenac & $41 \rightarrow 39$ & 4.9 & $8.3 \rightarrow 6.2$ & 25 \\
naproxen & $22 \rightarrow 20$ & 9.1 & $158 \rightarrow 146$ & 7.6 \\
\hline
\end{tabular}




\section{Supporting Information}

Fig. S1 The relationship between degradation efficiency and reaction condition of CPO catalyzed degradation of diclofenac (left) and naproxen (right).

(A)

(B)
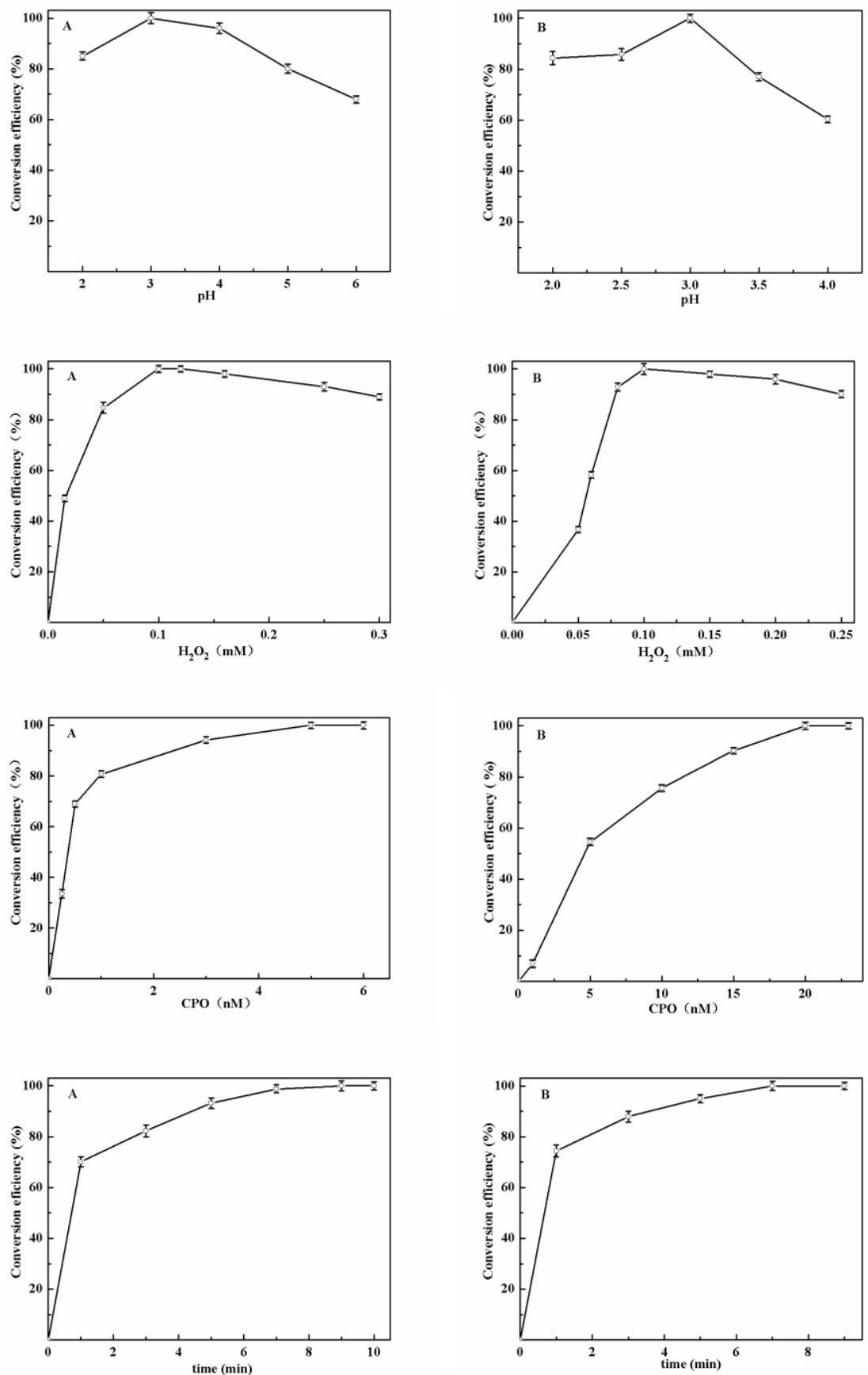
Fig. S2 The HPLC elution profile of degradation solution both of diclofenac and naproxen

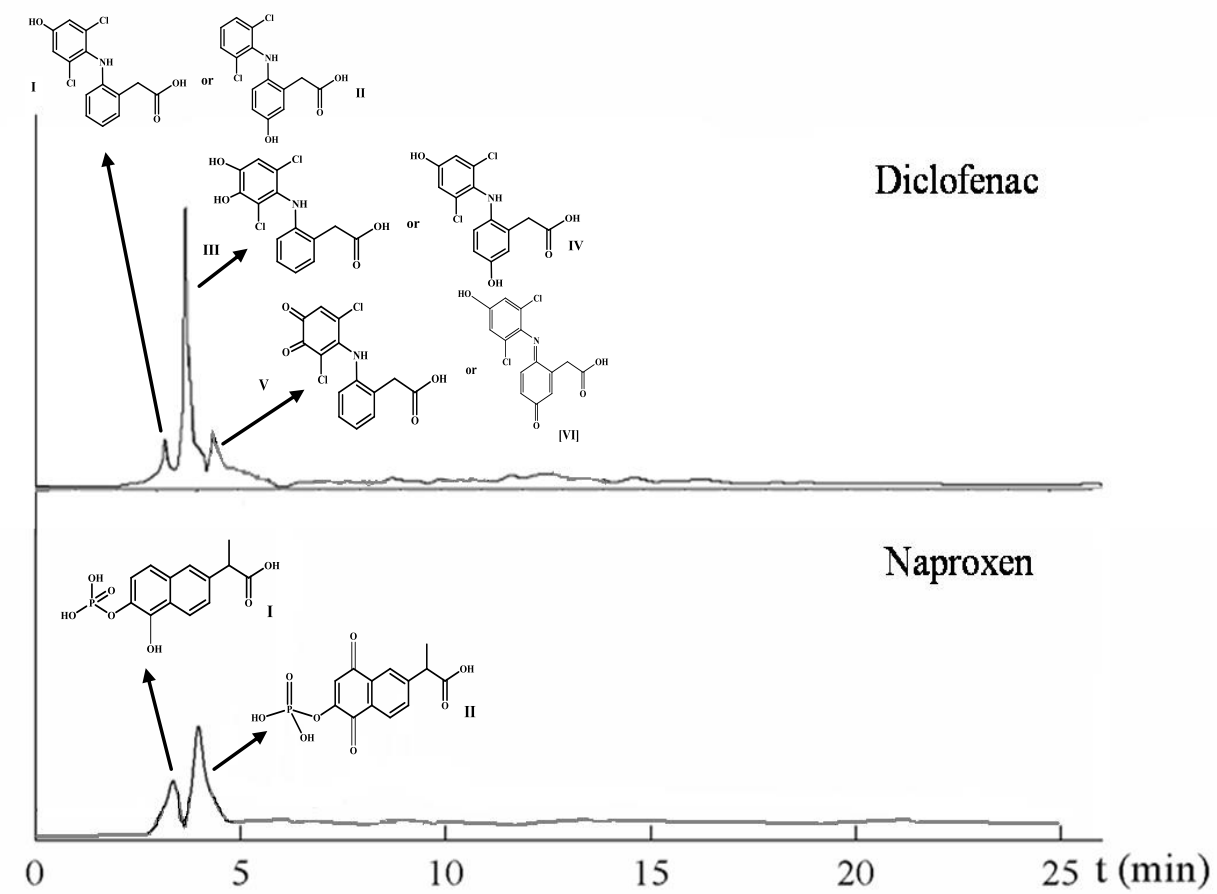


Fig. S3 NOESY of diclofenac product [II]

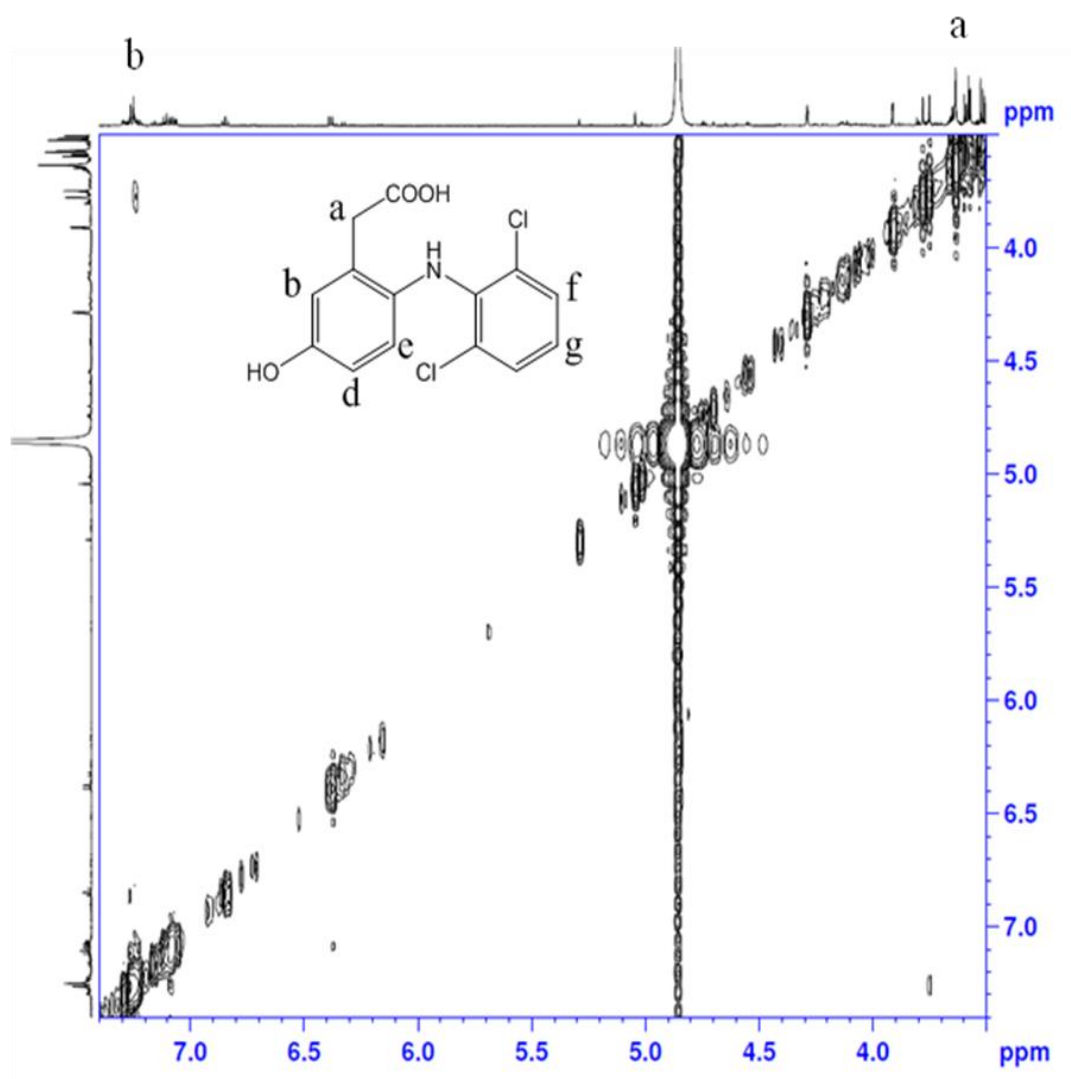


Fig. S4. COSY of authentic 4'-hydroxydiclofenac purchased from Sigma Aldrich

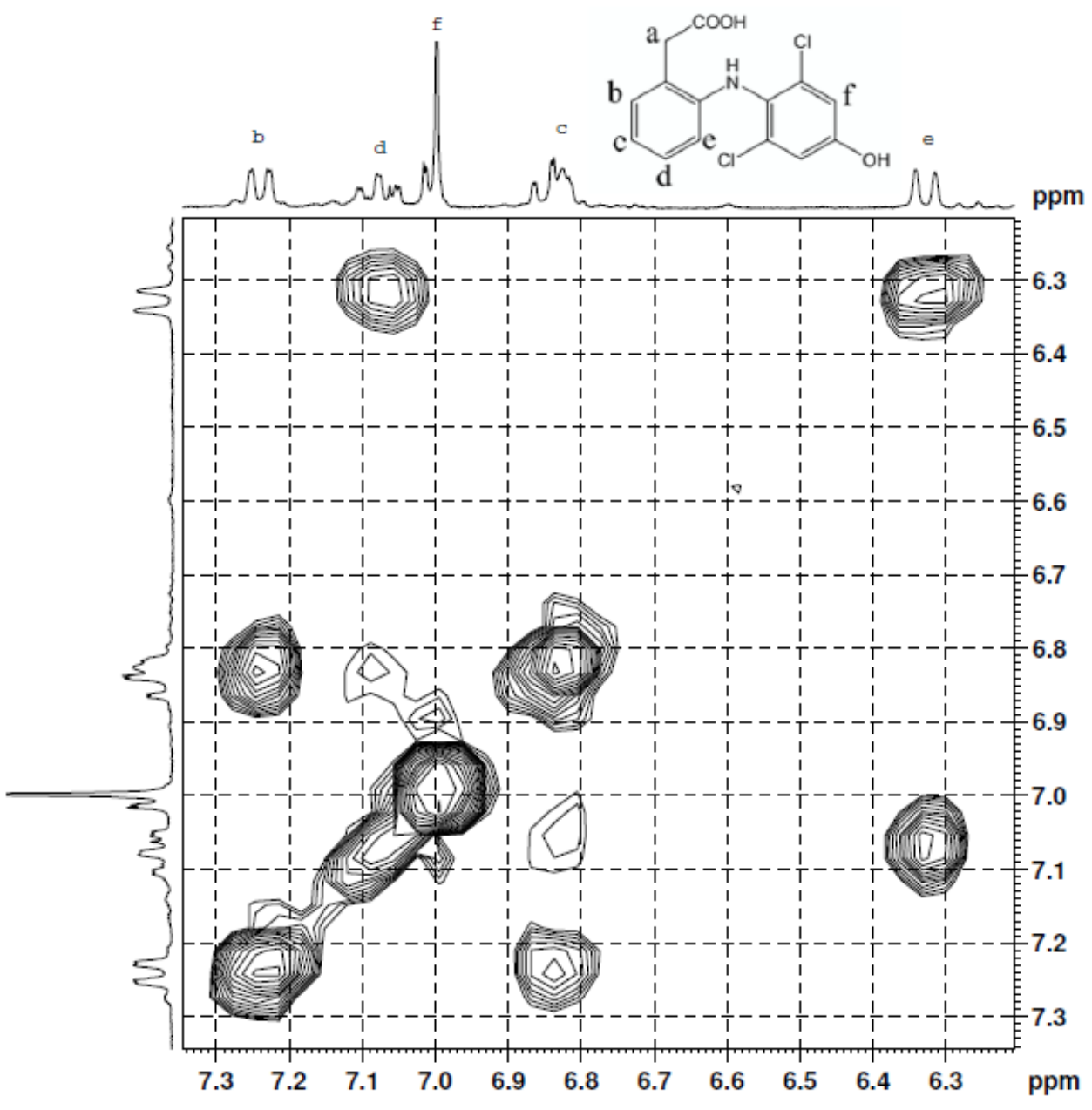


Fig. S5. NOESY of authentic 4'-hydroxydiclofenac purchased from Sigma Aldrich

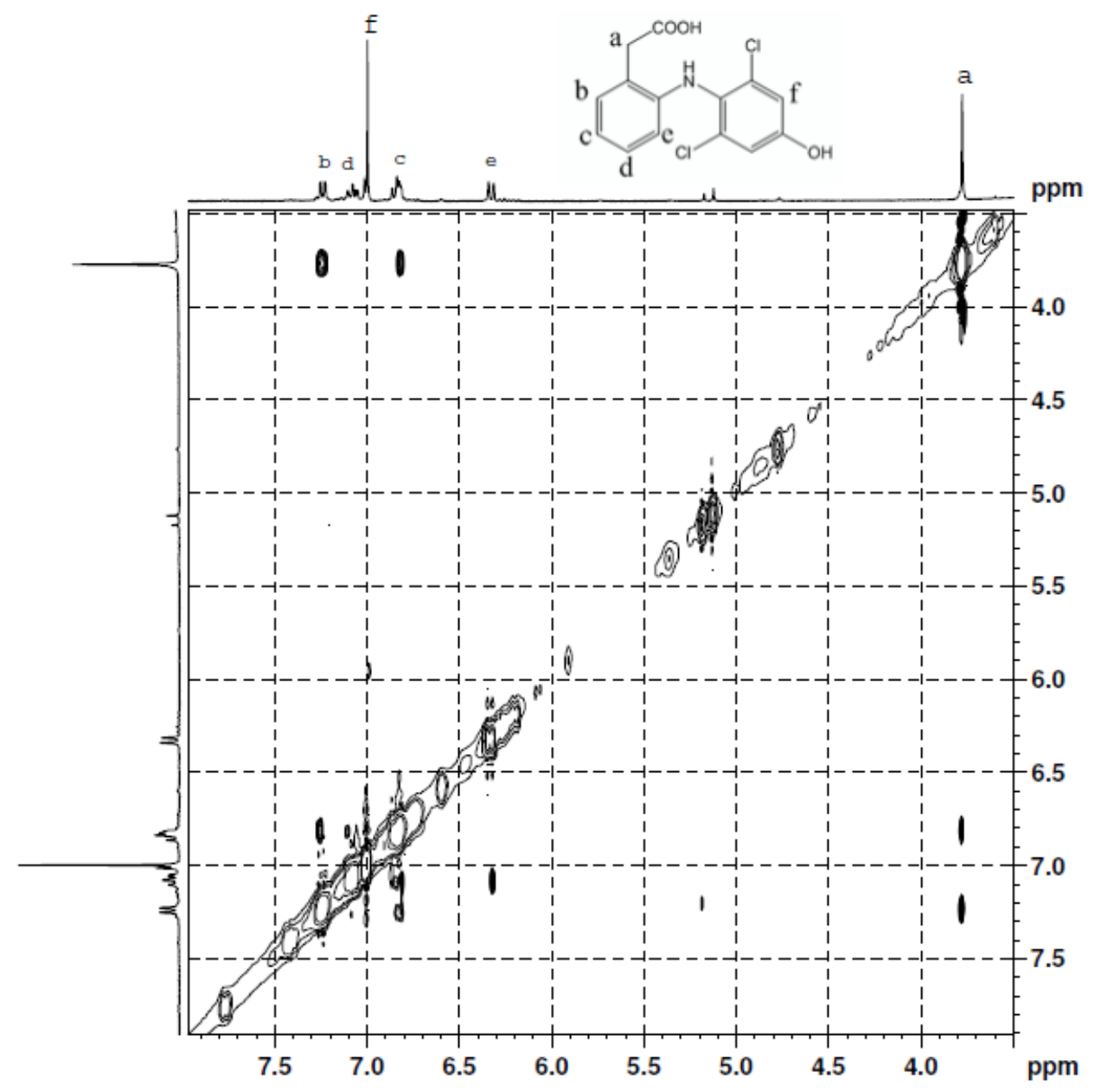


Fig. S6. MS of diclofenac

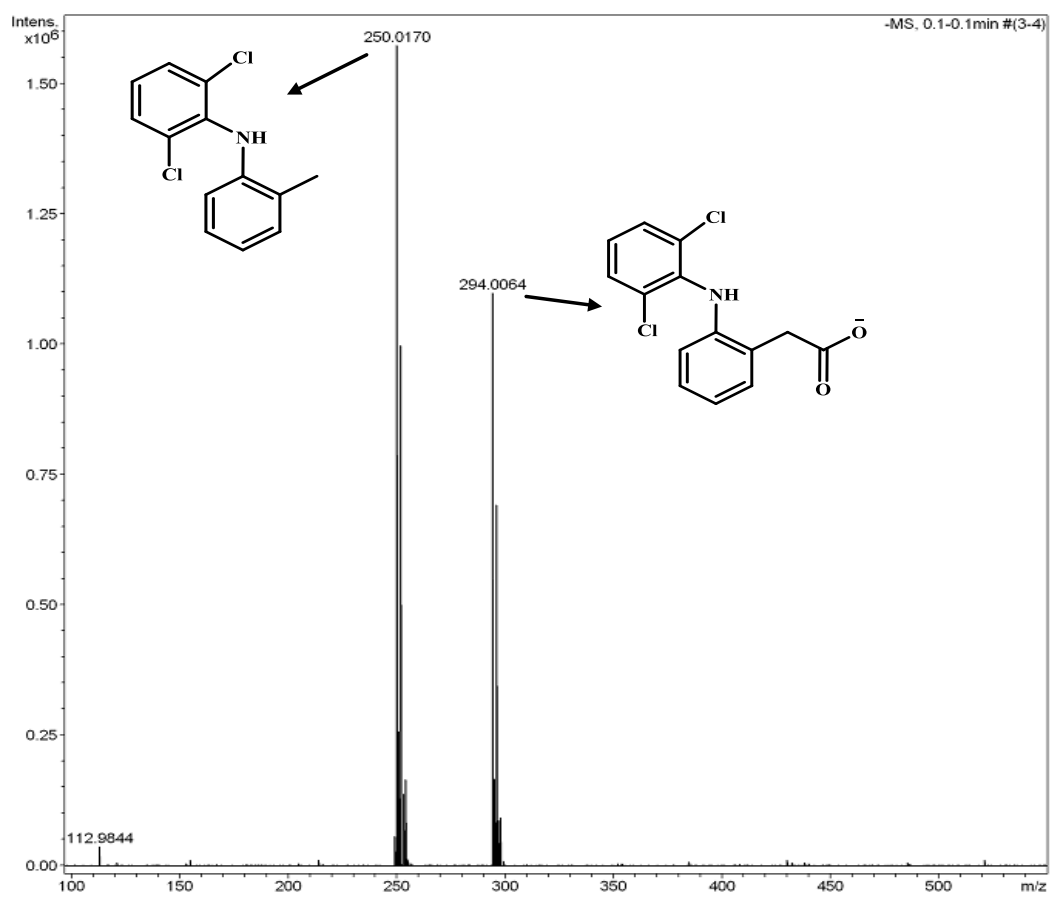

130 
Fig. S7. COSY of diclofenac product [IV]

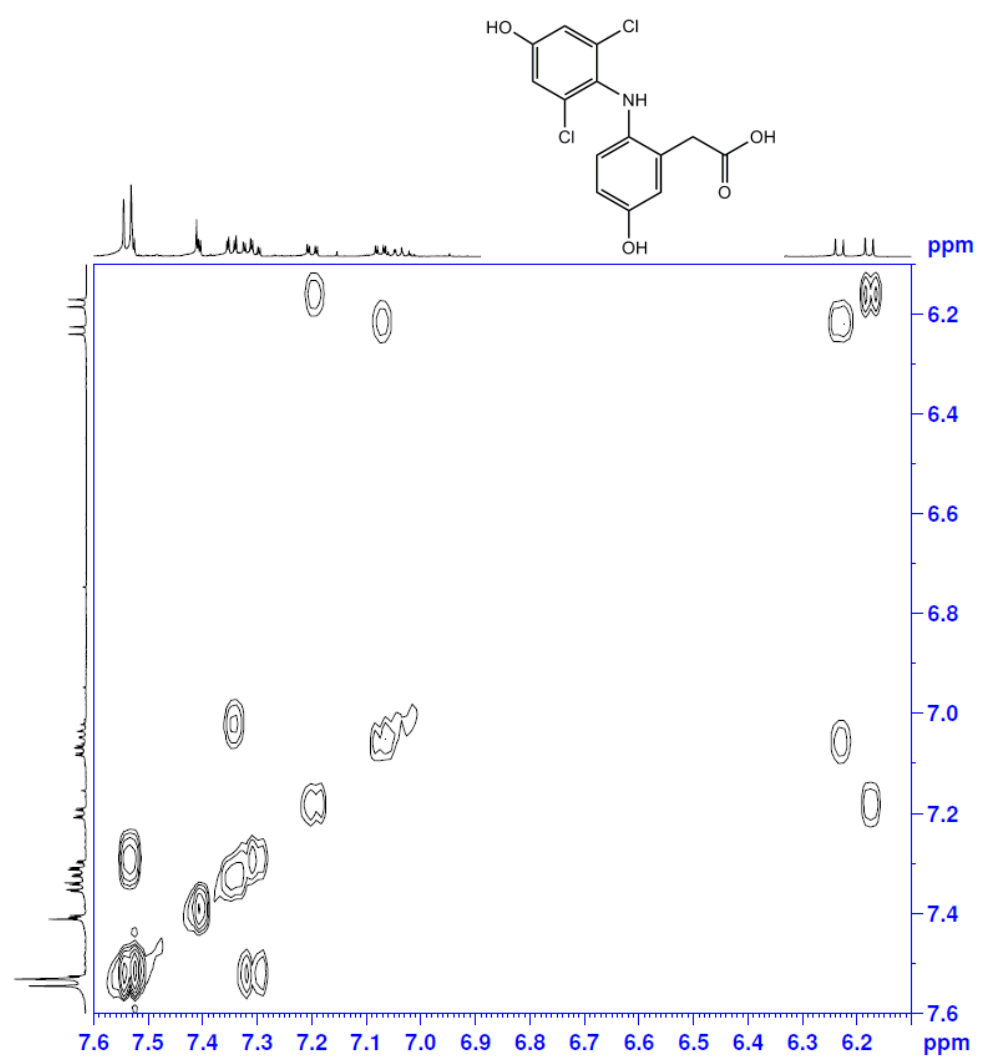


Fig. S8. COSY of naproxen

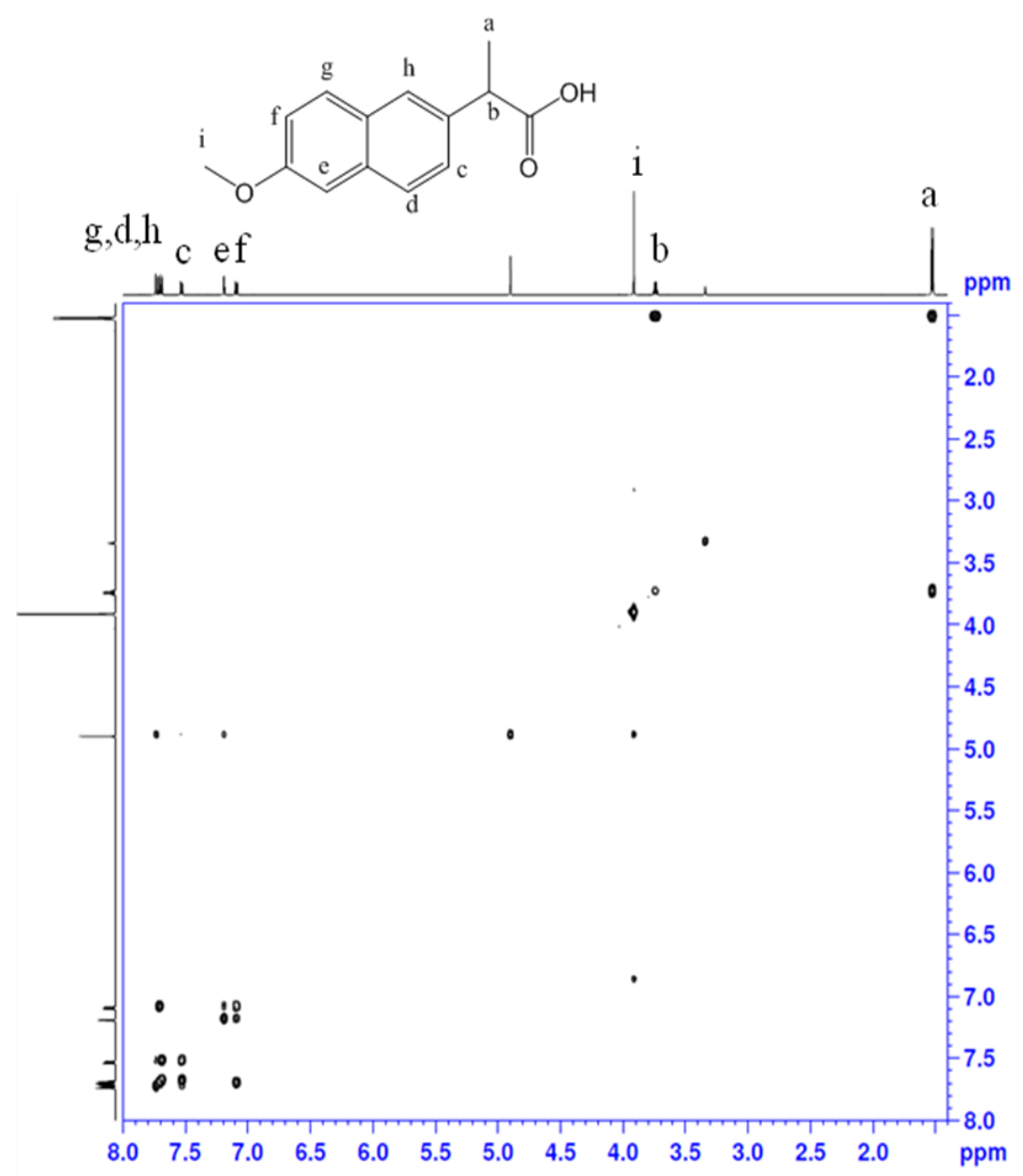


Fig. S9. NOESY of naproxen

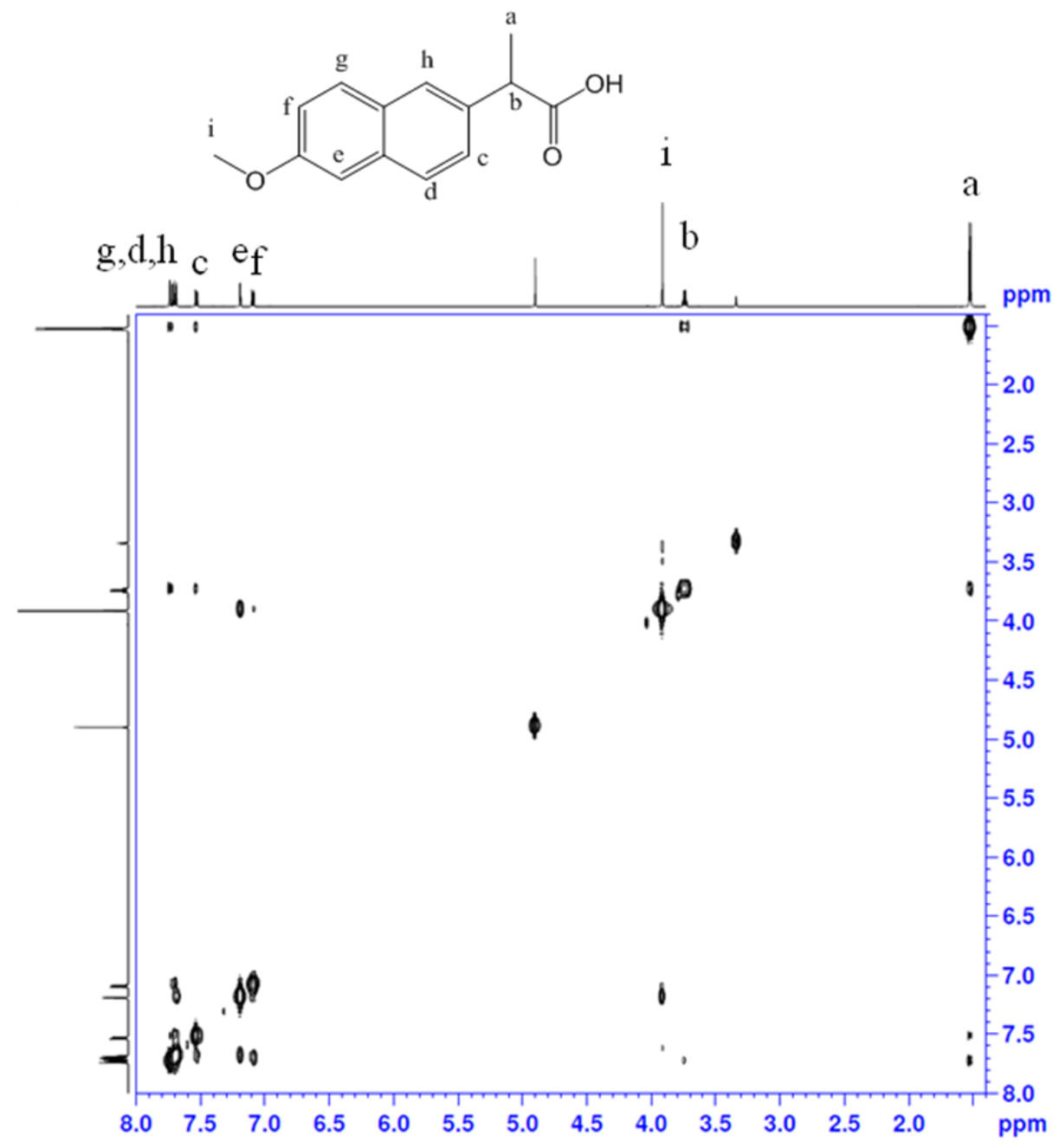


Fig. S10. COSY of authentic desmethylnaproxen purchased from Sigma Aldrich

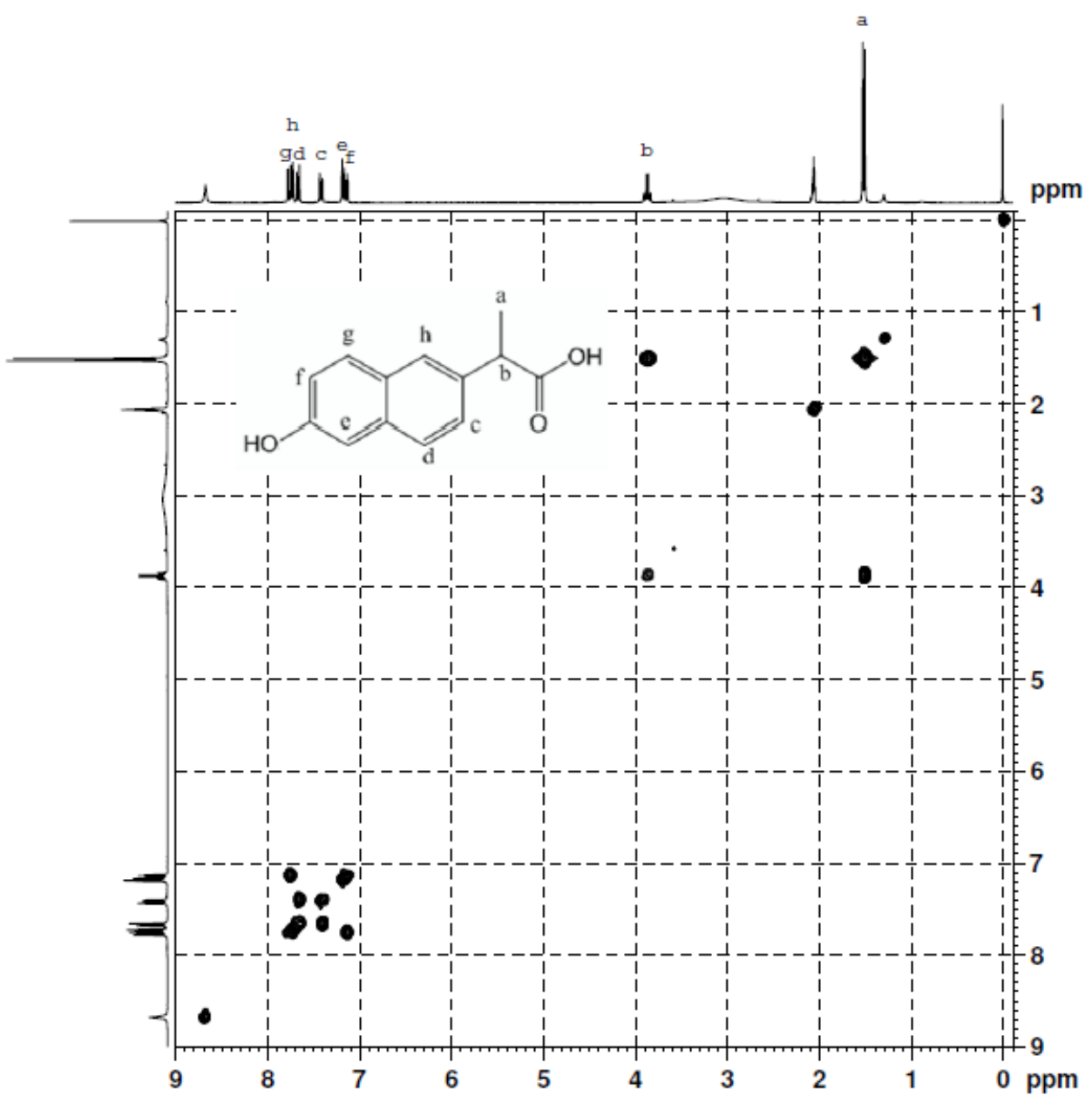


Fig. S11. NOESY of authentic desmethylnaproxen purchased from Sigma Aldrich

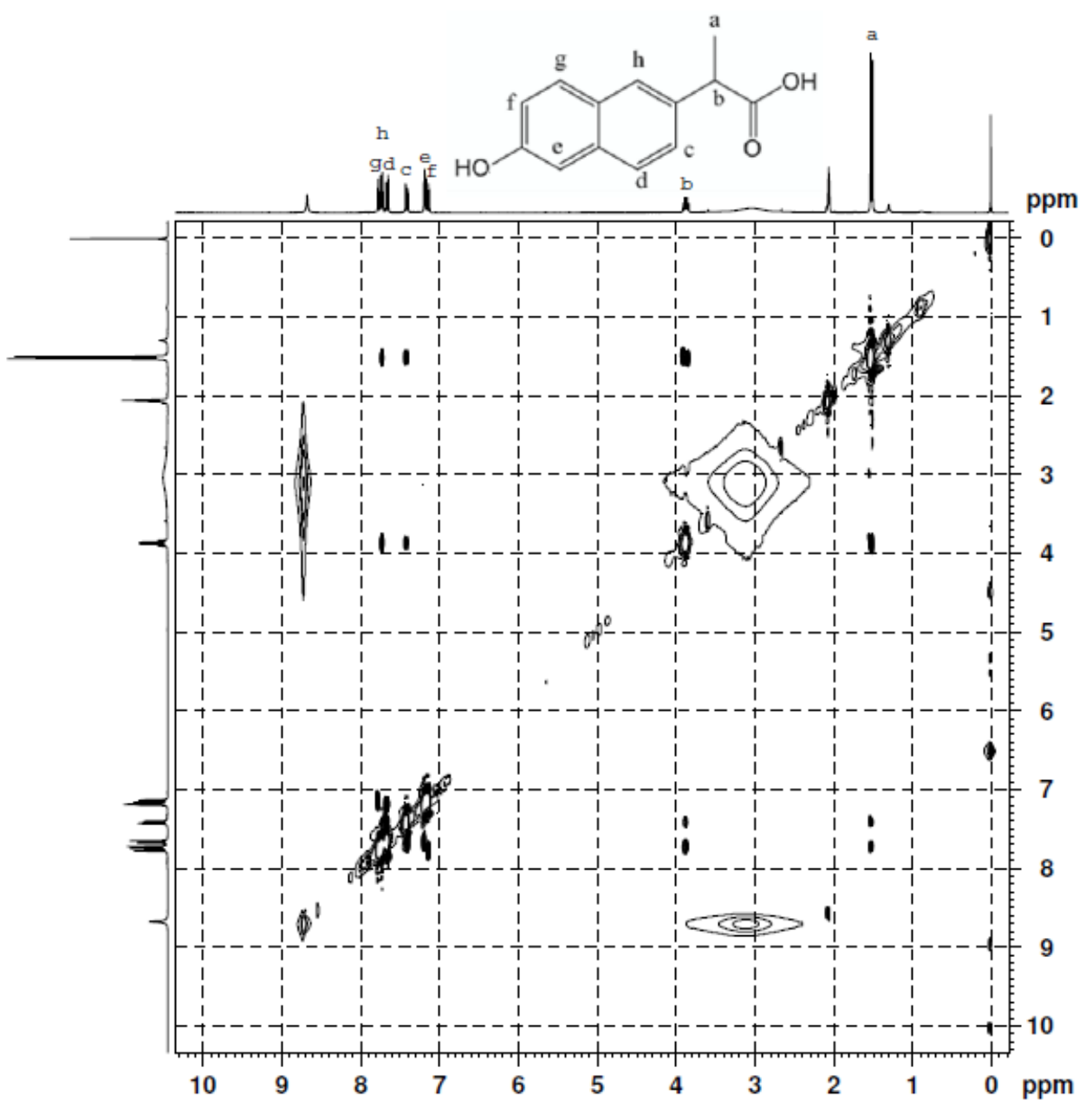


Fig. S12. Dependence of $E C_{50}$ value on degradation efficiency of diclofenac $(A)$ and naproxen (B). (Green algae $\left(\mathrm{OD}_{\mathrm{t} 0}=0.05\right)$ and final substrate concentration range $0.15-0.36 \mathrm{mg} \cdot \mathrm{L}^{-1}$ )
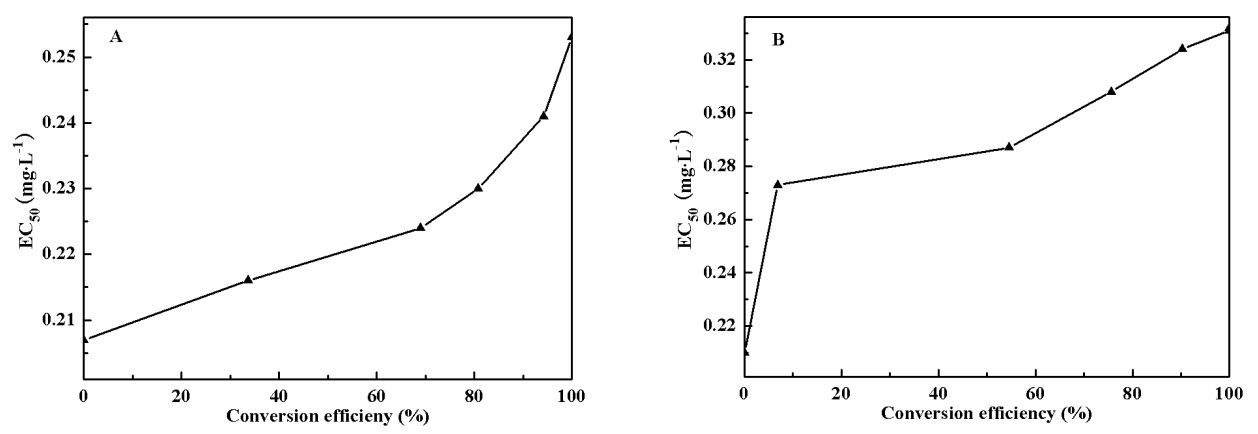


\section{REFERENCE}

1. W.H.O, Pharmaceuticals in drinking-water, W.L.C.-i.-P. Data, Editor. 2012.

2. Conesa, A., et al., Expression of the Caldariomyces fumago chloroperoxidase in Aspergillus niger and characterization of the recombinant enzyme. Journal of Biological Chemistry, 2001. 276(21): $p$. 17635-17640.

3. Holm, J.V., et al., Occurrence and distribution of pharmaceutical organic compounds in the groundwater doungradient of a landfill (Grindsted, Denmark). Environmental Science \& Technology, 1995. 29(5): p. 1415.

4. Ternes, T.A., Occurrence of drugs in German sewage treatment plants and rivers. Water research (Oxford), 1998. 32(11): p. 3245-3260.

5. Triebskorna, R., et al., Toxic effects of the non-steroidal anti-inflammatory drug diclofenac. Aquatic Toxicology, 2004. 68(2): p. 151-166.

6. Parrott, J.L. and B.R. Blunt, Life-cycle exposure of fathead minnows (Pimephales promelas) to an ethinylestradiol concentration below $1 \mathrm{ng} / \mathrm{L}$ reduces egg fertilization success and demasculinizes males.

Environmental Toxicology, 2004. 20(2): p. 131-141.

7. Fent, K., A.A. Weston, and D. Caminada, Ecotoxicology of human pharmaceuticals. Aquatic Toxicology, 2005. 76(2): p. 122-159.

8. Ou, D., et al., Contamination of sulfonamide antibiotics and sulfamethazine-resistant bacteria in the dounstream and estuarine areas of Jiulong River in Southeast China. Environmental Science and Pollution Research International, 2015. 22(16): p. 12104-12113.

9. Baquero, F., J.L. Martinez, and R. Canton, Antibiotics and antibiotic resistance in water environments. Current Opinion in Biotechnology, 2008. 19(3): p. 260-265. 
10. Jones, O.A., et al., Pharmaceuticals: a threat to drinking water? Trends in Biotechnology, 2005. 23(4): p. 163-167.

11. Benotti, M.J., et al., Pharmaceuticals and endocrine disrupting compounds in U.S. drinking water. Environmental Science \& Technology, 2009. 43(3): p. 597-603.

12. Reddersena, K., T. Heberera, and U. Dünnbierb, Identification and significance of phenazone drugs and their metabolites in ground-and drinking water. Chemosphere, 2002. 49(6): p. 539-544.

13. Vestel, J., et al., Use of acute and chronic ecotoxicity data in environmental risk assessment of pharmaceuticals Ecotoxicity data and environmental risk assessment. Environmental Toxicology and Chemistry, 2016. 35(5): p. 1201-1212.

14. Ziylan, A. and N.H. Ince, The occurrence and fate of anti-inflammatory and analgesic pharmaceuticals in sewage and fresh water: Treatability by conventional and non-conventional processes. Journal of Hazardous Materials, 2011. 187(1-3): p. 24-36.

15. Ternes, T.A., Occurrence of drugs in German sewage treatment plants and rivers. Water Research, 1998. 32(11): p. 3245-3260.

16. Kasprzyk-Hordern, B., The removal of pharmaceuticals, personal care products, endocrine disruptors and illicitdrugs during wastewater treatment and its impact on the quality of receiving waters. Water Research 2008. 43(2): p. 363-380.

17. Lin, A.Y.-C., J.H.-F. Hsueh, and P.K.A. Hong, Removal of antineoplastic drugs cyclophosphamide, ifosfamide, and 5-fluorouracil and a vasodilator drug pentoxifylline from wastewaters by ozonation. Environmental Science and Pollution Research International, 2015. 22(1): p. 508-515.

18. Morris, D.R. and L.P. Hager, Chloroperixdase I.Isolation and properties of the crystalline gylcoprotein. The Journal of Biological Chemistry, 1966. 241(8). 
19. Conesa, A., et al., C-terminal propeptide of the Caldariomyces fumago chloroperoxidase: an intramolecularchaperone? FEBS Lett., 2001. 503(2,3): p. 117-120.

20. Sundaramoorthy, M., J. Terner, and T.L. Poulos, The crystal structure of chloroperoxidase: a heme peroxidase-cytochrome $P 450$ functional hybrid. Structure, 1995. 3(12): p. 1367-1378.

21. Wang, X., et al., Two-dimensional NMR study of the heme active site structure of chloroperoxidase. The Journal of Biological Chemistry, 2003. 278(10): p. 7765-74.

22. Kuhnel, K., et al., Crystal structures of chloroperoxidase with its bound substrates and complexed with formate, acetate, and nitrate. The Journal of Biological Chemistry, 2006. 281(33): p. 23990-8.

23. $\mathrm{Yi}, \mathrm{X}$., et al., Examining the Role of Glutamic Acid 183 in Chloroperoxidase Catalysis. Journal of Biological Chemistry, 2003. 278(16): p. 13855-13859.

24. Manoj, K.M. and L.P. Hager, Chloroperoxidase, a Janus Enzyme. Biochemistry, 2008. 47(9): p. 2997-3003.

25. Hager, L.P., et al., Chloroperoxidase. IX. The structure of compound I. Journal of the American Chemical Society, 1972. 94(12): p. 4364-4366.

26. Palcic, M.M., et al., Spectrum of Chloroperoxidase Compound I. Biochemical and biophysical research communications, 1980. 94(4): p. 1123-1127.

27. Nakajima, R., I. Yamazaki, and B.W. Griffin, Spectra of chloroperoxidase Compounds II and III. Biochemical and Biophysical Research Communications, 1985. 128(1): p. 1-6.

28. Zhang, R., et al., Spectroscopic and QM/MM investigations of Chloroperoxidase catalyzed degradation of orange $G$. Archives of Biochemistry and Biophysics, 2016. 596: p. 1-9. 
29. Colonnaa, S., et al., Recent biotechnological developments in the use of peroxidases. Trends in Biotechnology 1999. 17(4): p. 163-168.

30. Hofrichter, M. and R. Ullrich, Heme-thiolate haloperoxidases: versatile biocatalysts with biotechnological and environmental significance. Applied Microbiology and Biotechnology, 2006. 71(3): p. 276-288.

31. Manoj, K.M., Chlorinations catalyzed by chloroperoxidase occur via diffusible intermediate(s) and the reaction components play multiple roles in the overall process. Biochimica et Biophysica Acta, 2006. 1764(8): p. 1325-1339.

32. Libby, R.D., et al., Defining the involvement of $\mathrm{HOCl}$ or $\mathrm{Cl} 2$ as enzymegenerated intermediates in chloroperoxidase-catalyzed reactions. Journal of Biological Chemistry, 1992. 267(3): p. 1769-75.

33. Osborne, R.L., et al., Caldariomyces fumago chloroperoxidase catalyzes the oxidative dehalogentation of chlorophenols by a mechanism involving two one-electron steps. Journal of the American Chemical Society, 2007. 129(48): p. 14838-14839.

34. Murphy, C.D., Fluorophenol oxidation by a fungal chloroperoxidase. Biotechnology letters, 2007. 29(1): p. 45-49.

35. Potter, D.W., D.W. Miller, and J.A. Hinson, Identification of acetaminophen polymerization products catalyzed by horseradish peroxidase. The Journal of Biological Chemistry, 1985. 260(22): p. 12174-80.

36. Gallati, H., Horseradish peroxidase: a study of the kinetics and the determination of optimal reaction conditions, using hydrogen peroxide and 2,2'-azinobis 3-ethylbenzthiazoline-6-sulfonic acid (ABTS) as substrates (author's trans/). Journal of Clinical Chemistry and Clinical Biochemistry, 1979. 17(1): p. 1-7.

37. Hager, L.P., et al., Chloroperoxidase. II. Utilization of halogen anions. The Journal of Biological Chemistry, 1965. 241(8): p. 1769-1777. 
38. Libby, R.D., et al., Chloroperoxidase halogenation reactions. Chemical versus enzymic halogenating intermediates. The Journal of Biological Chemistry, 1982. 257(9): p. 5030.

39. Vázquez-Duhalta, R., et al., Biocatalytic chlorination of aromatic hydrocarbons by chloroperoxidase of Caldariomyces fumago. Phytochemistry, 2001. 58(6): p. 929-933.

40. Zaks, A. and D.R. Dodds, Chloroperoxidase-catalyzed asymmetric oxidations: substrate specificity and mechanistic study. Journal of the American Chemical Society, 1995. 117(42): p. 10419.

41. Kiljunen, E. and L.T. Kanerva, Novel applications of chloroperoxidase: enantioselective oxidation of racemic epoxyalcohols. Tetrahedron: Asymmetry, 1999. 10(18): p. 3529-3535.

42. Zhang, J., et al., Efficient decolorization/degradation of aqueous azo dyes using buffered $\mathrm{H}_{2} \mathrm{O}_{2}$ oxidation catalyzed by a dosage below ppm level of chloroperoxidase. Chemical Engineering Journal, 2012. 191: p. 236.

43. Zhang, X., et al., Combination of enzymatic degradation by chloroperoxidase with activated sludge treatment to remove sulfamethoxazole: performance, and eco-toxicity assessment. Journal of Chemical Technology \& Biotechnology, 2016: p. n/a-n/a.

44. Wu, S., L. Zhang, and J. Chen, Paracetamol in the environment and its degradation by microorganisms. Applied microbiology and biotechnology, 2012. 96(4): p. 875-884.

45. Larsen, F.S. and J. Wendon, Understanding paracetamol-induced liver failure. Intensive care medicine, 2014. 40(6): p. 888-890.

46. Frama, M.S. and K. Belitzb, Occurrence and concentrations of pharmaceutical compounds in groundwater used for public drinking-water supply in California. The Science of the total environment, 2011.409(18): p. 3409-3417. 
47. Al Qarni, H., et al., Investigating the removal of some pharmaceutical compounds in hospital wastewater treatment plants operating in Saudi Arabia. Environmental science and pollution research international, 2016: p. 1-12.

48. Karaman, R., et al., Paracetamol biodegradation by activated sludge and photocatalysis and its removal by a micelle-clay complex, activated charcoal, and reverse osmosis membranes. Environmental technology, 2016: p. 1-14.

49. Bessems, J.G., et al., 3,5-Disubstituted analogues of paracetamol. Synthesis, analgesic activity and cytotoxicity. Chemico-Biological Interactions, 1995. 98(3): p. 237-50.

50. Xianwen Yi, M.M., Kelath M. Manoj, Xiaotang Wang, and Lowell P. Hager, Replacement of the proximal heme thiolate ligand in chloroperoxidase with a histidine residue. Proceedings of the National Academy of Sciences PNAS, 1999. 96(22).

51. Chiron, S., E. Gomez, and H. Fenetł, Nitration processes of acetaminophen in nitrifying activated sludge. Environmental Science \& Technology, 2010. 44(1): p. 284.

52. Tudur Smith, C., Carbamazepine versus phenytoin monotherapy for epilepsy. Cochrane database of systematic reviews, 2002(2): $p$. CD001911.

53. Donner, E., et al., Ecotoxicity of carbamazepine and its UV photolysis transformation products. The Science of the total environment, 2013. 443: p. $870-876$.

54. Parolini, M., et al., Cytotoxicity assessment of four pharmaceutical compounds on the zebra mussel (Dreissena polymorpha) haemocytes, gill and digestive gland primary cell cultures. Chemosphere (Oxford), 2011. 84(1): p. 91-100.

55. Andrade-Mena, C.E. and C.E. Andrade - mena, Effects of Carbamazepine on Murine Humoral and Cellular Immune Responses. Epilepsia (Copenhagen). 35(1): p. 205-208. 
56. Singh, G., P.H.i. Driever, and J.W. Sander1, Cancer risk in people with epilepsy: the role of antiepileptic drugs. Brain (London, England : 1878), 2005. 128(1): p. 7-17.

57. Xiong, J.-Q., Biodegradation of carbamazepine using freshwater microalgae Chlamydomonas mexicana and Scenedesmus obliquus and the determination of its metabolic fate. Bioresource technology, 2016. 205: p. $183-190$.

58. Ernest Marco-Urreaa, et al., Ability of white-rot fungi to remove selected pharmaceuticals and identification of degradation products of ibuprofen by Trametes versicolor. Chemosphere (Oxford), 2008. 74(6): p. 765-772.

59. Achilleos, A., et al., UV-A and solar photodegradation of ibuprofen and carbamazepine catalyzed by $\mathrm{TiO}_{2}$. Separation science and technology, 2010. 45(11): p. 1564-1570.

60. Thomas, J.A., D.R. Morris, and L.P. Hager, Chloroperoxidase. VII. Classical peroxidatic, catalatic, and halogenating forms of the enzyme. $\mathrm{J}$ Biol Chem, 1970. 245(12): p. 3129-34.

61. Manoj, K.M., et al., Explaining the atypical reaction profiles of heme enzymes with a novel mechanistic hypothesis and kinetic treatment. PloS one, 2010.5(5): p. e10601.

62. Kosjek, T., et al., Fate of carbamazepine during water treatment. Environmental science \& technology, 2009. 43(16): p. 6256-6261.

63. Kruglova, a., et al., Biodegradation of ibuprofen, diclofenac and carbamazepine in nitrifying activated sludge under $12^{\circ} \mathrm{C}$ temperature conditions. The Science of the total environment, 2014. 499: p. 394-401.

64. Monsalvo, V.M., et al., Application of Fenton-like oxidation as pretreatment for carbamazepine biodegradation. Chemical engineering journal (Lausanne, Switzerland : 1996), 2014. 264: p. 856-862. 
65. Mcdoqell, D., et al., Ozonation of Carbamazepine in Drinking Water: Identification and Kinetic Study of Major Oxidation Products.

Environmental science \& technology, 2005. 39(20): p. 8014-8022.

66. Golan-Rozen, et al., Transformation Pathways of the Recalcitrant Pharmaceutical Compound Carbamazepine by the White-Rot Fungus : Effects of Growth Conditions. Environmental science \& technology, 2015. 49(20): p. 12351-12362.

67. Ferguson, L.R. and W.A. Denny, The genetic toxicology of acridines. Mutation research, 1991. 258(2): p. 123-160.

68. Alastuey, A., D. Barceló, and SpringerLink, Emerging organic contaminants and human health. Handbook of environmental chemistry ; v. 20. 2012, Heidelberg ; New York: Springer.

69. Verlicchia, P., et al., Hospital effluents as a source of emerging pollutants: An overview of micropollutants and sustainable treatment options. Journal of hydrology (Amsterdam), 2010. 389(3-4): p. 416-428.

70. Haller, M.Y., et al., Quantification of veterinary antibiotics (sulfonamides and trimethoprim) in animal manure by liquid chromatography-mass spectrometry. Journal of chromatography. A, 2002. 952(1-2): p. 111-120.

71. Lee, T.A., A beginner's guide to mass spectral interpretation. 1998, Chichester ; New York: Wiley.

72. García-Galán, M.J., et al., Biodegradation of sulfamethazine by Trametes versicolor: Removal from sewage sludge and identification of intermediate products by UPLC-QqTOF-MS. The Science of the total environment, 2010. 409(24): p. 5505-5512.

73. Neafsey, K., X. Zeng, and A.T. Lemley, Degradation of sulfonamides inaqueous solution by membrane anodic fenton treatment. Journal of agricultural and food chemistry, 2010. 58(2): p. 1068-1076.

74. Saidi, l., et al., Flow electrolysis on high surface electrode for biodegradability enhancement of sulfamethazine solutions. Journal of 
electroanalytical chemistry (Lausanne, Switzerland), 2013. 707: p. 122128.

75. Carstens, K.L., et al., Sorption and photodegradation processes govern distribution and fate of sulfamethazine in freshwater-sediment microcosms. Environmental science \& technology, 2013. 47(19): p. 10877-10883.

76. Unold, M., et al., Transport and transformation of sulfadiazine in soil columns packed with a silty loam and a loamy sand. Journal of contaminant hydrology, 2009.103(1-2): p. 38-47.

77. Schwarz, J., M.-O. Austc, and S. Thiele-Bruhnc, Metabolites from fungal laccase-catalysed transformation of sulfonamides. Chemosphere (Oxford), 2010. 81(11): p. 1469-1476.

78. Gao, J., et al., Transformation of sulfamethazine by manganese oxide in aqueous solution. Environmental science \& technology, 2012. 46(5): p. 2642-2651.

79. Gaoa, Y.-q., et al., Ultraviolet (UV) light-activated persulfate oxidation of sulfamethazine in water. Chemical engineering journal (Lausanne, Switzerland : 1996), 2012. 195-196: p. 248-253.

80. Fana, Y., et al., Kinetic and mechanistic investigations of the degradation of sulfamethazine in heat-activated persulfate oxidation process. Journal of hazardous materials, 2015. 300: p. 39-47.

81. Fukahori, S. and T. Fujiwara, Photocatalytic decomposition behavior and reaction pathway of sulfamethazine antibiotic using TiO2. Journal of environmental management, 2015. 157: p. 103-110.

82. Ramakrishnan, K., et al., Stereoselectivity of chloroperoxidase-dependent halogenation. Biochemistry (Easton), 1983. 22(13): p. 3271-3277.

83. Melton, T.C. and S.D. Brown, The Fate of Sulfamethazine in SodiumHypochlorite-Treated Drinking Water: Monitoring by LC-MS. International Journal of Medicinal Chemistry (Online), 2012. 68(8): p. 1-6. 
84. Hutner, S.H., et al., Some Approaches to the Study of the Role of Metals in the Metabolism of Microorganisms. Proceedings of the American Philosophical Society, 1950. 94(2): p. 152-170. 

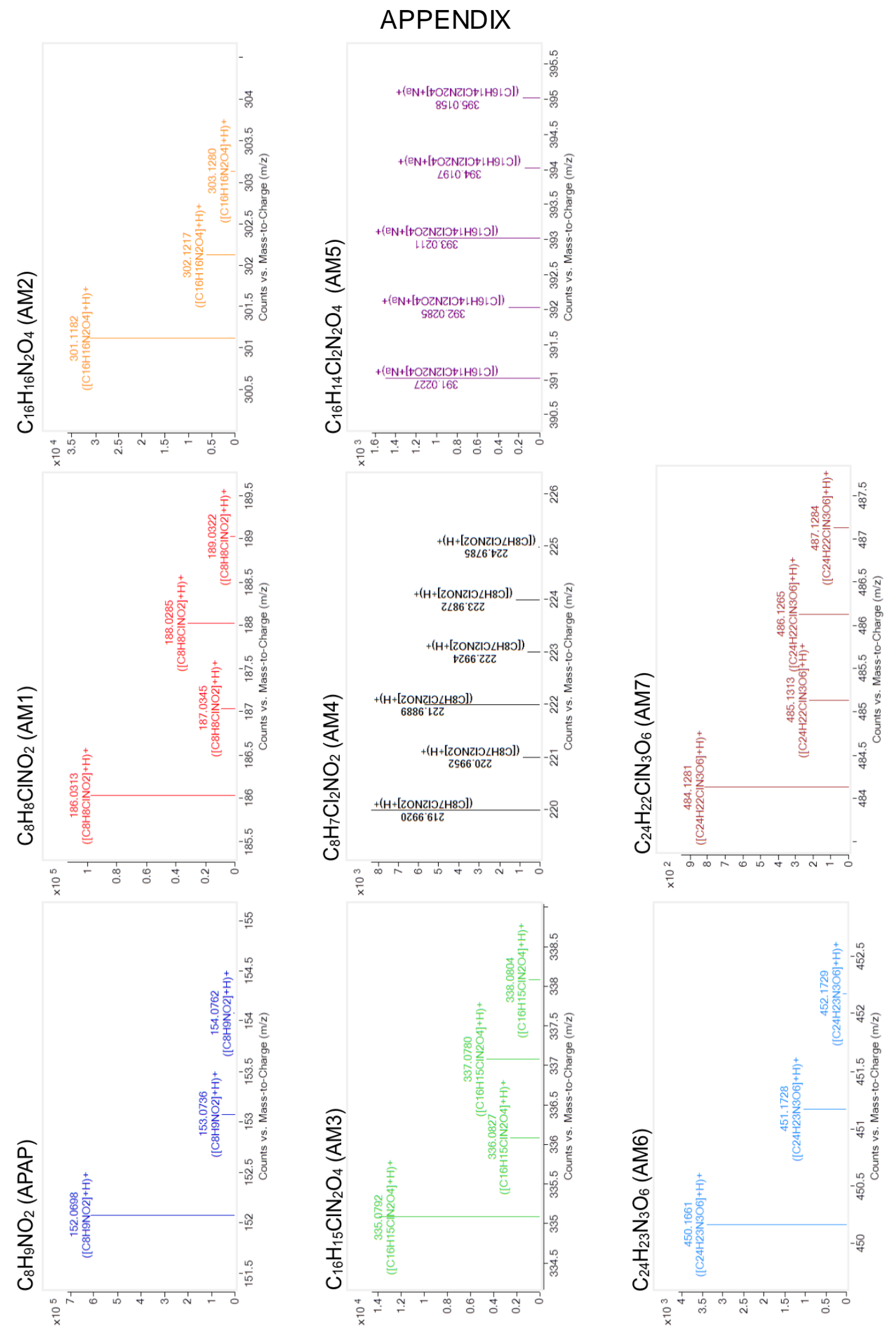

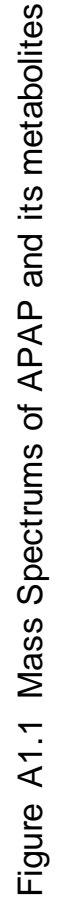


$\mathrm{C}_{15} \mathrm{H}_{12} \mathrm{~N}_{2} \mathrm{O}$ (CBZ)

x10 ${ }^{6}$ Cpd 1: C15 H12 N2 O: + FBF Spectrum (rt: 5.868, 5.962-5.984 min)...

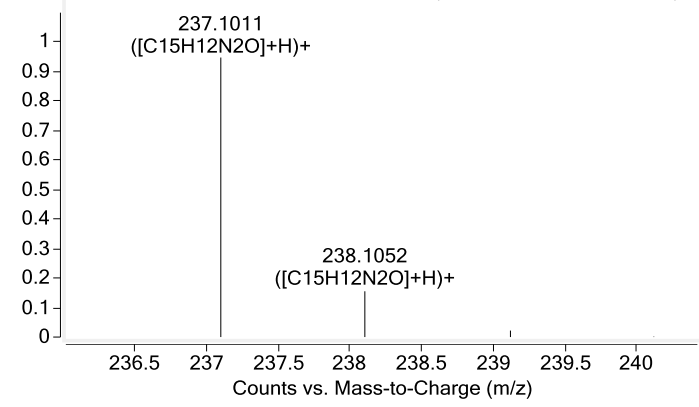

$\mathrm{C}_{15} \mathrm{H}_{14} \mathrm{~N}_{2} \mathrm{O}_{3} \quad(\mathrm{CM} 2)$

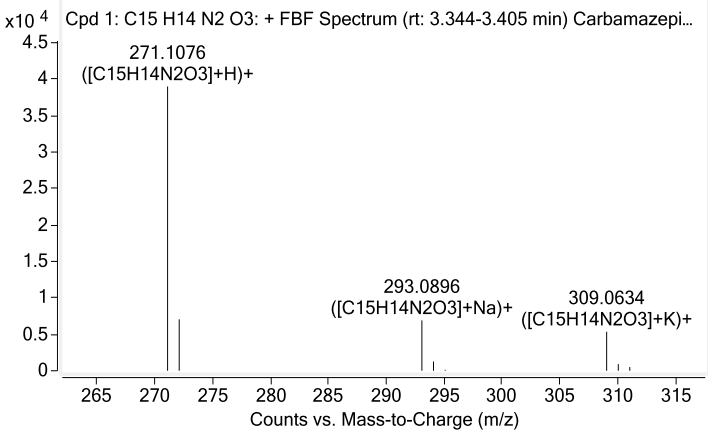

\section{$\mathrm{C}_{14} \mathrm{H}_{9} \mathrm{NO} \quad(\mathrm{CM} 4)$}

x10 5 Cpd 1: C14 H9 N O: + FBF Spectrum (rt: 6.665-6.821 min) Carbamazepine_...

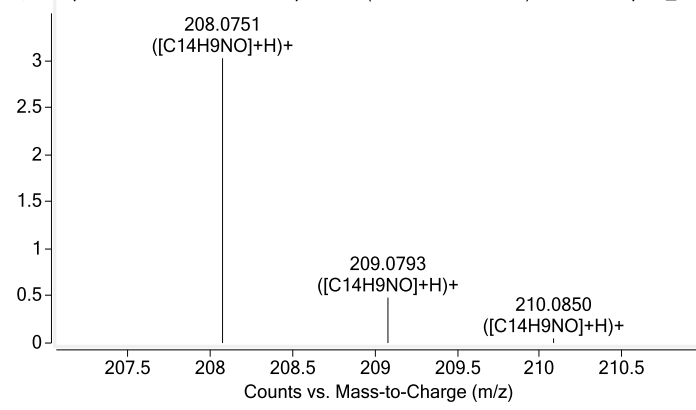

$\mathrm{C}_{13} \mathrm{H}_{9} \mathrm{NO} \quad(\mathrm{CM} 6)$

x10 5 Cpd 1: C13 H9 N O: + FBF Spectrum (rt: 5.157-5.229 min) Carbamazepine_...

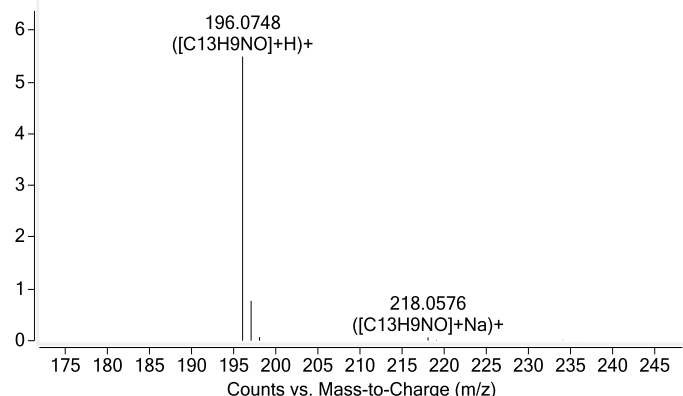

$\mathrm{C}_{15} \mathrm{H}_{12} \mathrm{~N}_{2} \mathrm{O}_{2}$ (CM1)

x10 4 Cpd 1: C15 H12 N2 O2: + FBF Spectrum (rt: 4.292-4.403 min) Carbamazepi...

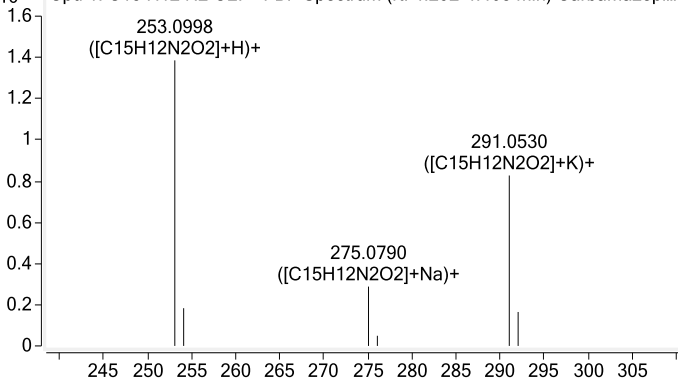

Counts vs. Mass-to-Charge $(\mathrm{m} / \mathrm{z})$

$\mathrm{C}_{14} \mathrm{H}_{11} \mathrm{NO}_{2}(\mathrm{CM} 3)$

x10 4 Cpd 1: C14 H11 N O2: + FBF Spectrum (rt: 2.817-2.878 min) Carbamazepin...

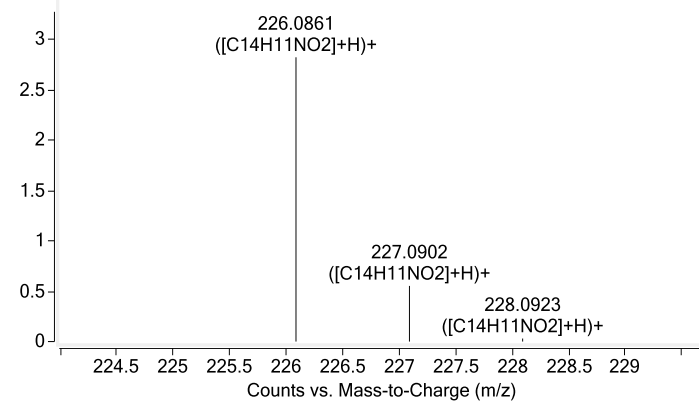

\section{$\mathrm{C}_{13} \mathrm{H}_{9} \mathrm{~N}(\mathrm{CM} 5)$}

x10 5 Cpd 1: C13 H9 N: + FBF Spectrum (rt: 3.942-4.015 min) Carbamazepine_1p...

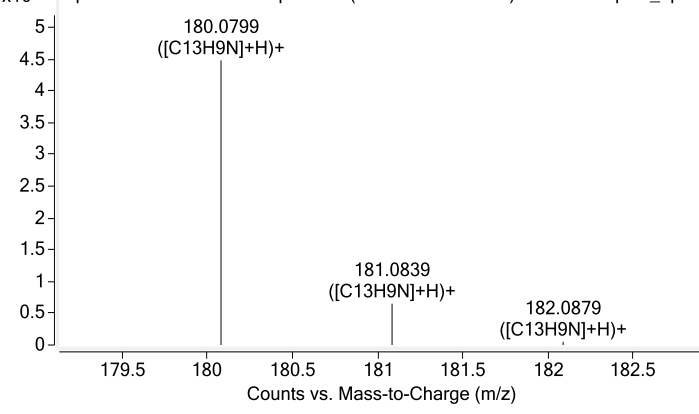

$\mathrm{C}_{15} \mathrm{H}_{13} \mathrm{NO}_{2}(\mathrm{CM} 7)$

x10 5 Cpd 1: C15 H13 N 02: + FBF Spectrum (rt: 3.771-3.832 min) Carbamazepin...

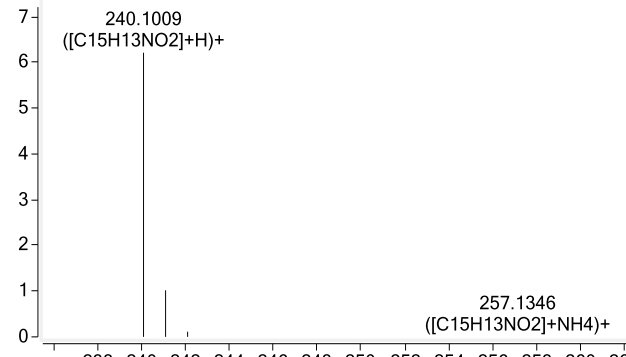

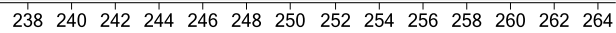
Counts vs. Mass-to-Charge (m/z)

Figure A1.2 The mass spectra of $\mathrm{CBZ}$ and its metabolites. 
$\mathrm{C}_{14} \mathrm{H}_{9} \mathrm{NO}_{2} \quad$ (CM8)

x10 5 Cpd 1: C14 H9 N O2: + FBF Spectrum (rt: 2.362-2.412 min) Carbamazepine...

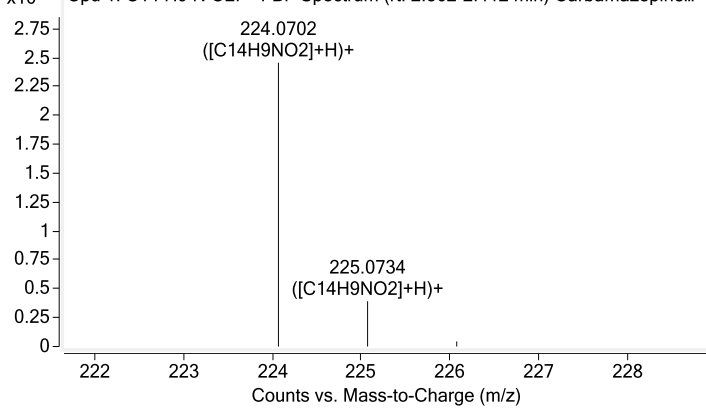

$\mathrm{C}_{16} \mathrm{H}_{14} \mathrm{~N}_{2} \mathrm{O}_{2} \quad(\mathrm{CM} 10)$

x10 5 Cpd 1: C16 H14 N2 O2: + FBF Spectrum (rt: 4.835-4.907 min) Carbamazepi...

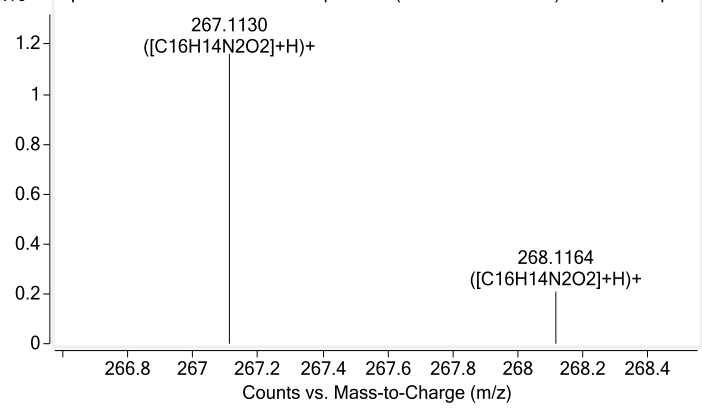

\section{$\mathrm{C}_{14} \mathrm{H}_{8} \mathrm{CINO} \quad(\mathrm{CM} 12)$}

x10 3 Cpd 1: C14 H8 Cl N O: + FBF Spectrum (rt: 7.924-8.030 min) Carbamazepin...

- 242.0367

$5-([\mathrm{C} 14 \mathrm{H} 8 \mathrm{CINO}]+\mathrm{H})+$

|

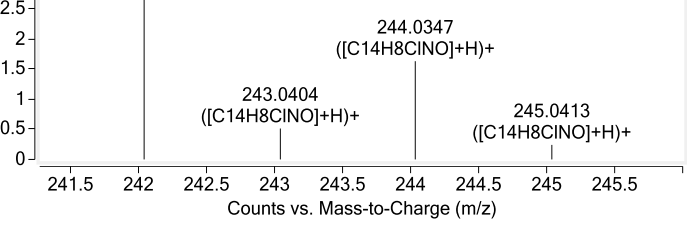

$\mathrm{C}_{13} \mathrm{H}_{8} \mathrm{CINO} \quad(\mathrm{CM} 14)$

x10 ${ }^{3}$ Cpd 1: C13 H8 Cl N: + FBF Spectrum (rt: 7.397-7.497 min) Carbamazepine_...

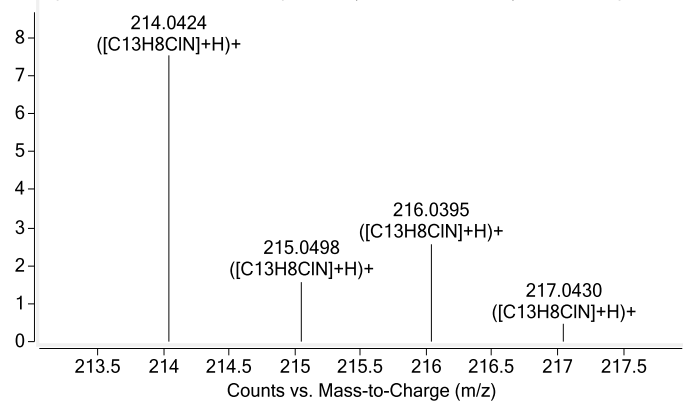

$\mathrm{C}_{15} \mathrm{H}_{11} \mathrm{NO}_{3}(\mathrm{CM} 9)$

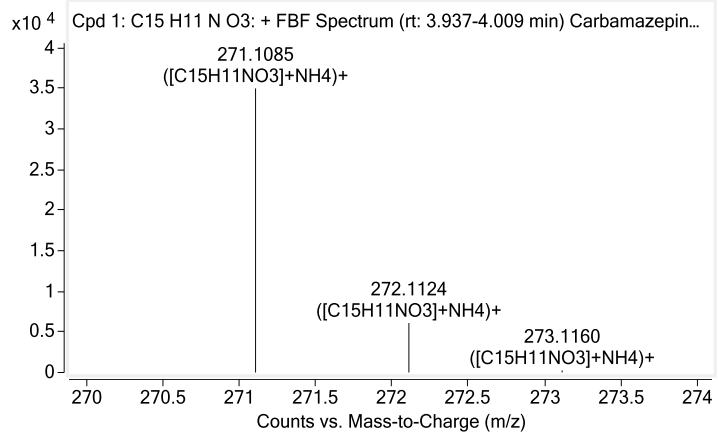

$\mathrm{C}_{15} \mathrm{H}_{12} \mathrm{ClNO}_{2}(\mathrm{CM} 11)$

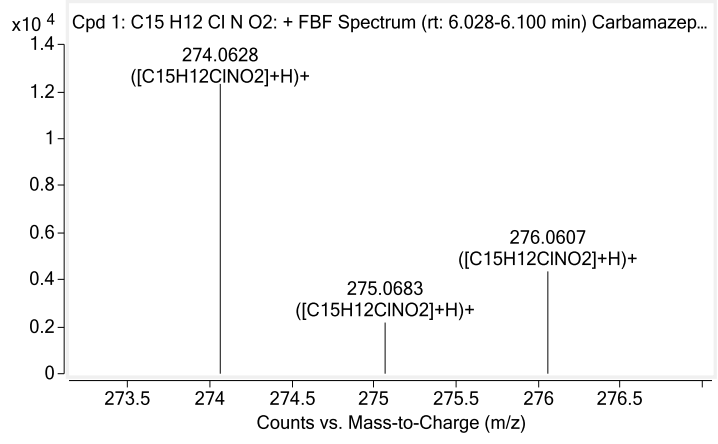

$\mathrm{C}_{13} \mathrm{H}_{8} \mathrm{CIN}(\mathrm{CM} 13)$

x10 4 Cpd 1: C13 H8 Cl N O: + FBF Spectrum (rt: 6.194-6.272 min) Carbamazepin...

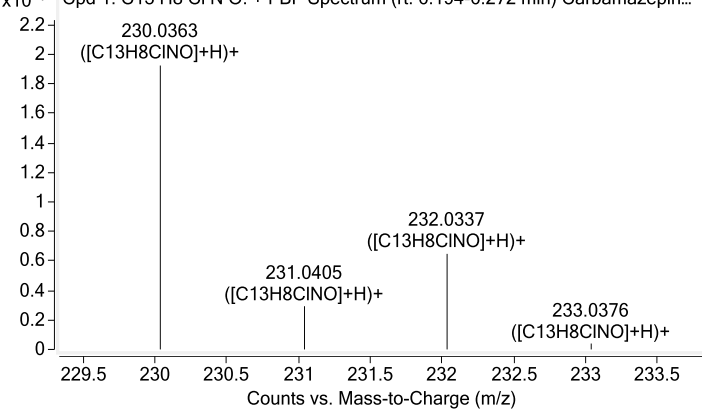

\section{$\mathrm{C}_{14} \mathrm{H}_{8} \mathrm{CINO}_{2}(\mathrm{CM} 15)$}

x10 3 Cpd 1: C14 H8 Cl N O2: + FBF Spectrum (rt: 3.088-3.149 min) Carbamazepi...

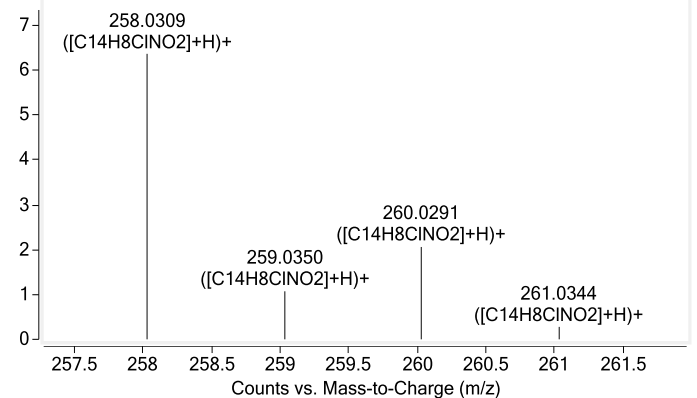

Figure A1.2 (cont.) The mass spectra of CBZ and its metabolites. 


\section{$\mathrm{C}_{12} \mathrm{H}_{14} \mathrm{~N}_{4} \mathrm{O}_{2} \mathrm{~S}(\mathrm{SMZ})$}

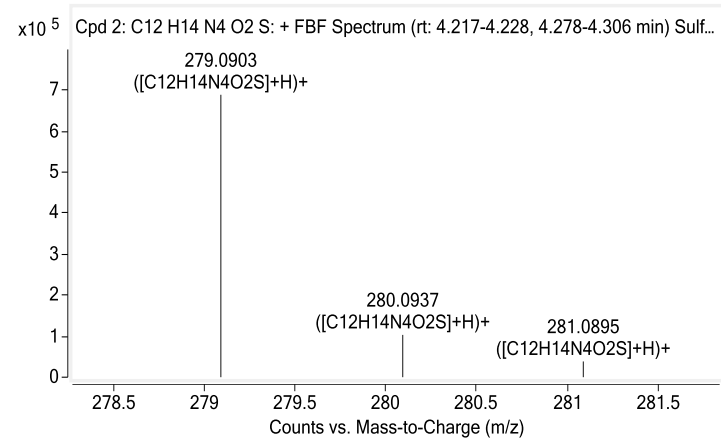

\section{$\mathrm{C}_{12} \mathrm{H}_{13} \mathrm{ClN}_{4}$ (SM2)}

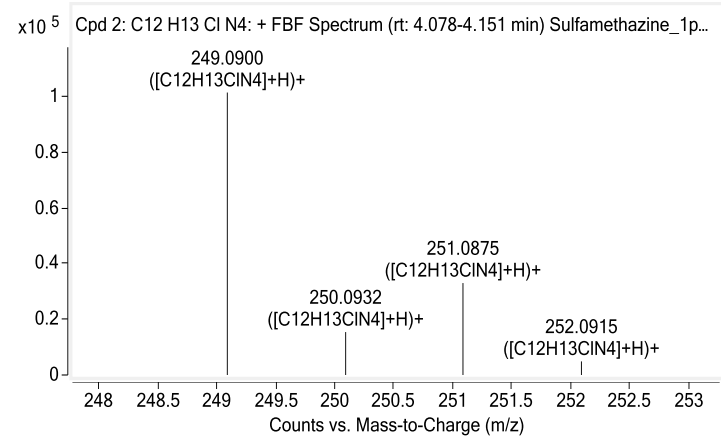

\section{$\mathrm{C}_{12} \mathrm{H}_{11} \mathrm{Cl}_{3} \mathrm{~N}_{4}(\mathrm{SM} 4)$}

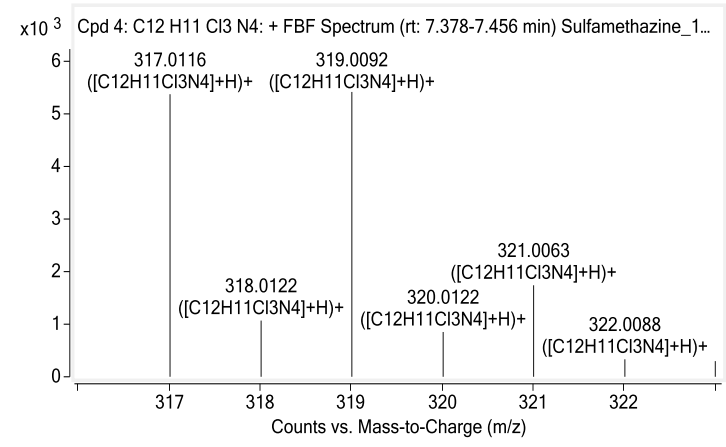

\section{$\mathrm{C}_{12} \mathrm{H}_{12} \mathrm{Cl}_{2} \mathrm{~N}_{4} \mathrm{O}_{2} \mathrm{~S}$ (SM6)}

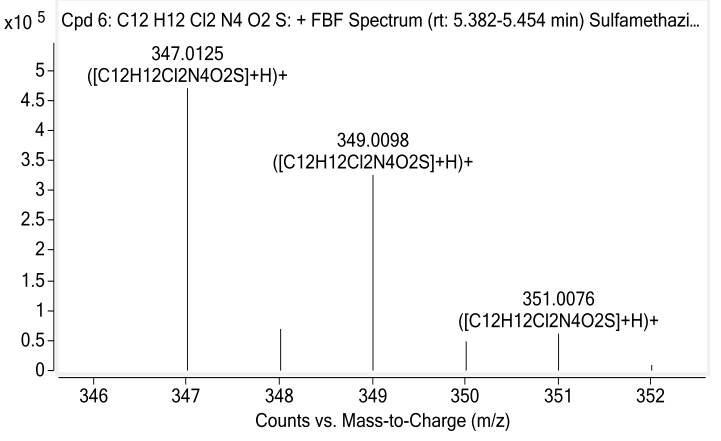

\section{$\mathrm{C}_{12} \mathrm{H}_{14} \mathrm{~N}_{4}$ (SM1)}

x10 5 Cpd 1: C12 H14 N4: + FBF Spectrum (rt: 3.191-3.263 min) Sulfamethazine_1ppm...

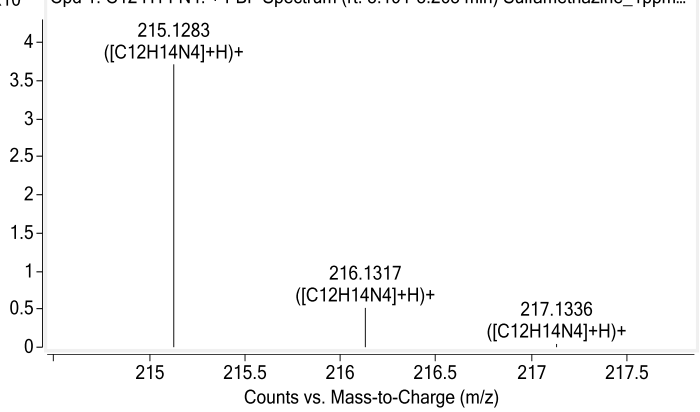

\section{$\mathrm{C}_{12} \mathrm{H}_{12} \mathrm{Cl}_{2} \mathrm{~N}_{4}$ (SM3)}

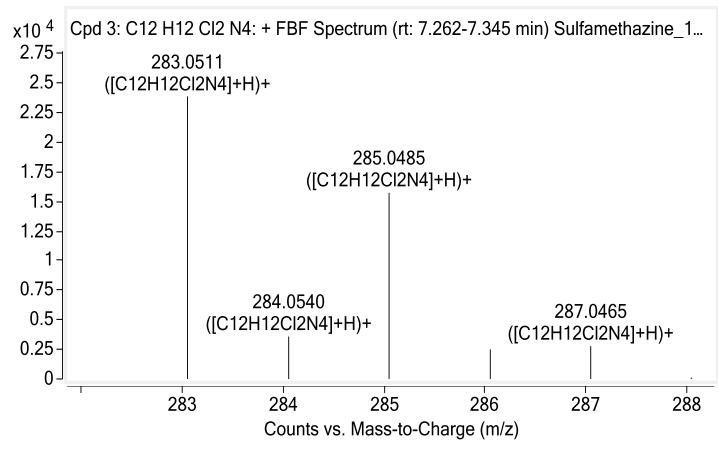

\section{$\mathrm{C}_{12} \mathrm{H}_{13} \mathrm{CIN}_{4} \mathrm{O}_{2} \mathrm{~S}$ (SM5)}

x10 ${ }^{3}$ Cpd 5: C12 H13 CI N4 O2 S: + FBF Spectrum (rt: 4.866-4.933 min) Sulfamethazin... $7-\quad \begin{gathered}313.0522 \\ \text { ([C12H13CIN4O2S }]\end{gathered}$

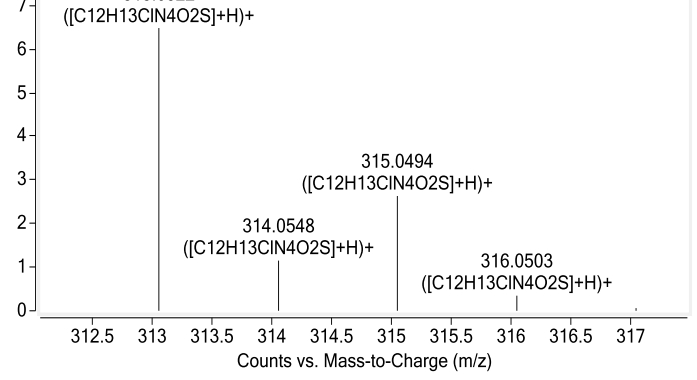

\section{$\mathrm{C}_{12} \mathrm{H}_{13} \mathrm{CIN}_{4} \mathrm{O}_{3} \mathrm{~S}$ (SM7)}

x10 ${ }^{3}$ Cpd 7: C12 H13 CI N4 O3 S: + FBF Spectrum (rt: 2.958-3.008 min) Sulfamethazin...

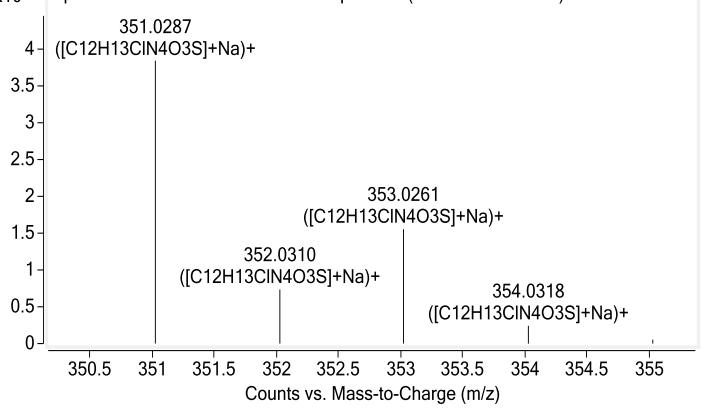

Figure A1.3 The mass spectra of SMZ and its metabolites. 


\section{$\mathrm{C}_{12} \mathrm{H}_{11} \mathrm{Cl}_{3} \mathrm{~N}_{4} \mathrm{O} 2 \mathrm{~S}$ (SM8)}

x10 ${ }^{3}$ Cpd 8: C12 H11 Cl3 N4 O2 S: + FBF Spectrum (rt: 7.245-7.317 min) Sulfamethazi...

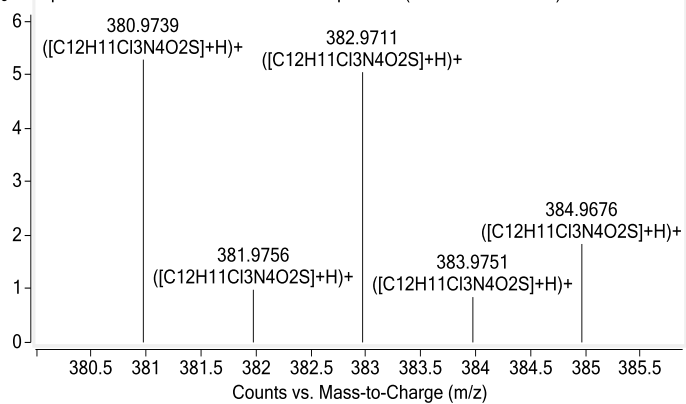

\section{$\mathrm{C}_{12} \mathrm{H}_{13} \mathrm{BrN}_{4} \mathrm{O}_{2} \mathrm{~S}(\mathrm{SM} 5-\mathrm{Br})$}

x10 ${ }^{3}$ Cpd 1: C12 H13 Br N4 O2 S: + FBF Spectrum (rt: 5.363-5.424 min) Sulfameth...

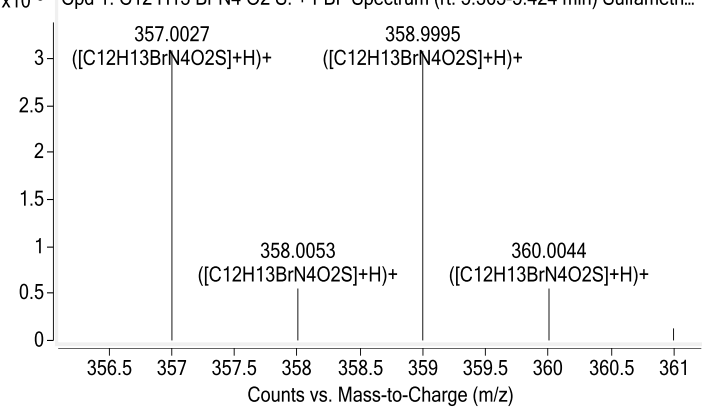

\section{$\mathrm{C}_{12} \mathrm{H}_{11} \mathrm{Br}_{3} \mathrm{~N}_{4} \mathrm{O}_{2} \mathrm{~S}$ (SM8-Br)}

x10 ${ }^{5}$ Cpd 1: C12 H11 Br3 N4 O2 S: + FBF Spectrum (rt: 8.225-8.230, 8.286-8.308...

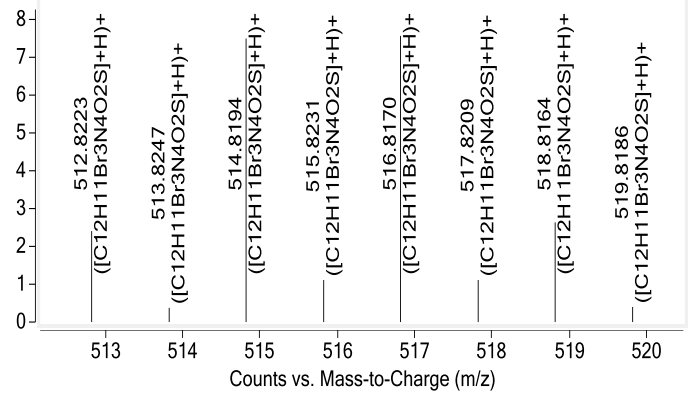

$\mathrm{C}_{12} \mathrm{H}_{14} \mathrm{~N}_{4} \mathrm{O}_{3} \mathrm{~S}$ (SM9)

$\times 10^{3}$ Cpd 1: C12 H14 N4 O3 S: + FBF Spectrum (rt: 1.003-1.048 min) Sulfamethazine t...

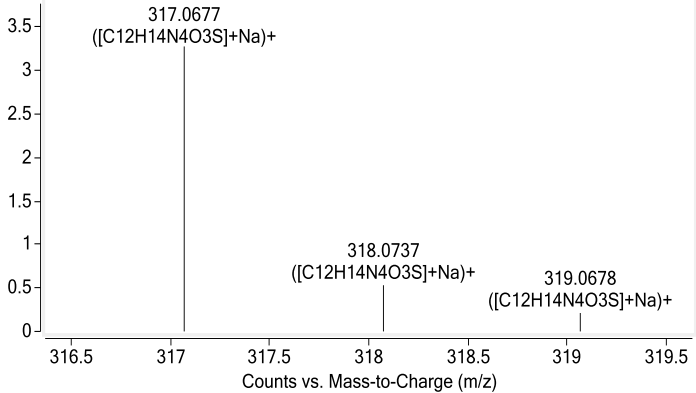

$\mathrm{C}_{12} \mathrm{H}_{12} \mathrm{Br}_{2} \mathrm{~N}_{4} \mathrm{O}_{2} \mathrm{~S}$ (SM6-Br)

x10 6 Cpd 1: C12 H12 Br2 N4 O2 S: + FBF Spectrum (rt: 6.067-6.073, 6.128-6.139

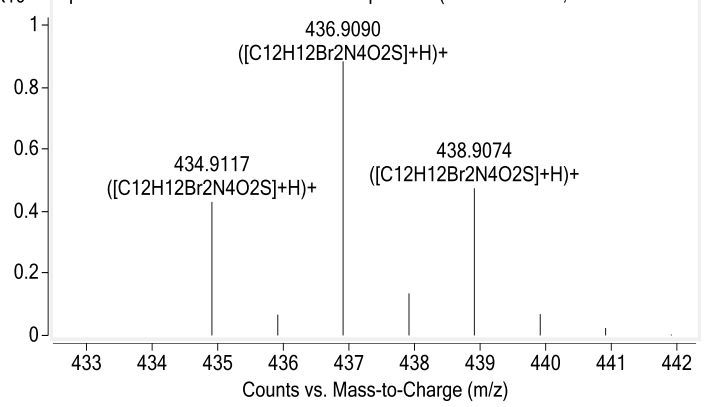

Figure A1.3 (cont.) The mass spectra of SMZ and its metabolites. 


\section{Optimizer Report}

\section{Instrument Information}

Project Name Amphetamines

Instrument Name Instrument 1

Instrument Model G6460A

$\begin{array}{llll}\text { Compound Name } & \text { Formula } & \text { Mass } & \text { Sample Position } \\ \text { Acetaminophen } & \text { C8H9NO2 } & 151.06 & \text { P1-A1 }\end{array}$

Method Name

D:IMassHunterIMethods $\mid$ OnLine SPEIFlexCubelFlexCube_Flow_Injection_analysis.m

$\begin{array}{llll}\text { Polarity Positive Ion Source AJSESI } & \text {. }\end{array}$

\begin{tabular}{|c|c|c|c|}
\hline Polatity & \multirow{2}{*}{ rositive } & \multicolumn{2}{|l|}{ ton source } \\
\hline Precursor Ion & & Fragmentor & \\
\hline 152.1 & & 108 & \\
\hline Product lon & Collision Energy & & Abundance \\
\hline 110 & 16 & & 1271629 \\
\hline 65.1 & 36 & & 522812 \\
\hline 43.1 & 40 & & 221110 \\
\hline 93 & 24 & & 316142 \\
\hline 39.1 & 60 & & 174190 \\
\hline 92 & 24 & & 136673 \\
\hline 80.1 & 56 & & 29381 \\
\hline 82.1 & 24 & & 44093 \\
\hline 67.1 & 36 & & 22965 \\
\hline 134 & 12 & & 28124 \\
\hline
\end{tabular}

$\begin{array}{llll}\text { Compound Name } & \text { Formula } & \text { Mass } & \text { Sample Position } \\ \text { AcetaminophenM1 } & \text { C8H8CINO2 } & 185.02 & \text { P1-A1 }\end{array}$

Method Name

D:IMassHunterlMethodsIOnLine SPEIFlexCubelFlexCube_Flow_Injection_analysis.m

\begin{tabular}{llll}
$\begin{array}{l}\text { Polarity } \\
\text { Precursor Ion }\end{array}$ & Positive & Ion Source & AJS ESI \\
186.03 & \multicolumn{2}{c}{ Fragmentor } \\
Product Ion & 96 & \\
109 & Collision Energy & Abundance \\
80.1 & 28 & 156551 \\
43.1 & 52 & 83677 \\
144 & 44 & 39417 \\
53.1 & 12 & 107318 \\
81.1 & 60 & 15715 \\
82.1 & 44 & 9643 \\
54.2 & 56 & 2741 \\
73 & 60 & 3453 \\
168.2 & 60 & 1922 \\
& 16 & 2420
\end{tabular}




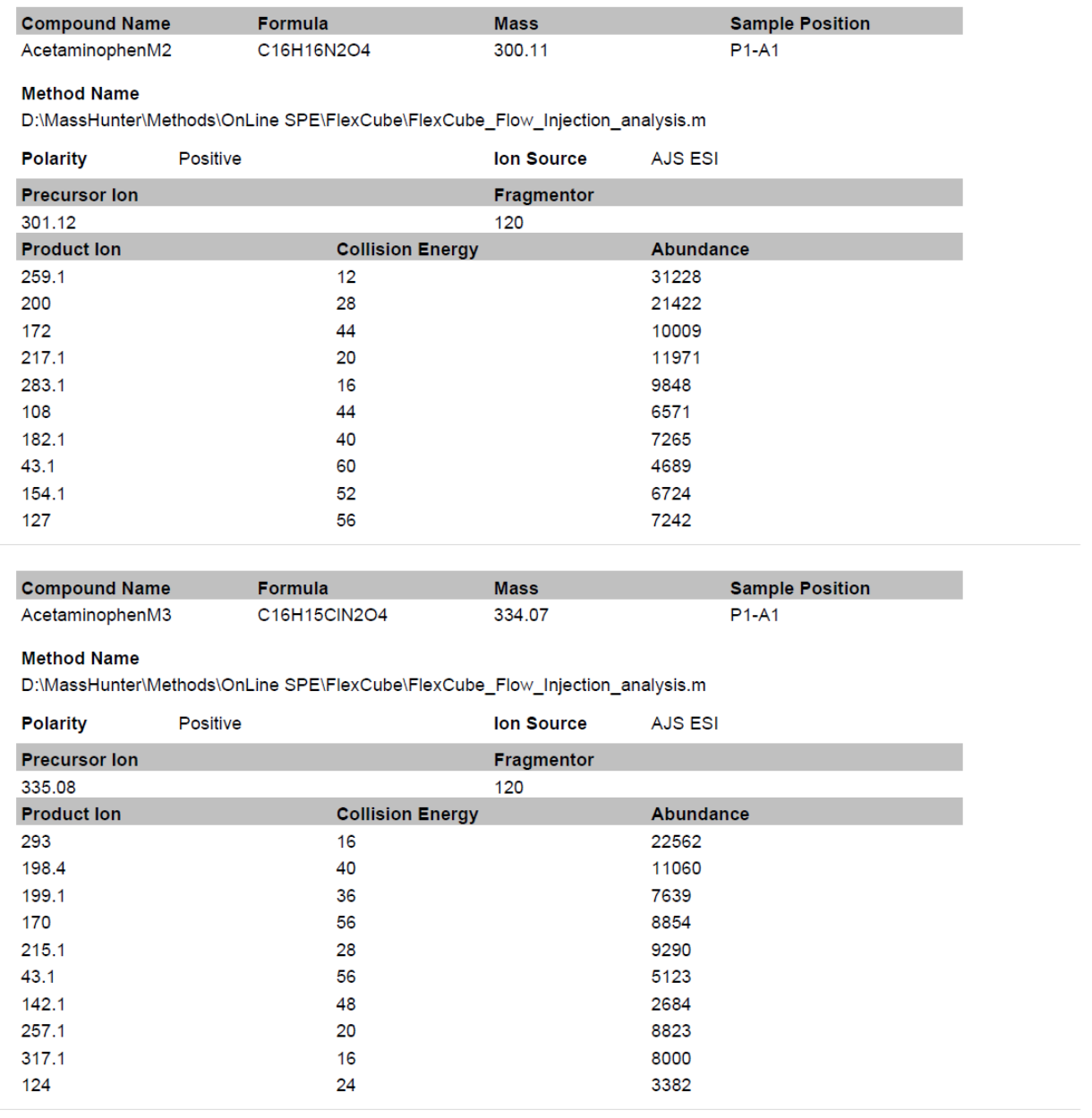




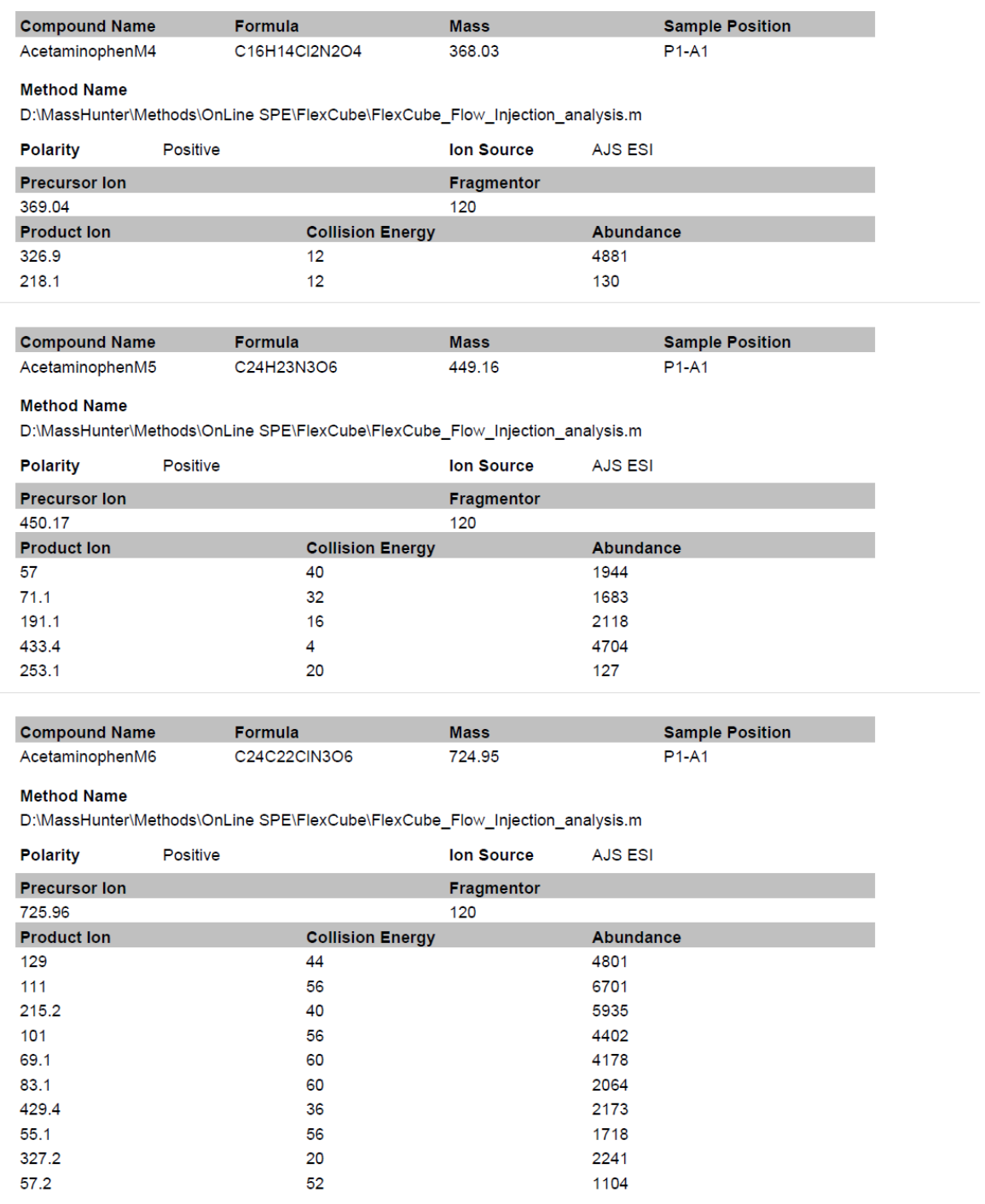




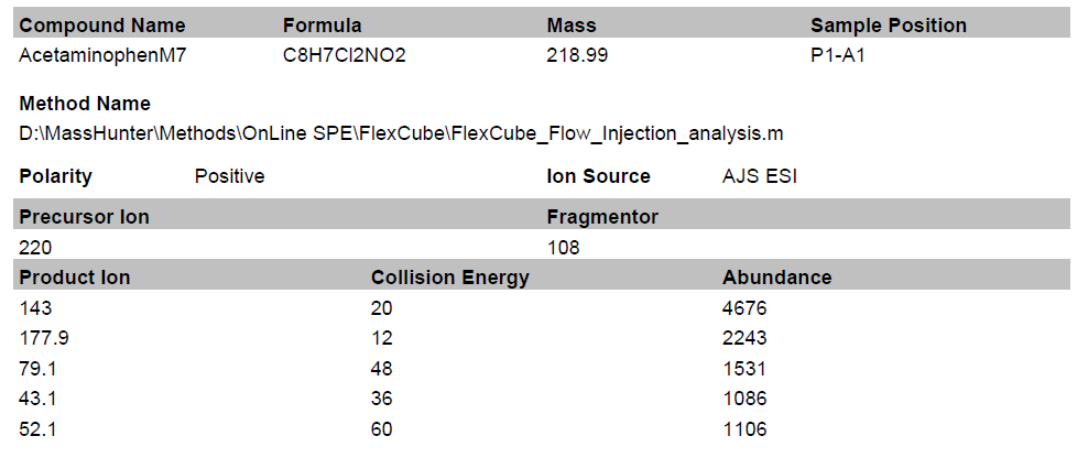


Optimizer Report

\section{Instrument Information}

Project Name Amphetamines

Instrument Name Instrument 1

Instrument Model G6460A

$\begin{array}{llll}\text { Compound Name } & \text { Formula } & \text { Mass } & \text { Sample Position } \\ \text { Carbamazepine drug } & \text { C15H12N2O } & 236.09 & \text { P1-A1 }\end{array}$

Method Name

D:IMassHunterIMethodsIOnLine SPEIFlexCubelFlexCube_Flow_Injection_analysis.m

Polarity Positive Ion Source AJS ESI

\begin{tabular}{|c|c|c|c|}
\hline \multirow{2}{*}{ Precursor Ion } & Positive & \multicolumn{2}{|l|}{ Ion source } \\
\hline & & Fragmentor & \\
\hline 237.1 & & 120 & \\
\hline Product lon & Collision Energy & & Abundance \\
\hline 194.1 & 16 & & 702396 \\
\hline 193.5 & 20 & & 111989 \\
\hline 165 & 52 & & 80398 \\
\hline 179 & 40 & & 100756 \\
\hline 167.1 & 52 & & 35826 \\
\hline 152 & 56 & & 34123 \\
\hline 151.6 & 60 & & 29833 \\
\hline 89 & 60 & & 25625 \\
\hline 181 & 16 & & 9979 \\
\hline
\end{tabular}

$\begin{array}{llll}\text { Compound Name } & \text { Formula } & \text { Mass } & \text { Sample Position } \\ \text { Carbamazepine M1 } & \text { C15H14N2O3 } & 270.1 & \text { P1-A1 }\end{array}$

Method Name

D:IMassHunterlMethodsIOnLine SPEIFlexCubelFlexCube_Flow_Injection_analysis.m

\begin{tabular}{lll} 
Polarity & Positive & \multicolumn{2}{c}{$\begin{array}{l}\text { Ion Source } \\
\text { Fragmentor }\end{array}$} & AJS ESI \\
Precursor lon & \multicolumn{2}{c}{120} \\
271.11 & \multicolumn{2}{c}{ Abundance } \\
Product lon & 28 & 56095 \\
193.1 & 32 & 44419 \\
180.1 & 12 & 34033 \\
228 & 4 & 29021 \\
253.1 & 44 & 11376 \\
167.1 & 12 & 19729 \\
210.1 & 56 & 8218 \\
165 & 8 & 26397 \\
236.1 & 20 & 6669 \\
226 & 24 & 10653 \\
182.1 & &
\end{tabular}




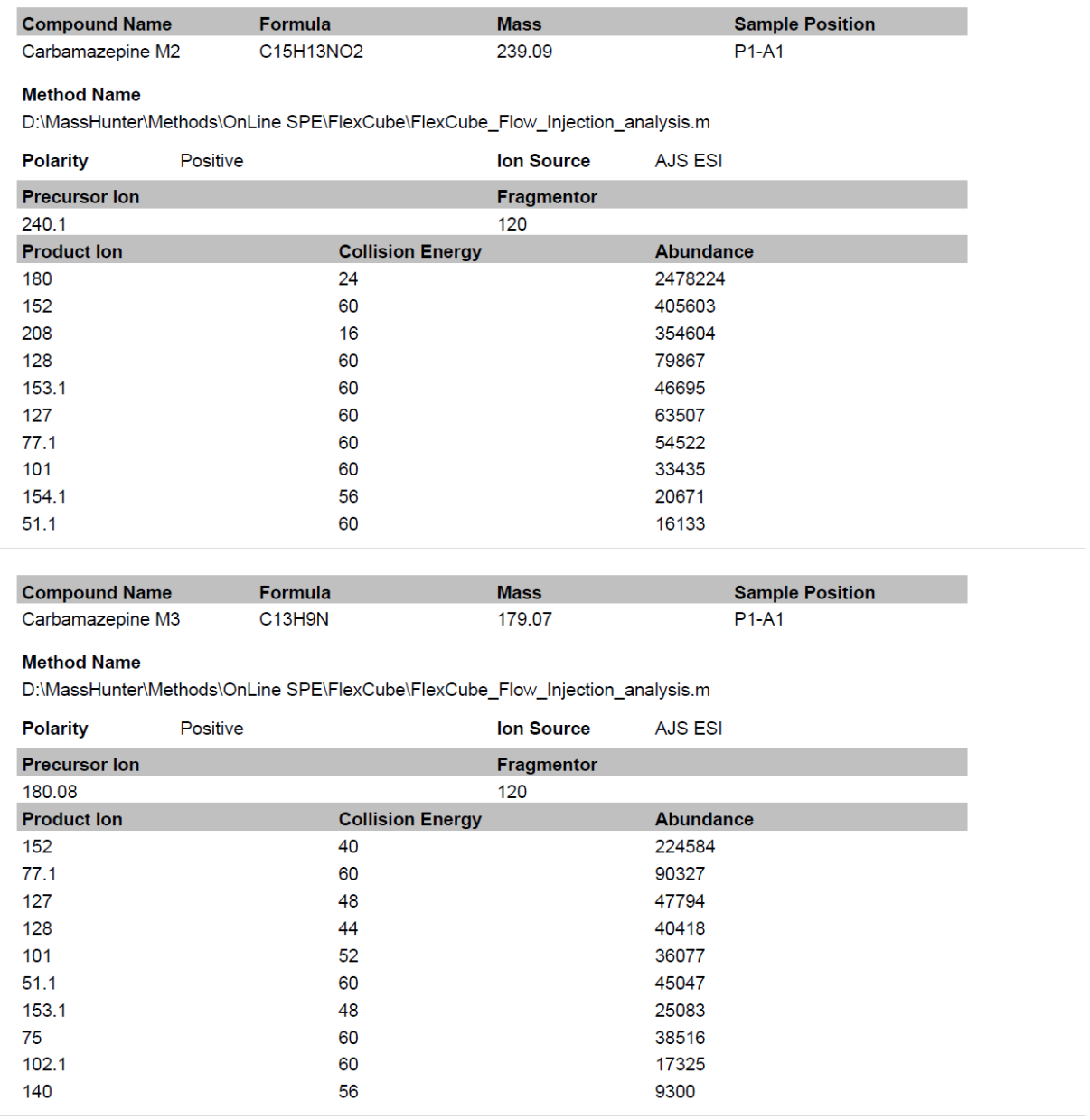




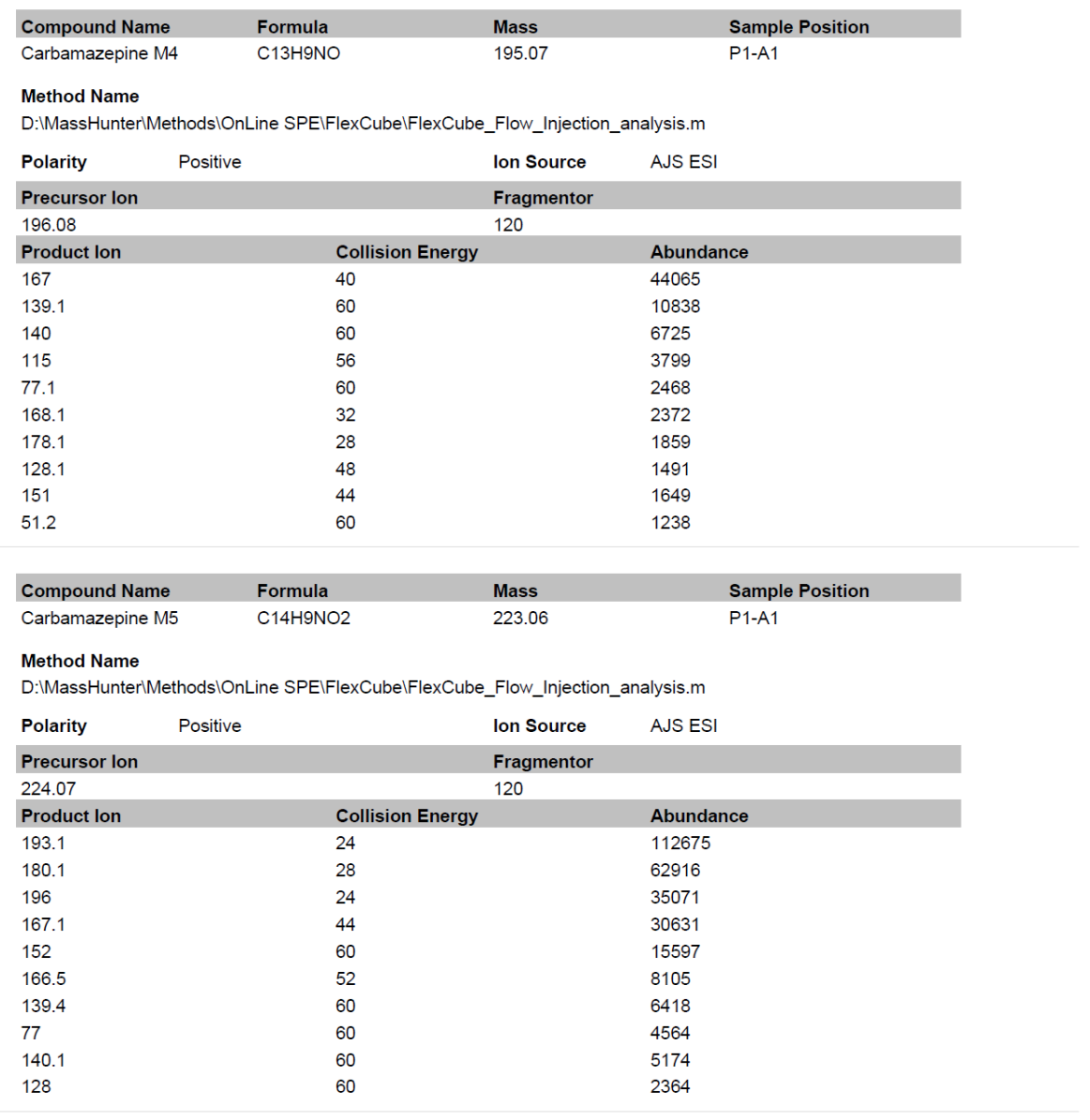




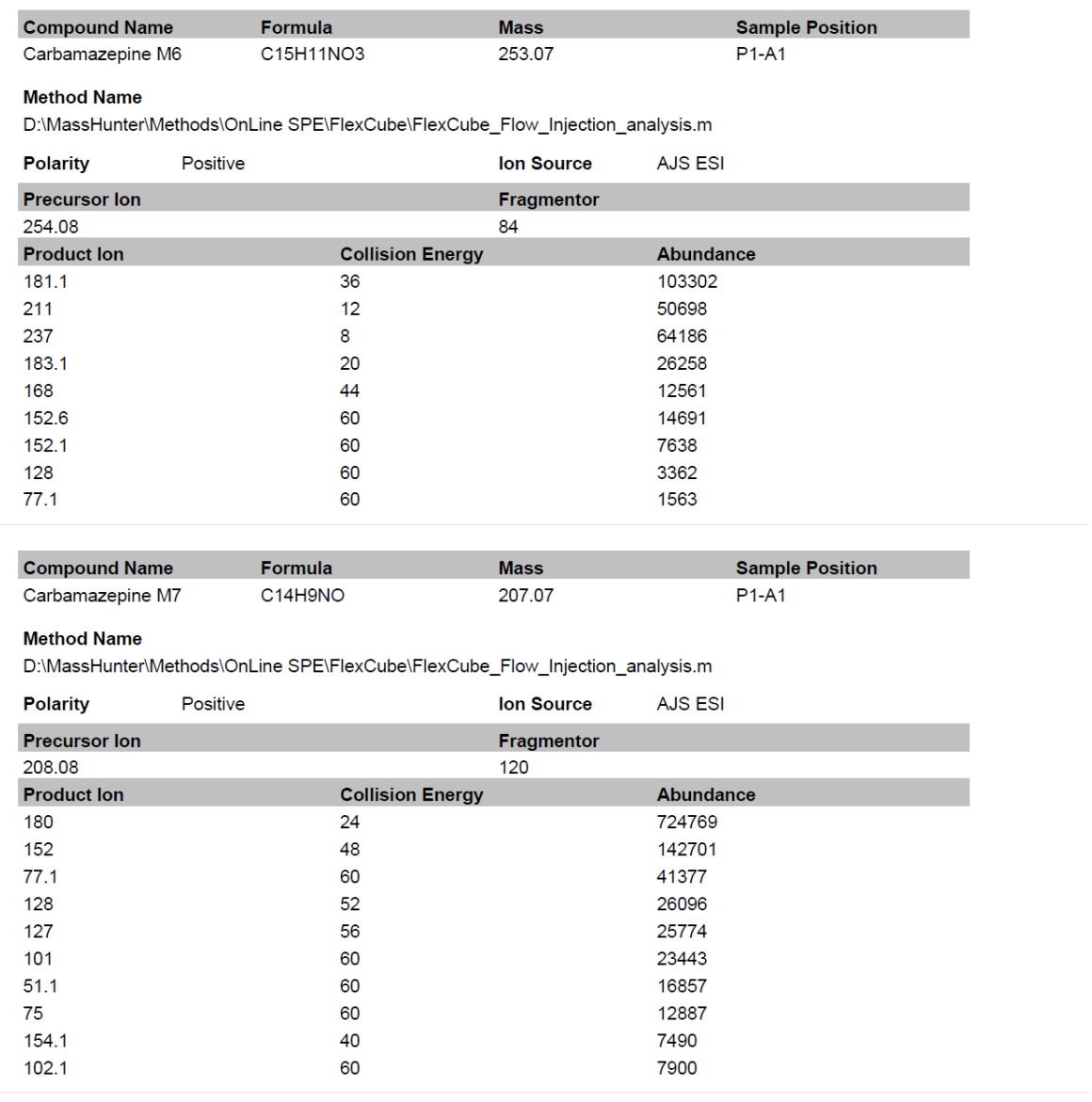




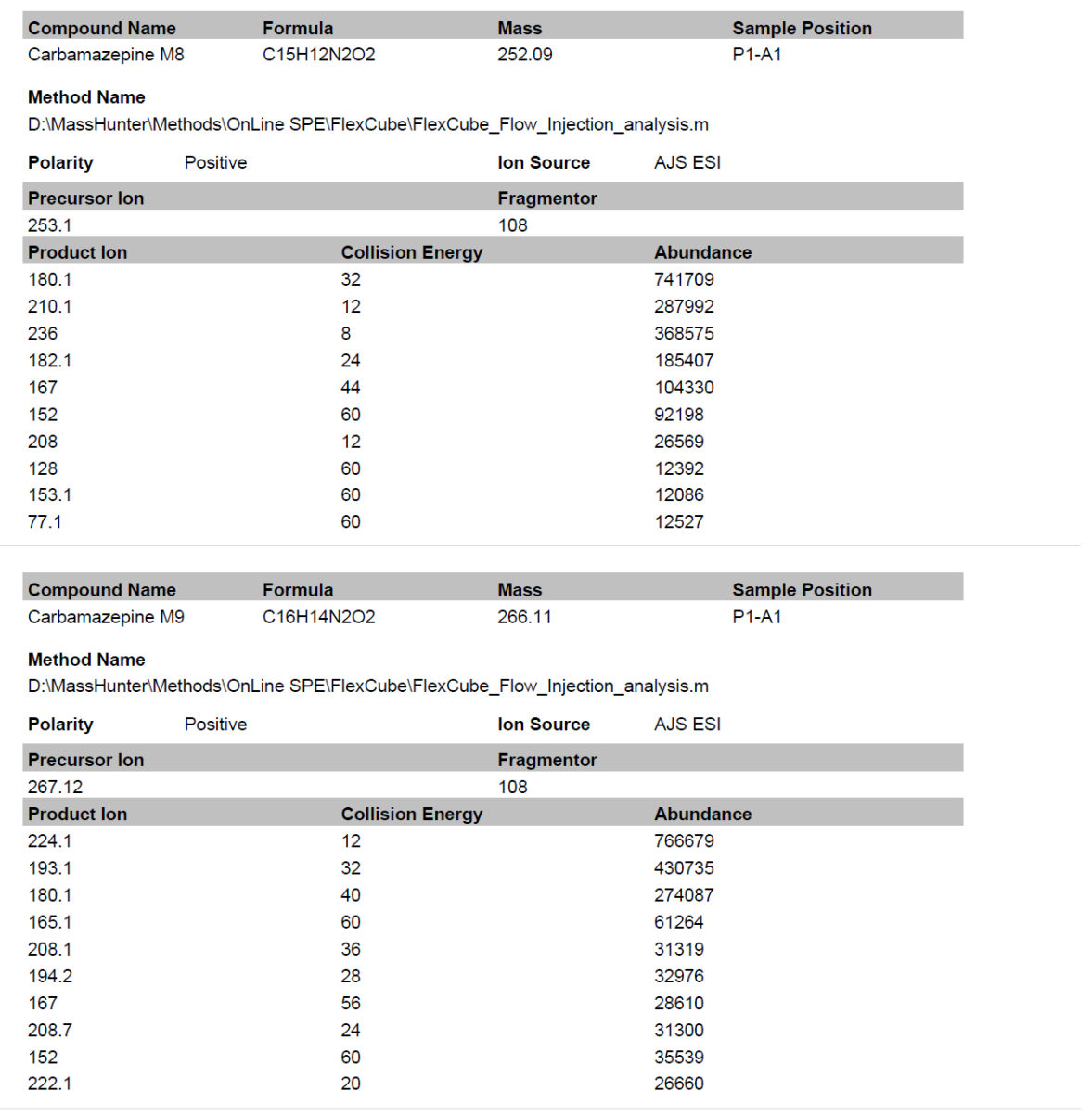




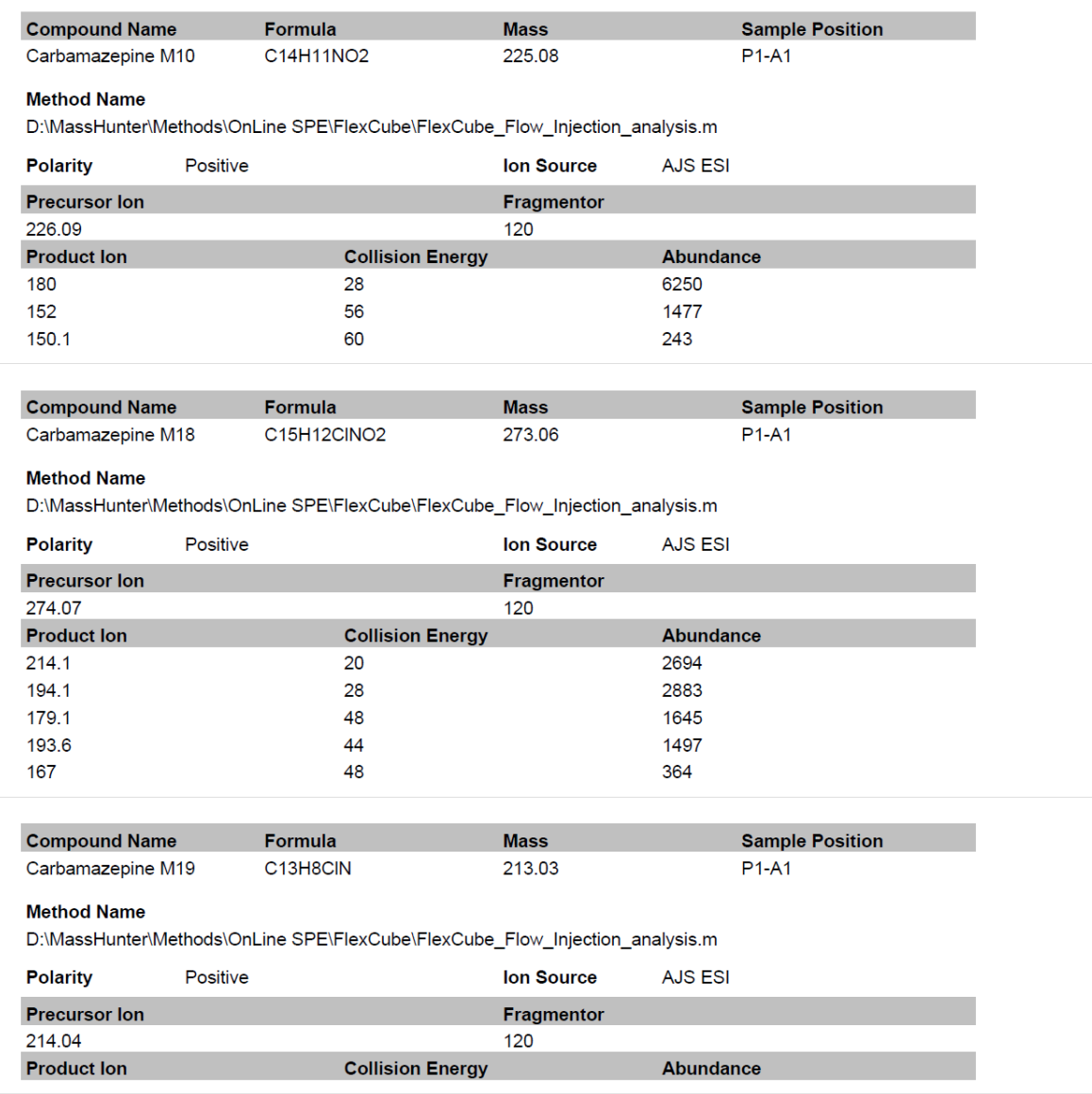




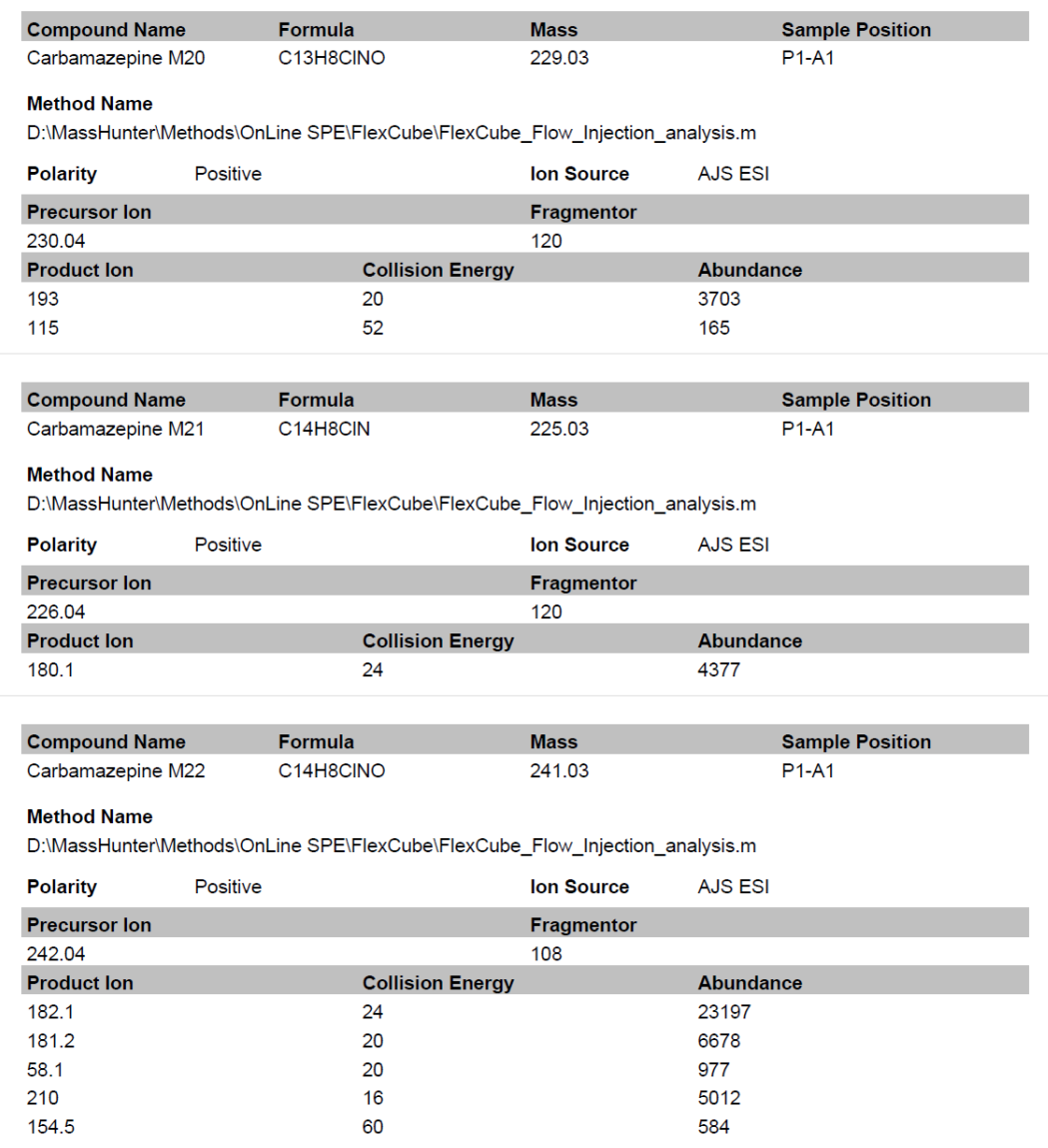


Figure A3.1 DNA sequence of full-length wide type CPO gene.

ATGTTCTCCAAGGTCCTTCCCTTCGTGGGAGCGGTTGCCGCCCTCCCTCACTC CGTCCGTCAGGAGCCTGGCTCCGGCATTGGCTACCCATACGACAACAACACC CTGCCATATGTCGCCCCAGGTCCTACCGACTCTCGTGCTCCTTGCCCAGCTCT GAACGCTCTTGCCAACCACGGTTACATTCCTCACGATGGCCGTGCCATCAGC AGGGAGACCCTCCAGAACGCTTTCCTCAACCACATGGGTATTGCCAACTCCG TCATTGAGCTTGCTCTGACCAACGCCTTCGTCGTCTGCGAGTACGTTACTGGC TCCGACTGTGGTGACAGCCTTGTCAACCTGACTCTGCTCGCCGAGCCCCACGC TTTCGAGCACGACCACTCCTTCTCCCGCAAGGATTACAAGCAGGGTGTCGCC AACTCCAACGACTTCATCGACAACAGGAACTTCGATGCCGAGACCTTCCAGA CCTCTCTGGATGTCGTTGCAGGCAAGACCCACTTCGACTATGCCGACATGAA CGAGATCCGCCTTCAGCGCGAGTCCCTCTCCAACGAGCTTGACTTCCCCGGTT GGTTCACCGAGTCCAAGCCAATCCAGAACGTCGAGTCTGGCTTCATCTTCGCC CTTGTCTCTGACTTCAACCTGCCCGACAACGATGAGAACCCTCTGGTTCGCAT TGACTGGTGGAAGTACTGGTTCACCAACGAGTCCTTCCCATACCACCTCGGCT GGCACCCCCCGTCTCCAGCCAGGGAGATCGAGTTCGTCACCTCCGCCTCCTCC GCTGTCCTGGCTGCCTCTGTCACCTCTACTCCATCTTCCCTTCCATCCGGTGCC ATCGGCCCAGGTGCCGAGGCTGTCCCTCTCTCCTTCGCCTCCACCATGACCCC ATTCCTCCTCGCCACCAATGCTCCTTACTACGCCCAGGACCCAACTCTCGGCC CCAACGACAAGCGTGAGGCTGCCCCAGCTGCCACCACCTCCATGGCCGTCTT CAAGAACCCATACCTCGAGGCCATTGGC ACCCAGGACATCAAGAACCAGCA GGCTTACGTCAGCTCCAAGGCTGCTGCCATGGCCTCTGCCATGGCCGCCAAC AAGGCCCGCAACCTTTAA 
Figure A3.2 Amino acid sequence of full-length of wide type CPO.

1 XEPGSGIGYP YDNNTLPYVA PGPTDSRAPC PALNALANHG YIPHDGRAIS

51 RETLQNAFLN HMGIANSVIE LALTNAFVVC EYVTGSDCGD SLVNLTLLAE

101 PHAFEHDHSF SRKDYKQGVA NSNDFIDNRN FDAETFQTSL DVVAGKTHFD

151 YADMNEIRLQ RESLSNELDF PGWFTESKPI QNVESGFIFA LVSDFNLPDN

201 DENPLVRIDW WKYWFTNESF PYHLGWHPPS PAREIEFVTS ASSAVLAASV

251 TSTPSSLPSG AIGPGAEAVP LSFASTMTPF LLATNAPYYA QDPTLGPND 


\section{QINGHAO HE}

Dec 07, 1988

2007-2011

2011-
Born, Nanjing, China

Bachelor of Management, Nanjing University of Chinese Medicine

Doctoral Candidate in Chemistry Florida international University

\section{PUBILICATIONS}

Rui Zhang, Qinghao He, David Chatfield, and Xiaotang Wang "Paramagnetic nuclear magnetic resonance relaxation and molecular mechanics studies of the chloroperoxidase-indole complex: insights into the mechanism of chloroperoxidase-catalyzed regioselective oxidation of indole". Biochemistry, 2013. 52(21): p. 3688-3701.

Rui Zhang , Qinghao He, Yi Huang and Xiaotang Wang "Spectroscopic and QM/MM investigations of Chloroperoxidase catalyzed degradation of orange G" Archives of Biochemistry and Biophysics, 2016. 596 P. 1-9 